INSTITUTO DE PESQUISAS ENERGÉTICAS E NUCLEARES

Autarquia associada à Universidade de São Paulo

Estudo da degradação de reagentes liofilizados para radiodiagnóstico por Cromatografia Líquida de Alta Eficiência (HPLC) e Espectrometria de Massas (MS)

Érika Vieira de Almeida

Tese apresentada como parte dos requisitos para obtenção do Grau de Doutor em Ciências na Área de Tecnologia Nuclear - Aplicações.

Orientadora:

Profa. Dra. Margareth Mie Nakamura

Matsuda

São Paulo

2015 


\section{AGRADECIMENTOS}

À Universidade de São Paulo (USP) pelo oferecimento do curso de pósgraduação e ao Instituto de Pesquisas Energéticas e Nucleares (IPEN) pela infraestrutura.

Ao Conselho Nacional de Pesquisa e Desenvolvimento Científico (CNPq), pelo auxílio financeiro.

Ao MSc. Jair Mengatti pela colaboração para a concretização deste trabalho.

À Dra. Constancia Pagano Gonçalves da Silva por me acolher e acreditar no meu trabalho.

À Dra. Marina Beatriz Vasconcellos por aceitar me orientar

À Dra. Margareth Mie Nakamura Matsuda pela orientação.

À MSc. Neuza Taeko Okasaki Fukumori pelas discussões valiosas e por ter acreditado, desde o início, na conclusão deste trabalho.

Ao aluno de iniciação científica Samuel Brito Levindo pela parceria nas análises por HPLC.

Ao Prof. Dr. Hernani Pinto e a Mariah Ultramari pelo apoio técnico nas análises por espectrometria de massas.

À Ana Maria Maiorino, Magali Barbieri e Romério pelo suporte técnicoadministrativo e pela amizade.

A todos do Centro de Radiofarmácia pela amizade e pelo convívio agradável. 
Dedico às pessoas que transformaram dias cruéis e desleais em dias de luta e esperança... 


\section{À minha mamãezinha Maria (in memoriam)}

Se eu perdesse minha MAMÃE... eu sofreria muito;

Se eu perdesse meu PAPAI... eu choraria;

Se eu perdesse minha AMIGA... eu sentiria um vazio;

Se eu perdesse minha CONFIDENTE... o que seriam dos meus segredos?

Se eu perdesse minha CONSELHEIRA... cometeria muitos erros;

Se eu perdesse minha COMPANHEIRA... eu me sentiria solitária;

Se eu perdesse meu ALICERCE... eu desmoronaria completamente; Mas... se eu perdesse uma única pessoa que era minha MAMÃE, meu PAPAI, minha AMIGA, minha CONFIDENTE, minha CONSELHEIRA, minha COMPANHEIRA e meu ALICERCE...eu me sentiria assim: Sem palavras para traduzir e expressar este sentimento! Sei apenas senti-lo com todas as minhas forças! E sei também, que isto:

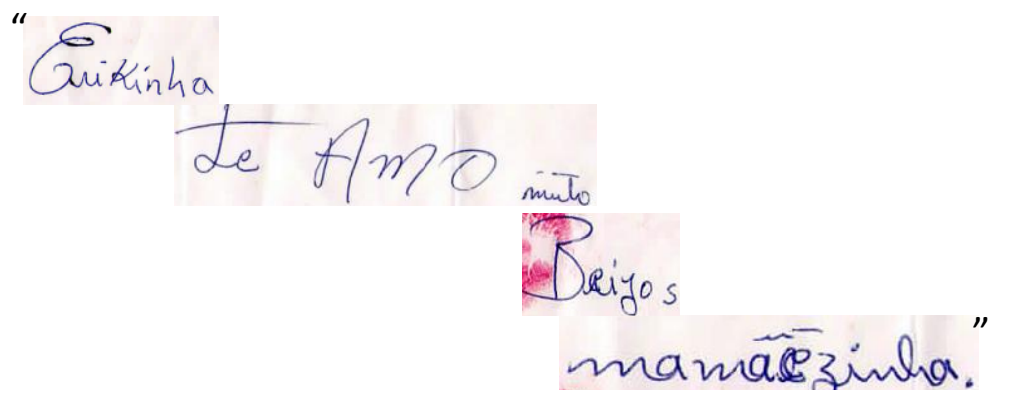

faz-me seguir e acreditar que tudo é possível!

Nós, minhas irmãs e eu, apesar da saudade, continuamos na luta e na fé que um dia a senhora nos ensinou. 


\section{Às minhas irmãs Erilânia e Erolândia,}

Pelas forças que nos unem em todos os momentos de nossas vidas;

Pela fé e garra que herdamos de nossa mãe!

Somos o que um dia planejamos ser!

Quantas dificuldades e quantas injustiças nos derrubaram durante nossa jornada?

Quantas vezes nossa mãe foi a nossa única esperança.

$\mathcal{E}$ isto, certamente foi suficiente!

Hoje, somos o que desejamos ser e a acima de tudo...

somos o que nossa mãe nos ensinou que era importante ser!

\section{Ao meu cunhado Ney e a sua família}

Pelo acolhimento nos momentos mais difíceis e indesejados;

Pelo carinho e compreensão!

Por compartilhar alegria e tristeza! 


\section{AO MEV QUERIDO NOIVO RICARDO}

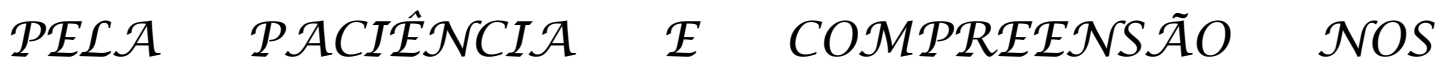
MOME $\mathcal{N}$ TOS DIFÍCEIS;

$\begin{array}{llllll}\mathcal{P O R} & \mathcal{E} \mathcal{N} \mathcal{T} \mathcal{E N D E R} & \mathcal{E} & \boldsymbol{C O M} \mathcal{M} \mathcal{A R} \mathcal{T} I \mathcal{L} \mathcal{H} \mathcal{A} R & O & \mathcal{M E U}\end{array}$ SONNHO;

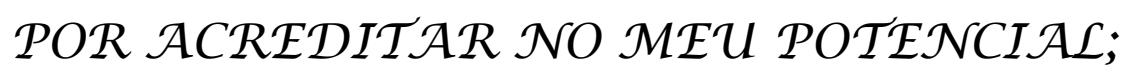

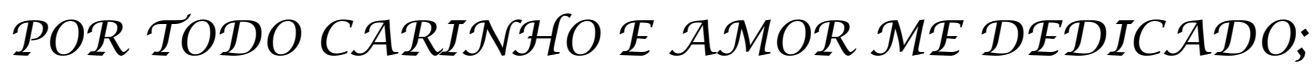

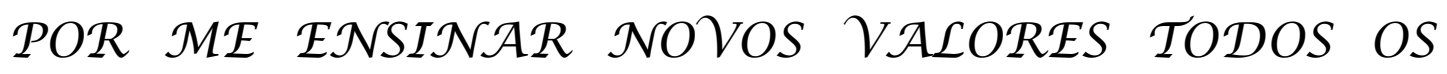
DIAS;

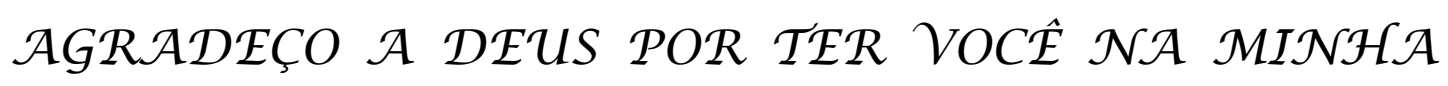
VID A ! 


\section{À minha eterna amiga Ruth}

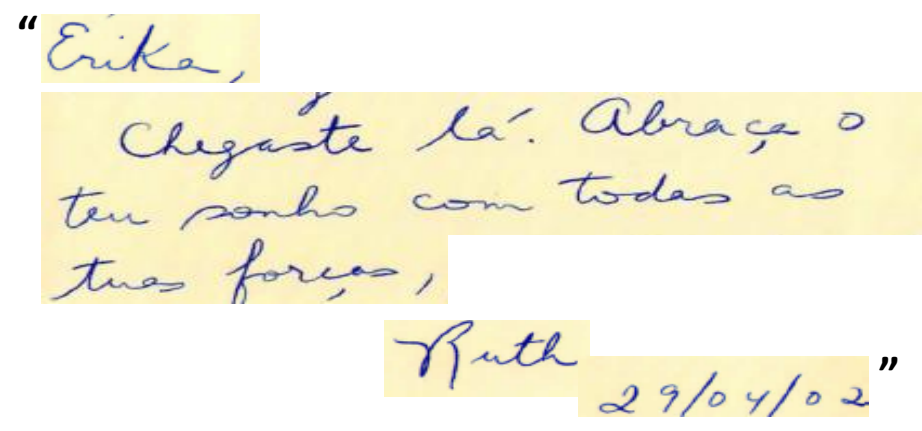

A tua CONFIANÇA e o teu CARINHO têm me alimentado todos estes anos.

Quero agradecer por compartilhar sonhos... por viver sonhos!

"Filha, quando você alcançar o maior de todos os teus sonhos... Não esqueça! Não se esqueça de olhar para trás, de erguer as tuas mãos e agradecer à DEUS. Também agradeça àquelas pessoas que escreveram a tua história!" (Maria Vieira de Almeida).

NÓs chegamos aqui minha amiga!

Estamos e continuaremos de mãos dadas!

E de mãos dadas comemoraremos esta vitória.

\section{À profa. Dra. Eny Maria Vieira}

"Recordo-me das dificuldades passadas em São Carlos;

Recordo-me dos dias de frio e fome...

Deus parecia ter se esquecido de mim!

Mamãe mais uma vez estava certa:

Deus jamais se esqueceria de mim!

Deus te colocara nos meus caminhos

Deus te deu o dom para melhorar a minha vida!" 


\title{
ESTUDO DA DEGRADAÇÃO DE REAGENTES LIOFILIZADOS PARA RADIODIAGNÓSTICO POR CROMATOGRAFIA LÍQUIDA DE ALTA EFICIÊNCIA (HPLC) E ESPECTROMETRIA DE MASSAS (MS)
}

\author{
Érika Vieira de Almeida \\ RESUMO
}

A utilização de radiofármacos no diagnóstico de doenças do organismo humano tem aumentado de forma significativa nas últimas décadas. $O$ crescente desenvolvimento de novos reagentes liofilizados $(R L)$ para a preparação de radiofármacos, embora proporcionem uma maior variedade para o mercado de radiofármacos, deixa evidente uma das lacunas na pesquisa radiofarmacêutica: a identificação de produtos de degradação. No presente trabalho, foram identificados os principais produtos de degradação dos $R \mathrm{~L}$ de ácido 2,3Dimercaptosuccínico (DMSA) e Etilenodicisteína Dietil Éster (ECD) utilizando as técnicas de cromatografia líquida de alta eficiência com Detecção por Arranjo de Diodos (HPLC-DAD) e cromatografia líquida acoplada à espectrometria de massas de múltiplos estágios (LC-MS ${ }^{n}$ ). Realizou-se o estudo de degradação forçada do RL de DMSA e do RL de ECD nas condições de estresse hidrolítico, fotolítico, oxidativo e termodegradação. As análises foram realizadas em equipamento HPLC-DAD Shimadzu e espectrômetro de massas Bruker Daltonics. Todas as análises foram desenvolvidas utilizando coluna cromatográfica Shim-Pack VP-ODS (150 mm x 4,6 mm; $5 \mu \mathrm{m})$. O DMSA apresentou tempo de retenção de 5,58 minutos e $\mathrm{m} / \mathrm{z} 204,8$. A hidrólise ácida do DMSA não apresentou produtos de degradação. O perfil de degradação do DMSA após hidrólise alcalina apresentou três picos cromatográficos com características mais apolares que o DMSA. No espectro de fragmentação do íon de $\mathrm{m} / \mathrm{z} 204,8\left(\mathrm{MS}^{2}\right)$ pode-se observar a presença do fragmento de $\mathrm{m} / \mathrm{z} 172,9$, correspondente ao aduto sodiado de ácido mercaptosuccínico (MSA); e o fragmento de $\mathrm{m} / \mathrm{z}$ 139,0 $\left(\mathrm{MS}^{3}\right)$, correspondente ao aduto sodiado do ácido fumárico. O íon estanho (Sn) apresentou-se coordenado ao DMSA em todos os produtos de degradação após hidrólise alcalina do RL de DMSA. As amostras submetidas à hidrólise neutra não apresentaram degradação. Nos estudos de fotólise do DMSA, o íon de $\mathrm{m} / \mathrm{z}$ 267,1 pode ser identificado como o ácido diacetil dimercaptosuccínico (BATSA). O íon de $\mathrm{m} / \mathrm{z}$ 127,1 foi associado ao ácido hidroximetil fosfônico e observado nos estudos de oxidação. A termodegradação do DMSA e do RL de DMSA, não apresentou uma relação de decaimento da concentração do DMSA em função do tempo. Quanto ao RL de ECD, foi observado o ECD protonado em 5,55 minutos (m/z 325,6). As análises por LC-MS ${ }^{n}$ do ECD sob hidrólise alcalina mostraram que o pico com tempo de retenção de 1,71 minutos foi identificado como o íon protonado do $\mathrm{EC}\left([\mathrm{M}+\mathrm{H}]^{+}\right)$ em $\mathrm{m} / \mathrm{z}$ 269,2. Os picos com tempo de retenção de 3,34 e 3,69 minutos foram identificados como o íon protonado do ECD na forma monoéster (ECDM). A degradação alcalina do RL de ECD apresentou os íons de m/z 441,9 (ECD-Sn) e $\mathrm{m} / \mathrm{z} 737,9$ ([ECD $\left.{ }_{2}+\mathrm{Sn}\right]-\mathrm{C}_{2} \mathrm{H}_{2}-2 \mathrm{H}$ ). ECD monoester monoácida (ECDM) de $\mathrm{m} / \mathrm{z}$ 295,2; ECD oxidado de $\mathrm{m} / \mathrm{z} 323,5$; ECD oxidado com duas pontes dissulfeto de $\mathrm{m} / \mathrm{z} 389,1$ e dímero de ECD de $\mathrm{m} / \mathrm{z}$ 645,9 foram observados da degradação oxidativa. Conclui-se que as análises por HPLC-DAD e LC-MS ${ }^{n}$ podem ser utilizadas no estudo de estabilidade de RL, identificando suas impurezas e produtos de degradação.

Palavras-chave: cromatografia líquida, espectrometria de massas, degradação, radiofarmácos, DMSA, ECD e controle de qualidade. 


\title{
STUDY OF DEGRADATION OF LYOPHILIZED REAGENTS FOR RADIODIAGNOSIS BY HIGH PERFORMANCE LIQUID CHROMATOGRAPHY (HPLC) AND MASS SPECTROMETRY (MS)
}

\author{
Érika Vieira de Almeida
}

\begin{abstract}
The use of radiopharmaceuticals in the diagnosis of diseases of the human organism has increased significantly in the last decades. The increasing development of new lyophilized reagents (LR) for the preparation of radiopharmaceuticals, although providing a greater variety of radiopharmaceuticals to the market, makes evident a gap in the radiopharmaceutical research: identification of degradation products. In the present work, the main degradation products of the 2,3-Dimercaptosuccinic acid (DMSA) and Ethylenedicysteine Diethyl Ester (ECD) LR were identified, using the techniques of high performance liquid chromatography with diode array detection (HPLC -DAD) and liquid chromatography multiple-stage mass spectrometry (LC-MS ${ }^{n}$ ). The study of forced degradation of DMSA and ECD LR was performed in the hydrolytic, photolytic and oxidative stress conditions and thermodegradation. Analyses were performed using an HPLC-DAD Shimadzu and mass spectrometer Bruker Daltonics equipment. All analyzes were carried out using Shim-Pack VP-ODS (150 mm x $4.6 \mathrm{~mm} ; 5 \mu \mathrm{m})$ chromatographic column. DMSA showed a retention time of 5.58 minutes and $\mathrm{m} / \mathrm{z}$ 204.8. Acid hydrolysis of DMSA showed no degradation products. The degradation profile of DMSA after alkaline hydrolysis presented three chromatographic peaks with more nonpolar characteristics than DMSA. In the fragmentation spectrum of the ion $\mathrm{m} / \mathrm{z} 204.8\left(\mathrm{MS}^{2}\right)$, the presence of a fragment of $\mathrm{m} / \mathrm{z} 172.9$ was observed, corresponding to sodium adduct of mercaptosuccinic acid (MSA); and a fragment of $\mathrm{m} / \mathrm{z} 139.0\left(\mathrm{MS}^{3}\right)$, corresponding to sodium adduct of fumaric acid. The tin ion was coordinated to DMSA in all degradation products after alkaline hydrolysis of DMSA LR. The samples submitted to neutral hydrolysis showed no degradation. In the studies of photolysis of DMSA, the ion $\mathrm{m} / \mathrm{z} 267.1$ can be related to diacetyl dimercaptosuccinic acid (BATSA). The ion of $\mathrm{m} / \mathrm{z} 127.1$ observed in the studies of oxidation can be related to phosphonic hydroxymethyl acid. The thermodegradation of DMSA and its LR did not show a relationship between the decrease in the DMSA concentration and the time. The protonated ECD was observed in 5.55 minutes $\left(\mathrm{m} / \mathrm{z}\right.$ 325.6). Analysis by $\mathrm{LC}^{-M S^{n}}$ of ECD under alkaline hydrolysis showed that the peak with retention time of 1.71 minutes could be identified as the protonated ion of $E C\left([M+H]^{+}\right)$at $\mathrm{m} / \mathrm{z}$ 269.2. The peaks with retention times of 3.34 and 3.69 minutes were identified as the protonated ion of ECD in its monoester form (ECDM). The alkaline degradation of ECD LR presented the $\mathrm{m} / \mathrm{z} 441.9$ (ECD-Sn) and $\mathrm{m} / \mathrm{z}$ $737.9\left(\left[E_{2} D_{2}+S n\right]-C_{2} H_{2}-2 H\right)$ ions. ECD monoester monoacid (ECDM) of $\mathrm{m} / \mathrm{z}$ 295.2; ECD oxidized of $\mathrm{m} / \mathrm{z}$ 323.5; ECD oxidized with two disulfide bonds of $\mathrm{m} / \mathrm{z} 389.1$ and ECD dimer of $\mathrm{m} / \mathrm{z} 645.9$ were observed in the oxidative degradation. It was concluded that the analysis by HPLC-DAD and LC-MS ${ }^{n}$ can be used in the stability of LR, identifying and quantifying its impurities and degradation products.
\end{abstract}

Keywords: liquid chromatography, mass spectrometry, degradation, radiopharmaceuticals, DMSA, ECD and quality control. 


\section{SUMÁRIO}

Página

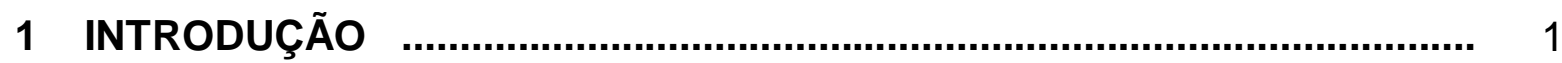

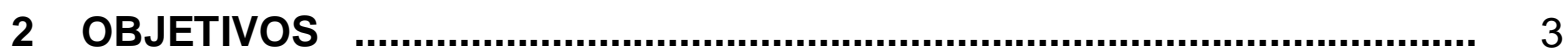

2.1 Objetivos específicos para estudo do API (DMSA e ECD) e RL de DMSA 3 e ECD

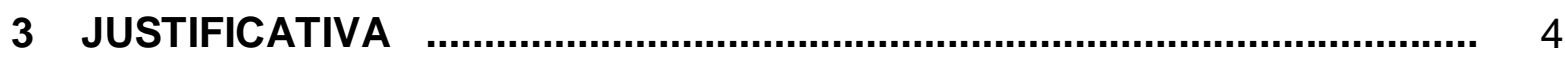

4 REVISÃO DA LITERATURA ……...................................................... 5

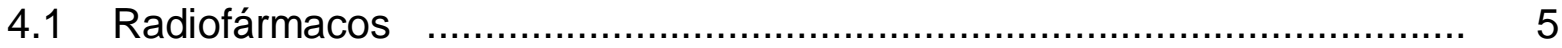

4.2 Radiodiagnóstico: radiofármacos de tecnécio-99m …............................ 6

4.3 Reagentes Liofilizados para marcação com tecnécio-99m ……............. 9

4.3.1 Ácido 2,3-Dimercaptosuccínico (DMSA) …….................................. 11

4.3.2 Etilenodicisteína Dietil Éster (ECD) …........................................... 12

4.4 Estudo de degradação forçada ………………………………..... 14

4.4.1 Condições de degradação forçada para API e RL …….................... 15

4.4.1.1 Hidrólise ....................................................................... 15

4.4.1.2 Fotólise .......................................................................... 16

4.4.1.3 Oxidação …......................................................................... 17

4.4.1.4 Termodegradação ……......................................................... 17

4.4.2 Cinética de degradação .................................................................... 18

4.5 Identificação de produtos de degradação …………………................ 19

4.5.1 Cromatografia Líquida de Alta Eficiência com Detecção por Arranjo de 19 Diodos (HPLC-DAD)

4.5.2 Cromatografia Líquida acoplada à Espectrometria de Massas de 21 Múltiplos Estágios (LC-MS ${ }^{\mathrm{n}}$ )

4.5.2.1 Ionização por electrospray (ESI) ………........................................ 24

4.5.2.2 Analisador de massas ion trap ........................................................ 25

5 MATERIAIS E MÉTODOS …............................................................... 27

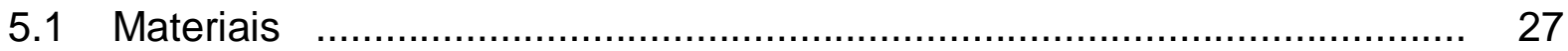

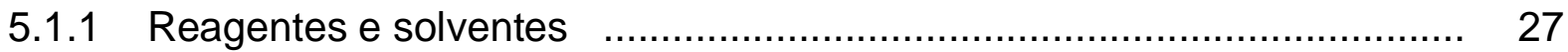

5.2 Preparação das amostras ........................................................... 28

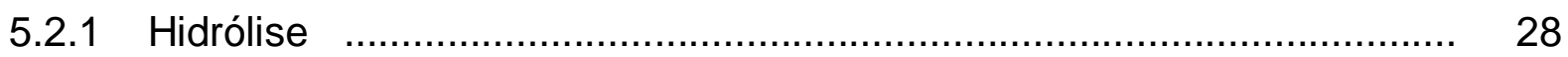

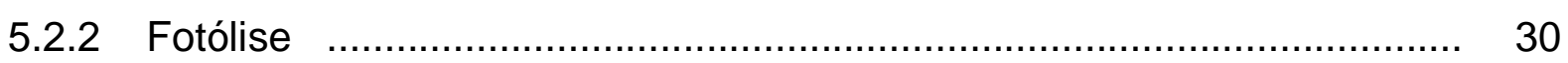




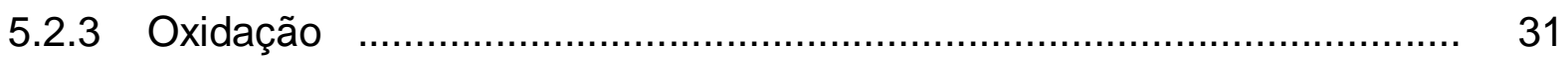

5.2.4 Termodegradação ...................................................................... 31

5.3 Avaliação da cinética de degradação ..................................................... 32

5.4 Avaliação do teor de DMSA e ECD nos RL …….............................. 33

5.5 Identificação dos produtos de degradação ………………….................. 33

5.5.1 Sistema HPLC-DAD ................................................................ 34

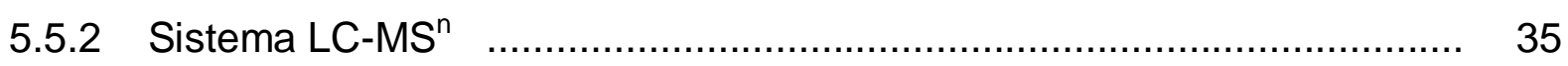

6 RESULTADOS E DISCUSSÃO …................................................. 37

6.1 Condições otimizadas para análise de DMSA e RL de DMSA por HPLC-DAD . 37

6.2 Condições otimizadas para análise de DMSA e RL de DMSA por LC-MS ${ }^{n} \quad 41$

6.3 Identificação do DMSA e cálculo do teor de DMSA nos RL. ………....... 42

6.4 Estudo de degradação forçada do DMSA e RL de DMSA ...................... 45

6.4.1 Hidrólise ácida ........................................................................... 45

6.4.2 Hidrólise alcalina ….................................................................. 51

6.4.2.1 Análise quantitativa e cinética de degradação de DMSA e RL de DMSA 62

6.4.3 Hidrólise neutra .............................................................................. 63

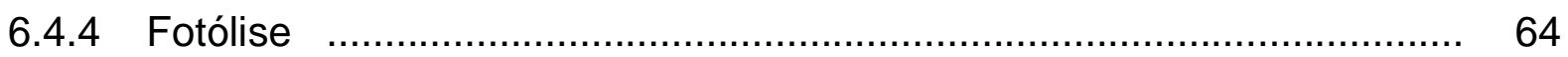

6.4.4.1 Análise quantitativa e cinética de degradação de DMSA e RL de DMSA 73

6.4.5 Oxidação ...................................................................... $\quad 74$

6.4.5.1 Análise quantitativa e cinética de degradação de DMSA e RL de DMSA 80

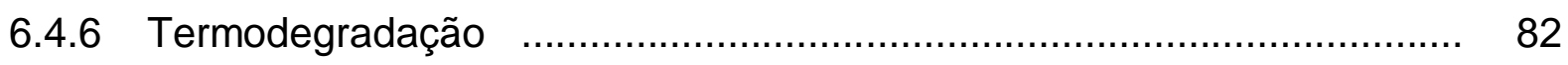

6.5 Condições otimizadas para análise de ECD e RL de ECD por HPLC-DAD... 83

6.6 Condições otimizadas para análise de ECD e RL de ECD por LC-MS ${ }^{n} \quad \ldots \ldots . \quad 85$

6.7 Identificação do ECD e cálculo do teor de EDC nos RL ......................... 86

6.8 Estudo de degradação forçada do ECD e RL de ECD .......................... 87

6.8.1 Hidrólise ácida ........................................................................ 89

6.8.2 Hidrólise alcalina ..................................................................... 91

6.8.2.1 Análise quantitativa e cinética de degradação de ECD e RL de ECD 101

6.8.3 Hidrólise neutra .............................................................................. 103

6.8 .4 Oxidação ....................................................................... 103

6.8.4.1 Análise quantitativa e cinética de degradação de ECD e RL de ECD 105

7 CONCLUSÕES ............................................................................ 107

8 REFERÊNCIAS BIBLIOGRÁFICAS _............................................... 108 


\section{LISTA DE FIGURAS}

Página

FIGURA 1- Esquema de decaimento radioativo do molibdênio-99 $\left({ }^{99} \mathrm{Mo}\right)$ : partículas beta $\left(\beta^{-}\right)$são emitidas e $0{ }^{99} \mathrm{Mo}$ decai a tecnécio-99 metaestável ${ }^{99 \mathrm{~m}} \mathrm{Tc}$ ). Este emite radiação gama $(\gamma)$ e decai a tecnécio-99 $\left({ }^{99} \mathrm{Tc}\right)$, que finalmente emite partículas $\beta^{-}$e decai a rutênio-99 estável $\left({ }^{99} \mathrm{Ru}\right)$. Tempo de meia vida física: ${ }^{99} \mathrm{Mo}=66$ horas; ${ }^{99 \mathrm{~m}} \mathrm{Tc}=6,02$ horas $\mathrm{e}$ ${ }^{99} \mathrm{~T} \mathrm{C}=2 \times 10^{5}$ anos (15).

FIGURA 2- Produtos comercializados pelo IPEN: (1) conjunto de reagentes liofilizados; (2) gerador de ${ }^{99} \mathrm{Mo} /{ }^{99 \mathrm{~m}} \mathrm{Tc}$; (3) frasco em vácuo; (4) solução salina e (5) castelinho de chumbo para armazenamento e transporte dos radiofármacos (16).

FIGURA 3- llustração do processo de eluição que ocorre no interior dos geradores de ${ }^{99} \mathrm{Mo}-{ }^{99 m} \mathrm{Tc}$ produzidos pelo IPEN (17).

FIGURA 4- llustração dos kits de reagentes liofilizados produzidos pelo IPEN (16).

FIGURA 5- Esquema das reações para obtenção dos radiofármacos de ${ }^{99 \mathrm{~m}} \mathrm{Tc}$ (10). O íon pertecnetato $\left({ }^{99 \mathrm{~m}} \mathrm{Tc}^{7+} \mathrm{O}_{4}\right)^{-}$é reduzido para um estado de oxidação menor $\left(\mathrm{n}^{+}=1\right.$ a 6) pela ação do íon estanoso $\left(\mathrm{Sn}^{2+}\right)$. $\mathrm{O}$ complexo do ligante desejado (fármaco) com o ${ }^{99 \mathrm{~m}} \mathrm{~T}$ cn é obtido após um período curto (5 - 30 minutos) com um alto rendimento (> 90\%) (10).

FIGURA 6- Estrutura molecular: (A) DMSA [Fórmula molecular: $\mathrm{C}_{4} \mathrm{H}_{6} \mathrm{O}_{4} \mathrm{~S}_{2}$; Massa molecular: $182,22 \mathrm{~g} \mathrm{~mol}^{-1}$; (B) DMSA-- ${ }^{99 \mathrm{~m}} \mathrm{Tc}$ (III) [Fórmula molecular: $\mathrm{C}_{8} \mathrm{H}_{6} \mathrm{O}_{8} \mathrm{~S}_{4} \mathrm{Tc}$; Massa molecular: $456,20 \mathrm{~g} \mathrm{~mol}^{-1}$ ] e (C) DMSA ${ }^{-99 \mathrm{~m}} \mathrm{Tc}(\mathrm{V})$ [Fórmula molecular: $\mathrm{C}_{8} \mathrm{H}_{8} \mathrm{O}_{9} \mathrm{~S}_{4} \mathrm{Tc}$; Massa molecular: $\left.474,34 \mathrm{~g} \mathrm{~mol}^{-1}\right](20,21)$.

FIGURA 7- Obtenção do radiofármaco ECD- ${ }^{99 m}$ TC. A reação de esterificação de EC (A) com etanol em meio de $\mathrm{HCl}$ origina o ECD (B). Pela adição de $\mathrm{NaCl} 0,9 \%$, tampão fosfato e ${ }^{99 \mathrm{~m}} \mathrm{TcO}_{4}{ }^{-}$ao conjunto de $\mathrm{RL}$ de ECD pode ser obtido o ECD-99m Tc (C) (10).

FIGURA 8- Principais componentes do cromatógrafo líquido: reservatório de fase móvel, sistema de bombeamento com medidor de pressão, injetor, coluna cromatográfica, detector e registrador de dados (10).

FIGURA 9- Esquema das principais partes de um espectrômetro de massas: sistema de introdução da amostra, fonte de ionização, analisador de massas, detector e sistema de análise de dados que gera o espectro de massas (53 - modificado).

FIGURA 10- Principais características das formas de ionização empregadas em LC-MS. Ionização por elétron (EI - do inglês Electron 
Ionization) é utilizada no acoplamento da cromatografia gasosa com MS; APPI - fotoionização a pressão atmosférica; APCI - ionização química a pressão atmosférica; ESI - ionização por electronspray (54).

FIGURA 11- Ionização por electronspray (ESI): solução contendo moléculas protonadas é nebulizada através de um tubo capilar onde é aplicada alta voltagem $(+2 \mathrm{kV} \mathrm{a}+5 \mathrm{kV})$, formando gotículas carregadas. O solvente dessas gotículas carregadas é evaporado na região de dessolvatação aquecida e transfere a molécula protonada da fase líquida para a fase gasosa (51-modificado).

FIGURA 12- Eletrodos que formam a parte principal do analisador de massas do tipo ion trap. O eletrodo central (em forma de anel, ou ring electrode) é circundado por dois eletrodos sendo um de entrada e outro de saída dos íons (end cap) $(55,57)$.

FIGURA 13- Fluxograma para realização de estudos de degradação em condições ácida e alcalina. $\mathrm{HCl}$ : ácido clorídrico; $\mathrm{NaOH}$ : hidróxido de sódio; h: horas (4).

FIGURA 14- Fluxograma para realização de estudos de degradação em condições fotolíticas. Lux: unidade de medida de intensidade de luz visível; h: hora (4).

FIGURA 15- Fluxograma para realização de estudos de degradação em condições oxidativas. $\mathrm{H}_{2} \mathrm{O}_{2}$ : peróxido de hidrogênio; h:horas; min: minuto; T.A.: temperatura ambiente (4).

FIGURA 16- Perfil de pureza dos espectros de absorção na região UV de DMSA 1,0 mg L-1 obtidos por HPLC-DAD. (A) Absorbância em função do comprimento de onda $(\lambda=210-350 \mathrm{~nm})$. (B) Absorbância em função do tempo de retenção.

FIGURA 17- Espectros de absorção na região UV de DMSA $1,0 \mathrm{mg} \mathrm{L}^{-1}$ obtidos por HPLC-DAD. Absorbância em função do comprimento de onda $(\lambda=210-350 \mathrm{~nm})$. Tempo de retenção: (A) 5,515 minutos; (B) 5,590 minutos e (C) 5,753 minutos. (D) Cromatograma de DMSA.

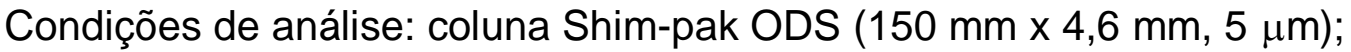
fase móvel: $0,1 \%$ de ácido fórmico: acetonitrila. Gradiente linear 560\%B em 15 minutos. Fluxo da fase móvel: $1 \mathrm{~mL} \mathrm{~min}^{-1}$; volume de amostra: $20 \mu \mathrm{L}$ e $\lambda=245 \mathrm{~nm}$.

FIGURA 18- Espectros de massas do DMSA: intervalo de varredura 50-500 m/z. (A) ESI+; condições de análise: voltagem do cone: $30 \mathrm{~V}$, voltagem do capilar: $3,0 \mathrm{kV}$ e temperatura de dessolvatação: $365^{\circ} \mathrm{C}$. (B) ESl': condições de análise: voltagem do cone: $40 \mathrm{~V}$, voltagem do capilar: $3,5 \mathrm{kV}$ e temperatura de dessolvatação: $365^{\circ} \mathrm{C}$.

FIGURA 19- (A) Cromatograma de DMSA $1 \mathrm{mg} \mathrm{mL}^{-1}$. (B) Cromatograma de RL de DMSA. Condições de análise: coluna Shim- 
pak ODS (150 mm x 4,6 mm, $5 \mu \mathrm{m}$ ); fase móvel: 0,1\% de ácido fórmico: acetonitrila. Gradiente linear 5-60\%B em 15 minutos. Fluxo da fase

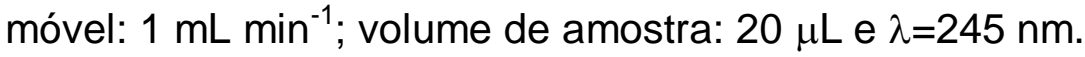

FIGURA 20- (A) Espectro de massas para o pico com tempo de retenção igual a 5,58 minutos da FIG.19A. (B) Espectro de massas para o pico com tempo de retenção igual a 11,32 minutos da FIG.19B. Prováveis estruturas químicas do íon base de m/z 204,8 e m/z 660,2 é destacada. Condições de análise: intervalo de varredura: 100-700 m/z; voltagem do cone: $30 \mathrm{~V}$, voltagem do capilar: $3,0 \mathrm{kV}$ e temperatura de dessolvatação: $365^{\circ} \mathrm{C}$.

FIGURA 21- (A) Cromatogramas de DMSA $1 \mathrm{mg} \mathrm{mL}^{-1}$ obtidos após hidrólise ácida com $\mathrm{HCl} 0,1 \mathrm{~mol} \mathrm{~L}^{-1}$. Tempos de degradação: 0,$5 ; 1 ; 2 ; 4$ e 24 horas. (B) Ampliação da FIG.21A no intervalo de 7-14 minutos. (C) Ampliação da FIG.21A no intervalo de 4-7 minutos. Condições da câmara de estabilidade: temperatura: $25{ }^{\circ} \mathrm{C}$, umidade relativa: $75 \%$. Condições da análise cromatográfica: coluna Shim-pak ODS (150 mm x 4,6 $\mathrm{mm}, 5 \mu \mathrm{m}$ ); fase móvel: $0,1 \%$ de ácido fórmico: acetonitrila. Gradiente linear 5-60\%B em 15 minutos. Fluxo da fase móvel: $1 \mathrm{~mL}$ $\mathrm{min}^{-1}$; volume de amostra: $20 \mu \mathrm{L}$ e $\lambda=245 \mathrm{~nm}$.

FIGURA 22- (A) Cromatogramas de RL de DMSA obtidos após hidrólise ácida com $\mathrm{HCl} 0,1 \mathrm{~mol} \mathrm{~L}^{-1}$. Tempos de degradação: 0,$5 ; 1 ; 2 ; 4$ e 24 horas. (B) Ampliação da FIG.22A no intervalo de 4,5-6,5 minutos. Condições da câmara de estabilidade: temperatura: $25^{\circ} \mathrm{C}$, umidade relativa: $75 \%$. Condições da análise cromatográfica: coluna Shim-pak ODS (150 mm x 4,6 mm, $5 \mu \mathrm{m}$ ); fase móvel: 0,1\% de ácido fórmico em água: acetonitrila. Gradiente linear 5-60\%B em 15 minutos. Fluxo da

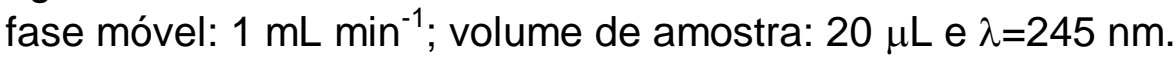

FIGURA 23- Hidrólise ácida (A) Espectro de massas obtido do pico com tempo de retenção igual a 4,81 minutos da FIG.21C. (B) Espectro de massas para o pico com tempo de retenção igual a 5,20 minutos da FIG.21C. (C) Espectro de massas para o pico com tempo de retenção igual a 5,76 minutos da FIG.21C. A estrutura química do íon base de cada espectro está em destaque. Condições de análise: full MS; intervalo de varredura: $50-500 \mathrm{~m} / \mathrm{z}$; voltagem do cone: $30 \mathrm{~V}$, voltagem do capilar: $3,0 \mathrm{kV}$ e temperatura de dessolvatação: $365^{\circ} \mathrm{C}$.

FIGURA 24- Estereoisômeros da molécula de DMSA (A) Forma meso; (B) Forma racêmica $\mathrm{D}$ e (C) Forma racêmica $L$ (21).

FIGURA 25- Cromatogramas de DMSA $1 \mathrm{mg} \mathrm{mL}^{-1}$ obtidos após hidrólise alcalina com $\mathrm{NaOH} 0,1 \mathrm{~mol} \mathrm{~L}^{-1}$. Tempos de reação: 0,$5 ; 1 ; 2 \mathrm{e}$ 4 horas. Tempo de retenção: (1) 4,98 minutos; (2) 5,59 minutos; (3) 9,73 minutos; (4) 10,61 minutos. Condições da câmara de estabilidade: temperatura: $25{ }^{\circ} \mathrm{C}$, umidade relativa: $75 \%$. Condições da análise cromatográfica: coluna Shim-pak ODS (150 mm x 4,6 mm, $5 \mu \mathrm{m}$ ); fase móvel: $0,1 \%$ de ácido fórmico: acetonitrila. Gradiente linear 5-60\%B em 
15 minutos. Fluxo da fase móvel: $1 \mathrm{~mL} \mathrm{~min}^{-1}$; volume de amostra: $20 \mu \mathrm{L}$ e $\lambda=245 \mathrm{~nm}$.

FIGURA 26- Espectros de massas obtidos dos produtos de degradação do DMSA sob hidrólise alcalina com $\mathrm{NaOH}$ apresentados na FIG.25. (A) pico (1); (B) pico (2) (C) pico (3) e (D) pico (4). A estrutura química do íon base de cada espectro está em destaque. Condições de análise: full MS, voltagem do cone: $30 \mathrm{~V}$, voltagem do capilar: 3,0 kV e temperatura de dessolvatação: $365^{\circ} \mathrm{C}$

FIGURA 27- Espectros $\mathrm{MS}^{2}$. (A) $\mathrm{m} / \mathrm{z} 204,9$ (FIG.27A); (B) $\mathrm{m} / \mathrm{z} 204,9$ (FIG.27B); (C) $\mathrm{m} / \mathrm{z} 321,0$ (FIG.27C); (D) $\mathrm{m} / \mathrm{z} 384,9$ (FIG.27D). $\quad \mathrm{A}$ estrutura química do íon base de cada espectro está em destaque. Condições de análise: $\mathrm{MS}^{2}$, voltagem do cone: $30 \mathrm{~V}$, voltagem do capilar: 3,0 kV e temperatura de dessolvatação: $365^{\circ} \mathrm{C}$.

FIGURA 28- Esquema sugerido para a formação dos produtos de degradação do DMSA após hidrólise alcalina com $\mathrm{NaOH} 0,1 \mathrm{~mol} \mathrm{~L}^{-1}$. Os números indicados nas setas referem-se ao ganho (+) ou a perda (-) de massa pelo íon. Condições de análise: full $\mathrm{MS}, \mathrm{MS}^{2}, \mathrm{MS}^{3}$ e $\mathrm{MS}^{4}$; voltagem do cone: $30 \mathrm{~V}$, voltagem do capilar: $3,0 \mathrm{kV}$ e temperatura de dessolvatação: $365^{\circ} \mathrm{C}$.

FIGURA 29- Esquema sugerido para a formação dos produtos de degradação do DTGA após hidrólise alcalina com $\mathrm{NaOH} 0,1 \mathrm{~mol} \mathrm{~L}^{-1}$. Os números indicados nas setas referem-se ao ganho (+) ou a perda (-) de massa pelo íon. Condições de análise: full $\mathrm{MS} \mathrm{e} \mathrm{MS}^{2}$; voltagem do cone: $30 \mathrm{~V}$, voltagem do capilar: 3,0 kV e temperatura de dessolvatação: 365 ${ }^{\circ} \mathrm{C}$.

FIGURA 30- Cromatogramas de RL de DMSA obtidos após hidrólise alcalina com $\mathrm{NaOH} 0,1 \mathrm{~mol} \mathrm{~L}^{-1}$. Tempos de reação: 0,$5 ; 1 ; 2$ e 4 horas. Tempos de retenção: (1) 5,62 minutos; (2) 8,21minutos; (3) 9,11 minutos e (4) 10,90 minutos. Condições da câmara de estabilidade: temperatura: $25{ }^{\circ} \mathrm{C}$, umidade relativa: $75 \%$. Condições da análise cromatográfica: coluna Shim-pak ODS (150 mm x 4,6 mm, $5 \mu \mathrm{m})$; fase móvel: 0,1\% de ácido fórmico: acetonitrila. Gradiente linear 5-60\%B em 15 minutos. Fluxo da fase móvel: $1 \mathrm{~mL} \mathrm{~min}^{-1}$; volume de amostra: $20 \mu \mathrm{L}$ e $\lambda=245 \mathrm{~nm}$.

FIGURA 31- Espectros de massas obtidos dos produtos de degradação do $\mathrm{RL}$ de DMSA sob hidrólise alcalina com $\mathrm{NaOH}$ apresentados na FIG.29. (A) pico (2); (B) pico (3) e (C) pico (4). A estrutura química do íon base de cada espectro está em destaque. Condições de análise: full MS, voltagem do cone: $30 \mathrm{~V}$, voltagem do capilar: $3,0 \mathrm{kV}$ e temperatura de dessolvatação: $365^{\circ} \mathrm{C}$.

FIGURA 32- Esquema sugerido para a formação dos produtos de degradação do DMSA no RL após hidrólise alcalina com $\mathrm{NaOH} 0,1 \mathrm{~mol}$ $\mathrm{L}^{-1}$. Os número indicados nas setas referem-se ao ganho (+) ou a perda 
(-) de massa pelo íon. Condições de análise: full MS, $\mathrm{MS}^{2}, \mathrm{MS}^{3}$ e $\mathrm{MS}^{4}$; voltagem do cone: $30 \mathrm{~V}$, voltagem do capilar: $3,0 \mathrm{kV}$ e temperatura de dessolvatação: $365{ }^{\circ} \mathrm{C}$

FIGURA 33-. Cinética degradação das amostras de DMSA (•) e RL de DMSA (-) submetidas à hidrólise alcalina com $\mathrm{NaOH} 0,1 \mathrm{~mol} \mathrm{~L}^{-1}$ por 24 horas, onde $\mathrm{C}=\%$ área.

FIGURA 34- Cromatogramas de DMSA obtidos após degradação com radiação UV. (A) DMSA em solução aquosa; (B) DMSA na forma sólida (pó). Tempos de exposição: 6 e 24 horas. Tempos de retenção (minutos): (1) 5,55; (2) 7,30; (3) 7,72; (4) 8,66; (5) 8,92; (6) 9,41; (7) 10,31; (8) 10,61; (9) 12,57. Condições da câmara de estabilidade: temperatura: $25{ }^{\circ} \mathrm{C}$, umidade relativa: $75 \%$, Intensidade luz UV: $200 \mathrm{~W}$ $\mathrm{m}^{-2}$ por hora. Condições da análise cromatográfica: coluna Shim-pak ODS (150 mm x 4,6 mm, $5 \mu \mathrm{m}$ ); fase móvel: 0,1\% de ácido fórmico em água: acetonitrila. Gradiente linear 5-60\%B em 15 minutos. Fluxo da

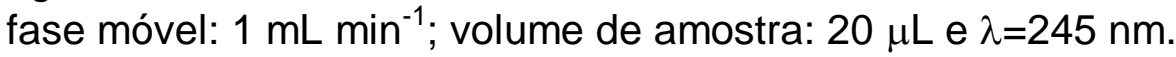

FIGURA 35- Espectros de massas referentes aos produtos de degradação do DMSA após degradação fotolítica por luz UV. Os espectros correspondem aos picos cromatográficos na FIG.34. (A) pico (1); (B) picos (2) e (3) (C) pico (4) e (5). A estrutura química do íon base de cada espectro está em destaque. Condições de análise: full MS, voltagem do cone: $30 \mathrm{~V}$, voltagem do capilar: $3,0 \mathrm{kV}$ e temperatura de dessolvatação: $365^{\circ} \mathrm{C}$.

FIGURA 35- Continuação. Espectros de massas referentes aos produtos de degradação do DMSA após degradação fotolítica por luz UV. Os espectros correspondem aos picos cromatográficos na FIG.35. (D) pico (6); (E) pico (7) e (8) e (F) pico (9). A estrutura química do íon base de cada espectro está em destaque. Condições de análise: full MS, voltagem do cone: $30 \mathrm{~V}$, voltagem do capilar: $3,0 \mathrm{kV}$ e temperatura de dessolvatação: $365^{\circ} \mathrm{C}$.

FIGURA 36- Espectros $\mathrm{MS}^{2}$. (A) $\mathrm{m} / \mathrm{z}$ 267,1 (FIG.35B); (B) $\mathrm{m} / \mathrm{z} 352,9$ (FIG.35C); (C) m/z 398,9 (FIG.35F). A estrutura química do íon base de cada espectro está em destaque. Condições de análise: $\mathrm{MS}^{2}$, voltagem do cone: $30 \mathrm{~V}$, voltagem do capilar: $3,0 \mathrm{kV}$ e temperatura de dessolvatação: $365^{\circ} \mathrm{C}$.

FIGURA 37- Esquema sugerido para a formação dos produtos de degradação do DMSA após fotólise sob radiação de luz UV. Os números indicados nas setas referem-se ao ganho (+) ou a perda (-) de massa pelo íon. Condições de análise: full $\mathrm{MS} \mathrm{MS}^{2}$ e $\mathrm{MS}^{3}$; voltagem do cone: $30 \mathrm{~V}$, voltagem do capilar: $3,0 \mathrm{kV}$ e temperatura de dessolvatação: $365^{\circ} \mathrm{C}$.

FIGURA 38- Cromatogramas de RL de DMSA em solução aquosa obtidos após degradação fotolitica com radiação UV. Tempos de 
exposição: 6 e 24 horas. Condições da câmara de estabilidade: temperatura: $25{ }^{\circ} \mathrm{C}$, umidade relativa: $75 \%$, Intensidade luz UV: $200 \mathrm{~W}$ $\mathrm{m}^{-2}$ por hora. Condições da análise cromatográfica: coluna Shim-pak ODS (150 mm x 4,6 mm, $5 \mu \mathrm{m}$ ); fase móvel: 0,1\% de ácido fórmico em água: acetonitrila. Gradiente linear 5-60\%B em 15 minutos. Fluxo da

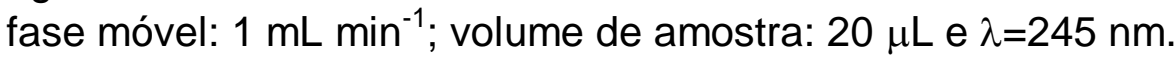

FIGURA 39- Espectros de massas referentes aos produtos de degradação do RL de DMSA após degradação fotolítica por luz UV. Os espectros correspondem ao pico cromatográficos na FIG.38. Condições de análise: full MS, voltagem do cone: $30 \mathrm{~V}$, voltagem do cailar: $3,0 \mathrm{kV}$ e temperatura de dessolvatação: $365^{\circ} \mathrm{C}$.

FIGURA 40-. Cinética da degradação das amostras de DMSA (•) e RL de DMSA (-) submetidas à fotólise com luz UV por até 24 horas, onde $\mathrm{C}=\%$ área.

FIGURA 41- (A) Cromatogramas de DMSA obtidos após degradação por oxidação com $\mathrm{H}_{2} \mathrm{O}_{2} 1 \%$. Tempos de reação: 0,5; $1 ; 2$ e 4 horas. (B) Ampliação da FIG.41A no intervalo de 7-15 minutos. Tempos de retenção: (1) 2,14 minutos; (2) 5,58 minutos; (3) 8,73 minutos; (4) 8,97 minutos; (5) 9,44 minutos; (6) 10,67 minutos; (7) 11,83 minutos e (8) 13,25 minutos. Condições da câmara de estabilidade: temperatura: 25 ${ }^{\circ} \mathrm{C}$, umidade relativa: $75 \%$. Condições da análise cromatográfica: coluna Shim-pak ODS (150 mm x 4,6 mm, $5 \mu \mathrm{m}$ ); fase móvel: 0,1\% de ácido fórmico: acetonitrila. Gradiente linear 5-60\%B em 15 minutos. Fluxo da fase móvel: $1 \mathrm{~mL} \mathrm{~min}{ }^{-1}$; volume de amostra: $20 \mu \mathrm{L}$ e $\lambda=245 \mathrm{~nm}$.

FIGURA 42- Espectros de massas referentes ao pico cromatográfico eluido em 2,14 minutos após degradação do DMSA por oxidação com $\mathrm{H}_{2} \mathrm{O}_{2} 1 \%$. (A) full MS e (B) $\mathrm{MS}^{2}$. A estrutura química do íon base de cada espectro está em destaque. Condições de análise: voltagem do cone: $30 \mathrm{~V}$, voltagem do capilar: $3,0 \mathrm{kV}$ e temperatura de dessolvatação: $365^{\circ} \mathrm{C}$.

FIGURA 43- Espectros de massas referentes ao pico cromatográfico eluido em 11,53 minutos após degradação do DMSA por oxidação com $\mathrm{H}_{2} \mathrm{O}_{2} 1 \%$. (A) full MS e (B) $\mathrm{MS}^{2}$. A estrutura química do íon base de cada espectro está em destaque. Condições de análise: voltagem do cone: $30 \mathrm{~V}$, voltagem do capilar: $3,0 \mathrm{kV}$ e temperatura de dessolvatação: $365{ }^{\circ} \mathrm{C}$.

FIGURA 44- Esquema sugerido para a formação do produto de degradação do DMSA após oxidação com $\mathrm{H}_{2} \mathrm{O}_{2} 1 \%$. Condições de análise: full $\mathrm{MS}$ e $\mathrm{MS}^{2}$; voltagem do cone: $30 \mathrm{~V}$, voltagem do capilar: 3,0 kV e temperatura de dessolvatação: $365^{\circ} \mathrm{C}$.

FIGURA 45- Cromatogramas de RL de DMSA obtidos após degradação por oxidação com $\mathrm{H}_{2} \mathrm{O}_{2} 1 \%$. Tempos de reação: 0,$5 ; 1 ; 2$ e 4 horas. Tempos de retenção: (1) 5,57 minutos e (2) 9,46 minutos. Condições da 
câmara de estabilidade: temperatura: $25{ }^{\circ} \mathrm{C}$, umidade relativa: $75 \%$. Condições da análise cromatográfica: coluna Shim-pak ODS (150 mm x 4,6 $\mathrm{mm}, 5 \mu \mathrm{m}$ ); fase móvel: $0,1 \%$ de ácido fórmico: acetonitrila. Gradiente linear 5-60\%B em 15 minutos. Fluxo da fase móvel: $1 \mathrm{~mL}$ $\min ^{-1}$; volume de amostra: $20 \mu \mathrm{L}$ e $\lambda=245 \mathrm{~nm}$

FIGURA 46-. Cinética da degradação das amostras de DMSA (•) e RL de DMSA (匹) submetidas à oxidação $c o m \mathrm{H}_{2} \mathrm{O}_{2}$ por até 4 horas, onde $\mathrm{C}=\%$ área.

FIGURA 47- Cromatogramas de DMSA (A) e do RL de DMSA (B) obtidos após termodegradação nas temperaturas de 35, 40, 45, 50 e 60 ${ }^{\circ} \mathrm{C}$. Condições da câmara de estabilidade: tempo de exposição: 24 horas. umidade relativa: $75 \%$. Condições da análise cromatográfica: coluna Shim-pak ODS (150 mm x 4,6 mm, $5 \mu \mathrm{m}$ ); fase móvel: 0,1\% de ácido fórmico: acetonitrila. Gradiente linear 5-60\%B em 15 minutos. Fluxo da fase móvel: $1 \mathrm{~mL} \mathrm{~min}^{-1}$; volume de amostra: $20 \mu \mathrm{L}$ e $\lambda=245$ nm.

FIGURA 48- Espectro de absorção na região UV em função do comprimento de onda $(\lambda=210-350 \mathrm{~nm})$ de ECD $1 \mathrm{mg} \mathrm{mL}^{-1}$. Condições da análise cromatográfica: coluna Shim-pak ODS (150 mm x 4,6 mm, 5 $\mu \mathrm{m})$; fase móvel: água (A): metanol (B). Modo isocrático: 40\%A-60\%B em 15 minutos. Fluxo da fase móvel: $1 \mathrm{~mL} \mathrm{~min}^{-1}$; volume de amostra: 20 $\mu \mathrm{L}$ e $\lambda=215 \mathrm{~nm}$.

FIGURA 49- Espectros de massas do ECD (A) ESI+; condições de 86 análise: voltagem do cone: $25 \mathrm{~V}$, voltagem do capilar: $3,0 \mathrm{kV}$ e temperatura de dessolvatação: $325^{\circ} \mathrm{C}$. (B) ESl': condições de análise: voltagem do cone: $35 \mathrm{~V}$, voltagem do capilar: $3,5 \mathrm{kV}$ e temperatura de dessolvatação: $325^{\circ} \mathrm{C}$.

FIGURA 50- (A) Cromatograma de ECD $1 \mathrm{mg} \mathrm{mL}^{-1}$. (B) Cromatograma de RL de ECD. Condições de análise: coluna Shim-pak ODS (150 mm x 4,6 $\mathrm{mm}, 5 \mu \mathrm{m})$; fase móvel água: metanol. Modo isocrático (40\%A:60\%B, v/v) em 15 minutos. Fluxo da fase móvel: $1 \mathrm{~mL} \mathrm{~min}^{-1}$; volume de amostra: $20 \mu \mathrm{L}$ e $\lambda=215 \mathrm{~nm}$.

FIGURA 51- (A) Espectro de massas para o pico com tempo de retenção igual a 5,40 minutos da FIG.50A. (B) Espectro de massas para o pico com tempo de retenção igual a 5,55 minutos da FIG.50B. Prováveis estruturas químicas do íon base de $\mathrm{m} / \mathrm{z} 325,6$ e $\mathrm{m} / \mathrm{z} 325,8$ é destacada. Condições de análise: Full MS ESI+; voltagem do cone: $25 \mathrm{~V}$, voltagem do capilar: $3,0 \mathrm{kV}$ e temperatura de dessolvatação: 325 ${ }^{\circ} \mathrm{C}$.

FIGURA 52- (A) Cromatogramas de ECD $1 \mathrm{mg} \mathrm{mL}^{-1}$ obtidos após hidrólise ácida com $\mathrm{HCl} 0,1 \mathrm{~mol} \mathrm{~L}^{-1}$. Tempos de degradação: 0,$5 ; 1 ; 2 ; 4$ e 24 horas. (B) Ampliação da FIG.52A no intervalo de 5-6 minutos. 
Condições da câmara de estabilidade: temperatura: $25^{\circ} \mathrm{C}$, umidade relativa: $75 \%$. Condições da análise cromatográfica: coluna Shim-pak ODS (150 mm x 4,6 mm, $5 \mu \mathrm{m}$ ); fase móvel: água: metanol. Modo isocrático (40\%A:60\%B, v/v) em 15 minutos. Fluxo da fase móvel: $1 \mathrm{~mL}$ $\min ^{-1}$; volume de amostra: $20 \mu \mathrm{L}$ e $\lambda=215 \mathrm{~nm}$.

FIGURA 53- Cromatogramas de ECD $1 \mathrm{mg} \mathrm{mL}^{-1}$ obtidos após hidrólise alcalina com NaOH 0,1 mol L-1. Tempos de reação: 0,$5 ; 1 ; 2$ e 4 horas. Tempo de retenção: (1) 1,71 minutos; (2) 3,34 minutos; (3) 3,69 minutos; (4) 5,74 minutos; (5) 6,60 minutos e (6) 10,15 minutos. Condições da câmara de estabilidade: temperatura: $25^{\circ} \mathrm{C}$, umidade relativa: $75 \%$. Condições da análise cromatográfica: coluna Shim-pak ODS (150 mm x 4,6 mm, $5 \mu \mathrm{m}$ ); fase móvel: água: metanol. Modo isocrático $(40 \% \mathrm{~A}: 60 \% \mathrm{~B}, \mathrm{v} / \mathrm{v})$ em 15 minutos. Fluxo da fase móvel: $1 \mathrm{~mL}$ $\min ^{-1}$; volume de amostra: $20 \mu \mathrm{L}$ e $\lambda=215 \mathrm{~nm}$.

FIGURA 54- Espectros de massas obtidos dos produtos de degradação do ECD sob hidrólise alcalina com $\mathrm{NaOH}$ apresentados na FIG.53 . (A) pico (1); (B) pico (2) e (C) pico (3). A estrutura química do íon base de cada espectro está em destaque. Condições de análise: full MS, voltagem do cone: $25 \mathrm{~V}$, voltagem do capilar: $3,0 \mathrm{kV}$ e temperatura de dessolvatação: $325^{\circ} \mathrm{C}$..

FIGURA 54- Continuação. Espectros de massas obtidos dos produtos de degradação do ECD após hidrólise alcalina com $\mathrm{NaOH} 0,1 \mathrm{molL}^{-1}$ apresentados na FIG.54 . (D) pico (4); (E) pico (5); (F) pico (6). A estrutura química do íon base de cada espectro está em destaque. Condições de análise: full MS, voltagem do cone: $25 \mathrm{~V}$, voltagem do capilar: $3,0 \mathrm{kV}$ e temperatura de dessolvatação: $325^{\circ} \mathrm{C}$..

FIGURA 55- Esquema sugerido para a formação dos produtos de degradação do EC após hidrólise alcalina. Os grupos indicados nas setas referem-se a perda (-) de massa pelo íon. Condições de análise: full MS, $\mathrm{MS}^{2}, \mathrm{MS}^{3}$ e $\mathrm{MS}^{4}$; voltagem do cone: $25 \mathrm{~V}$, voltagem do capilar: $3,0 \mathrm{kV}$ e temperatura de dessolvatação: $325^{\circ} \mathrm{C}$.

FIGURA 56- Esquema sugerido para a formação dos produtos de degradação do ECD após hidrólise alcalina. Os grupos indicados nas setas referem-se à perda (-) ou ganho (+) de massa pelo íon. Condições de análise: full $\mathrm{MS}, \mathrm{MS}^{2}, \mathrm{MS}^{3} \mathrm{e} \mathrm{MS}^{4}$; voltagem do cone: $25 \mathrm{~V}$, voltagem do capilar: $3,0 \mathrm{kV}$ e temperatura de dessolvatação: $325^{\circ} \mathrm{C}$.

FIGURA 57- Cromatogramas de RL de ECD obtidos após hidrólise alcalina com NaOH 0,1 mol L-1. Tempos de reação: 0,5; $1 ; 2$ e 4 horas. Tempos de retenção: (1) 2,17 minutos; (2) 3,16minutos; (3) 6,72 minutos; (4) 9,17 minutos; (5) 10,18 minutos e (6) 13,07 minutos. Condições da câmara de estabilidade: temperatura: $25^{\circ} \mathrm{C}$, umidade relativa: $75 \%$. Condições da análise cromatográfica: coluna Shim-pak ODS (150 mm x 4,6 mm, $5 \mu \mathrm{m})$; fase móvel: água: metanol. Modo isocrático (40\%A:60\%B, v/v) em 15 minutos. Fluxo da fase móvel: $1 \mathrm{~mL}$ 
$\min ^{-1}$; volume de amostra: $20 \mu \mathrm{L}$ e $\lambda=215 \mathrm{~nm}$.

FIGURA 58- Espectros de massas obtidos dos produtos de degradação

do $R L$ de ECD sob hidrólise alcalina com $\mathrm{NaOH}$ apresentados na FIG.58 . (A) pico (4) e (B) pico (6). A estrutura química do íon base de cada espectro está em destaque. Condições de análise: full MS, voltagem do cone: $25 \mathrm{~V}$, voltagem do capilar: $3,0 \mathrm{kV}$ e temperatura de dessolvatação: $325^{\circ} \mathrm{C}$.

FIGURA 59- Esquema sugerido para a formação dos produtos de degradação do $R L$ de ECD após hidrólise alcalina. Os grupos indicados nas setas referem-se a perda (-) de massa pelo íon. Condições de análise: full MS, $\mathrm{MS}^{2}, \mathrm{MS}^{3}$ e $\mathrm{MS}^{4}$; voltagem do cone: $25 \mathrm{~V}$, voltagem do capilar: $3,0 \mathrm{kV}$ e temperatura de dessolvatação: $325^{\circ} \mathrm{C}$.

FIGURA 60- Cinética da degradação das amostras de (A) ECD (•) e (B) $\mathrm{RL}$ de $\mathrm{ECD}(\mathbf{-})$ submetidas à hidrólise alcalina com $\mathrm{NaOH} 0,1 \mathrm{~mol} \mathrm{~L}^{-1}$ por 4 horas, onde $\mathrm{C}=\%$ área.

FIGURA 61- Cromatogramas obtidos após degradação do ECD por oxidação com $\mathrm{H}_{2} \mathrm{O}_{2}$ 1\%. Tempos de reação: 0,$5 ; 1 ; 2$ e 4 horas. Tempos de retenção: (1) 2,17 minutos; (2) 3,59 minutos; (3) 6,28 minutos; (4) 8,71 minutos e (5) 10,16 minutos. Condições da câmara de estabilidade: temperatura: $25{ }^{\circ} \mathrm{C}$, umidade relativa: $75 \%$. Condições da análise cromatográfica: coluna Shim-pak ODS $(150 \mathrm{~mm} \times 4,6 \mathrm{~mm}, 5$ $\mu \mathrm{m})$; fase móvel: água: metanol. Modo isocrático (40\%A:60\%B, v/v) em 15 minutos. Fluxo da fase móvel: $1 \mathrm{~mL} \mathrm{~min}^{-1}$; volume de amostra: $20 \mu \mathrm{L}$ e $\lambda=215 \mathrm{~nm}$.

FIGURA 62-. Cinética da degradação das amostras de ECD submetidas à oxidação com $\mathrm{H}_{2} \mathrm{O}_{2} 1 \%$ por até 4 horas, onde $\mathrm{C}=\%$ área. 


\section{LISTA DE TABELAS}

TABELA 1- Composição dos reagentes liofilizados de DMSA e ECD Página produzidos no CR.

TABELA 2- Parâmetros otimizados da fonte de ionização ESI para as análises de DMSA e ECD e seus reagentes liofilizados ( $R L)$.

TABELA 3- Índice de similaridade de pureza de pico para DMSA e RL de DMSA por HPLC-DAD.

TABELA 4 - Teor de DMSA em reagentes liofilizados obtidos por HPLCDAD.

TABELA 5- Porcentagem de degradação do DMSA (API) e do DMSA no $R L$ nas diferentes condições de degradação alcalina.

TABELA 6- Porcentagem de degradação do DMSA (API) e do DMSA no $\mathrm{RL}$ após fotólise.

TABELA 7- Porcentagem de degradação do DMSA (API) e do DMSA no $R L$ após oxidação.

TABELA 8- Índice de similaridade de pureza de pico para ECD e RL de ECD por HPLC-DAD.

TABELA 9 - Teor de ECD em reagentes liofilizados obtidos por HPLCDAD.

TABELA 10- Porcentagem de degradação do ECD (API) e do ECD no $R L$ nas diferentes condições de degradação alcalina.

TABELA 11- Porcentagem de degradação do ECD (API) e do ECD no 105 $R L$ após oxidação. 


\section{LISTA DE ABREVIATURAS E/ OU SIGLAS}

${ }^{99 m}$ Tc - tecnécio-99 metaestável

ANVISA - Agência Nacional de Vigilância Sanitária

APCI - Ionização Química à Pressão Atmosférica (do inglês Atmospheric Pressure Chemical Ionization)

API - Insumo Farmacêutico Ativo (do inglês Active Pharmaceutical Ingredient)

APPI - Fotoionização a Pressão Atmosférica (do inglês Atmospheric Pressure Photoionization)

$\mathrm{Da}-$ Dalton $=1 \mathrm{Da}=1 \mathrm{u}$

DAD - Detecção por Arranjo de Diodos (do inglês Diode array detector)

DMSA - Ácido 2,3-Dimercaptosuccínico (do inglês Dimercaptosuccinic Acid)

ECD - Etilenodicisteína Dietil Éster (do inglês Ethyl Cysteinate Dimer),

ESI - do inglês Electrospray ou Electrospray Ionization

FDA - Food and Drug Administration

HPLC - Cromatografia Líquida de Alta Eficiência (do inglês High Performance Liquid Chromatography)

ICH - Conferência Internacional sobre Harmonização (do inglês International Conference on Harmonization)

LC-MS ${ }^{\mathbf{n}}$ - Cromatografia Líquida acoplada à Espectrometria de Massas de múltiplos estágios (do inglês Liquid Chromatography-multiple-stage Mass Spectrometry)

PC - Cromatografia em Papel (do inglês Paper Chromatography)

RDC - Resolução da Diretoria Colegiada

$\mathbf{R L}$ - reagente(s) liofilizado(s)

TLC - Cromatografia em Camada Delgada (do inglês Thin Layer Chromatography)

TOF - Tempo de Vôo (do inglês Time of Flight)

USP - Farmacopeia Americana (do inglês United States Pharmacopeia) 


\section{INTRODUÇÃO}

A utilização de radiofármacos na terapia e no diagnóstico de doenças e outras disfunções do organismo humano tem aumentado de forma significativa nas últimas décadas. $O$ crescente desenvolvimento de novos reagentes liofilizados $(R L)$ para a preparação de radiofármacos e o aumento da produção de radioisótopos em cíclotron, embora proporcionem uma variedade de radiofármacos para uso clínico, deixa evidente uma das lacunas na pesquisa radiofarmacêutica, a identificação e a quantificação de impurezas e/ou produtos de degradação $(1,2)$.

A identificação de impurezas é um constante desafio porque muitas vezes estas impurezas são estruturalmente desconhecidas e presentes em número e quantidades aleatórias, encontrando-se na maioria dos casos em pequenas concentrações e frequentemente apresentam estruturas similares àquela do ingrediente farmacêutico ativo (API - do inglês Active Pharmaceutical Ingredient) (3).

Entre as impurezas encontradas nos radiofármacos destacamse os produtos de degradação os quais podem ter origem no API, no RL, na degradação durante estocagem ou na marcação do $\mathrm{RL}$ com um radioisótopo específico $(1,2)$.

No intuito de garantir a qualidade dos radiofármacos e proteger os pacientes dos possíveis danos causados pela presença de impurezas em medicamentos, regulamentos cada vez mais rígidos têm sido impostos às indústrias farmacêuticas convencionais e às radiofarmacêuticas. A Agência Nacional de Vigilância Sanitária (ANVISA), através da Resolução da Diretoria Colegiada (RDC) $n^{\circ} 45 / 2012$, estabelece os procedimentos adotados para os estudos de degradação forçada (4).

O estudo e a elucidação dos compostos de degradação gerados a partir de um estudo de degradação forçada são necessários para o reconhecimento de sua toxicidade. Uma vez elucidada a estrutura e a toxicidade, é possível propor alterações nas condições de produção do 
radiofármaco ou mesmo a exclusão de algum excipiente visando reduzir a quantidade dessas substâncias no radiofármaco $(1,5)$.

Estudos de degradação forçada envolvem a exposição de amostras representativas do API e RL às condições de estresse causadas por ação da hidrólise ácida, hidrólise alcalina, hidrólise neutra, fotólise, oxidação e temperatura (calor) (5).

Muitos estudos têm focado na quantificação de impurezas químicas ou radioquímicas por cromatografia em papel (PC - do inglês Paper Chromatography), cromatografia em camada delgada (TLC - do inglês Thin Layer Chromatography) e cromatografia líquida de alta eficiência (HPLC - do inglês High Performance Liquid Chromatography). Entretanto, estudos encontrados na literatura não identificaram essas impurezas $(5,6)$.

As técnicas de cromatografia líquida de alta eficiência com Detecção por Arranjo de Diodos (HPLC-DAD - do inglês High Performance Liquid Chromatography- Diode array detector) e cromatografia líquida acoplada à espectrometria de massas de múltiplos estágios (LC-MS ${ }^{n}-$ do inglês Liquid Chromatography-multiple-stage Mass Spectrometry) possibilitam a obtenção de informações de impurezas e/ou produtos de degradação presentes nos API e RL, que técnicas como PC e TLC não permitem identificar $(6,7)$.

HPLC-DAD e LC-MS ${ }^{n}$ têm se tornado referência na análise de fármacos e radiofármacos por apresentarem alta sensibilidade, seletividade e velocidade de análise. Devido a essas vantagens, HPLC-DAD e LC-MS ${ }^{n}$ possibilitam avaliar os riscos que substâncias indesejáveis presentes em medicamentos impõem a saúde humana, evitando efeitos maléficos (tóxicos), através da identificação e quantificação de impurezas (6-9).

Assim, com o intuito de contribuir para o conhecimento da estabilidade dos $\mathrm{RL}$ de ácido 2,3-Dimercaptosuccínico (DMSA) e Etilenodicisteína Dietil Éster (ECD), que marcados com tecnécio-99m $\left({ }^{99 \mathrm{~m}} \mathrm{Tc}\right)$ são utilizados para radiodiagnóstico em medicina nuclear, este trabalho visou identificar os principais produtos de degradação desses $R L$ e suas respectivas matérias-primas precursoras utilizando as técnicas HPLC-DAD e LC-MS . 


\section{OBJETIVOS}

Os objetivos deste trabalho foram realizar o estudo de estabilidade em condições forçadas de degradação dos reagentes liofilizados DMSA ( $R L$ de DMSA) e ECD (RL de ECD), a fim de verificar os possíveis fatores que conduzem a sua degradação; isolar e identificar seus produtos de degradação utilizando as técnicas de cromatografia líquida de alta eficiência com detecção por arranjo de diodos (HPLC-DAD) e cromatografia líquida acoplada à espectrometria de massas de múltiplos estágios (LC-MS $\left.{ }^{n}\right)$.

\subsection{Objetivos específicos para estudo dos API (DMSA e ECD) e RL de DMSA e ECD.}

- Desenvolver um método analítico indicativo de estabilidade capaz de detectar simultâneamente o API no RL e seus produtos de degradação por HPLC-DAD e LC-MS

- Realizar o estudo de degradação hidrolítico (condições ácida, alcalina e neutra), fotolítica, oxidativa e termodegradação;

- $\quad$ Propor as estruturas químicas dos principais produtos de degradação de DMSA, ECD e RL de DMSA e de ECD.

- $\quad$ Avaliar a cinética de degradação do DMSA e do ECD. 


\section{JUSTIFICATIVA}

Um dos problemas mais comuns associado ao uso dos radiofármacos é a alteração da biodistribuição em um determinado órgão ou tecido, a qual pode ter um significante impacto clínico. Muitos fatores podem alterar a biodistribuição normal do radiofármaco dentre eles destacam-se os produtos de degradação. Todo medicamento pode sofrer degradação, e os produtos formados podem ser tóxicos, comprometendo sua segurança e eficácia.

O Centro de Radiofarmácia (CR) do IPEN-CNEN/SP produz e comercializa kits de RL para marcação com tecnécio-99m e posterior uso em radiodiagnóstico. O CR realiza estudos de estabilidade para estabelecer o prazo de validade de seus medicamentos, porém nenhum estudo é feito com relação à identificação e quantificação dos produtos de degradação provenientes do API, RL ou do próprio radiofármaco.

$\mathrm{Na}$ Europa e nos Estados Unidos, há algum tempo, já são exigidos testes para identificar os produtos de degradação de medicamentos. No Brasil, a ANVISA ainda não exige estes testes para medicamentos já disponíveis no mercado, porém essa exigência vem sendo aplicada a testes de novos medicamentos, como forma de preparar as indústrias para o cumprimento de normas em processo de redação.

A versatilidade das moléculas de DMSA e ECD devido à presença de grupos funcionais $(\mathrm{COOH}$ e $\mathrm{SH})$ despertou grande interesse. $\mathrm{O}$ desafio deste trabalho foi identificar os principais produtos de degradação dos RL de DMSA e ECD utilizando as técnicas analíticas HPLC-DAD e LC$M^{n}$, visando atender futuras exigências da legislação brasileira. 


\section{REVISÃO DA LITERATURA}

\subsection{Radiofármacos}

A Radiofarmácia existe desde a primeira administração de uma preparação radioativa em um organismo vivo, com o objetivo de verificar os efeitos e a trajetória metabólica. Este fato antecede à Segunda Guerra Mundial (1932), quando os radioisótopos artificiais disponíveis eram produzidos através do bombardeamento por partículas positivas aceleradas em núcleos-alvo. Entretanto, foi o programa Átomos para a Paz, lançado pelo governo americano, após 1945, visando ao aproveitamento da produção de radioisótopos oriundos do reator de urânio, que tornou possível ao mundo o uso dos radiofármacos (10).

Radiofármacos são preparações farmacêuticas com finalidade diagnóstica ou terapêutica que, quando prontas para o uso, contêm um ou mais radioisotópos. Compreendem também os componentes não radioativos para marcação com um componente radioativo e os radioisótopos, incluindo eluatos de geradores de radioisótopos (11).

A utilização de radiofármacos para imagem da função do órgão e estados de doença é uma capacidade única da medicina nuclear. Ao contrário de outras modalidades de imagem, a saber: Tomografia computadorizada (TC), Ressonância Magnética (RM) e ultra-sonografia (US), procedimentos de medicina nuclear são capazes de mapear a função fisiológica e atividade metabólica, fornecendo informações mais específicas da função do órgão e de possíveis disfunções (12).

As características físico-químicas do radiofármaco determinam a sua farmacocinética, isto é, a fixação no órgão alvo, metabolização e eliminação do organismo, enquanto que as características físicas determinam a aplicação do composto em diagnóstico ou terapia. Um radiofármaco deve ser de baixo custo e facilmente acessível aos centros de medicina nuclear (10). 
Os radiofármacos que se destinam ao diagnóstico clínico possuem na sua composição um radioisótopo emissor gama $(\gamma)$ e/ou pósitron $\left(\beta^{+}\right)$. Nesta situação é desejável que o radioisótopo incorporado ao radiofármaco não emita partículas alfa $(\alpha)$ ou beta $\left(\beta^{-}\right)$, uma vez que estas apenas aumentam a dose de radiação no paciente (13).

Para diagnóstico, os radiofármacos estão classificados em radiofármacos de perfusão e radiofármacos específicos. Os radiofármacos de perfusão são transportados no sangue e atingem o órgão alvo. Não têm locais específicos de ligação e acredita-se que são distribuídos de acordo com o tamanho e a carga do composto. Os radiofármacos específicos são direcionados por moléculas biologicamente ativas, como, por exemplo, anticorpos e peptídeos, que se ligam a receptores celulares ou são transportados para o interior de determinadas células (13).

Para terapia, são indicados os radioisótopos que emitem partículas ionizantes, a saber: partículas $\alpha$, partículas $\beta$, ou elétrons Auger. O tipo de partícula a ser utilizada depende do tamanho do tumor, da distribuição intratumoral e da farmacocinética do radiofármaco. A meia-vida física também é um parâmetro essencial na escolha de radioisótopos para terapia (10).

\section{2 Radiodiagnóstico: radiofármacos de tecnécio-99m}

Tecnécio-99 metaestável ${ }^{99 \mathrm{~m}} \mathrm{Tc}$ ) é o radioisótopo mais utilizado em medicina nuclear para diagnóstico, estimando-se que mais de $80 \%$ dos quase 25 milhões de diagnóstico realizados anualmente é feito com este isótopo (12).

Com relação a outros radioisótopos emissores gama, o ${ }^{99 \mathrm{~m}} \mathrm{Tc}$ apresenta as seguintes vantagens: meia-vida física curta (6,02 horas); ausência de radiação particulada ou de alta energia, o que minimiza a dose de radiação absorvida pelo paciente; decaimento para tecnécio-99 $\left({ }^{99} \mathrm{Tc}\right)$ que representa uma dose de radiação negligenciável e monoemissão gama 
de energia $140 \mathrm{keV}$, compatível com os sistemas de aquisição de imagens (10).

As características físicas do ${ }^{99 \mathrm{~m}} \mathrm{Tc}$, em conjunto, possibilitam a aquisição de imagens cintilográficas com excelente resolução, utilizando-se os equipamentos de detecção de radiação atualmente disponíveis, sem comprometimento dosimétrico para o paciente. Assim, a grande maioria dos radiofármacos utilizados atualmente são preparados a partir desse radioisótopo (14).

O ${ }^{99 \mathrm{~m}}$ Tc é produto do decaimento radioativo do molibdênio-99 $\left({ }^{99} \mathrm{Mo}\right)$. Cerca de $87,5 \%$ dos átomos de ${ }^{99} \mathrm{Mo}$ de uma amostra desintegramse por emissão de radiação $\beta^{-}$e originam núcleos de ${ }^{99 m}$ Tc que, por sua vez, desintegram-se por emissão de radiação gama para originar $0{ }^{99} \mathrm{Tc}$, o qual se desintegra a rutênio $\left({ }^{99} \mathrm{Ru}\right.$ ) (estável) (FIG.1). Dessa forma, ${ }^{99}$ Mo é chamado de elemento "pai" e ${ }^{99 m}$ Tc de elemento "filho" (15).

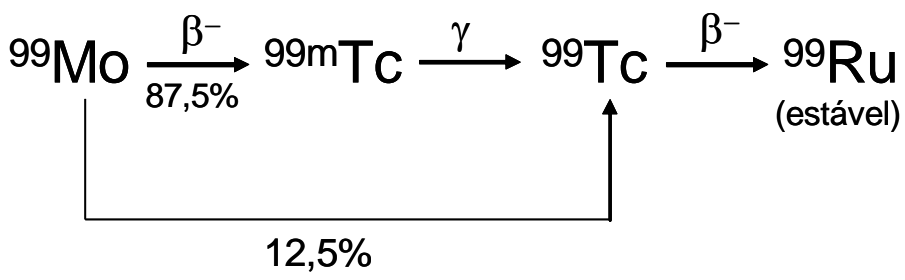

FIGURA 1- Esquema de decaimento radioativo do molibdênio-99 ( $\left.{ }^{99} \mathrm{Mo}\right)$ : partículas beta $\left(\beta^{-}\right)$são emitidas e o ${ }^{99}$ Mo decai a tecnécio-99 metaestável $\left({ }^{99 m} \mathrm{Tc}\right)$. Este emite radiação gama $(\gamma)$ e decai a tecnécio-99 $\left({ }^{99} \mathrm{Tc}\right)$, que finalmente emite partículas $\beta^{-}$e decai a rutênio-99 estável $\left({ }^{99} \mathrm{Ru}\right)$. Tempo de meia vida física: ${ }^{99} \mathrm{Mo}=66$ horas; ${ }^{99 \mathrm{~m}} \mathrm{Tc}=6,02$ horas $\mathrm{e}^{99} \mathrm{Tc}=2 \times 10^{5}$ anos (15).

${ }^{99} \mathrm{Mo} \mathrm{e}{ }^{99 m} \mathrm{Tc}$ formam um par radioativo em equilíbrio transiente, já que o tempo de meia-vida físico do pai é cerca de dez vezes maior que o tempo de meia-vida do filho. Esse equilíbrio possibilita a fabricação do sistema gerador de radionuclídeo de ${ }^{99} \mathrm{Mo} /{ }^{99 \mathrm{~m}} \mathrm{Tc}$ (FIG.2) (15). 


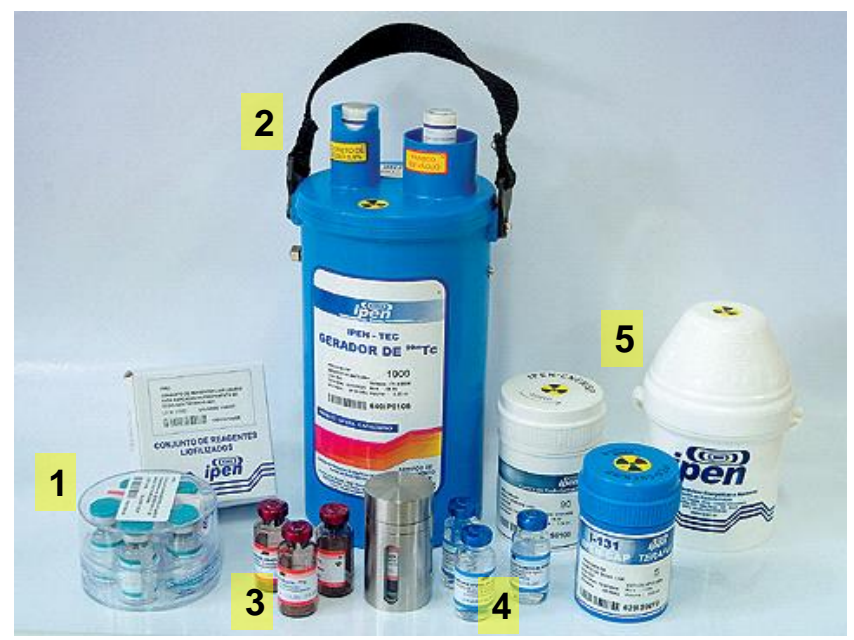

FIGURA 2- Produtos comercializados pelo IPEN: (1) conjunto de reagentes liofilizados; (2) gerador de ${ }^{99} \mathrm{Mo} /{ }^{99 \mathrm{~m}} \mathrm{Tc}$; (3) frasco em vácuo; (4) solução salina e (5) castelinho de chumbo para armazenamento e transporte dos radiofármacos (16).

Por meio do sistema gerador de ${ }^{99} \mathrm{Mo} /{ }^{99 \mathrm{~m}} \mathrm{Tc}$, o elemento tecnécio-99m pode ser facilmente disponibilizado no hospital ou serviço de medicina nuclear. O gerador é um sistema fechado, composto por uma coluna cromatográfica de óxido de alumínio $\left(\mathrm{Al}_{2} \mathrm{O}_{3}\right)$, na qual é depositada uma atividade conhecida de ${ }^{99}$ Mo. O ${ }^{99}$ Mo desintegra-se e origina o ${ }^{99 m} \mathrm{Tc}$. Fazendo-se passar através da coluna uma solução salina estéril (solução de $\mathrm{NaCl}$ 0,9\%), coleta-se no líquido eluente somente o ${ }^{99 m} \mathrm{Tc}$ na forma de pertecnetato de sódio $\left(\mathrm{Na}^{99 \mathrm{~m}} \mathrm{TcO}_{4}\right)$, enquanto que o ${ }^{99} \mathrm{Mo}$ permanece adsorvido à coluna de alumina (FIG.3) $(10,14)$.

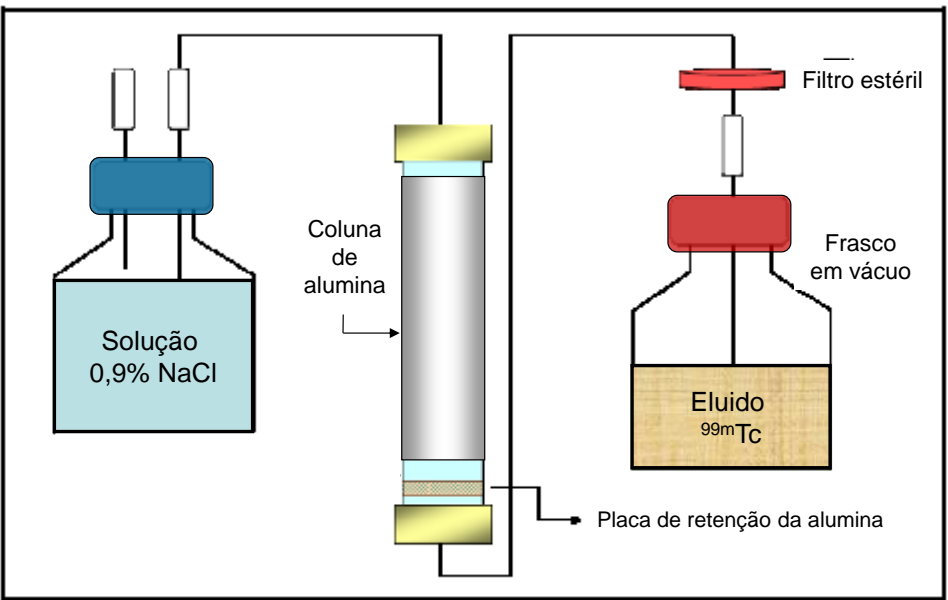

FIGURA 3- Ilustração do processo de eluição que ocorre no interior dos geradores de ${ }^{99} \mathrm{Mo} /{ }^{99 m} \mathrm{Tc}$ produzidos pelo IPEN (17). 
O pertecnetato $\left({ }^{99 \mathrm{~m}} \mathrm{TcO}_{4}{ }^{-}\right)$é um íon no qual o tecnécio apresenta o maior estado de oxidação possível $(+7)$. Apesar de tal solução poder ser por si só utilizada para fins diagnósticos na maioria das aplicações médicas, contudo, o ${ }^{99 \mathrm{~m}} \mathrm{Tc}(+7)$ é reduzido aos estados de oxidação inferiores de modo a formar complexo com um ligante específico (processo conhecido como marcação), cuja biodistribuição é definida por sua própria natureza bioquímica, constituindo os chamados radiofármacos marcados com ${ }^{99 \mathrm{~m}} \mathrm{Tc}$ (14).

\subsection{Reagentes Liofilizados para marcação com tecnécio-99m}

A grande versatilidade do uso do ${ }^{99 m} \mathrm{Tc}$ se deve a sua capacidade em complexar com eficiência, pelo método direto, uma série de substâncias liofilizadas, chamadas comercialmente de reagentes liofilizados $(R L)$ para radiodiagnóstico ou simplesmente reagentes liofilizados $(R L)$ (FIG.4) (18).
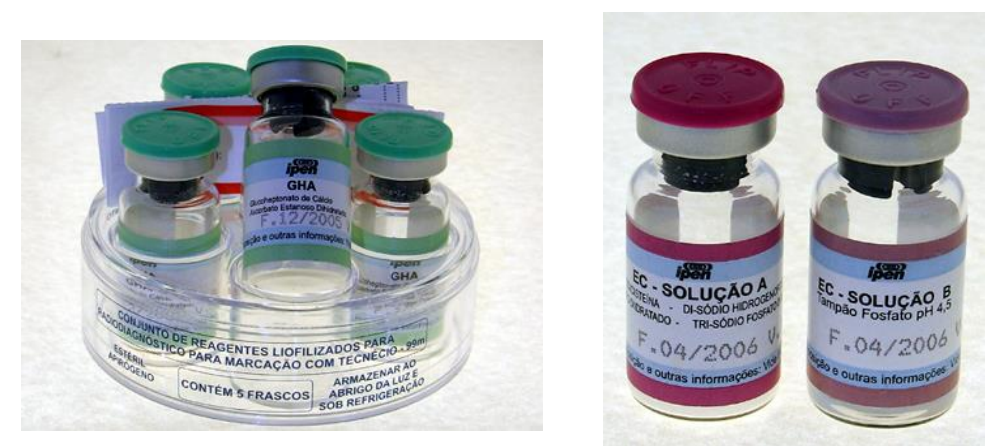

FIGURA 4- Ilustração dos kits de reagentes liofilizados produzidos pelo IPEN (16).

No processo de liofilização para produção de $R L$, a água é removida por sublimação, sob pressão reduzida, em baixas temperaturas. Esta técnica permite a redução da perda de constituintes voláteis, redução na tendência de aglomeração que alguns produtos apresentam quando são desidratados, facilidade na reconstituição devido sua estrutura porosa promover maior superfície de contato com o solvente, e maior estabilidade 
do produto final liofilizado comparado às soluções aquosas equivalentes (19).

A liofilização é um método bastante utilizado para desidratação de produtos que possuem constituintes sujeitos a alterações por calor, presença de oxigênio e umidade, como é o caso dos RL. O prazo de estabilidade de um RL é de aproximadamente seis meses, e por isso podem ser comprados, estocados e utilizados mediante preparação $(18,19)$.

Os RL são constituídos de uma substância a ser complexada e do agente redutor, normalmente cloreto estanoso $\left(\mathrm{SnCl}_{2}\right)$. O procedimento de reconstituição e marcação do $\mathrm{RL}$ com solução estéril de ${ }^{99 \mathrm{~m}} \mathrm{TcO}_{4}^{-}$envolve reações de oxi-redução e complexação e resulta na formação de um novo composto químico (FIG.5) (10).

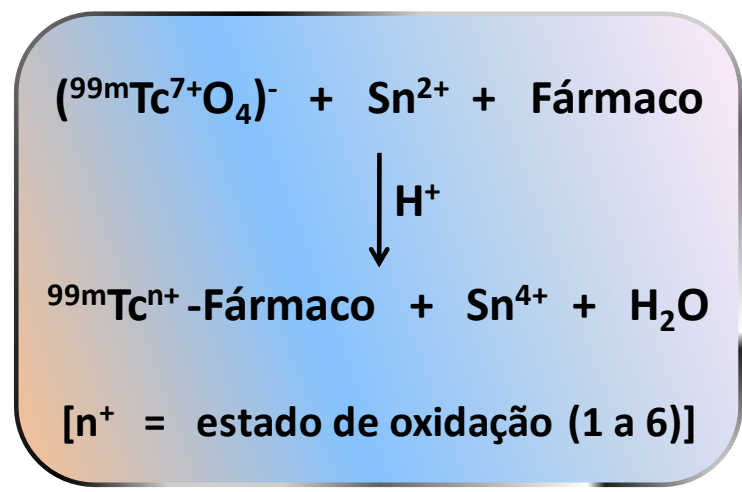

FIGURA 5- Esquema das reações para obtenção dos radiofármacos de ${ }^{99 \mathrm{~m}} \mathrm{Tc}$ (10). O íon pertecnetato $\left.{ }^{99 \mathrm{~m}} \mathrm{Tc}^{7+} \mathrm{O}_{4}\right)^{-}$é reduzido para um estado de oxidação menor $\left(\mathrm{n}^{+}=1\right.$ a 6$)$ pela ação do íon estanoso $\left(\mathrm{Sn}^{2+}\right)$. O complexo do ligante desejado (fármaco) com o ${ }^{99 \mathrm{~m}} \mathrm{Tcn}$ é obtido após um período curto (5 - 30 minutos) com um alto rendimento (> 90\%) (10).

Contudo, o grau de redução dependerá de vários fatores: (1) a relação estequiométrica $\mathrm{Sn} / \mathrm{Tc}$; (2) as condições em que se realiza a reação; (3) a presença de um ligante; (4) a natureza química do ligante e (5) oxigênio presente em solução. As moléculas dos ligantes, por sua vez, devem apresentar átomos doadores de elétrons, a exemplo do que ocorre com as oxotioaminas, que se unem ao metal por meio de ligações com átomos de oxigênio, enxofre e nitrogênio (15). 


\subsection{1 Ácido 2,3-Dimercaptosuccínico (DMSA)}

Complexos de ${ }^{99 m} \mathrm{Tc}$ com ácido meso-2,3-dimercaptosuccínico (DMSA) tem sido largamente utilizado em medicina nuclear para diagnóstico de doenças. DMSA (FIG.6A) reage com ${ }^{99 \mathrm{~m}} \mathrm{Tc}$ reduzido a vários estados de oxidação para formar diferentes complexos (FIG.6B e FIG.6C), os quais apresentam diferentes biodistribuição (20).

(A)<smiles>O=C(O)C(S)C(S)C(=O)O</smiles>

(B)<smiles>O=C1O[Te]23(OC(=O)C(S[As])C(S2)C(C(=O)O)S3)SC(C(=O)O)C1S</smiles>

(C)<smiles>O=C(O)C1S[Te]2(=O)(SC1C(=O)O)SC2C(=O)O</smiles>

FIGURA 6- Estrutura molecular: (A) DMSA [Fórmula molecular: $\mathrm{C}_{4} \mathrm{H}_{6} \mathrm{O}_{4} \mathrm{~S}_{2}$; Massa molecular: 182,22 $\mathrm{g} \mathrm{mol}^{-1}$ ]; (B) DMSA-- ${ }^{99 \mathrm{~m}} \mathrm{Tc}$ (III) [Fórmula molecular: $\mathrm{C}_{8} \mathrm{H}_{6} \mathrm{O}_{8} \mathrm{~S}_{4} \mathrm{Tc}$; Massa molecular: $456,20 \mathrm{~g} \mathrm{~mol}^{-1}$ ] e (C) DMSA- ${ }^{99 m} \mathrm{Tc}(\mathrm{V})$ [Fórmula molecular: $\mathrm{C}_{8} \mathrm{H}_{8} \mathrm{O}_{9} \mathrm{~S}_{4} \mathrm{Tc}$; Massa molecular: 474,34 $\mathrm{g} \mathrm{mol}^{-1}$ ] $(20,21)$.

A estrutura do complexo DMSA- ${ }^{99 \mathrm{~m}} \mathrm{Tc}$ (III) (FIG.6B) foi sugerida por Moretti e colaboradores e a identidade de DMSA- ${ }^{99 \mathrm{~m}} \mathrm{Tc}(\mathrm{V})$ (FIG.6C) foi extensivamente estudada por Blower e colaboradores $(22,23)$.

A aplicação de complexos DMSA- ${ }^{99 m}$ Tc em medicina nuclear é estritamente dependente das condições químicas de reação, especialmente $\mathrm{pH}$ e quantidade de agente redutor (24). 
Os radiofármacos $\mathrm{DMSA}^{99 \mathrm{~m}} \mathrm{Tc}$ preparados em meio ácido originam DMSA- ${ }^{99 \mathrm{~m}} \mathrm{Tc}$ (III) e são utilizados para cintilografia renal ou diagnóstico de funções renais (24).

DMSA- ${ }^{99 \mathrm{~m}} \mathrm{Tc}(\mathrm{V})$ pode ser preparado via uso do reagente liofilizado (RL) utilizado para preparar o $\mathrm{DMSA}-{ }^{-99 \mathrm{~m}} \mathrm{Tc}(\mathrm{III})$. Adiciona-se a este $\mathrm{RL}$, bicarbonato de sódio $\left(\mathrm{NaHCO}_{3}\right)$, o qual aumenta o $\mathrm{pH}$ de 3,0 - 3,5 para $\mathrm{pH} 8,0-8,5$, seguido pela adição de pertecnetato de sódio $\left(\mathrm{Na}^{99 \mathrm{~m}} \mathrm{TcO}_{4}\right)$ e incubação em temperatura ambiente (25).

Complexos DMSA ${ }^{-99 \mathrm{~m}} \mathrm{Tc}$ preparados em meio alcalino (DMSA${ }^{99 \mathrm{~m}} \mathrm{Tc}(\mathrm{V})$ ) são utilizados para detectar câncer de pulmão, câncer de mama ou carcinoma medular de tireóide. Além disso, este composto é útil na localização de tumores de cabeça e pescoço, cérebro, metástases de fígado e ossos, provenientes de carcinoma de mama, e de tumores de tecidos moles (tecido conjuntivo, linfáticos, vasos, músculos liso e estriado, gordura, fáscia muscular, tecido sinovial, endotélio e reticuloendotélio). $O$ exame cintilográfico com $\mathrm{DMSA}^{-99 \mathrm{~m}} \mathrm{Tc}(\mathrm{V})$ também foi proposto como uma ferramenta útil e não invasiva para deteç̧ão e localização de inflamação intestinal $(17,26-35)$.

\subsubsection{Etilenodicisteína Dietil Éster (ECD)}

ECD (Etilenodicisteína Dietil Éster) é sintetizado pela reação de esterificação de etilenodicisteína (EC) com etanol em meio de ácido clorídrico (FIG.7A). O ECD.2HCl é purificado por recristalização, originando o ECD (FIG.7B) com rendimento de cerca de 80\% (10).

O complexo de ECD- ${ }^{99 m}$ Tc é uma molécula que contém dois nitrogênios e dois tióis como grupos doadores $\left(\mathrm{N}_{2} \mathrm{~S}_{2}\right)$ dentro de uma estrutura quelante formando um complexo mono-oxo ${ }^{99 \mathrm{~m}} \mathrm{Tc}(\mathrm{V})$ estável e lipofílico. O ECD- ${ }^{99 \mathrm{~m}} \mathrm{Tc}$ (FIG.7C) é obtido pela marcação do RL de ECD com ${ }^{99} \mathrm{TcO}_{4}^{-}(10)$. 
<smiles>CCOC(=O)CC(CS)NCCN[C@@H](CS)C(=O)OCC</smiles>

(A)

(B)

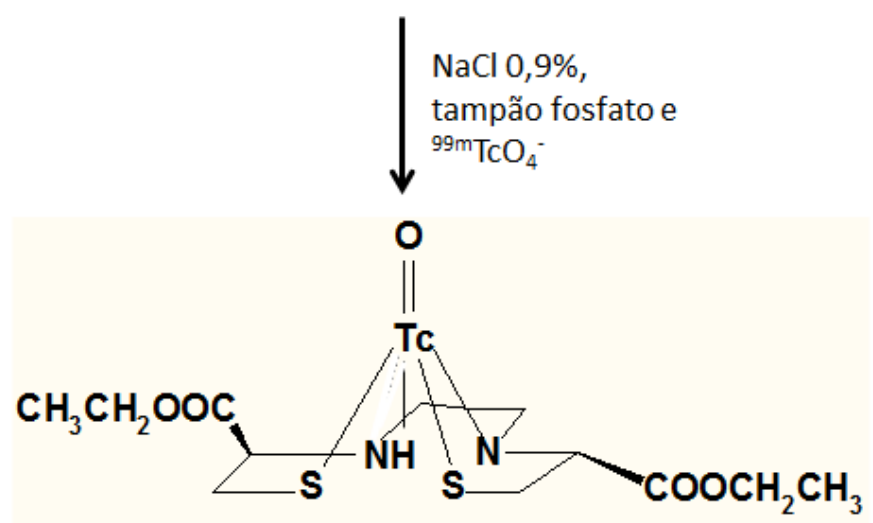

(C)

FIGURA 7- Obtenção do radiofármaco ECD- ${ }^{99 m} \mathrm{~T}$ c. A reação de esterificação de EC (A) com etanol em meio de $\mathrm{HCl}$ origina o $\mathrm{ECD}$ (B). Pela adição de $\mathrm{NaCl} 0,9 \%$, tampão fosfato e ${ }^{99 m} \mathrm{TCO}_{4}{ }^{-}$ao conjunto de RL de ECD pode ser obtido o ECD-- ${ }^{99 \mathrm{~m}} \mathrm{Tc}$ (C) (10).

O ligante ECD possui dois centros quirais, podendo ser obtidos os isômeros L,L-ECD- ${ }^{99 \mathrm{~m}} \mathrm{Tc}$ e D,D-ECD- ${ }^{99 \mathrm{~m}} \mathrm{Tc}$. O ECD- ${ }^{99 \mathrm{~m}} \mathrm{Tc}$ é indicado para cintilografia cerebral, para obtenção de imagens de fluxo sanguíneo da região cerebral em pacientes com anomalias do sistema nervoso central, a saber: epilepsia, demência, acidentes vasculares cerebrais, traumas entre outros (36).

Estudos cintilográficos realizados em macacos demonstraram que ambos os complexos (L,L-ECD- ${ }^{99 \mathrm{~m}} \mathrm{Tc}$ e D,D-ECD- ${ }^{99 \mathrm{~m}} \mathrm{~T}$ c) atravessam a barreira hematoencefálica e oferecem imagens similares cerca de 5 minutos após a administração da dose. Imagens mais tardias, contudo, evidenciaram o clareamento total do D,D-ECD ${ }^{99 \mathrm{~m}} \mathrm{Tc}$ do cérebro e a retenção do L,L-ECD${ }^{99 \mathrm{~m}} \mathrm{Tc}$ (36).

Radiofármacos de tecnécio-99m destinados à avaliação do fluxo sanguíneo regional cerebral devem ser lipofílicos para atravessar a barreira hematoencefálica. A permanência destes compostos no cérebro estará condicionada aos mecanismos de aprisionamento que envolvem a 
conversão das espécies neutras e lipofílicas em espécies polares hidrofílicas $(37,38)$.

\subsection{Estudo de degradação forçada}

Estudo de degradação forçada é um processo em que a taxa de degradação natural de um produto farmacêutico é aumentada pela aplicação de condições extremas de temperatura, umidade, oxidação, fotólise e suscetibilidade à hidrólise por variação dos valores de $\mathrm{pH}$ (39).

Degradação forçada sobre o fármaco (API) e produto final (além do estabelecimento de especificidade) também fornecem as seguintes informações: (1) determinação dos caminhos de degradação do API; (2) o discernimento de produtos de degradação e formulações que estão relacionados com substâncias medicamentosas contra aqueles que estão relacionados com substâncias não-medicamentosas (por exemplo, excipientes); (3) a elucidação da estrutura de produtos de degradação; (4) determinação da estabilidade intrínseca de uma molécula de API, em solução e no estado sólido, e (5) revelar o mecanismo de degradação termolítica, hidrolítica, oxidativa e fotolítica do API (40).

As impurezas em produtos farmacêuticos são produtos químicos indesejados que podem aparecer durante a síntese ou com envelhecimento do API. Presença de impurezas, mesmo em pequena quantidade, pode influenciar a eficácia e segurança de produtos farmacêuticos e radiofarmacêuticos. Assim, existe um interesse crescente em identificar a quantificar impurezas presentes em APIs e medicamentos $(39,41)$.

Várias autoridades reguladoras, como a Conferência Internacional sobre Harmonização ( $\mathrm{ICH}$ - do inglês International Conference on Harmonization) e Food and Drug Administration (FDA) recomendam o relato de impurezas presentes em API e medicamentos. A Farmacopeia Europeia e a Farmacopeia Americana (USP- do inglês United States Pharmacopeia) também têm descrito limites admissíveis de impurezas presentes no API e formulações $(39,42,43)$. 
No Brasil, a Agência Nacional de Vigilância Sanitária (ANVISA), através da Resolução da Diretoria Colegiada - RDC n 45 de 09 agosto de 2012, dispõe sobre a realização de estudos de estabilidade de API e estabelece procedimentos a serem seguidos nos testes de degradação (seção VIII) (4).

\subsubsection{Condições de degradação forçada para API e RL}

A instabilidade química de API e RL sob condições de calor, umidade, solventes, $\mathrm{pH}$ e luz encontradas durante a fabricação, purificação, secagem, armazenamento, transporte e/ou formulação é a principal causa de sua degradação. As principais vias de degradação de uma substância em um produto incluem hidrólise (ácida, alcalina e neutra), fotólise, oxidação, termodegradação (44).

\subsubsection{Hidrólise}

A hidrólise é um processo em que a água reage com o fármaco, agindo como catalisador em reações de degradação. Muitos fármacos são considerados como instáveis nesse meio e necessitam de intervenções durante a formulação e armazenamento, para que a eficácia e estabilidade da forma farmacêutica final não sejam comprometidas (45). Para a avaliação da instabilidade sob a condição de hidrólise, também deve ser levado em consideração $\mathrm{opH}$ do meio, pois íons hidrogênio $\left(\mathrm{H}^{+}\right)$e hidroxila $\left(\mathrm{OH}^{-}\right)$podem acelerar ou retardar o processo de degradação (46).

Para realizar o estudo de degradação forçada em condições de hidrólise ácida, utiliza-se principalmente ácido clorídrico $(\mathrm{HCl})$ e para a hidrólise alcalina utiliza-se hidróxido de sódio $(\mathrm{NaOH})$, sendo que, muitas variações são observadas no tempo e na temperatura de exposição de fármacos para essa condição. Existem poucos relatos na literatura sobre a hidrólise realizada em pH neutro (umidade), onde geralmente se utiliza água 
como agente de hidrólise. Nessa condição, a taxa de decomposição é lenta (45).

As condições de estresse iniciais são realizadas, assumindo que o fármaco seja instável, portanto, sujeito a receber condições mais amenas. Dependendo dos resultados obtidos, aumenta-se ou diminui-se a condição de reação utilizada (47).

\subsubsection{Fotólise}

A reação de fotólise é iniciada após absorção de radiação eletromagnética. A maioria dos princípios ativos (API) empregados na preparação de medicamentos apresenta máximos de absorção na região do ultravioleta (UV) do espectro eletromagnético. A radiação ultravioleta é muito energética e pode propiciar a clivagem de muitas ligações químicas, resultando em degradação da molécula. Desta forma, é importante conhecer a fotoestabilidade das drogas utilizadas como medicamentos e os produtos formados devido à fotólise, além de avaliar a toxicidade destes produtos (45).

O estudo de fotoestabilidade é uma ferramenta importante para a indicação de estabilidade de fármacos e formas farmacêuticas dentro da indústria. Estes estudos são feitos em fármacos e formas farmacêuticas na forma sólida ou em solução (40).

Existe muita variação da maneira na qual o estresse de fotoestabilidade é realizado. Os fármacos podem sofrer exposição a comprimentos de onda curtos ou longos dentro da faixa de UV, ou luz fluorescente de iluminação, sob temperatura ambiente (39). De acordo com a ANVISA, a dose de irradiação UV mínima recomendada para testes de fotoestabilidade é de $200 \mathrm{~W} / \mathrm{m}^{2}$, e de luz visível 1.200.000 Lux $(4,45)$.

Produtos farmacêuticos podem ser adequadamente protegidos da decomposição induzida pela luz com o uso de recipientes de vidro colorido e estocagem no escuro. Vidros de cor âmbar filtram luzes de comprimento de onda menores que $470 \mathrm{~nm}$ e oferecem considerável proteção aos compostos sensíveis à luz UV (45). 


\subsubsection{Oxidação}

A oxidação envolve a remoção de um átomo eletropositivo, radical ou elétron, ou a adição de um átomo eletronegativo ou radical. Muitas oxidações são reações em cadeia, que procedem lentamente sob a influência do oxigênio molecular. Tal processo de reação é referido como uma auto-oxidação (39).

$\mathrm{O}$ peróxido de hidrogênio $\left(\mathrm{H}_{2} \mathrm{O}_{2}\right)$ é utilizado para criar as condições de estresse empregadas no estudo de oxidação. A concentração de $\mathrm{H}_{2} \mathrm{O}_{2}$ utilizada varia entre $1 \%$ a $30 \%$. A estabilização de fármacos frente a condições oxidativas envolve a observação de um número de precauções durante a manufatura e estocagem. O oxigênio em recipientes farmacêuticos deve ser substituído por nitrogênio ou dióxido de carbono; assim como o contato com íons de metais pesados que catalisam a oxidação deve ser evitado e a estocagem deve ser realizada em temperaturas reduzidas (45).

\subsubsection{Termodegradação}

Em geral, a taxa de reação aumenta com o aumento da temperatura. Assim, os medicamentos são susceptíveis à degradação em temperatura mais elevada. Muitos princípios ativos são sensíveis ao calor ou temperaturas tropicais (39).

Estudo de degradação térmica é realizado em temperaturas que variam de $40{ }^{\circ} \mathrm{C}$ a $80{ }^{\circ} \mathrm{C}$, em baixa e alta umidade. De acordo com as condições climáticas às quais o produto é exposto, este pode apresentar um comportamento diferente, e ainda causar efeitos tóxicos devido a possíveis produtos de degradação que podem ser gerados durante a sua síntese ou armazenamento (39). 


\subsubsection{Cinética de degradação}

A degradação compreende uma ou mais reações, cuja velocidade pode ser calculada cineticamente. O estudo da cinética de degradação, fundamental para o estudo de fármacos e radiofármacos apresenta como objetivos obter experimentalmente, os dados cinéticos e correlacioná-los, por equações matemáticas, além de propor mecanismos para as reações de degradação e estabelecer condições para acelerar ou diminuir a velocidade das reações envolvidas $(2,5,39)$.

As velocidades de reação podem classificar-se como de ordem zero, primeira ordem ou segunda ordem, de acordo com os expoentes que afetam as concentrações dos reagentes. A ordem de reação é uma grandeza experimental determinada a partir da lei de velocidade da reação química (47-49).

A reação de ordem zero ocorre quando a velocidade de reação é independente da concentração da substância ativa. Nesse caso, um gráfico de concentração $(\mathrm{C})$ em função do tempo $(\mathrm{t})$ dá origem a uma reta, cuja inclinação corresponde à constante de velocidade da reação (k) (47-49).

Quando a velocidade da reação depende da concentração do reagente, a reação segue cinética de primeira ordem, obtendo-se uma reta com a representação do logaritmo neperiano da concentração (In C) em função do tempo (t) (47-49).

A cinética de segunda ordem ocorre quando a velocidade de reação depende da concentração de dois reagentes, ou a segunda potência da concentração de um deles. Para esse tipo de reação, a representação do inverso da concentração (1/C) em função do tempo (t) fornece uma reta (3941, 47-49).

A umidade, presente no ar, pode afetar a cinética de degradação dos produtos farmacêuticos, principalmente se associada a temperaturas elevadas (39). 


\subsection{Identificação de produtos de degradação}

Produtos de degradação provenientes de um API precisam ser identificados quando os níveis encontrados excedem aos limites regulamentares $(\sim 0,1-0,2 \%)(50)$.

Atualmente existe uma crescente preocupação em desenvolver e utilizar técnicas que apresentem grande potencial para caracterizar pequenas quantidades de produtos de degradação. As técnicas hifenadas HPLC-DAD (Cromatografia Líquida de Alta Eficiência com Detecção por Arranjo de Diodos) e LC-MS $^{n}$ (Cromatografia Líquida acoplada à Espectrometria de Massas de Múltiplos Estágios) têm despontado como técnicas importantes na indústria farmacêutica e radiofarmacêutica, devido principalmente à alta seletividade e sensibilidade que apresentam (51).

\subsubsection{Cromatografia Líquida de Alta Eficiência com Detecção por Arranjo de Diodos (HPLC-DAD)}

Cromatografia é um método físico-químico de separação de misturas, identificação e quantificação de seus componentes. A separação depende da interação dos componentes da mistura com a fase móvel e com a fase estacionária. A interação dos componentes da mistura com estas duas fases é influenciada por diferentes forças intermoleculares, incluindo iônica, dipolar, apolar, e específicos efeitos de afinidade e solubilidade. A identificação se dá mediante a comparação da interação de padrões com as fases estacionárias $(52,53)$.

A cromatografia líquida de alta eficiência (HPLC) utiliza pressão elevada para forçar a passagem de solvente através de colunas analíticas contendo partículas muito finas capaz de proporcionar separações eficientes $(52,53)$.

O cromatógrafo líquido (FIG.8) é composto por: reservatório de fase móvel, sistema de bombeamento com medidor de pressão, injetor, coluna cromatográfica, detector e registrador (10). 


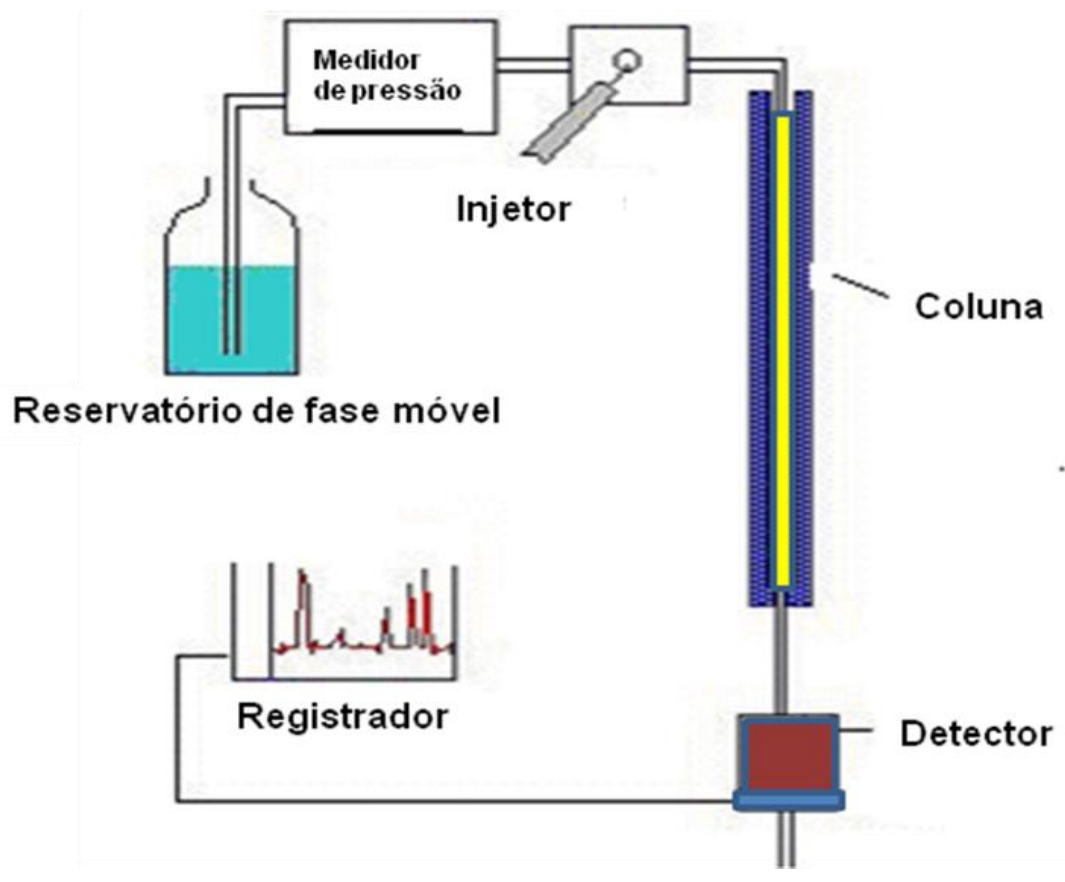

FIGURA 8- Principais componentes do cromatógrafo líquido: reservatório de fase móvel, sistema de bombeamento com medidor de pressão, injetor, coluna cromatográfica, detector e registrador de dados (10).

O sistema de bombas é utilizado para conduzir a fase móvel sob alta pressão, a uma vazão determinada, levando-a para uma câmara de mistura. O solvente empregado deve ter baixa viscosidade, alto grau de pureza ou ser facilmente purificado, não dissolver a fase estacionária e polaridade adequada para permitir uma separação conveniente para a detecção de todas as espécies presentes (53).

O injetor automático introduz a amostra na fase móvel, conduzindo a mistura através da coluna, onde ocorrem as separações dos analitos de interesse (53).

Os detectores são usados para 0 monitoramento e quantificação dos componentes que eluem da coluna. O sinal elétrico emitido pelo detector é armazenado e processado pelo sistema formado por computador e software. O registro gráfico, obtido na forma de cromatograma, é representado pelo sinal emitido pelo detector em função do tempo (53). 
A detecção feita na região do UV em vários comprimentos de onda utilizando detecção por arranjo de diodos (DAD, do inglês Diode Array Detector) é comumente empregada em HPLC. O detector DAD consiste em uma série de detectores fotodiodo posicionados lado a lado em um cristal de silício, de modo que cada comprimento de onda difratado pela grade atinge um ponto deste arranjo, e consequentemente o detector. Deste modo, a absorbância em vários comprimentos de onda é determinada de modo simultâneo (54).

Durante a análise por HPLC-DAD, a amostra passa através de uma célula de vidro incolor, transparente, chamada célula de fluxo. Quando a luz UV incide nessa célula, parte da luz é absorvida pela amostra. Assim, as intensidades da luz UV observadas para a fase móvel (sem amostra) e para o eluente contendo amostra serão diferentes. Medindo-se essa diferença, a quantidade de amostra pode ser determinada (54).

HPLC-DAD não é muito informativo com respeito à elucidação de estruturas químicas de produtos de degradação; às vezes ele pode fornecer informações de diagnóstico sobre a estrutura da impureza bem como o grau de pureza do analito de interesse (39).

O uso de um recurso de software disponível quando o detector de DAD é utilizado permite detectar a pureza de pico cromatográfico através de varreduras espectrais no início, meio e fim dos picos. Os espectros do padrão de referência e das amostras são comparados e o índice de similaridade entre eles é avaliado. Desta forma verifica-se a especificidade do método cromatográfico desenvolvido (54).

\subsubsection{Cromatografia Líquida acoplada à Espectrometria de Massas de Múltiplos Estágios (LC-MS ${ }^{\mathrm{n}}$ )}

A Cromatografia Líquida acoplada à Espectrometria de Massas de Múltiplos Estágios (LC-MS ${ }^{n}$ ) é a técnica analítica hifenada mais utilizada para identificação de impurezas e produtos de degradação de fármacos e medicamentos pelas seguintes razões: as técnicas de ionização à pressão atmosférica são adequadas para a ionização da maioria dos compostos 
farmaceuticamente relevantes e a sensibilidade da espectrometria de massas permite a investigação de impurezas e produtos de degradação em níveis traço. $\mathrm{O}$ espectrômetro de massas (MS) é usado como detector da cromatografia líquida (LC), a qual funciona como sistema de introdução da amostra (54).

O MS é composto por uma fonte de íons, analisador de massas e o detector. A FIG.9 demonstra uma representação esquemática do espectrômetro de massas.

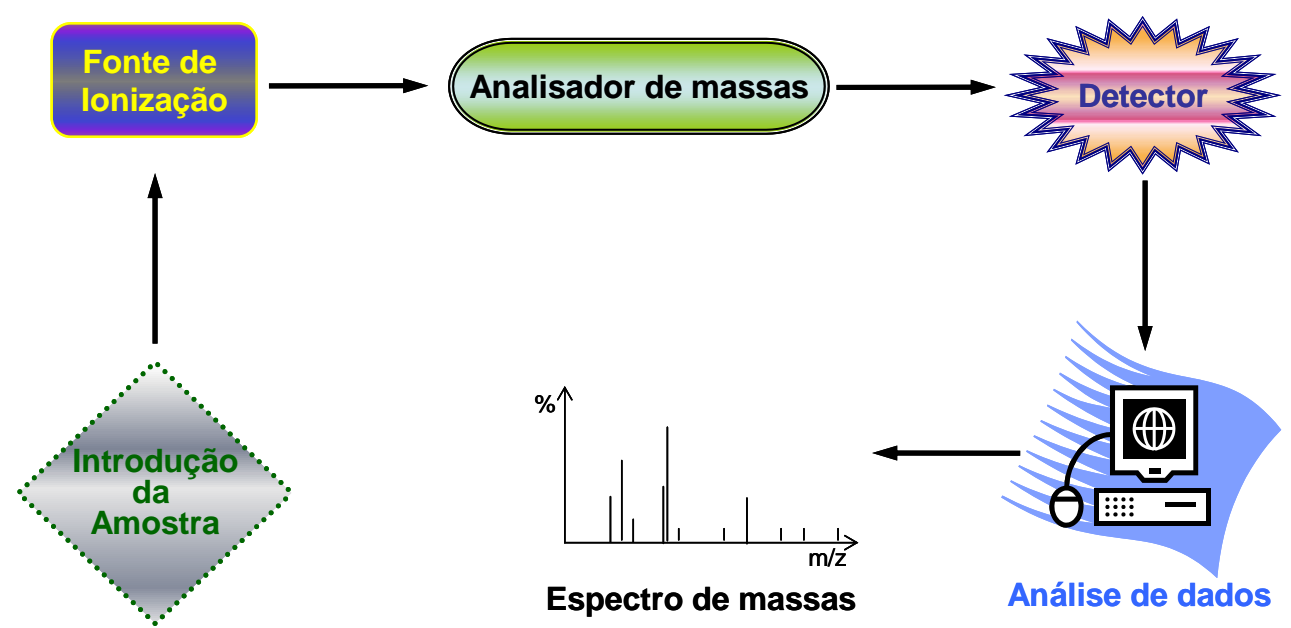

FIGURA 9- Esquema das principais partes de um espectrômetro de massas: sistema de introdução da amostra, fonte de ionização, analisador de massas, detector e sistema de análise de dados que gera o espectro de massas (55 - modificado)

No espectrômetro de massa, introduz-se uma quantidade muito pequena de amostra. $\mathrm{Na}$ fonte de íons, o bombardeio da amostra com elétrons, íons, moléculas ou fótons produz íons gasosos que são extraídos e acelerados para dentro do analisador de massas. $O$ analisador de massas separa os íons pela relação $\mathrm{m} / \mathrm{z}$ (massa/carga), quantidade adimensional formada pela divisão do número de massa de um íon pelo seu grau de ionização. O detector é responsável por converter os sinais elétricos recebidos do analisador e convertê-los em sinais analógicos mensuráveis enviados ao sistema de análise, normalmente um computador (55).

A seleção do modo de ionização é, dependendo da polaridade, massa molecular e estabilidade térmica da substância a ser analisada. A ionização por electrospray (ESI - do inglês Electrospray lonization), 
Fotoionização a Pressão Atmosférica (APPI - do inglês Atmospheric Pressure Photoionization) e lonização Química à Pressão Atmosférica (APCl - do inglês Atmospheric Pressure Chemical Ionization) são as técnicas de ionização mais comumente utilizadas, no acoplamento com cromatografia líquida, na análise de API, impurezas e produtos de degradação (55).

A FIG.10 ilustra a faixa aproximada de aplicações das principais formas de ionização utilizadas em LC-MS (56).

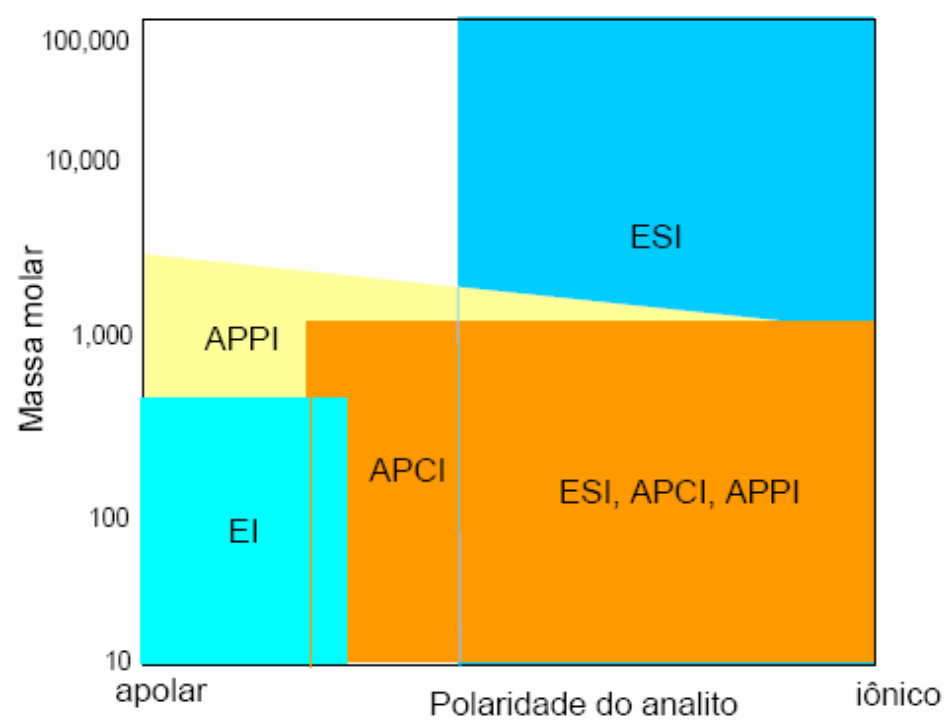

FIGURA 10- Principais características das formas de ionização empregadas em LC-MS. Ionização por elétron (EI - do inglês Electron Ionization) é utilizada no acoplamento da cromatografia gasosa com MS; APPI fotoionização a pressão atmosférica; APCI - ionização química a pressão atmosférica; ESI - ionização por electrospray (56).

A ionização por electrospray é preferível para a análise de compostos bastante polares ou iônicos, termolábeis, ou com massa molecular elevada (superior a $1.000 \mathrm{Da}$ ). Compostos não polares ou de polaridade muito baixa tendem a apresentar melhor ionização empregandose APPI, enquanto que os pouco polares e de polaridade intermediária geralmente dão bons resultados com $\mathrm{APCl}$ (57).

O efluente da coluna cromatográfica, após ser ionizado é direcionado para o analisador de massas. As características de construção e operação diferem de um analisador para outro, assim como seus benefícios 
e limitações. Os principais analisadores são o quadrupolo, ion trap e tempo de vôo TOF (TOF - do inglês time of flight) (57).

A ionização por eletrospray (ESI) e o analisador de massas do tipo ion trap foram utilizados neste trabalho e terão uma abordagem mais detalhada.

\subsubsection{Ionização por eletrospray (ESI)}

$\mathrm{Na}$ técnica de ionização por eletrospray (ESI), o eluente proveniente da coluna cromatográfica é conduzido por um tubo capilar metálico ao qual é aplicado um potencial elétrico (positivo ou negativo), que leva à separação de cargas do solvente, podendo também haver dissociação iônica do fármaco ou radiofármaco de interesse, dependendo de suas características físico-químicas. Ao deixar o capilar, o líquido é vaporizado, formando minúsculas gotículas carregadas eletricamente que, por sua vez, são submetidas a um fluxo de nitrogênio, destinado à evaporação do solvente (58).

$\mathrm{Na}$ medida em que as gotículas vão reduzindo de tamanho, devido à evaporação do solvente, ocorre o aumento da força de repulsão entre os íons de mesma carga, até o ponto em que a força coulômbica seja suficientemente forte para romper a tensão superficial dessas gotículas, implicando na dissorção dos íons para a fase gasosa. A FIG.11 apresenta um diagrama do processo de ionização por eletrospray $(55,57)$. 


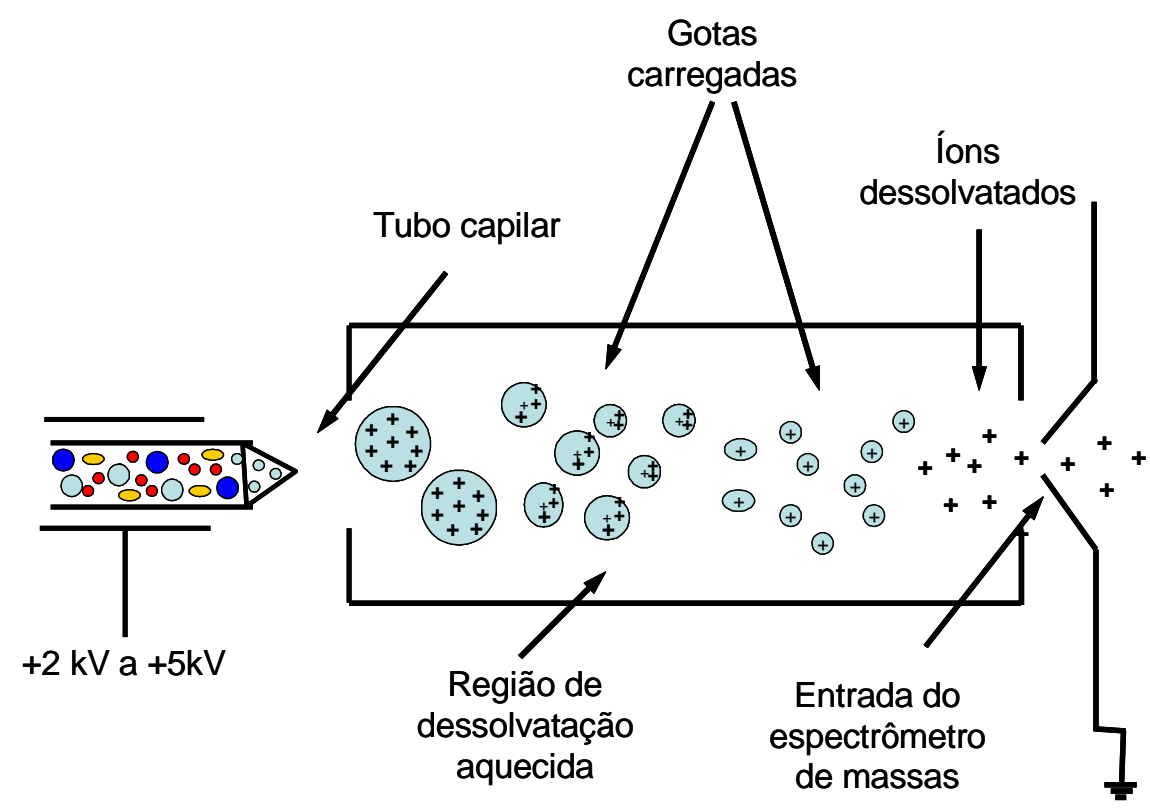

FIGURA 11- Ionização por electrospray (ESI): solução contendo moléculas protonadas é nebulizada através de um tubo capilar onde é aplicada alta voltagem $(+2 \mathrm{kV}$ a $+5 \mathrm{kV})$, formando gotículas carregadas. O solvente dessas gotículas carregadas é evaporado na região de dessolvatação aquecida e transfere a molécula protonada da fase líquida para a fase gasosa $(55,57$-modificado).

Já em fase gasosa, ocorrem reações químicas, resultando na ionização dos compostos de interesse. Os íons formados são tipicamente moléculas protonadas $\left([\mathrm{M}+\mathrm{H}]^{+}\right)$ou adutos $\left(\left[\mathrm{M}+\mathrm{NH}_{4}\right]^{+},[\mathrm{M}+\mathrm{Na}]^{+}\right)$, no caso de ionização em modo positivo, ou moléculas desprotonadas $\left.([\mathrm{M}-\mathrm{H}]]^{-}\right)$, no caso de ionização em modo negativo e que, portanto, mantém intactas as estruturas moleculares originais $(60,61)$.

\subsubsection{Analisador de massas ion trap}

Nos analisadores de massas do tipo ion trap, um eletrodo hiperbólico na forma de um anel (do inglês ring electrode) é colocado entre dois eletrodos hiperbólicos finais (do inglês eletrodos end cap). Uma voltagem de radiofrequência ( $\mathrm{Rf}$ ) (corrente alternada, $\mathrm{AC}$ ), de amplitude variável e com frequência de $1 \mathrm{MHz}$, é aplicada ao ring electrode, enquanto que os eletrodos end cap são aterrados (FIG.12A). Os dois eletrodos end cap apresentam um orifício no centro; o eletrodo superior permite a 
passagem dos íons provenientes da fonte de ionização (eletrodo de entrada) e direcionados para o ring electrode, enquanto que o orifício do eletrodo de saída serve para direcionar os íons ejetados para detecção (FIG.12B) (57, $59)$.

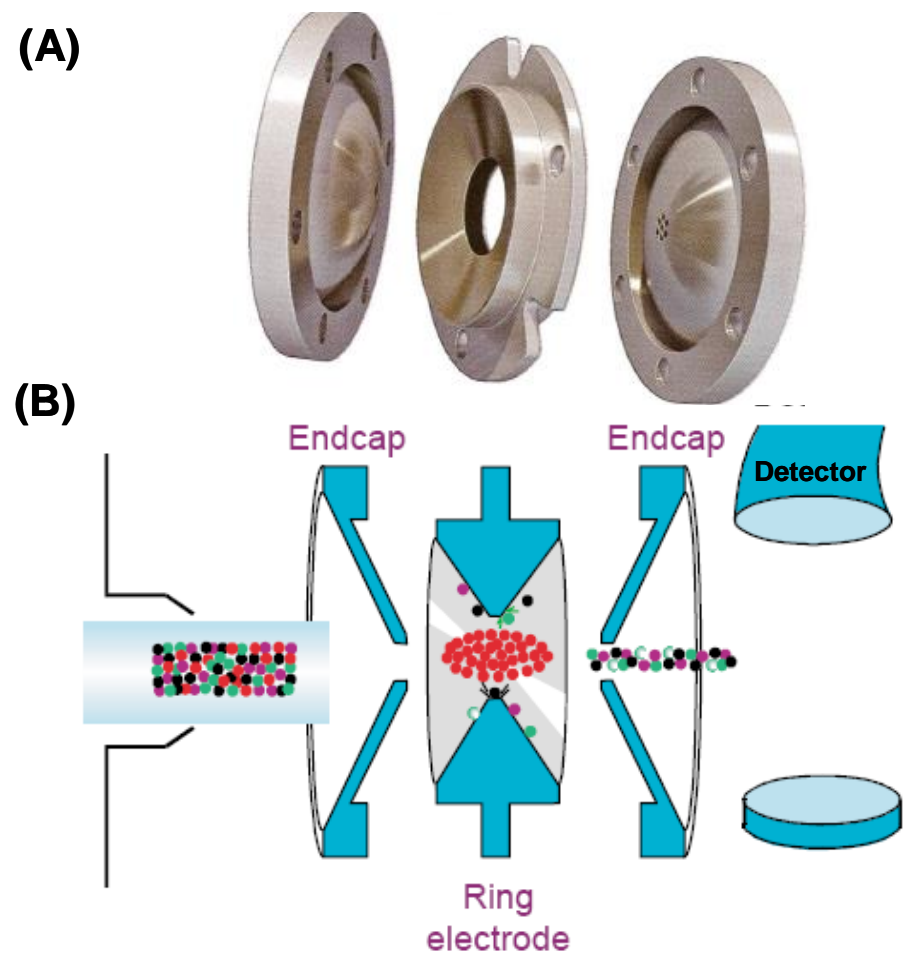

FIGURA 12- (A) Eletrodos que formam a parte principal do analisador de massas do tipo ion trap. (B) O eletrodo central (em forma de anel, ou ring electrode) é circundado por dois eletrodos sendo um de entrada e outro de saída dos íons (end cap) $(57,59)$.

A repulsão entre íons de mesma carga confinados no centro do trap tende a desestabilizar suas trajetórias por dispersão. Para contornar este problema, adiciona-se um gás, usualmente hélio ou hidrogênio, o qual "resfria" os íons por colisão, mantendo-os aprisionados com refocalização para o centro do trap e aumentando a resolução e sensibilidade (57). 


\section{MATERIAIS E MÉTODOS}

A fase experimental do trabalho foi realizada nos laboratórios de controle de qualidade do Centro de Radiofarmácia (CR) no IPEN e no Laboratório de Análises Toxicológicas da Faculdade de Ciências Farmacêuticas da USP.

\subsection{Materiais}

\subsubsection{Reagentes e solventes}

Sistema Elix 10 da Merck-Millipore foi utilizado para obtenção de água purificada. Os reagentes utilizados, listados a seguir, foram de grau analítico (P.A.) ou de grau HPLC, pureza $\geq 99,9 \%$ :

- Acetato de amônio $\left(\mathrm{C}_{2} \mathrm{H}_{7} \mathrm{NO}_{2}\right)$ - Merck;

- Acetonitrila $\left(\mathrm{CH}_{3} \mathrm{CN}\right)$ - Merck;

- Ácido clorídrico $(\mathrm{HCl})$ - Merck;

- Ácido fórmico $\left(\mathrm{CH}_{2} \mathrm{O}_{2}\right)$ - Merck;

- Hidróxido de sódio $(\mathrm{NaOH})$ - Merck;

- Metanol $\left(\mathrm{CH}_{4} \mathrm{O}\right)$ - Merck;

- Peróxido de hidrogênio $\left(\mathrm{H}_{2} \mathrm{O}_{2}\right)-$ Merck.

O API DMSA foi obtido da Sigma Aldrich (Canadá) e o API ECD da Advanced Biochemical Compounds (ABX, Alemanha), com pureza $\geq 95 \%$.

A TAB.1 apresenta a composição dos RL de DMSA e de EDC utilizados neste estudo e produzidos no $\mathrm{CR}$ no Instituto de Pesquisas Energéticas e Nucleares da Comissão Nacional de Energia Nuclear (CRIPEN/CNEN-SP). 
TABELA 1- Composição dos reagentes liofilizados de DMSA e ECD produzidos no $\mathrm{CR}$.

\begin{tabular}{ccc}
\hline Reagente liofilizado & Componente & mg/frasco \\
\hline \multirow{2}{*}{ DMSA } & DMSA & 1,0 \\
& $\mathrm{SnCl}_{2} \cdot 2 \mathrm{H}_{2} \mathrm{O}$ & 0,44 \\
& Inositol & 50,0 \\
& Ácido ascórbico & 0,70 \\
\hline \multirow{2}{*}{ ECD } & $\mathrm{ECD}$ & 1,0 \\
& ${ }^{*} \mathrm{SnCl}_{2} \cdot 2 \mathrm{H}_{2} \mathrm{O}$ & 0,125 \\
& Manitol & 24,0 \\
& "EDTA & 0,36 \\
\hline
\end{tabular}

${ }^{*} \mathrm{SnCl}_{2} \cdot 2 \mathrm{H}_{2} \mathrm{O}-$ Cloreto estanoso diidratado

"EDTA - Ácido etilenodiamino tetra-acético

\subsection{Preparação das amostras}

As soluções estoque e controle de DMSA e ECD (API) foram preparadas dissolvendo-se $100 \mathrm{mg}$ de DMSA ou ECD em $100 \mathrm{~mL}$ de água purificada (concentração final: $1 \mathrm{mg} \mathrm{mL}{ }^{-1}$ ). Os reagentes liofilizados foram reconstituídos em $1 \mathrm{~mL}$ de água purificada.

Os estudos de DMSA e RL de DMSA foram realizados separadamente dos estudos de ECD e RL de ECD.

\subsubsection{Hidrólise}

Soluções de DMSA (API) e ECD (API) na concentração final de $1 \mathrm{mg} \mathrm{mL}^{-1}$ foram preparadas, separadamente, em solução de $\mathrm{HCl} 0,1 \mathrm{~mol} \mathrm{~L}^{-1}$ e submetidas à refluxo em câmara de estabilidade por 0,$5 ; 1 ; 2 ; 4$ e 24 horas para estudo da hidrólise ácida. A temperatura da câmara de estabilidade (Weiss Gallenkamp, Alemanha) foi mantida a $25{ }^{\circ} \mathrm{C}$ e a umidade relativa de $75 \%$. 
Para os estudos de hidrólise alcalina das amostras de DMSA e ECD foram mantidas as mesmas condições da hidrólise ácida, substituindose apenas a solução de $\mathrm{HCl} 0,1 \mathrm{~mol} \mathrm{~L}^{-1}$ por solução de $\mathrm{NaOH} 0,1 \mathrm{~mol} \mathrm{~L}^{-1}$.

A hidrólise neutra foi avaliada deixando as amostras de DMSA e ECD na câmara de estabilidade sob refluxo por 2, 4 e 6 horas, sem adição de $\mathrm{HCl}$ ou $\mathrm{NaOH}$. Utilizou-se apenas água ultrapura no preparo das amostras. $\mathrm{O}$ mesmo procedimento descrito anteriormente foi seguido para os estudos de degradação hidrolítica dos RL de DMSA e ECD.

O fluxograma apresentado na FIG.13 foi utilizado como guia para os estudos de hidrólise ácida e hidrólise alcalina.

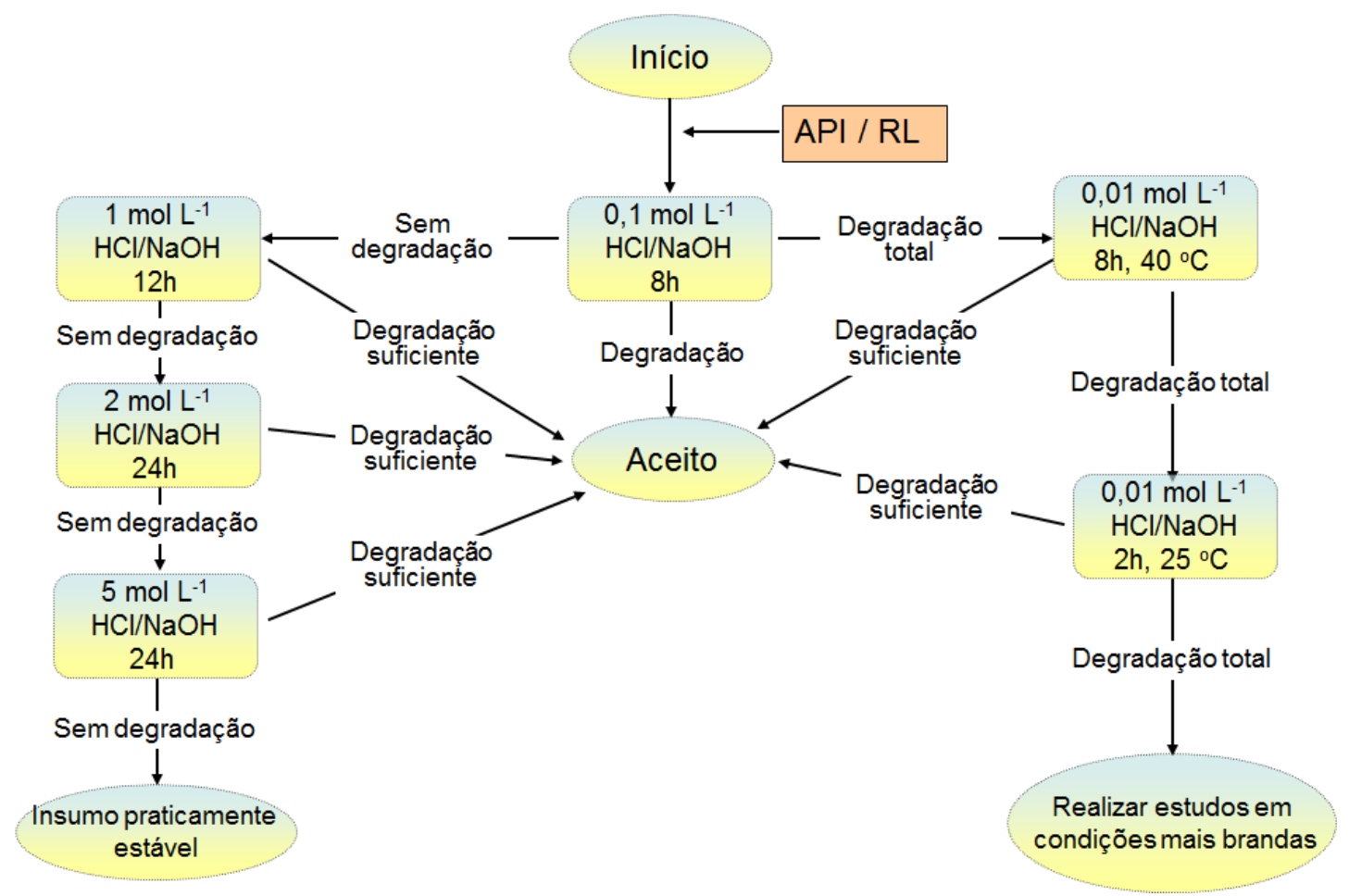

FIGURA 13- Fluxograma para realização de estudos de degradação em condições ácida e alcalina. $\mathrm{HCl}$ : ácido clorídrico; $\mathrm{NaOH}$ : hidróxido de sódio; h: horas (4). 


\subsubsection{Fotólise}

Soluções aquosas de DMSA e RL de DMSA (1 mg mL $\mathrm{mL}^{-1}$ ) foram colocadas, separadamente, em câmara de fotoestabilidade Weiss Gallenkamp (Alemanha). Esta câmara de fotoestabilidade pode ser utilizada associando-se ou não lâmpadas UV e fluorescente.

Os estudos de fotodegradação foram realizados com irradiação de 1.200.000 lux (luz visível) e $200 \mathrm{~W} \mathrm{~m}^{-2}$ por hora (luz UV), em temperatura de $25^{\circ} \mathrm{C}$ e em intervalos de tempo de exposição de 6; 12 e 24 horas.

Amostras sólidas (pó para o API e pastilhas para o $R L$ ) de DMSA foram expostas à mesma dose de irradiação e mesmos tempos de exposição foram avaliados.

O fluxograma da FIG.14 foi utilizado como guia nos estudos de fotólise.

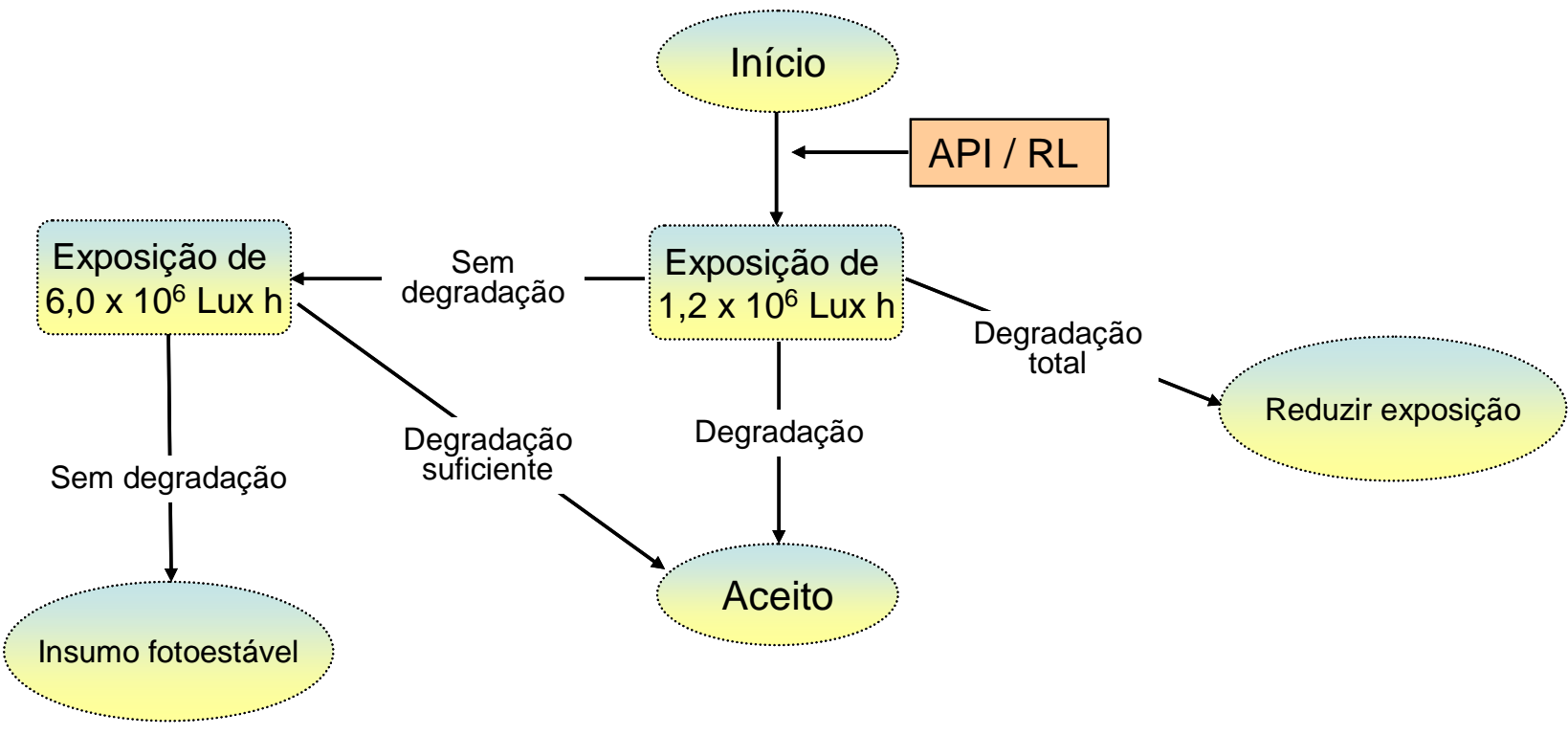

FIGURA 14- Fluxograma para realização de estudos de degradação em condições fotolíticas. Lux: unidade de medida de intensidade de luz visível; h: hora (4). 


\subsubsection{Oxidação}

Condições forçadas de oxidação das amostras de DMSA, ECD e RL de DMSA e ECD foram realizadas pela adição de peróxido de hidrogênio $\left(\mathrm{H}_{2} \mathrm{O}_{2}\right)$ 1\%. A concentração das amostras foi $1 \mathrm{mg} \mathrm{mL}^{-1}$. $\mathrm{O}$ fluxograma apresentado na FIG.15 foi utilizado como guia para os estudos de degradação por oxidação. Os tempos de reação avaliados foram 0,$5 ; 1 ; 2$ e 4 horas. As soluções resultantes foram aquecidas em banho-maria (temperatura de $30 \stackrel{\circ}{\circ}$ ) por 10 minutos para remoção do excesso de $\mathrm{H}_{2} \mathrm{O}_{2}$.

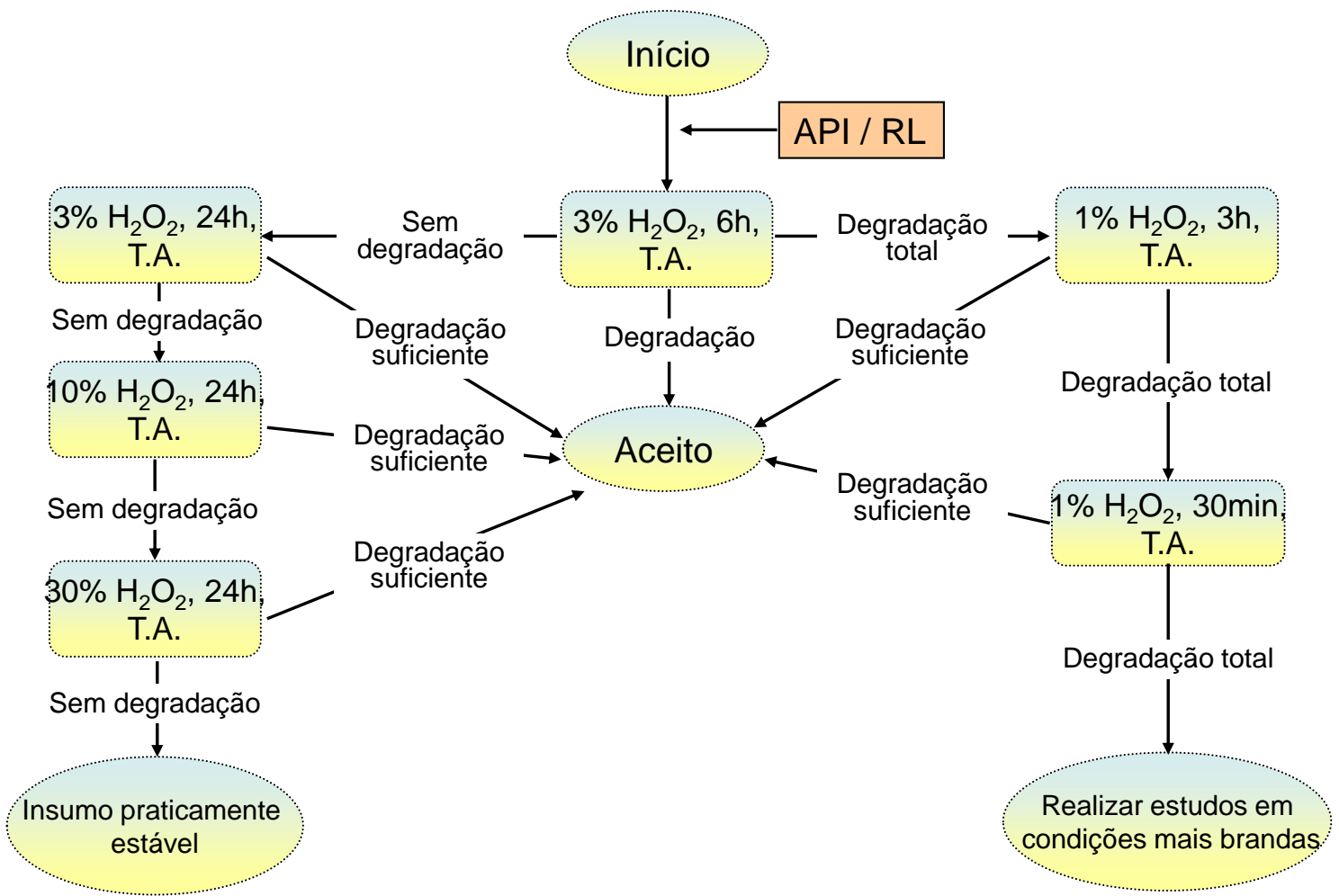

FIGURA 15- Fluxograma para realização de estudos de degradação em condições oxidativas. $\mathrm{H}_{2} \mathrm{O}_{2}$ : peróxido de hidrogênio; h: horas; min: minuto; T.A.: temperatura ambiente (4).

\subsubsection{Termodegradação}

Os estudos de termodegradação de DMSA e RL de DMSA foram realizados em solução e em estado sólido (pó de API ou pastilha de $\mathrm{RL}$ ). As temperaturas avaliadas foram: $35,40,45,50$ e $60{ }^{\circ} \mathrm{C}$. Para todas as 
análises a umidade relativa foi mantida em $75 \%$ e os tempos de exposição de 6, 12 e 24 horas.

Todas as soluções foram diluídas na fase móvel e filtradas em unidades filtrantes de poro 0,22 $\mu \mathrm{m}$. As amostras foram analisadas em triplicata.

\subsection{Avaliação da cinética de degradação}

A ordem de reação para as cinéticas de hidrólise alcalina, oxidação e fotólise (apenas DMSA) em solução aquosa foram determinadas. O modelo cinético descrito por Sinko e apresentado nas Equações 1, 2 e 3 foi utilizado (62).

$$
\begin{gathered}
C=C_{0}-k \cdot t \\
\ln C=\ln C_{0}-k \cdot t \\
1 / C=1 / C_{0}+k \cdot t
\end{gathered}
$$

Onde $\mathrm{C}_{0}$ é a concentração inicial dos reagentes no tempo zero $(\mathrm{t}=0)$; $\mathrm{C}$ é a concentração após a reação; $\mathrm{t}$ é o tempo de reação e $\mathrm{k}$ é a constante de reação (62).

Os gráficos representativos dos estudos de cinética de degradação dos API (DMSA e ECD) foram construídos representando o percentual do API residual em função do tempo (ordem zero), In do percentual do API em função do tempo (primeira ordem) e inverso do percentual do API em função do tempo (segunda ordem). Os coeficientes de regressão linear também foram obtidos $(48,49,62)$.

Todos os gráficos foram feitos utilizando o programa gráfico Origin 5.0. 


\subsection{Avaliação do teor de DMSA e ECD nos RL}

Os desvios-padrão (DP) e a exatidão das medidas do teor de DMSA e ECD em diferentes lotes de RL foram calculados conforme equações 4 e 5 , respectivamente (10).

$$
\begin{gathered}
D P=\sqrt{\frac{\sum\left(C_{i}-C M D\right)^{2}}{n-1}} \\
\operatorname{Exatidão}(\%)=\frac{(C M D \times 100)}{C T}
\end{gathered}
$$

Onde $C_{i}$ é a concentração determinada; $C M D$ é a concentração média determinada; $n$ é o número de medições e $C T$ é a concentração teórica (1 mg/frasco de RL, conforme descrito na TAB.1, página 28).

\subsection{Identificação dos produtos de degradação}

O API (DMSA e ECD) foi submetido a teste de degradação forçada nas condições ácida, alcalina, neutra, fotolítica, oxidante e termodegradação conforme descrito anteriormente. Em seguida as amostras foram analisadas por HPLC-DAD e LC-MS ${ }^{n}$. Os parâmetros avaliados foram: percentual de degradação do API (DMSA e ECD) e aparecimento de picos com absorção na faixa do UV. Os espectros de massas dos picos suplementares obtidos por LC-MS ${ }^{n}$ foram utilizados para a identificação estrutural dos possíveis produtos de degradação.

Após serem estabelecidas as condições de degradação para o API, de forma a visualizar o aparecimento de picos, o método desenvolvido foi repetido com os $\mathrm{RL}$ comerciais de DMSA e de ECD. 


\subsubsection{Sistema HPLC-DAD}

As análises por cromatografia líquida foram realizadas no CRIPEN-CNEN/SP. Utilizou-se equipamento HPLC com sistema quaternário de solventes marca Shimadzu, modelo LC-20AT Prominence, composto por duas bombas, forno de coluna modelo CTO 20A, sistema de controle modelo CBM 20A, degaseificador modelo DGU-20A $A_{5}$, injetor automático de amostras modelo SIL-20A e detector com arranjo de diodos (DAD) UV-visível modelo SPD-M20A. A aquisição e o tratamento dos dados foram realizados pelo software LC Solutions $\AA^{\circledR}$ e Origin 5.0.

Todas as análises foram desenvolvidas utilizando coluna cromatográfica Shim-Pack VP-ODS (150 mm x 4,6 mm; $5 \mu \mathrm{m}$ (fase reversa)). A fase móvel utilizada nas análises de DMSA foi constituída de $0,1 \%$ de ácido fórmico em água (solvente $A$ ) e acetonitrila (solvente $B$ ). Gradiente linear 5-60\%B em 15 minutos foi utilizado. A fase móvel para as análises de ECD foi água (solvente $\mathrm{A}$ ): metanol (solvente $\mathrm{B}$ ). $\mathrm{O}$ tempo de análise foi de 15 minutos no modo isocrático (40\%A:60\%B, v/v).

O fluxo da fase móvel utilizado foi de $1 \mathrm{~mL} \mathrm{~min}^{-1}$ para todas as análises de DMSA e de ECD. O volume de injeção foi $20 \mu \mathrm{L}$. O comprimento de onda de detecção $(\lambda)$ foi $245 \mathrm{~nm}$ e $215 \mathrm{~nm}$ para as análises de DMSA e $E C D$, respectivamente.

A especificidade do método desenvolvido foi determinada através de injeções de soluções padrão de DMSA e ECD nas concentrações de $1 \mathrm{mg} \mathrm{mL} \mathrm{m}^{-1}$. Para verificar a similaridade foram realizadas varreduras espectrais no início, meio e fim dos picos e os espectros de absorbância em função do tempo de retenção (Abs [mUA] x $\mathrm{[min]}$ ) e absorbância em função do comprimento de onda (Abs [mUA] $\times \lambda$ [nm]) do padrão DMSA e do RL de DMSA, assim como padrão de ECD e RL de ECD, foram comparados e o índice de similaridade avaliado. 


\subsubsection{Sistema LC-MS ${ }^{n}$}

Espectrômetro de massas modelo Esquire 3000 Plus (Bruker Daltonics) com fonte de ionização do tipo ESI e analisador de massas ion trap foi utilizado. O sistema LC acoplado foi um HPLC Shimadzu, modelo LC-20AT Prominence. A aquisição e o tratamento dos dados foram realizados pelo software LC Solutions® e DataAnalysis.

A separação cromatográfica foi realizada na mesma coluna analítica Shim-Pack VP-ODS (150 mm x 4,6 mm; $5 \mu \mathrm{m}$ (fase reversa)) anteriormente descrita (seção 4.2.1). Utilizou-se um divisor de fluxo na interface LC-MS ${ }^{n}$, cujo fluxo direcionado ao espectrômetro de massas foi $450 \mu \mathrm{L} \min ^{-1}$. O volume de injeção foi de $20 \mu \mathrm{L}$.

O espectrômetro de massas foi calibrado automaticamente nos modos de íons positivos e negativos com padrão de calibração de reserpina 0,167 pmol $\mathrm{mL}^{-1}$. Infusão direta (introdução contínua da amostra) foi realizada para tuning e otimização do composto. Soluções padrão de DMSA (50 ng $\left.\mathrm{mL}^{-1}\right)$ e ECD (50 $\left.\mathrm{ng} \mathrm{mL}^{-1}\right)$ foram preparadas em 50:50 acetonitrila $/ 0,1 \%$ de ácido fórmico e infundidas, separadamente, a um fluxo de $10 \mu \mathrm{L} \min ^{-1}$.

O espectrômetro de massas foi otimizado nos modos MS (All $M S=$ varredura) e MS $^{n}$ (Product Ion Scan e Precursor ĺon Scan = fragmentaçao), cujas informações são referentes à ionização do composto (identificação do íon precursor) e ao padrão de fragmentação estrutural, respectivamente.

Otimização da fonte de ionização ESI foi realizada por injeção de fluxo (FIA - do inglês Flow Inject Analysis) utilizando o auto-injetor e a bomba do sistema cromatográfico. Os parâmetros otimizados da fonte de ionização ESI para as análises dos princípios ativos de DMSA e ECD e reagentes liofilizados de DMSA e de ECD estão descritos na TAB.2. 
TABELA 2- Parâmetros otimizados da fonte de ionização ESI para as análises de DMSA e ECD e seus reagentes liofilizados (RL).

\section{Parâmetro Otimizado}

DMSA ECD

\begin{tabular}{lll}
\hline Fonte de ionização & ${ }^{*}{ }^{E S I+}$ & ESI+ \\
Modo de aquisição & ${ }^{* *} \mathrm{SCAN} \mathrm{e} \mathrm{MS}{ }^{n}$ & SCAN e MS \\
Voltagem do capilar & $3,0 \mathrm{kV}$ & $3,0 \mathrm{kV}$ \\
Voltagem do cone & $30 \mathrm{~V}$ & $25 \mathrm{~V}$ \\
Skimmer & $40 \mathrm{~V}$ & $40 \mathrm{~V}$ \\
Gás nebulizador $\left({ }^{* * *} \mathrm{~N}_{2}\right)$ & $40 \mathrm{psi}$ & $40 \mathrm{psi}$ \\
Gás de dessolvatação $\left(\mathrm{N}_{2}\right)$ & $9,0 \mathrm{~L} \mathrm{~min}^{-1}$ & $9,0 \mathrm{~L} \mathrm{~min}{ }^{-1}$ \\
Temperatura de dessolvatação & $365^{\circ} \mathrm{C}$ & $325^{\circ} \mathrm{C}$ \\
Trap drive & $95 \%$ & $95 \%$ \\
Tempo de acúmulo dos íons no trap & $100,00 \mathrm{~ms}$ & $100,00 \mathrm{~ms}$ \\
Espectros acumulados & 5 & 5 \\
\hline
\end{tabular}

${ }^{*}$ ESI+: Eletrospray no modo positivo; ${ }^{*}$ SCAN: faixa de varredura: $50-700 \mathrm{~m} / \mathrm{z}$;

${ }^{* \star *} \mathrm{~N}_{2}$ : Nitrogênio; 


\section{RESULTADOS E discusSÃo}

Para obter as condições de análise para o sistema HPLC-DAD (item 5.5.1 - página 34) e LC-MS ${ }^{n}$ (item 5.5.2 página 35), descritas em materiais e métodos foram necessários sucessivos ensaios, que envolveram a definição da composição da fase móvel, fluxo e pH mais adequados para o sistema HPLC-DAD e a definição das melhores condições de funcionamento do sistema LC-MS ${ }^{n}$.

\subsection{Condições otimizadas para análise de DMSA e RL de DMSA por HPLC-DAD}

Para o desenvolvimento do método cromatográfico de análise por HPLC-DAD a modalidade de separação por fase reversa foi utilizada. A composição da fase móvel foi ajustada para obter melhor separação entre o DMSA e seus principais produtos de degradação. Foram testadas vários tipos e misturas de solventes como água: metanol, $0,1 \%$ de ácido fórmico: acetonitrila e acetato de sódio $20 \mathrm{mmol} \mathrm{L}^{-1}$ : metanol. O sistema de solventes que apresentou os melhores resultados (picos de eluição simétricos e maior resolução) foi a mistura $0,1 \%$ de ácido fórmico: acetonitrila. Esta mistura foi utilizada em todos os estudos de degradação de DMSA e RL de DMSA por HPLC-DAD.

A influência do fluxo da fase móvel foi estudada. Não foram observadas modificações significativas na resolução cromatográfica para os fluxos de $0,5 \mathrm{~mL} \mathrm{~min}$; $0,7 \mathrm{~mL} \mathrm{~min}{ }^{-1}$ e $1,0 \mathrm{~mL} \mathrm{~min}^{-1}$. O fluxo de $1,0 \mathrm{~mL} \mathrm{~min}{ }^{-1}$ foi selecionado.

O espectro de absorção na região do ultravioleta (UV: 210-350 nm) obtido no sistema HPLC-DAD para o DMSA na concentração de $1,0 \mathrm{mg}$ $\mathrm{L}^{-1}$ (FIG.16) mostrou que o comprimento de onda de máxima absorção $\left(\lambda_{\max }\right)$ do DMSA, sem interferentes, é $245 \mathrm{~nm}$. 

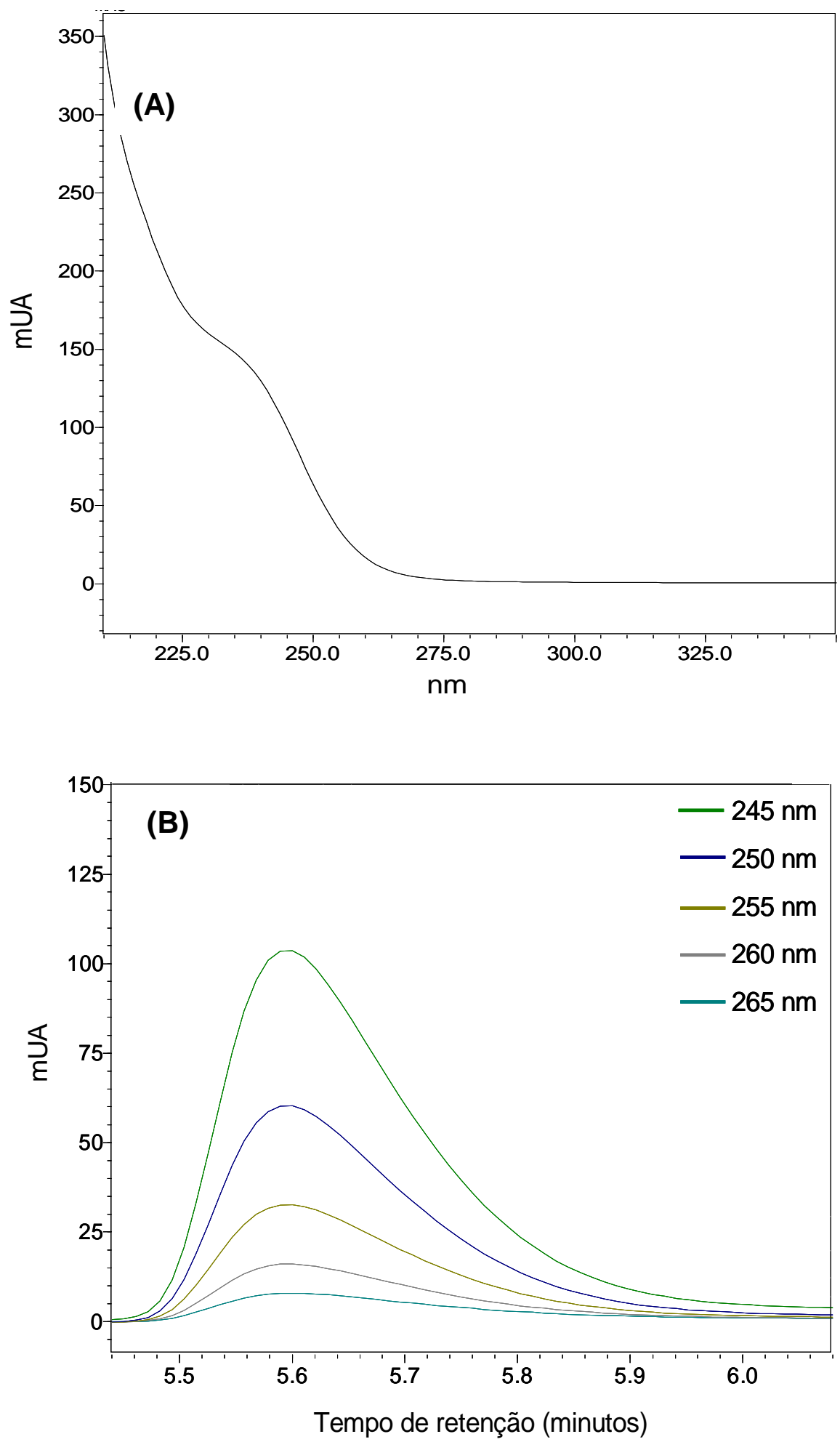

FIGURA 16- Perfil de pureza dos espectros de absorção na região UV de DMSA $1,0 \mathrm{mg} \mathrm{L}^{-1}$ obtidos por HPLC-DAD. (A) Absorbância em função do comprimento de onda $(\lambda=210-350 \mathrm{~nm})$. (B) Absorbância em função do tempo de retenção. 
O pico cromatográfico do DMSA no RL de DMSA foi identificado de duas maneiras: primeiro injetando, o RL de DMSA e comparando o tempo de retenção do DMSA no RL com o tempo de retenção obtido no DMSA (API), e segundo, fazendo uma adição de padrão de DMSA no RL de DMSA e observando o aumento do sinal de absorbância do DMSA.

A especificidade do método, bem como a identificação do DMSA, foi verificada pela sobreposição dos cromatogramas e sobreposição do espectro no UV obtido para o padrão de DMSA e para as amostras de $\mathrm{RL}$, comparando-se o tempo de retenção no cromatograma e a absorção no espectro de UV em $\lambda_{\max }=245 \mathrm{~nm}$.

A pureza do pico foi estimada através do índice de similaridade. Para isso, foram obtidos os espectros de absorção no UV de três pontos distintos do pico $(5,515 ; 5,590$ e 5,753 minutos). A TAB.3 apresenta os índices de similaridades de pureza de pico obtidos para o DMSA e o RL de DMSA.

TABELA 3- Índice de similaridade de pureza de pico para DMSA e RL de DMSA por HPLC-DAD.

DMSA

RL de DMSA

\begin{tabular}{|c|c|c|c|}
\hline $\begin{array}{l}\text { Tempo de } \\
\text { retenção }\end{array}$ & $\begin{array}{c}\text { Índice de } \\
\text { similaridade }\end{array}$ & $\begin{array}{l}\text { Tempo de } \\
\text { retenção }\end{array}$ & $\begin{array}{c}\text { Índice de } \\
\text { similaridade }\end{array}$ \\
\hline 5,590 minutos* & 0,999739 & 5,580 minutos* & 0,999341 \\
\hline 5,515 minutos & 0,999742 & 5,538 minutos & 0,999432 \\
\hline 5,753 minutos & 0,999736 & 5,719 minutos & 0,999573 \\
\hline
\end{tabular}

*ponto de referência (região de máxima absorbância no pico)

A FIG.17 mostra qualitativamente a similaridade entre os espectros de UV do DMSA. Não houve coeluição de interferentes no tempo de retenção do DMSA.

Diante dos espectros e índices de similaridade obtidos, podese inferir que o método consegue separar especificamente DMSA de impurezas e produtos de degradação. 


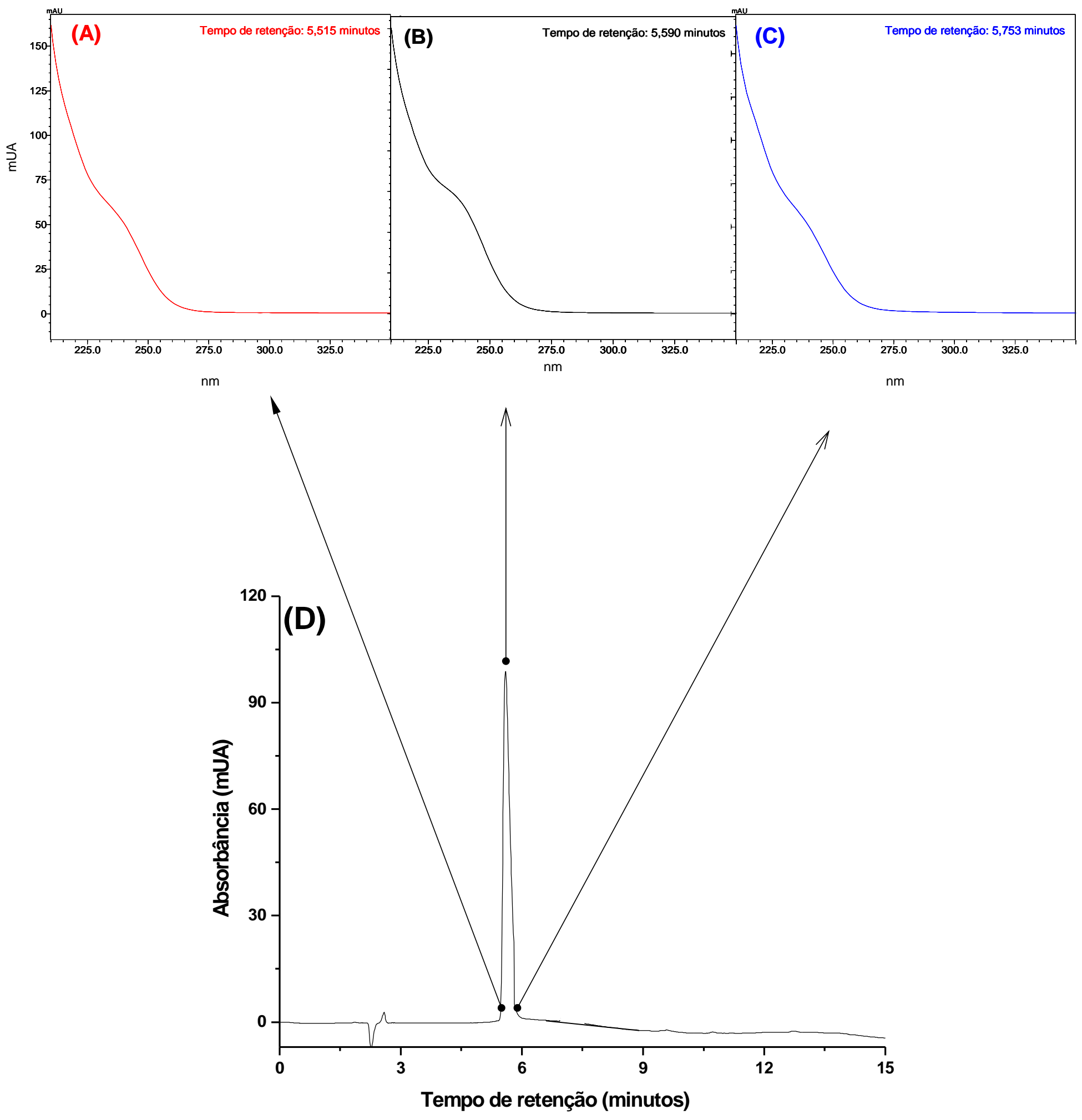

FIGURA 17- Espectros de absorção na região UV de DMSA $1,0 \mathrm{mg} \mathrm{L}^{-1}$ obtidos por HPLC-DAD. Absorbância em função do comprimento de onda ( $\lambda=210-350 \mathrm{~nm}$ ). Tempo de retenção: (A) 5,515 minutos; (B) 5,590 minutos e (C) 5,753 minutos. (D) Cromatograma de DMSA. Condições de análise: coluna Shim-pak ODS (150 mm x 4,6 mm, $5 \mu \mathrm{m}$ ); fase móvel: 0,1\% de ácido fórmico: acetonitrila. Gradiente linear 5-60\%B em 15 minutos. Fluxo da fase móvel: $1 \mathrm{~mL} \min ^{-1}$; volume de amostra: $20 \mu \mathrm{L}$ e $\lambda=245 \mathrm{~nm}$. 


\subsection{Condições otimizadas para análise de DMSA e RL de DMSA por LC-}

MS $^{\text {n }}$

O espectrômetro de massas foi otimizado nos modos MS (full $M S=$ varredura $)$ e MS $^{n}$ (Product lon Scan e Precursor íon Scan = fragmentação).

Dados da literatura indicam que o modo de ionização por APCI (Ionização química a pressão atmosférica, do inglês Atmospheric Pressure Chemical lonization) é menos suscetível a problemas de supressão iônica (56, 58, 60). Porém, no desenvolvimento do método, verificou-se a necessidade de maior fluxo de fase móvel, alta temperatura e voltagem para obtenção de resultados satisfatórios. Desta forma, selecionou-se a ionização por electrospray (ESI).

Os modos de ionização positivo $\left(\mathrm{ESI}^{+}\right)$e negativo $\left(\mathrm{ESI}^{-}\right)$foram avaliados para as amostras de DMSA $50 \mathrm{ng} \mathrm{mL}^{-1}$. As FIG.18A e FIG.18B apresentam os espectros de massas obtidos no modo positivo e no modo negativo, respectivamente.

Pode-se verificar que a análise de DMSA no modo de ionização positivo (FIG.18A), aplicando uma energia de ionização de $3,0 \mathrm{kV}$, resultou em melhor intensidade de sinal. $O$ íon de interesse foi observado em m/z 204,8 e corresponde ao DMSA coordenado com o íon metálico de sódio $\left({ }^{23} \mathrm{Na}\right)$, conhecido como aduto sodiado e representado por $[\mathrm{M}+\mathrm{Na}]^{+}$, onde $\mathrm{M}$ é a massa molecular do DMSA $\left(\mathrm{M}=182 \mathrm{~g} \mathrm{~mol}^{-1}\right)$. Esta coordenação depende do número e da disposição espacial de átomos contendo pares de elétrons não ligantes $(60,61)$.

No modo de ionização negativo (FIG.18B) houve um aumento significativo do ruído da linha de base quando comparado com o ruído da linha de base no modo de ionização positivo (aproximadamente o triplo). 0 íon de DMSA desprotonado $\left[\mathrm{M}-\mathrm{H}^{+}\right]^{-}$de $\mathrm{m} / \mathrm{z} \quad 181,1$ apresentou baixa intensidade comparada com a intensidade de outros íons interferentes. 

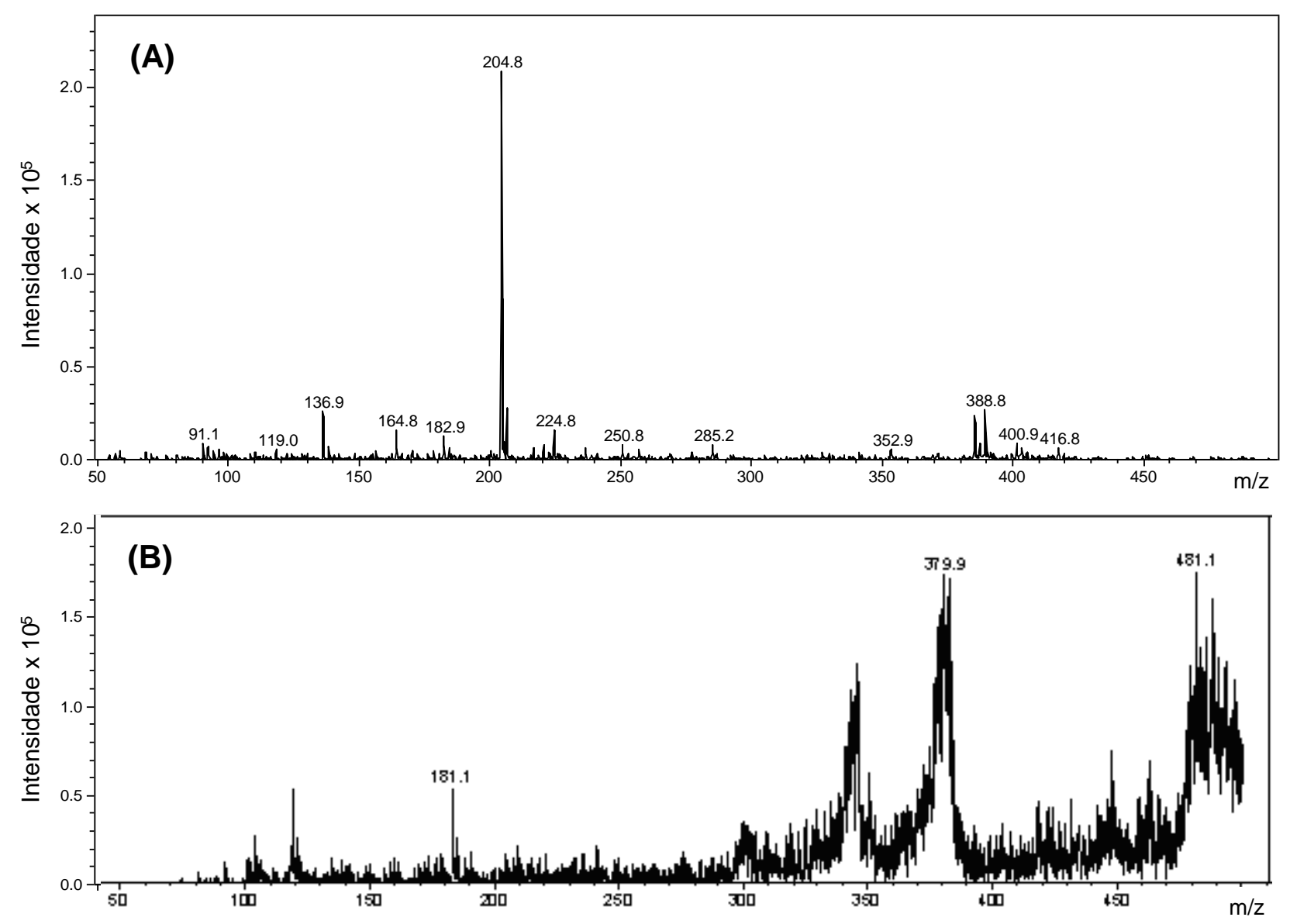

FIGURA 18- Espectros de massas do DMSA: intervalo de varredura 50-500 $\mathrm{m} /$ z. (A) $\mathrm{ESI}^{+}$; condições de análise: voltagem do cone: $30 \mathrm{~V}$, voltagem do capilar: $3,0 \mathrm{kV}$ e temperatura de dessolvatação: $365^{\circ} \mathrm{C}$. (B) ESI': condições de análise: voltagem do cone: $40 \mathrm{~V}$, voltagem do capilar: $3,5 \mathrm{kV}$ e temperatura de dessolvatação: $365^{\circ} \mathrm{C}$.

\subsection{Identificação do DMSA e cálculo do teor de DMSA nos RL.}

O perfil cromatográfico do DMSA (API) e do RL de DMSA obtidos por HPLC-DAD estão apresentados nas FIG.19A e FIG.19B, respectivamente. O DMSA, tanto no $\mathrm{API}$ quanto no $\mathrm{RL}$, apresentou tempo de retenção de 5,58 minutos. 


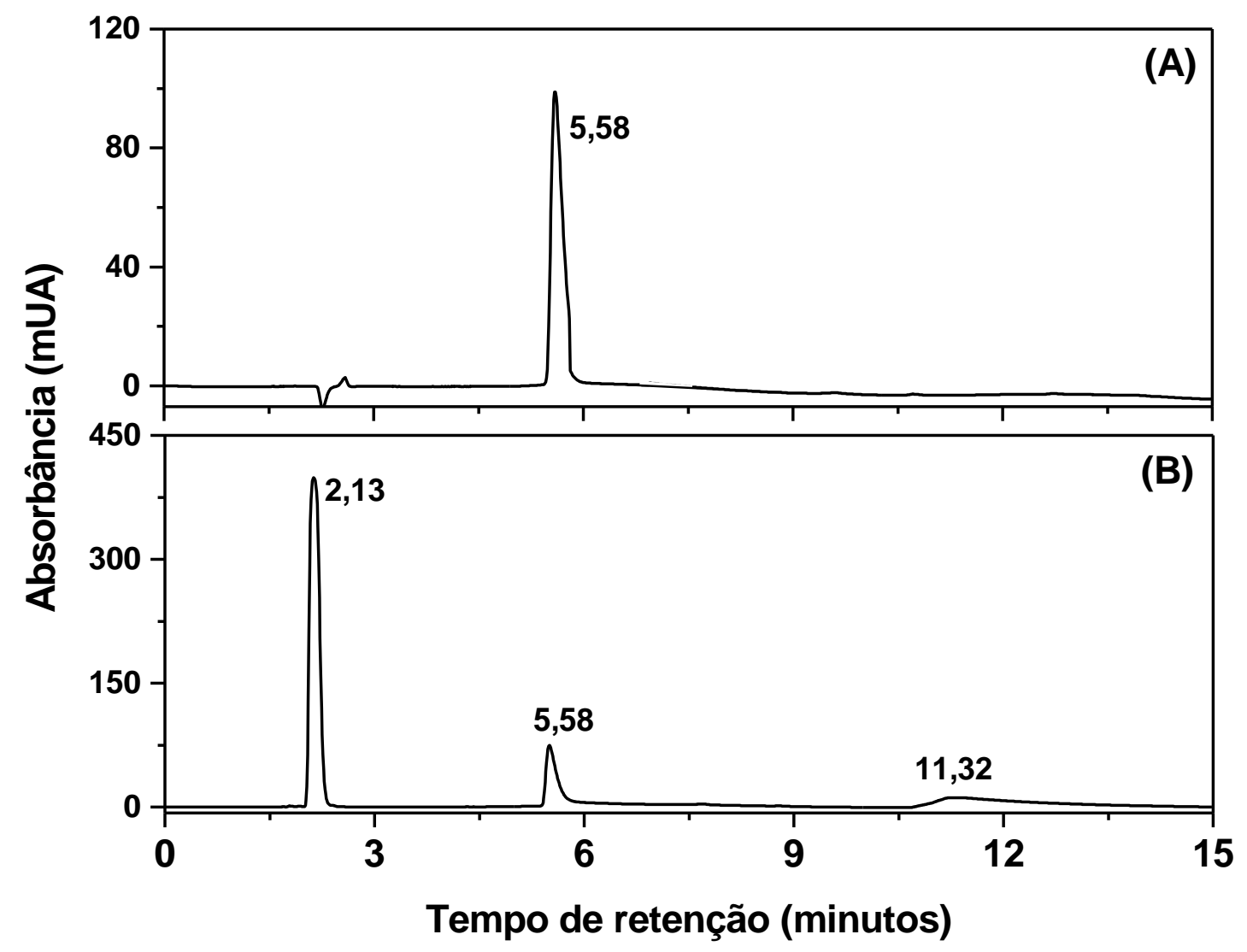

FIGURA 19- (A) Cromatograma de DMSA $1 \mathrm{mg} \mathrm{mL}^{-1}$. (B) Cromatograma de $\mathrm{RL}$ de DMSA. Condições de análise: coluna Shim-pak ODS (150 mm x 4,6 $\mathrm{mm}, 5 \mu \mathrm{m}$ ); fase móvel: 0,1\% de ácido fórmico: acetonitrila. Gradiente linear 5-60\%B em 15 minutos. Fluxo da fase móvel: $1 \mathrm{~mL} \mathrm{~min}^{-1}$; volume de amostra: $20 \mu \mathrm{L}$ e $\lambda=245 \mathrm{~nm}$.

O analito com tempo de retenção em 2,13 minutos (FIG.19A) pode ser atribuído ao ácido ascórbico, componente da formulação do $R L$ de DMSA conforme descrito na TAB.1 (página 28).

Os espectros de massas referentes aos picos cromatográficos com tempo de retenção em 5,58 e 11,32 minutos (FIG.19) estão apresentados na FIG.20. 


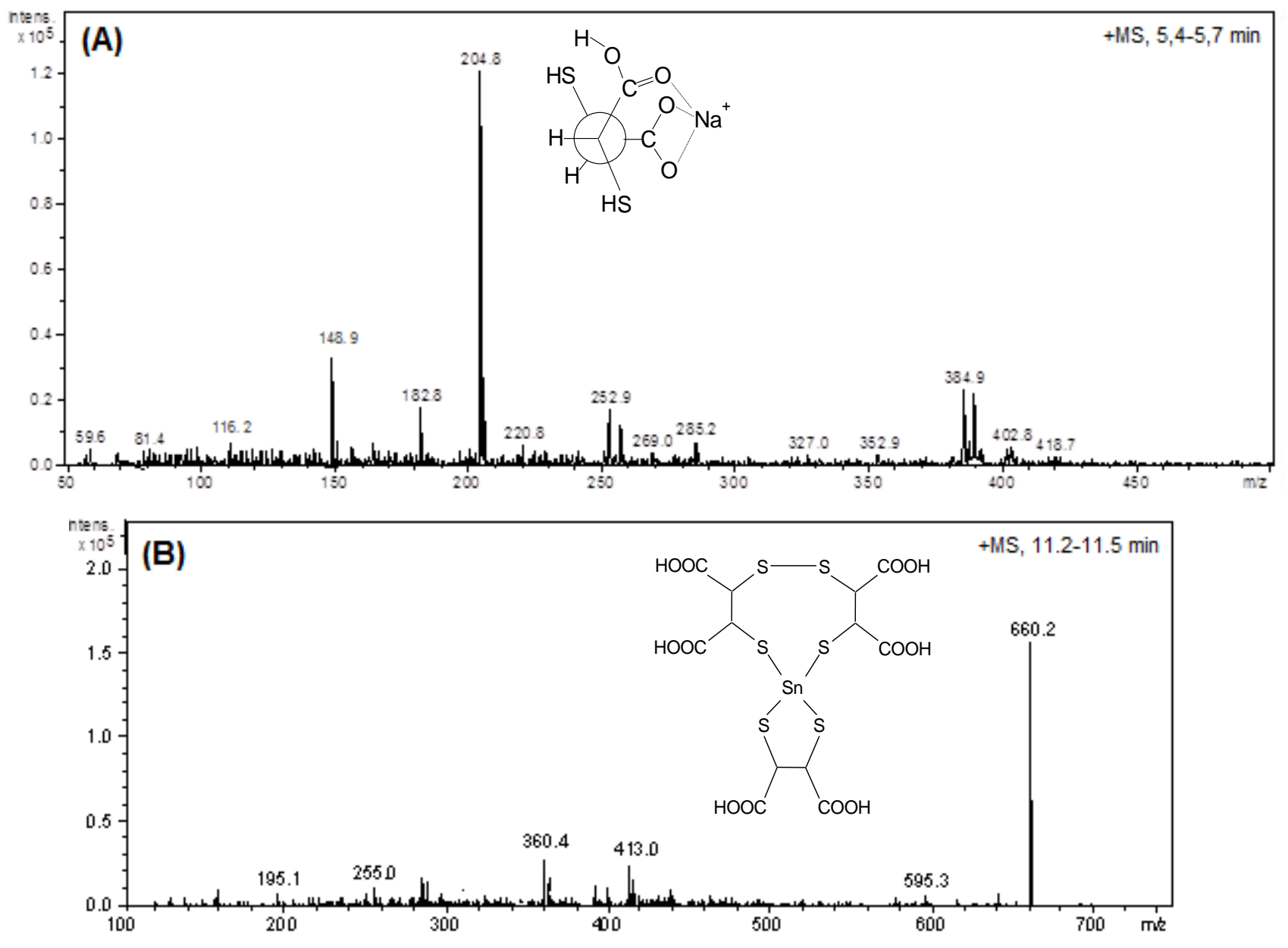

FIGURA 20- (A) Espectro de massas para o pico com tempo de retenção igual a 5,58 minutos da FIG.19A. (B) Espectro de massas para o pico com tempo de retenção igual a 11,32 minutos da FIG.19B. Prováveis estruturas químicas do íon base de m/z 204,8 e m/z 660,2 é destacada. Condições de análise: intervalo de varredura: $100-700 \mathrm{~m} / \mathrm{z}$; voltagem do cone: $30 \mathrm{~V}$, voltagem do capilar: $3,0 \mathrm{kV}$ e temperatura de dessolvatação: $365^{\circ} \mathrm{C}$.

Os picos com tempo de retenção de 5,58 minutos (FIG.19A e FIG.19B) e 11,32 minutos (FIG.19B) foram identificados por LC-MS. Os espectros de massas da FIG.20 mostram que o íon de m/z 204,8 corresponde ao aduto sodiado de DMSA $[\mathrm{M}+\mathrm{Na}]^{+}$(FIG.20A), enquanto que 0 íon de $\mathrm{m} / \mathrm{z}$ 660,2 (FIG.20B) corresponde ao trímero de DMSA ligado ao átomo de estanho $[3 \mathrm{M}+\mathrm{Sn}]^{+}$.

Empregando o método previamente desenvolvido e validado segundo a Resolução RE $n^{\circ} 899$ (guia para validação de métodos analíticos e bioanalíticos) (dados de validação não mostrados), os $\mathrm{RL}$ foram analisados 
quanto ao teor médio de DMSA (63). A TAB.4 apresenta os valores médios, obtidos por HPLC-DAD de DMSA em 5 lotes de RL e os respectivos coeficientes de variação.

TABELA 4-Teor de DMSA em reagentes liofilizados obtidos por HPLC-DAD.

\begin{tabular}{ccc}
\hline $\mathbf{R L}$ & $\begin{array}{c}\mathbf{C M D} \pm \mathbf{D P} \\
\left(\mathbf{m g ~ m L}^{-1}\right)\end{array}$ & $\begin{array}{c}\text { Exatidão } \\
(\%)\end{array}$ \\
\hline Lote A & $1,05 \pm 0,10$ & 105,00 \\
Lote B & $0,95 \pm 0,21$ & 95,00 \\
Lote C & $0,93 \pm 0,14$ & 93,00 \\
Lote D & $1,01 \pm 0,32$ & 101,00 \\
Lote E & $0,93 \pm 0,51$ & 93,00 \\
\hline
\end{tabular}

CMD: concentração média determinada

DP: desvio-padrão

De acordo com a TAB.4, os RL analisados apresentaram teor de DMSA dentro de $90-110 \%$ e os DP ficaram abaixo de $1,5 \%$ demonstrando estarem de acordo com o especificado pela RE 899 da ANVISA (63).

\subsection{Estudo de degradação forçada do DMSA e RL de DMSA}

\subsubsection{Hidrólise ácida}

Os resultados obtidos nas análises por HPLC-DAD após degradação ácida com $\mathrm{HCl} 0,1 \mathrm{~mol} \mathrm{~L}^{-1}$ do DMSA e do RL de DMSA estão apresentados nas FIG.21 e FIG.22, respectivamente. Os tempos de degradação ácida avaliados foram 0,5; 1; 2; 4 e 24 horas. 

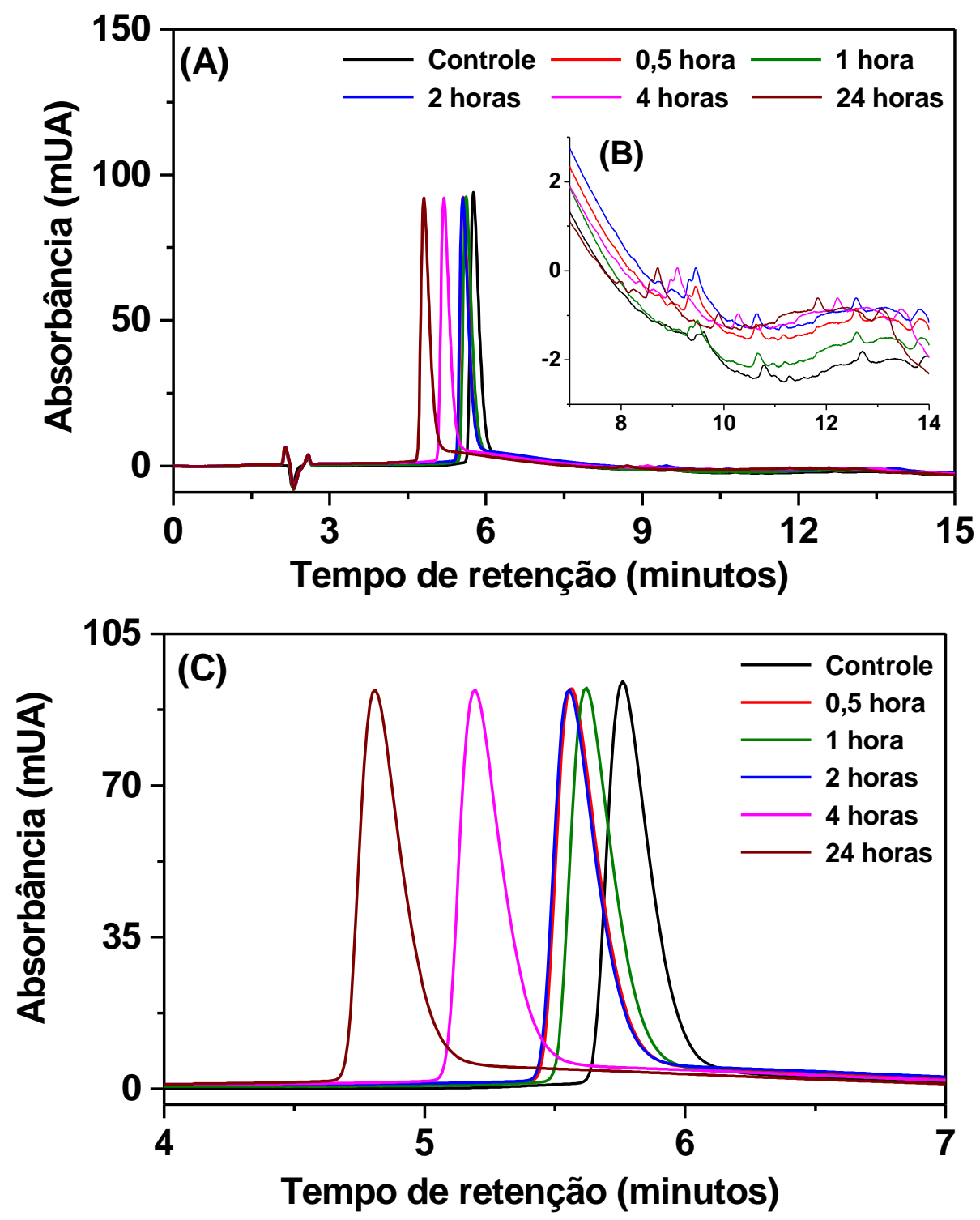

FIGURA 21- (A) Cromatogramas de DMSA $1 \mathrm{mg} \mathrm{mL}^{-1}$ obtidos após hidrólise ácida com HCl 0,1 mol L-1. Tempos de degradação: 0,5; $1 ; 2 ; 4$ e 24 horas. (B) Ampliação da FIG.21A no intervalo de 7-14 minutos. (C) Ampliação da FIG.21A no intervalo de 4-7 minutos. Condições da câmara de estabilidade: temperatura: $25{ }^{\circ} \mathrm{C}$, umidade relativa: $75 \%$. Condições da análise cromatográfica: coluna Shim-pak ODS (150 mm x 4,6 mm, $5 \mu \mathrm{m})$; fase móvel: 0,1\% de ácido fórmico: acetonitrila. Gradiente linear 5-60\%B em 15 minutos. Fluxo da fase móvel: $1 \mathrm{~mL} \mathrm{~min}^{-1}$; volume de amostra: $20 \mu \mathrm{L}$ e $\lambda=245 \mathrm{~nm}$. 

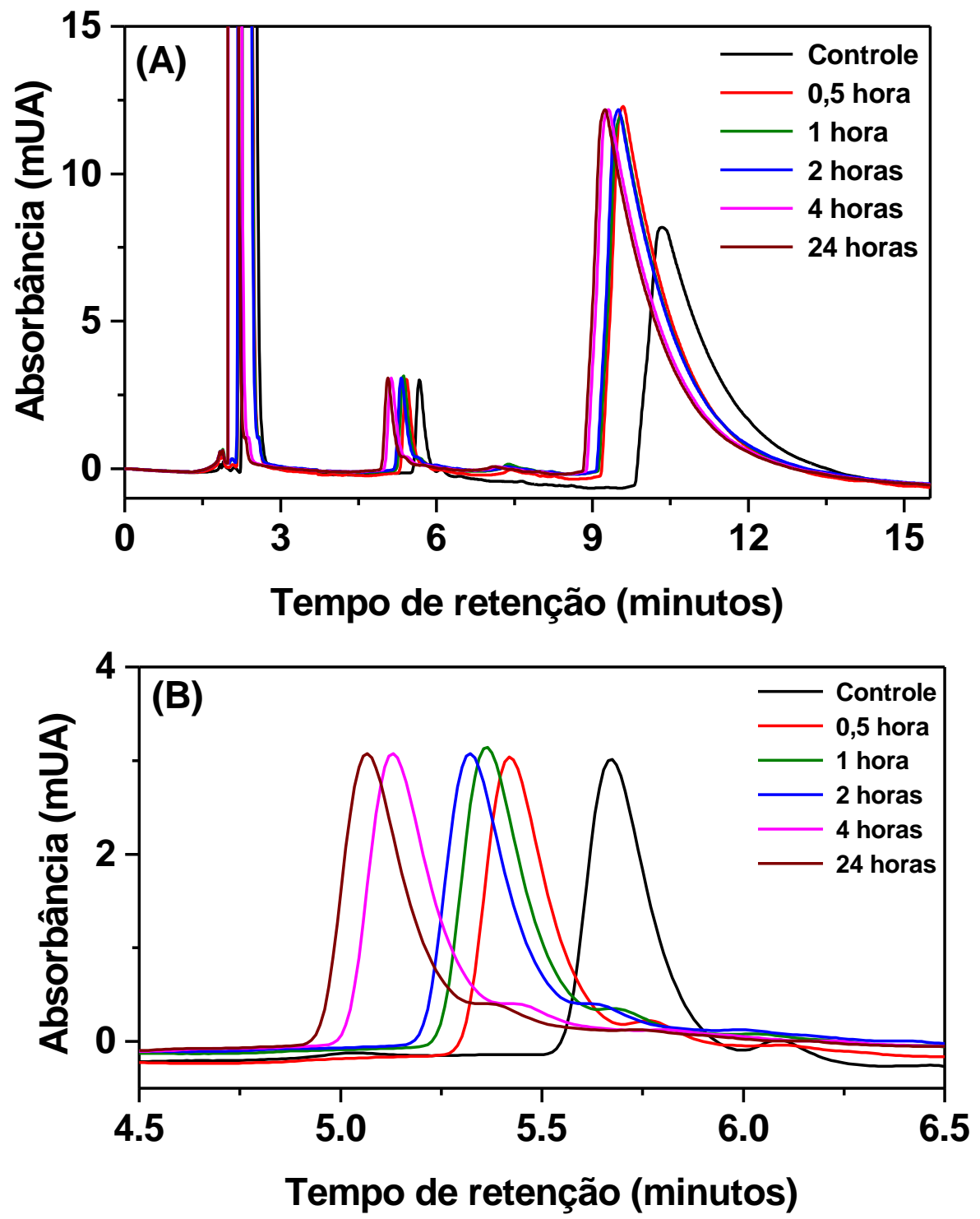

FIGURA 22- (A) Cromatogramas de RL de DMSA obtidos após hidrólise ácida com HCl 0,1 mol L-1. Tempos de degradação: 0,5; $1 ; 2 ; 4$ e 24 horas. (B) Ampliação da FIG.22A no intervalo de 4,5-6,5 minutos. Condições da câmara de estabilidade: temperatura: $25{ }^{\circ} \mathrm{C}$, umidade relativa: $75 \%$. Condições da análise cromatográfica: coluna Shim-pak ODS (150 mm x 4,6 $\mathrm{mm}, 5 \mu \mathrm{m}$ ); fase móvel: $0,1 \%$ de ácido fórmico: acetonitrila. Gradiente linear 5-60\%B em 15 minutos. Fluxo da fase móvel: $1 \mathrm{~mL} \mathrm{~min}^{-1}$; volume de amostra: $20 \mu \mathrm{L}$ e $\lambda=245 \mathrm{~nm}$.

As amostras de DMSA e RL de DMSA foram submetidas à hidrólise ácida com $\mathrm{HCl} 0,1 \mathrm{~mol} \mathrm{~L}^{-1}$ por tempo total de 24 horas (FIG.21 e FIG.22), resultando na degradação máxima de $12 \%$ do DMSA quando comparado com o DMSA da amostra controle. 
Não foi observada a formação de impurezas adicionais àquelas presentes na amostra controle (FIG.21B). Após 24 horas de exposição à solução ácida de $\mathrm{HCl} 0,1 \mathrm{~mol} \mathrm{~L}^{-1}$ o pico referente ao DMSA apresentou um deslocamento para menor tempo de retenção (DMSA controle: 5,76 minutos e DMSA após 24 horas sob hidrólise ácida: 4,81 minutos - FIG.21C).

Os espectros UV $(\lambda=245 \mathrm{~nm})$ das amostras em todos os tempos de degradação foram avaliados (dados não mostrados) e permitiram sugerir que os picos eluídos entre 4,5 - 6,2 minutos (FIG.21C e FIG.22B) referem-se ao mesmo analito. A pureza de pico obtida foi maior que $98,99 \%$ tanto para o DMSA API (FIG.21) quanto para o DMSA no RL (FIG.22).

Para confirmação da identidade dos três compostos encontrados nas análises por HPLC-DAD sob hidrólise ácida e eluídos em 4,81 minutos (amostra 24 horas), 5,20 minutos (amostra 4 horas) e 5,76 minutos (amostra controle) da FIG.21C, análises por LC-MS $^{n}$ foram realizadas e os espectros de massas obtidos estão apresentados na FIG. 23.

A estrutura química sugerida para o íon base de todos os espectros da FIG.23 está em destaque. 

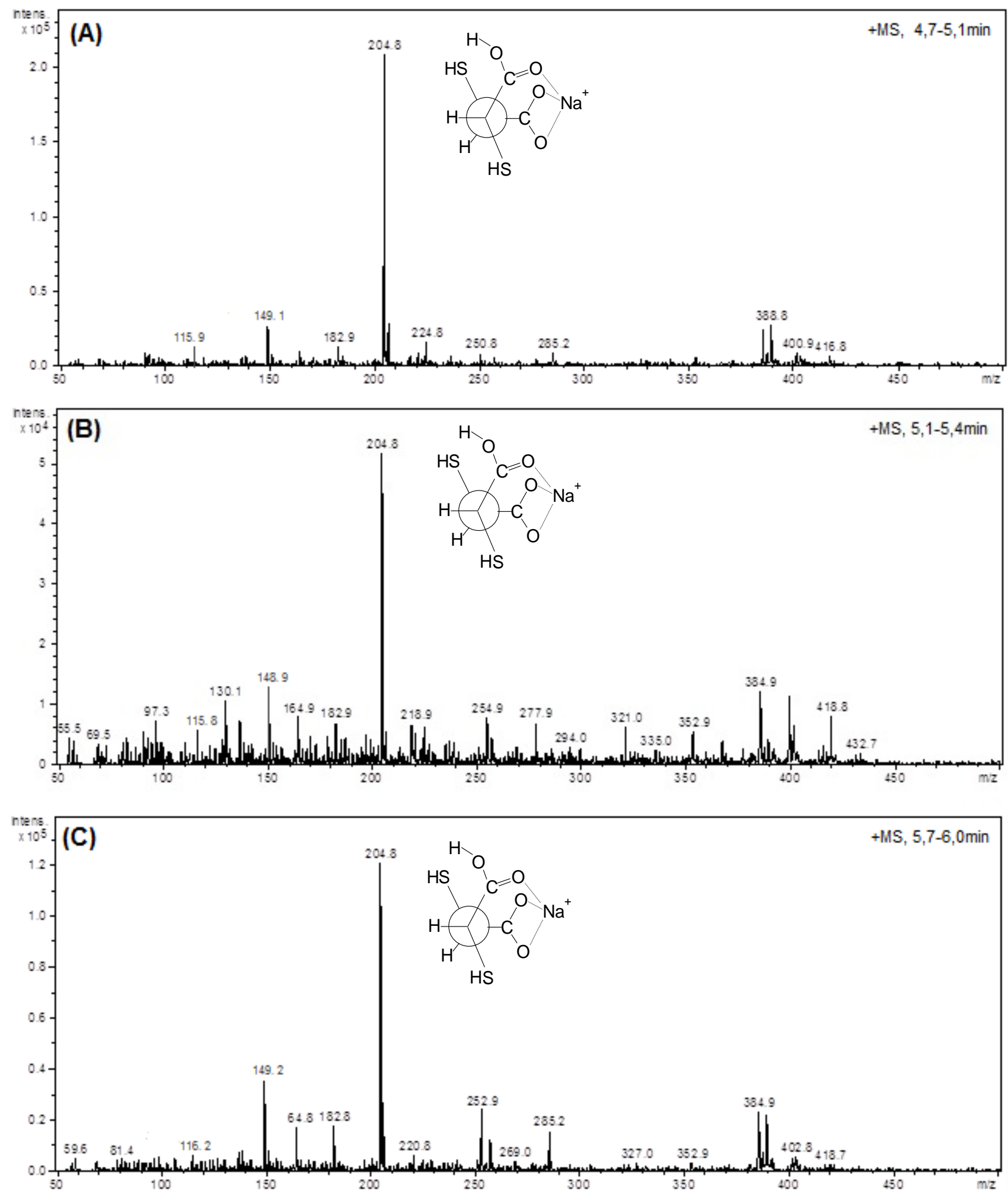

FIGURA 23- Hidrólise ácida (A) Espectro de massas obtido do pico com tempo de retenção igual a 4,81 minutos da FIG.21C. (B) Espectro de massas para o pico com tempo de retenção igual a 5,20 minutos da FIG.21C. (C) Espectro de massas para o pico com tempo de retenção igual a 5,76 minutos da FIG.21C. A estrutura química do íon base de cada espectro está em destaque. Condições de análise: full MS; intervalo de varredura: $50-500 \mathrm{~m} / \mathrm{z}$; voltagem do cone: $30 \mathrm{~V}$, voltagem do capilar: 3,0 kV e temperatura de dessolvatação: $365^{\circ} \mathrm{C}$. 
Os espectros de massas (FIG.23) para os três picos cromatográficos obtidos durante os estudos de degradação ácida (FIG.21) apresentaram um íon intenso de $\mathrm{m} / \mathrm{z}$ 204,8 referente ao íon de DMSA sodiado. Pode-se observar que o tempo de incubação do DMSA em meio ácido favoreceu a presença de uma ou outra forma estereoisomérica do DMSA.

A literatura científica descreve que a molécula de DMSA apresenta uma estrutura simples e existe como três estereoisômeros conforme apresentado na FIG.24. A forma meso é a mais fácil de preparar e a mais prontamente disponível, porém as formas racêmicas são mais solúveis em soluções ácidas $(21,64)$.

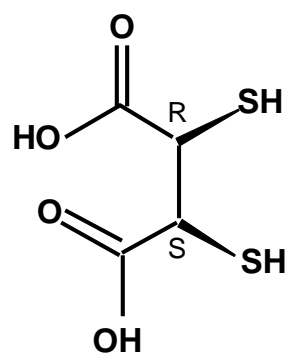

(A)<smiles>O=C(O)[C@H](S)[C@H](S)C(=O)O</smiles>

(B)<smiles>O=C(O)[C@H](S)[C@@H](S)C(=O)O</smiles>

(C)

FIGURA 24- Estereoisômeros da molécula de DMSA (A) Forma meso; (B) Forma racêmica $\mathrm{D}$ e (C) Forma racêmica $\mathrm{L}$ (21).

A orientação do grupo SH na molécula de DMSA influencia suas propriedades físicas e químicas, desta forma justificando diferentes interações com a fase estacionária da coluna cromatográfica e com a fase móvel utilizada, resultando em tempo de retenção diferentes. Quanto maior o tempo de interação do DMSA no meio ácido, menor foi o tempo de retenção observado (FIG.21 e FIG.22). Os espectros de massas apresentados na FIG.23 confirmaram a presença de formas estereoisoméricas.

Alguns pesquisadores observaram a presença de estereoisômeros marcados com ${ }^{99 \mathrm{~m}} \mathrm{Tc}$. Blower e colaboradores observaram a presença dos isômeros syn-endo, syn-exo e anti utilizando as técnicas de HPLC-UV-vis e espectroscopia no infravermelho. Além disso, observaram a presença dos três isômeros coexistindo em solução na amostra de ${ }^{99 \mathrm{~m}} \mathrm{Tc}$ - 
DMSA, porém não foi mencionado sobre qual das três formas seria a mais especifica ao tumor de interesse (23).

Guhlke e colaboradores estudaram a estabilidade química dos três estereoisômeros (syn-endo, syn-exo e anti) presentes na preparação de ${ }^{188} \mathrm{Re}(\mathrm{V})$-DMSA (análogo do ${ }^{99 \mathrm{~m}} \mathrm{Tc}$-DMSA) e avaliaram a biodistribuição dos isômeros puros comparados à mistura isomérica. Eles observaram que a cinética de interconversão da forma anti para as formas racêmicas $(D, L)$ (estudos in-vitro) é dependente do tempo de incubação e do pH do meio. Desta forma, para um tempo de incubação de 24 horas (temperatura ambiente de $22{ }^{\circ} \mathrm{C}$ ) e variando o $\mathrm{pH}$ do meio de 1 para 6 resultou em taxa de interconversão de $55 \%$, ou seja, $55 \%$ da forma anti inicial foi convertida a formas racêmicas $D, L$. Entretanto, os estudos in-vivo em ratos não mostraram diferenças significativas na biodistribuição do ${ }^{188} \mathrm{Re}(\mathrm{V})$-DMSA com relação às diferentes formas isoméricas (64).

Em outro estudo, Park e colaboradores observaram que ${ }^{188} \operatorname{Re}(\mathrm{V})$-rac-DMSA pode apresentar melhor potencial como agente terapêutico contra tumores neuroendócrinos que ${ }^{188} \mathrm{Re}(\mathrm{V})$-meso-DMSA (65).

O DMSA apresentou-se estável sob hidrólise ácida, nas condições de análise estudada. Não houve decaimento cinético estatisticamente significativo do DMSA nas amostras de DMSA e RL de DMSA.

As formas estereoisoméricas observadas por HPLC-DAD e confirmadas por LC-MS ${ }^{n}$ estão em concordância com os estudos descritos na literatura.

\subsubsection{Hidrólise alcalina}

Os resultados obtidos nas análises por HPLC-DAD após degradação alcalina com $\mathrm{NaOH} 0,1 \mathrm{~mol} \mathrm{~L}^{-1}$ do DMSA estão apresentados na FIG.25. Os tempos de degradação avaliados foram 0,5; 1; 2 e 4 horas. 


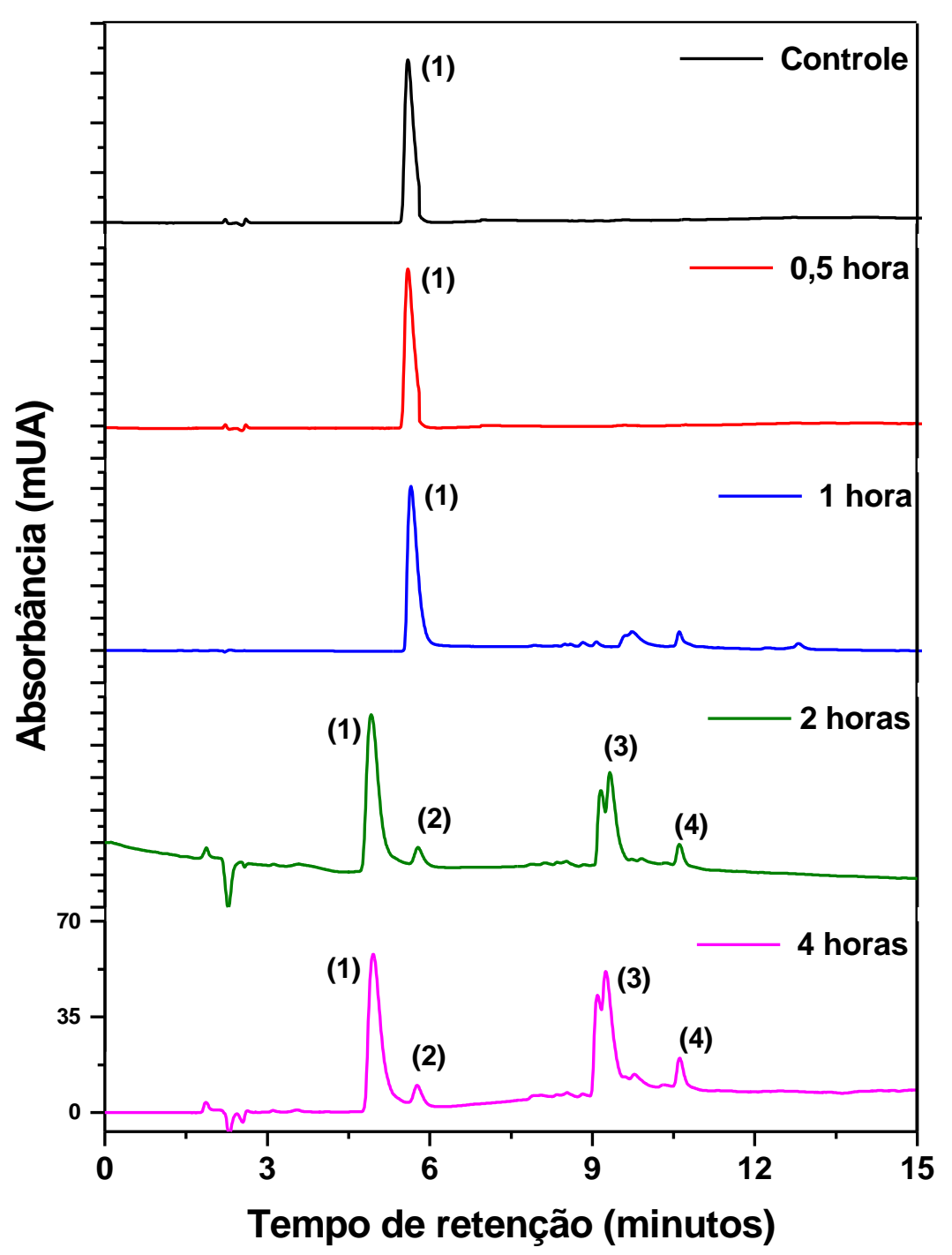

FIGURA 25- Cromatogramas de DMSA $1 \mathrm{mg} \mathrm{mL}^{-1}$ obtidos após hidrólise alcalina com $\mathrm{NaOH} 0,1 \mathrm{~mol} \mathrm{~L}^{-1}$. Tempos de reação: 0,$5 ; 1 ; 2$ e 4 horas. Tempo de retenção: (1) 4,98 minutos; (2) 5,59 minutos; (3) 9,73 minutos; (4) 10,61 minutos. Condições da câmara de estabilidade: temperatura: $25^{\circ} \mathrm{C}$, umidade relativa: $75 \%$. Condições da análise cromatográfica: coluna Shimpak ODS (150 mm x 4,6 mm, $5 \mu \mathrm{m}$ ); fase móvel: 0,1\% de ácido fórmico: acetonitrila. Gradiente linear 5-60\%B em 15 minutos. Fluxo da fase móvel: 1 $\mathrm{mL} \mathrm{min}^{-1}$; volume de amostra: $20 \mu \mathrm{L}$ e $\lambda=245 \mathrm{~nm}$.

O perfil de degradação do DMSA após hidrólise alcalina por 4 horas com NaOH 0,1 mol L-1 (FIG. 25) apresentou três picos cormatográficos com características mais apolares que o DMSA (picos em 5,59; 9,73 e 10,61 minutos, referentes aos números (2), (3) e (4) da FIG.25, respectivamente). 
Os produtos de degradação do DMSA obtidos nas análises por HPLC-DAD, após hidrólise alcalina (FIG.25), foram identificados por LC-MS ${ }^{n}$ e os espectros encontrados estão apresentados na FIG.26. A estrutura química do íon base de cada espectro também esta apresentada na FIG.26.
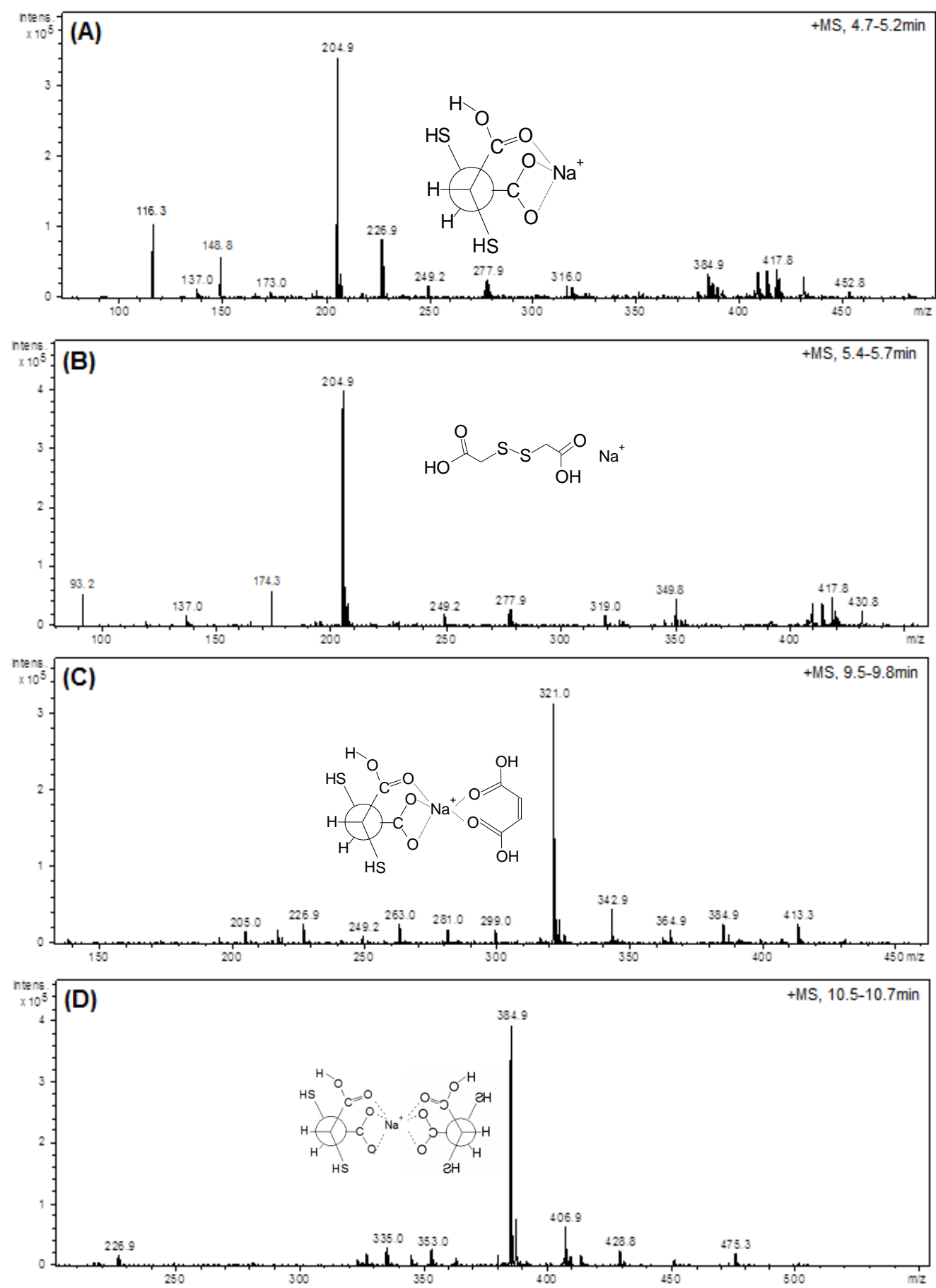

FIGURA 26- Espectros de massas obtidos dos produtos de degradação do DMSA sob hidrólise alcalina com $\mathrm{NaOH}$ apresentados na FIG.25. (A) pico (1); (B) pico (2) (C) pico (3) e (D) pico (4). A estrutura química do íon base de cada espectro está em destaque. Condições de análise: full MS, voltagem do cone: $30 \mathrm{~V}$, voltagem do capilar: $3,0 \mathrm{kV}$ e temperatura de dessolvatação: $365{ }^{\circ} \mathrm{C}$. 
As análises por LC-MS ${ }^{n}$ do DMSA sob hidrólise alcalina (FIG.26) mostraram que os picos eluidos em 4,98 minutos e 5,59 minutos, correspondentes aos espectros de massas das FIG.26A e FIG.26B são isômeros de $\mathrm{m} / \mathrm{z}$ 204,9. O pico 3 (FIG.25) apresentou íon de $\mathrm{m} / \mathrm{z} 321,0$ (FIG.26C) enquanto o pico 4 (FIG.25) apresentou íon de $\mathrm{m} / \mathrm{z} 384,9$ (FIG.26D). A identificação das estruturas químicas dos íons base apresentados na FIG.26 foi possível analisando-se os íons fragmentos em experimentos $\mathrm{MS}^{2}$ (FIG.27) e $\mathrm{MS}^{3}$.

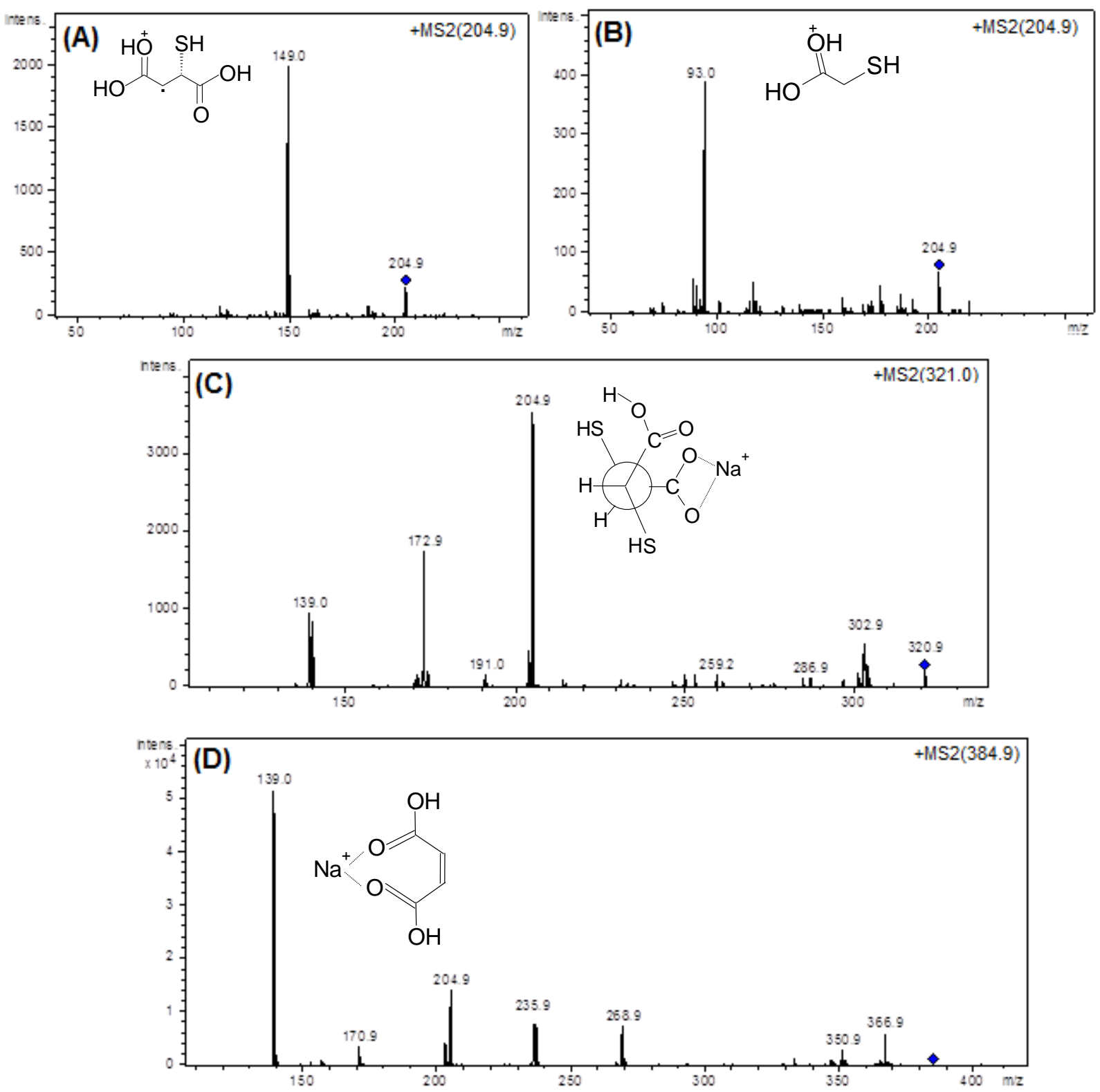

FIGURA 27- Espectros $\mathrm{MS}^{2}$. (A) $\mathrm{m} / \mathrm{z}$ 204,9 (FIG.27A); (B) $\mathrm{m} / \mathrm{z} \quad 204,9$ (FIG.27B); (C) $\mathrm{m} / \mathrm{z}$ 321,0 (FIG.27C); (D) $\mathrm{m} / \mathrm{z}$ 384,9 (FIG.27D). A estrutura química do ín base de cada espectro está em destaque. Condições de análise: $\mathrm{MS}^{2}$, voltagem do cone: $30 \mathrm{~V}$, voltagem do capilar: $3,0 \mathrm{kV}$ e temperatura de dessolvatação: $365^{\circ} \mathrm{C}$. 
A utilização da espectrometria de massas de múltiplos estágios $\left(M^{n}\right)$ possibilitou sugerir esquema de formação dos principais produtos de degradação do DMSA após hidrólise alcalina com $\mathrm{NaOH} 0,1 \mathrm{~mol} \mathrm{~L}^{-1}$ (FIG. 28).

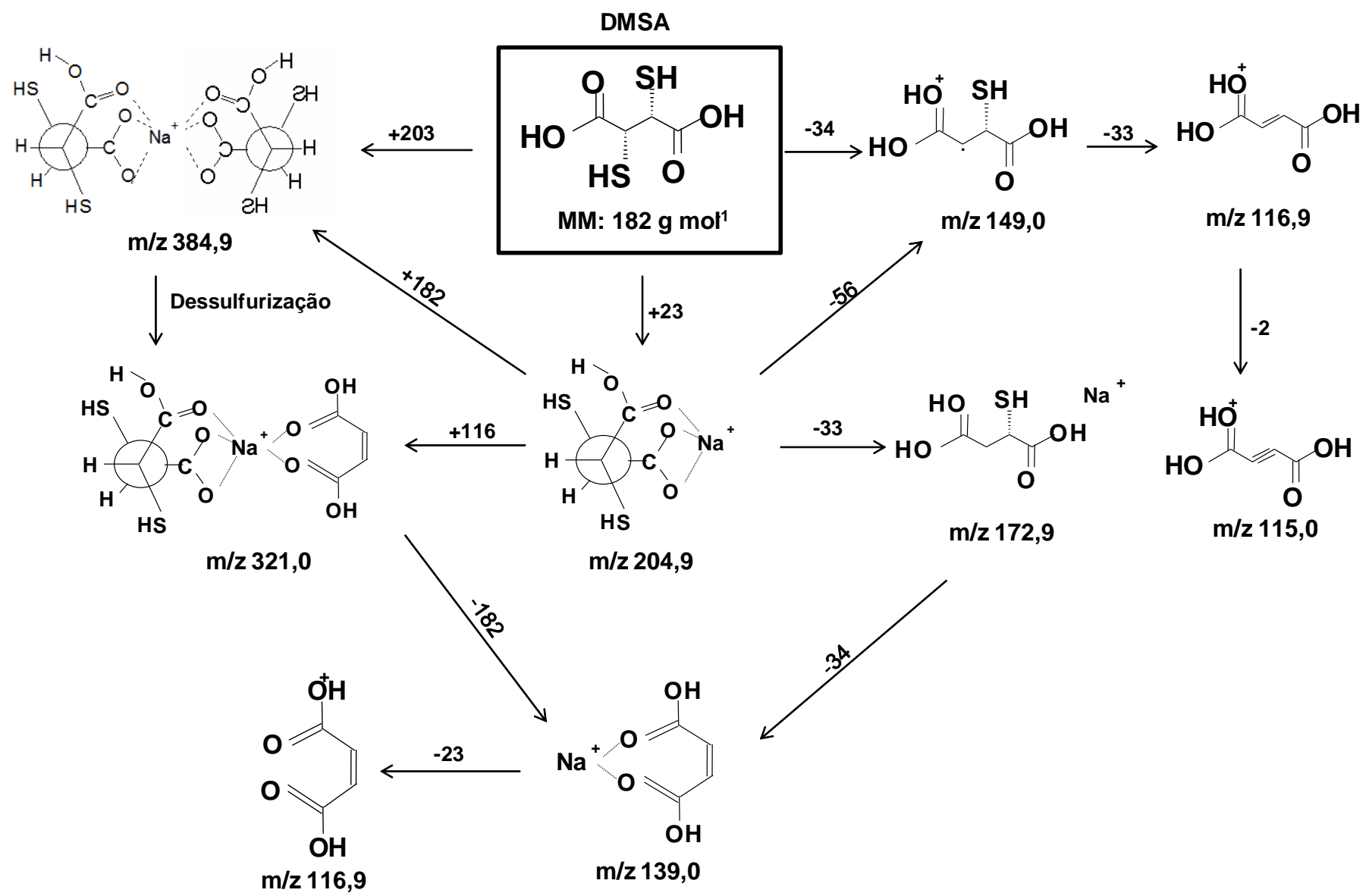

FIGURA 28- Esquema sugerido para a formação dos produtos de degradação do DMSA após hidrólise alcalina com $\mathrm{NaOH} 0,1 \mathrm{~mol} \mathrm{~L}^{-1}$. Os números indicados nas setas referem-se ao ganho (+) ou a perda (-) de massa pelo íon. Condições de análise: full MS, $\mathrm{MS}^{2}, \mathrm{MS}^{3}$ e $\mathrm{MS}^{4}$; voltagem do cone: $30 \mathrm{~V}$, voltagem do capilar: $3,0 \mathrm{kV}$ e temperatura de dessolvatação: 365 ${ }^{\circ} \mathrm{C}$.

Experimentos de hidrólise alcalina do DMSA no modo full MS permitiram identificar o íon molecular na forma de aduto sodiado de $\mathrm{m} / \mathrm{z} 205$ $\left([\mathrm{M}+23]^{+}\right)$. No espectro de fragmentação do íon de $\mathrm{m} / \mathrm{z} 205\left(\mathrm{MS}^{2}\right)$ pode-se observar a presença do fragmento de $\mathrm{m} / \mathrm{z}$ 172,9, com perda do grupo $\mathrm{SH}$ e correspondente ao aduto sodiado de ácido mercaptosuccínico (MSA); e o 
fragmento de $\mathrm{m} / \mathrm{z}$ 139,0 $\left(\mathrm{MS}^{3}\right)$, com perda do grupo $\mathrm{H}_{2} \mathrm{~S}$ e correspondente ao aduto sodiado do ácido fumárico. Este, quando fragmentado $\left(\mathrm{MS}^{4}\right)$ resulta no ácido fúmárico de m/z 116,9 (FIG.28).

A coordenação de MSA com molibdênio (Mo) e tungstênio (W) em soluções aquosas está descrito na literatura $(66,67)$. A presença deste produto de degradação nos $R L$ de DMSA pode causar uma complexação com a impureza radionuclídica ${ }^{99} \mathrm{Mo}$, proveniente do gerador ${ }^{99} \mathrm{Mo} /{ }^{99 \mathrm{~m}} \mathrm{Tc}$.

Já o ácido fumárico é um dos principais precursores utilizados na síntese do DMSA e pode ser resultante de síntese incompleta, estando presente nos RL como impureza ou pode ser um produto de degradação. Alguns pesquisadores tem estudado o efeito da presença de ácido fumárico nos RL e no radiofarmáco resultante (68-73). Staník e colaboradores avaliaram a degradação do DMSA sob condições alcalinas a fim de monitorar a produção de ácido fumárico. Eles observaram que após 21 dias em que o DMSA ficou em solução alcalina, a proporção encontrada de DMSA para ácido fumárico foi 1:1 $(21,24)$.

Aposhian e colaboradores bem como Liebman observaram a capacidade que moléculas ligantes têm de oxidar e formar dímeros $(74,75)$. Dímero de DMSA sodiado foi observado com m/z 384,9 ([2DMSA-2H+Na] $]^{+}$) (FIG.29). A fragmentação do íon de $\mathrm{m} / \mathrm{z} 384,9$ por um processo de dessulfurização, gerou o íon de $\mathrm{m} / z$ 321,0 (MS ${ }^{2}$ ) correspondente ao DMSA e ácido fumárico sodiados. Experimentos revelaram o íon de m/z 139,0 (MS ${ }^{3}$ ) e $\mathrm{m} / \mathrm{z} 116,9\left(\mathrm{MS}^{4}\right)$ também podem ser gerados por este mecanismo de degradação (FIG.28).

Íon de m/z 115,0 também foi observado após fragmentação do ácido fumárico $\left(\mathrm{MS}^{3}\right)$ e refere-se ao ácido acetileno dicarboxílico. Alguns fabricantes de DMSA utilizam o ácido acetileno dicarboxílico como precursor de síntese. A preparação de DMSA envolve a adição de 2 moles de ácido tiolacético através da ligação tripla do ácido acetileno dicarboxílico seguida de hidrólise alcalina (75).

A FIG.29 apresenta um esquema proposto para a formação dos principais produtos de degradação do isômero do DMSA de $\mathrm{m} / \mathrm{z} 204,9$ após hidrólise alcalina com $\mathrm{NaOH} 0,1 \mathrm{~mol} \mathrm{~L}^{-1}$. 


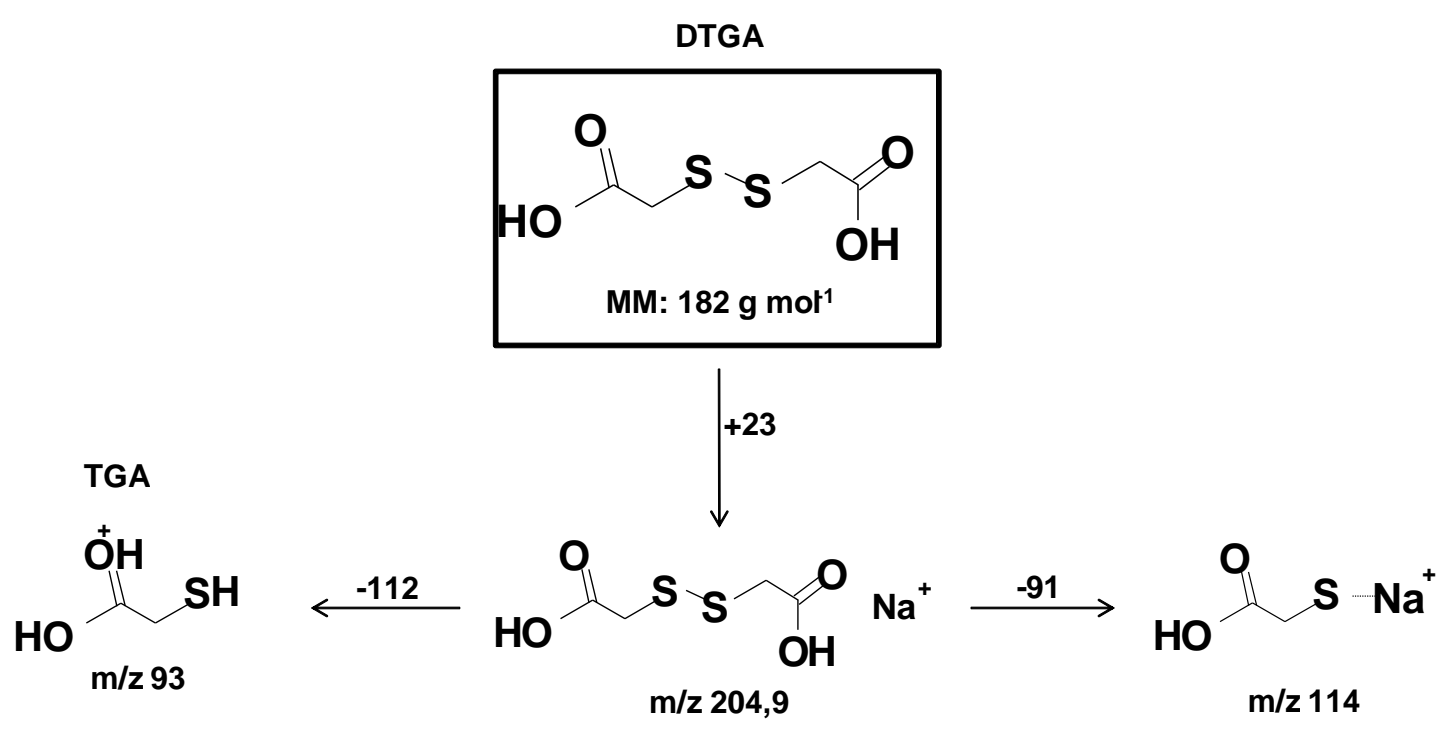

FIGURA 29- Esquema sugerido para a formação dos produtos de degradação do DTGA após hidrólise alcalina com $\mathrm{NaOH} 0,1 \mathrm{~mol} \mathrm{~L}^{-1}$. Os números indicados nas setas referem-se ao ganho $(+)$ ou a perda $(-)$ de massa pelo íon. Condições de análise: full $\mathrm{MS}$ e $\mathrm{MS}^{2}$; voltagem do cone: 30 $\mathrm{V}$, voltagem do capilar: $3,0 \mathrm{kV}$ e temperatura de dessolvatação: $365^{\circ} \mathrm{C}$.

O íon de m/z 204,9 (pico 2 da FIG.25 e espectro full MS da FIG.26B) foi verificado ser um isômero de DMSA sodiado. Trata-se do ácido ditiodiglicólico (DTGA). O espectro $\mathrm{MS}^{2}$ proveniente deste íon gera um íon produto de $\mathrm{m} / \mathrm{z}$ 93,0 (FIG.27B), característico da quebra da ponte dissulfeto do DTGA e resultando no ácido tioglicólico (TGA). O íon de $\mathrm{m} / \mathrm{z} 114,0$ pode ser relacionado ao tioglicolato de sódio. A presença deste produto de degradação pode ser observada em soluções de DMSA no meio alcalino que apresentam coloração amarela (76).

Deve-se destacar que os produtos de degradação detectados e as impurezas podem ser considerados como potenciais agentes quelantes. Eles podem formar complexos com o ${ }^{99 \mathrm{~m}} \mathrm{Tc}$ e subsequentemente causar o aumento de impureza radioquímica em preparações radiofarmacêuticas (21, 24).

Os resultados obtidos nas análises por HPLC-DAD após degradação alcalina com $\mathrm{NaOH} 0,1 \mathrm{~mol} \mathrm{~L}^{-1}$ do $\mathrm{RL}$ de DMSA estão apresentados na FIG.30. Os tempos de degradação avaliados foram 0,5; 1; 2 e 4 horas. 


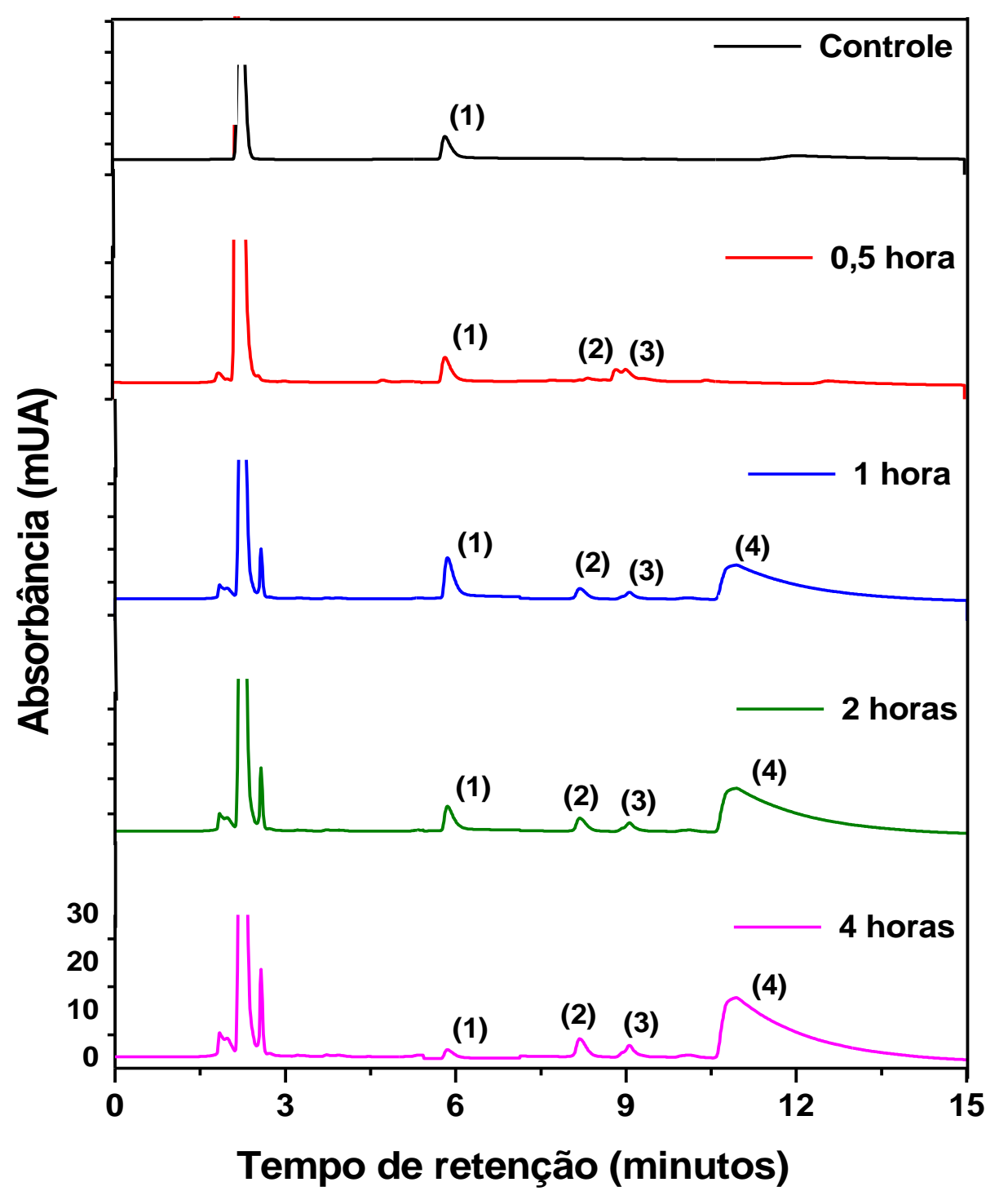

FIGURA 30- Cromatogramas de RL de DMSA obtidos após hidrólise alcalina com NaOH 0,1 mol L-1. Tempos de reação: 0,5; 1; 2 e 4 horas. Tempos de retenção: (1) 5,62 minutos; (2) 8,21 minutos; (3) 9,11 minutos e (4) 10,90 minutos. Condições da câmara de estabilidade: temperatura: $25^{\circ} \mathrm{C}$, umidade relativa: $75 \%$. Condições da análise cromatográfica: coluna Shim-pak ODS (150 mm x 4,6 mm, $5 \mu \mathrm{m}$ ); fase móvel: 0,1\% de ácido fórmico em água: acetonitrila. Gradiente linear 5-60\%B em 15 minutos. Fluxo da fase móvel: 1 $\mathrm{mL} \mathrm{min}^{-1}$; volume de amostra: $20 \mu \mathrm{L}$ e $\lambda=245 \mathrm{~nm}$.

O cromatograma do RL de DMSA apresentou três produtos de degradação mais apolares que o DMSA (pico 1 em 5,62 minutos) e estão representados como (2), (3) e (4) na FIG.30. A identificação desses picos cromatográficos foi realizada pelo uso da espectrometria de massas.

A FIG.31 apresenta os espectros de massas no modo full MS referente aos picos (2), (3) e (4) da FIG.30. 

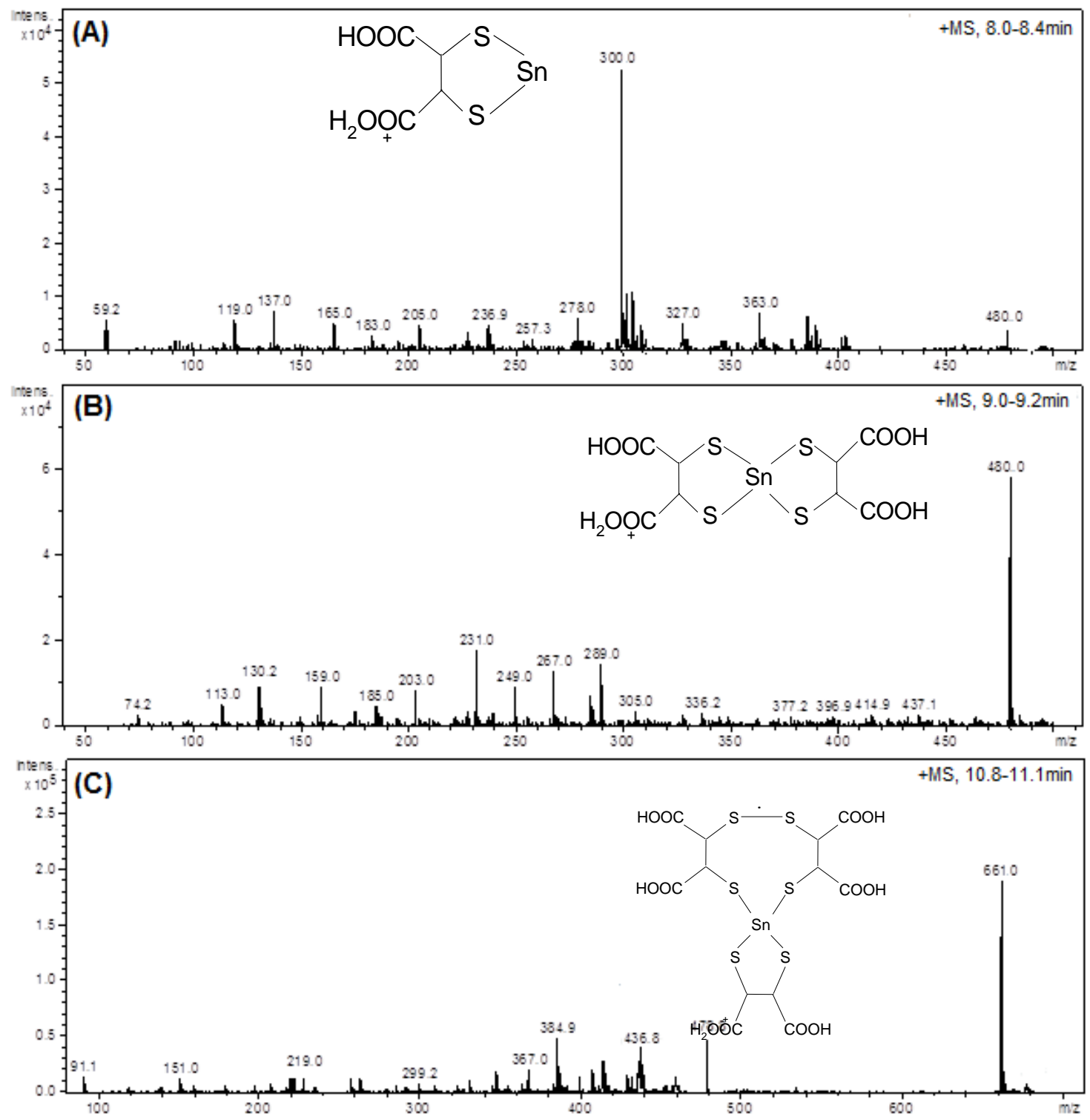

FIGURA 31- Espectros de massas obtidos dos produtos de degradação do $\mathrm{RL}$ de DMSA sob hidrólise alcalina com $\mathrm{NaOH}$ apresentados na FIG.29. (A) pico (2); (B) pico (3) e (C) pico (4). A estrutura química do íon base de cada espectro está em destaque. Condições de análise: full MS, voltagem do cone: $30 \mathrm{~V}$, voltagem do capilar: $3,0 \mathrm{kV}$ e temperatura de dessolvatação: 365 ${ }^{\circ} \mathrm{C}$.

Os picos (2), (3) e (4), eluidos no cromatograma da FIG.30, apresentaram íons de $\mathrm{m} / \mathrm{z} 300,0 ; 480,1$ e 661,0, respectivamente.

Os resultados de $\mathrm{MS}^{2}, \mathrm{MS}^{3}$ e $\mathrm{MS}^{4}$ realizadas para os íons de $\mathrm{m} / \mathrm{z}$ 300,0; 480,1 e 660,1 permitiram sugerir um esquema de formação dos principais produtos de degradação alcalina do DMSA no RL conforme apresentado na FIG.32. 


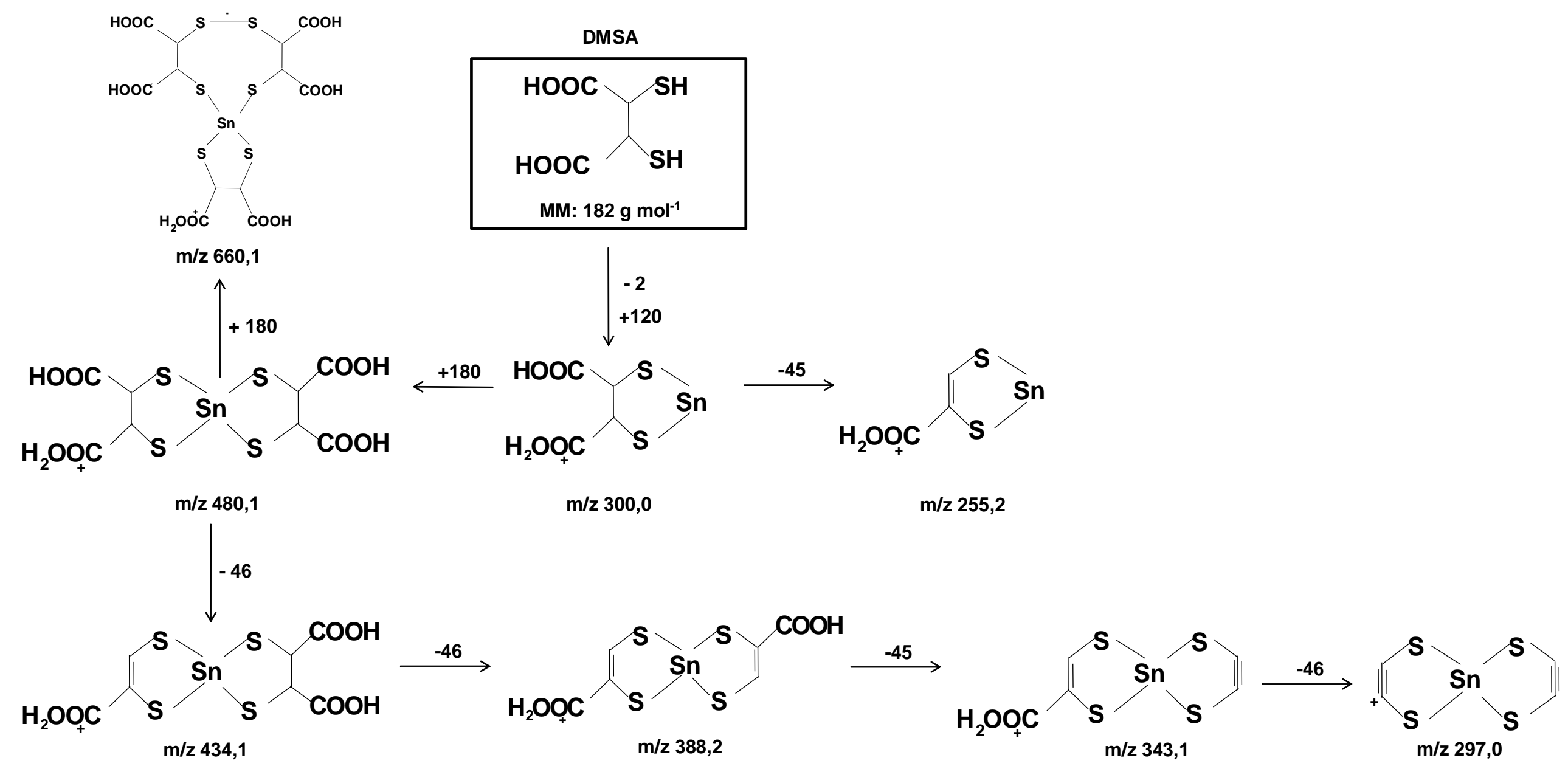

FIGURA 32- Esquema sugerido para a formação dos produtos de degradação do DMSA no RL após hidrólise alcalina com

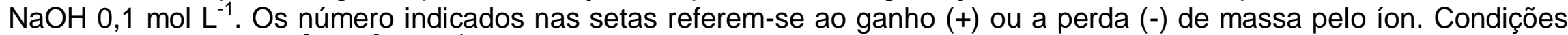
de análise: full $\mathrm{MS}, \mathrm{MS}^{2}, \mathrm{MS}^{3}$ e $\mathrm{MS}^{4}$; voltagem do cone: $30 \mathrm{~V}$, voltagem do capilar: $3,0 \mathrm{kV}$ e temperatura de dessolvatação: $365^{\circ} \mathrm{C}$. 
Pode-se observar a coordenação do íon estanho (Sn), proveniente do agente redutor cloreto estanoso (componente do $R L$ de DMSA, TAB.2-página 36), com o DMSA em todos os produtos de degradação após hidrólise alcalina do RL de DMSA.

Os compostos de coordenação de estanho se apresentam numa grande variedade de números de coordenação e de geometrias. A facilidade de expandir seu número de coordenação é uma característica notável do estanho. No caso de compostos organoestânicos, o número de coordenação varia de 2 a $7(77,78)$.

O esquema de degradação proposto na FIG. 32 apresenta alguns compostos de estanho. $O$ íon precursor de $\mathrm{m} / \mathrm{z} 300,0$ gerou o íon de $\mathrm{m} / \mathrm{z} 255,2$ resultante da perda do grupo $\mathrm{COOH}(45 \mathrm{Da})$. O íon de $\mathrm{m} / \mathrm{z}$ 480,1(dímero de DMSA com estanho) gerou os íons produtos de $\mathrm{m} / \mathrm{z} 434,1$ (perda de um grupo $\mathrm{COOH}$ ), m/z 388,2 (perda de dois grupos $\mathrm{COOH}$ ), m/z 343,1 (perda de três grupos $\mathrm{COOH}$ ) e $\mathrm{m} / \mathrm{z} 297,0$ (perda de quatro grupos $\mathrm{COOH}$ ). $\mathrm{O}$ íon de m/z 660,1 corresponde ao trímero de DMSA com estanho.

Complexos de Sn-DMSA já haviam sido observados na literatura por Moretti e colaboradores. Preocupados com a grande variabilidade na biodistribuição de ${ }^{99 \mathrm{~m}} \mathrm{Tc}$-DMSA em tecidos, eles estudaram a natureza dos complexos formados após a marcação com ${ }^{99 \mathrm{~m}} \mathrm{Tc}$ Concluíram que a quantidade de cloreto estanoso (agente redutor) deve ser otimizada e que a melhor escolha é manter a razão DMSA-Sn 3:1 e utilizar um estabilizante na preparação do $R L$ a fim de garantir a redução do tecnécio pelo estanho. A presença de complexos DMSA-Sn favorece captação do fígado nas imagens cintilográficas e variação do background (22).

Por outro lado, Galvez e colaboradores estudaram a marcação de DMSA com ${ }^{99 m} \mathrm{Tc}$ sem a utilização de agente redutor exógeno. Eles observaram que o próprio DMSA pode reduzir o pertecnetato numa etapa lenta enquanto a formação do ${ }^{99 \mathrm{~m}} \mathrm{Tc}$-DMSA é muito rápida (79). 


\subsubsection{Análise quantitativa e cinética de degradação de DMSA e RL de DMSA}

As porcentagens de degradação do DMSA e do DMSA no RL obtidos por HPLC-DAD sob condições de hidrólise alcalina com $\mathrm{NaOH} \mathrm{0,1}$ mol L ${ }^{-1}$ estão apresentadas na TAB.5

TABELA 5- Porcentagem de degradação do DMSA (API) e do DMSA no RL nas diferentes condições de degradação alcalina.

\begin{tabular}{ccccc}
\hline & \multicolumn{2}{c}{ DMSA } & \multicolumn{2}{c}{ RL de DMSA } \\
\hline $\begin{array}{c}\text { Tempo de } \\
\text { degradação }\end{array}$ & $\begin{array}{c}\text { (") Porcentagem } \\
\text { de degradação }\end{array}$ & $\begin{array}{c}\text { Índice de } \\
\text { pureza }\end{array}$ & $\begin{array}{c}\text { (") Porcentagem } \\
\text { de degradação }\end{array}$ & $\begin{array}{c}\text { Índice de } \\
\text { pureza }\end{array}$ \\
\hline 0 & 0 & 0,9997 & 0 & 0,9996 \\
\cline { 2 - 5 } 0,5 hora & $(4,13 \pm 0,32) \%$ & 0,9997 & $(3,11 \pm 0,11) \%$ & 0,9993 \\
\cline { 2 - 5 } 1 hora & $(10,19 \pm 0,18) \%$ & 0,9995 & $(8,31 \pm 0,09) \%$ & 0,9989 \\
\cline { 2 - 5 } 2 horas & $(15,42 \pm 0,21) \%$ & 0,9983 & $(13,28 \pm 0,35) \%$ & 0,9978 \\
\cline { 2 - 5 } 4 horas & $(22,71 \pm 0,19) \%$ & 0,9981 & $(25,65 \pm 0,41) \%$ & 0,9974 \\
\hline
\end{tabular}

${ }^{(*)(*)}$ Expressa em (média \pm desvio padrão)

$\mathrm{Na}$ hidrólise alcalina com $\mathrm{NaOH} 0,1 \mathrm{~mol} \mathrm{~L}^{-1}$, a porcentagem residual de DMSA após 4 horas de exposição foi de $(77,29 \pm 0,24) \%$ para 0 DMSA e de $(74,35 \pm 0,37) \%$ para o DMSA no RL (TAB.5).

A maior estabilidade, frente às condições de hidrólise alcalina, do DMSA no RL pode ser atribuída ao efeito protetor causado pela presença dos excipientes constituintes do $\mathrm{RL}$ (TAB.1, página 28). O índice de pureza do pico de DMSA foi maior que 0,99 para todos os tempos de exposição analisados.

O gráfico representativo do estudo de cinética da hidrólise alcalina do DMSA e do RL de DMSA está apresentado na FIG.33.

Os parâmetros cinéticos obtidos demonstraram que a decomposição hidrolítica do DMSA em condições alcalina segue uma reação de segunda ordem. 


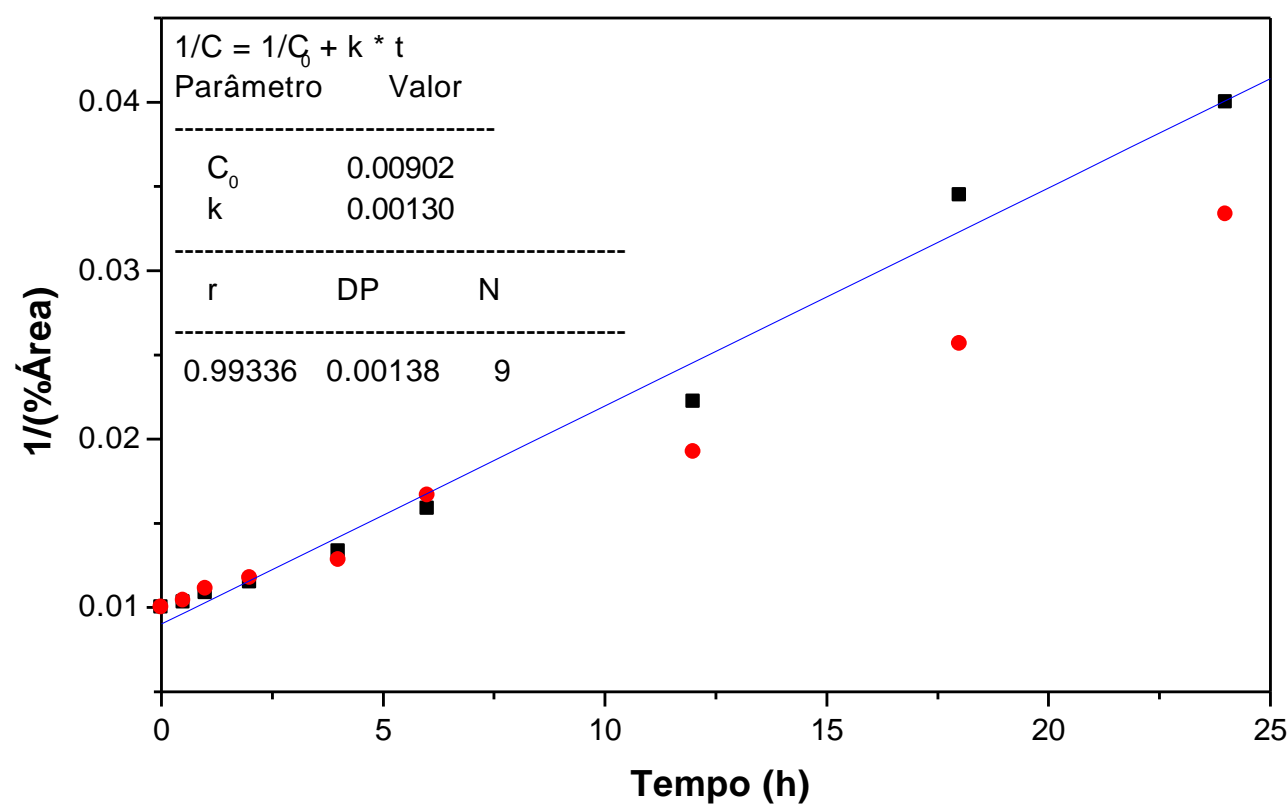

FIGURA 33-. Cinética da degradação das amostras de DMSA (•) e RL de DMSA (-) submetidas à hidrólise alcalina com $\mathrm{NaOH} 0,1 \mathrm{~mol} \mathrm{~L}^{-1}$ por 24 horas, onde $\mathrm{C}=\%$ área.

Pode-se verificar que a hidrólise alcalina do DMSA e do $R L$ de DMSA depende da concentração tanto de DMSA quanto de $\mathrm{NaOH}$. A constante de velocidade da reação foi igual à inclinação da reta obtida (FIG.33) e sua análise revelou que, nas condições experimentais avaliadas, a taxa da constante de decomposição hidrolítica do DMSA em meio alcalino foi $k=1,30 \times 10^{-3}$ horas $^{-1}$. O coeficiente de correlação linear $(r)$ obtido foi 0,99307 .

\subsubsection{Hidrólise neutra}

As amostras submetidas à hidrólise neutra não apresentaram degradação após o período avaliado de 24 horas, evidenciando a estabilidade do DMSA em solução aquosa.

Nessa condição, a taxa de decomposição é lenta, o que é compreensível, porque reações em pH neutro são não-catalíticas e por isso podem ser necessários períodos muito longos sob condições extremas de 
temperatura, para conseguir quantidades suficientes de produtos de degradação (47).

\subsubsection{Fotólise}

Os resultados obtidos nas análises por HPLC-DAD após degradação do DMSA em solução aquosa e DMSA na forma sólida (pó), sob radiação UV por 6 e 24 horas encontram-se na FIG. 34.

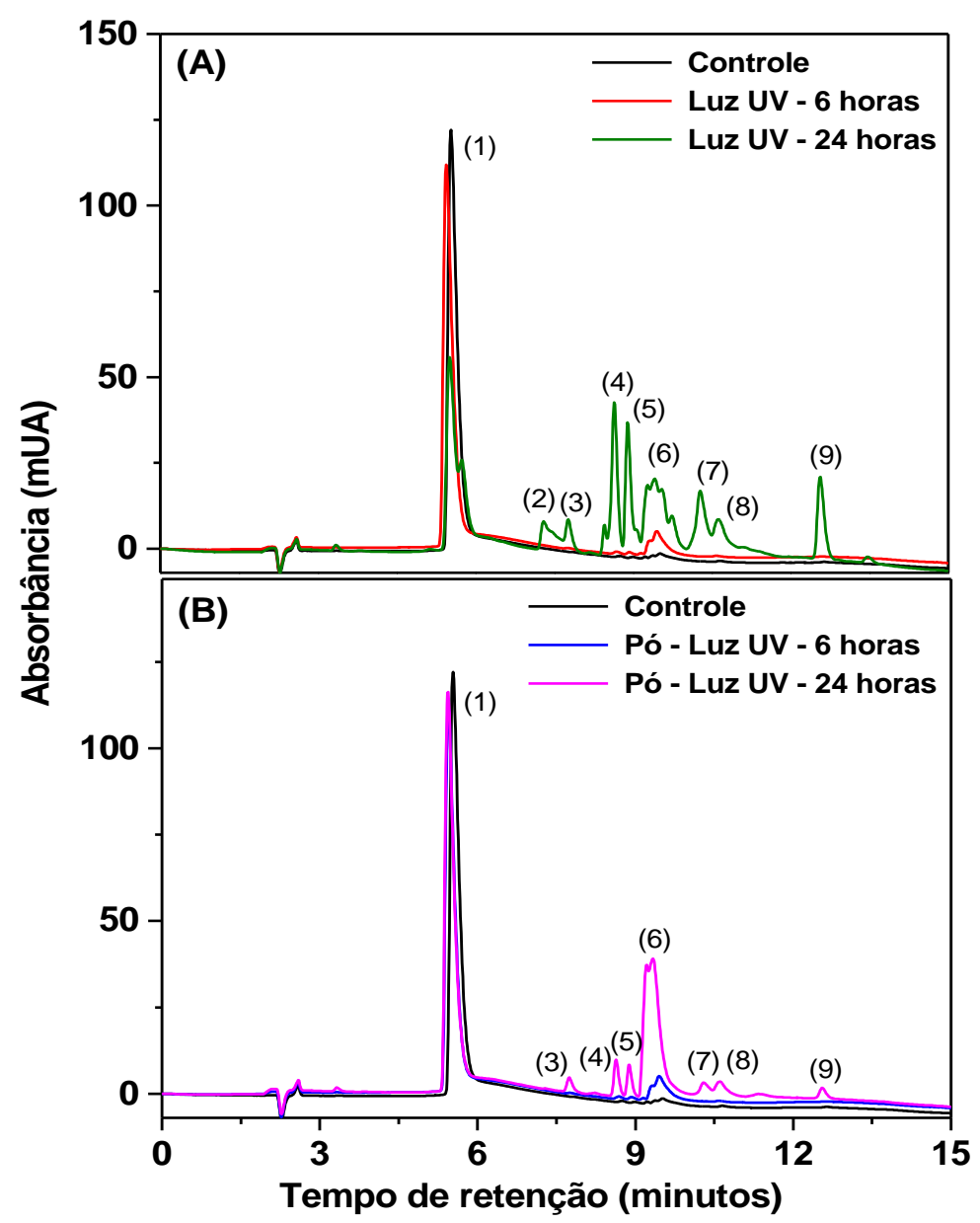

FIGURA 34- Cromatogramas de DMSA obtidos após degradação pela radiação UV. (A) DMSA em solução aquosa; (B) DMSA na forma sólida (pó). Tempos de exposição: 6 e 24 horas. Tempos de retenção (minutos): (1) 5,55 ; (2) 7,30; (3) 7,72; (4) 8,66; (5) 8,92; (6) 9,41; (7) 10,31; (8) 10,61; (9) 12,57. Condições da câmara de estabilidade: temperatura: $25{ }^{\circ} \mathrm{C}$, umidade relativa: $75 \%$, Intensidade luz UV: $200 \mathrm{~W} \mathrm{~m}^{-2}$ por hora. Condições da análise cromatográfica: coluna Shim-pak ODS (150 mm x 4,6 mm, $5 \mu \mathrm{m}$ ); fase móvel: 0,1\% de ácido fórmico: acetonitrila. Gradiente linear 5-60\%B em 15 minutos. Fluxo da fase móvel: $1 \mathrm{~mL} \min ^{-1}$; volume de amostra: $20 \mu \mathrm{L}$ e $\lambda=245 \mathrm{~nm}$. 
Os cromatogramas (FIG. 34) apresentaram picos referentes a potenciais produtos de degradação nas condições estabelecidas para avaliação da fotólise. Todos os picos cromatográficos apresentaram tempo de retenção posterior ao tempo de retenção do pico principal referente ao DMSA (pico (1) em 5,55 minutos), ou seja, são compostos mais apolares que o DMSA.

O DMSA no estado sólido (FIG.34B) mostrou-se mais estável diante da exposição à luz UV quando comparado ao DMSA em solução aquosa (FIG.34A).

As soluções de DMSA foram avaliadas por LC-MS ${ }^{n}$ objetivando elucidar as estruturas químicas dos principais produtos de degradação fotolítica. Os espectros de massas referentes aos picos cromatográficos obtidos por HPLC-DAD (FIG.34) estão apresentados na FIG.35. 

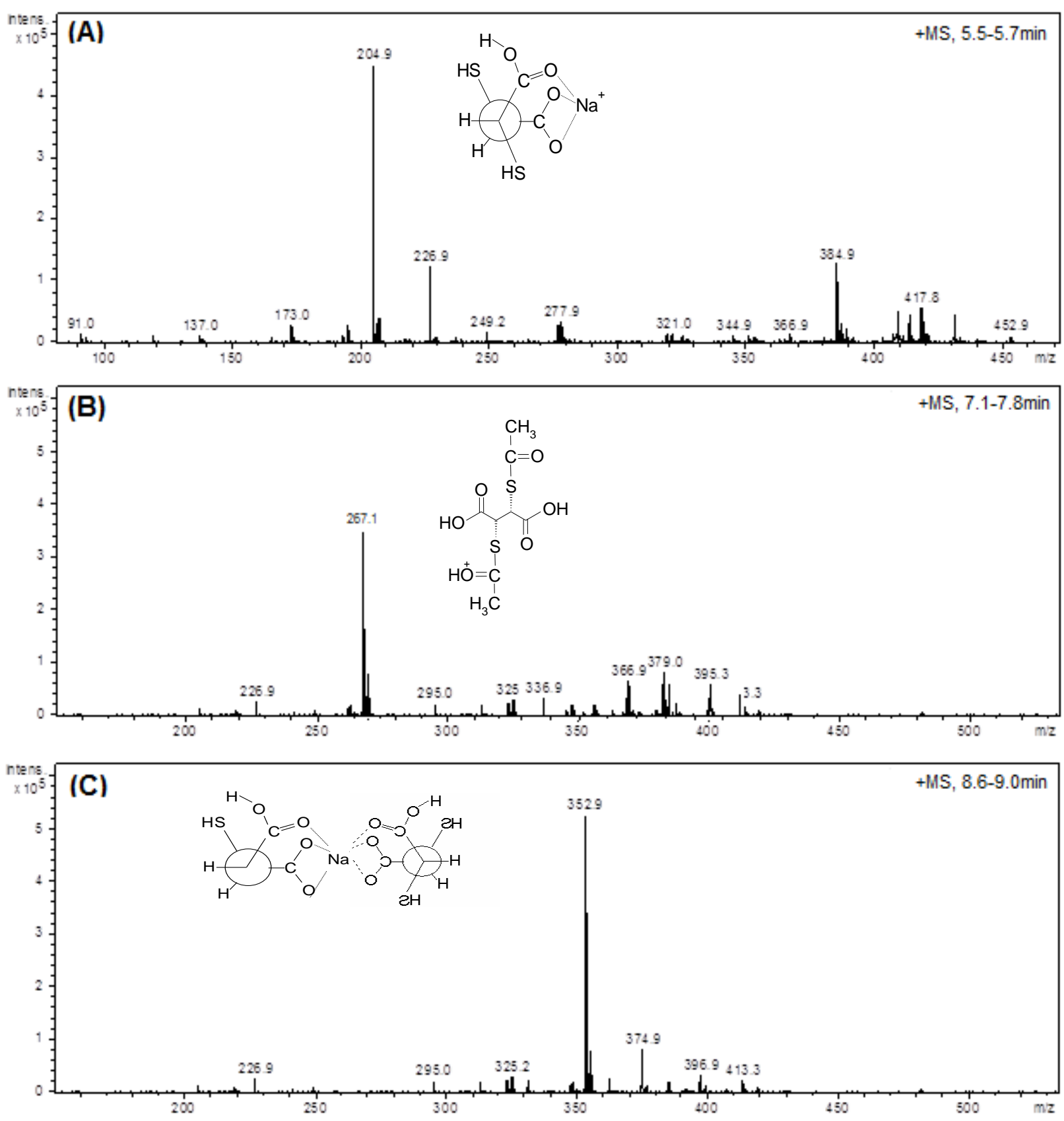

FIGURA 35- Espectros de massas referentes aos produtos de degradação do DMSA após degradação fotolítica por luz UV. Os espectros correspondem aos picos cromatográficos na FIG.34. (A) pico (1); (B) picos (2) e (3) (C) pico (4) e (5). A estrutura química do íon base de cada espectro está em destaque. Condições de análise: full MS, voltagem do cone: $30 \mathrm{~V}$, voltagem do capilar: $3,0 \mathrm{kV}$ e temperatura de dessolvatação: $365^{\circ} \mathrm{C}$. 

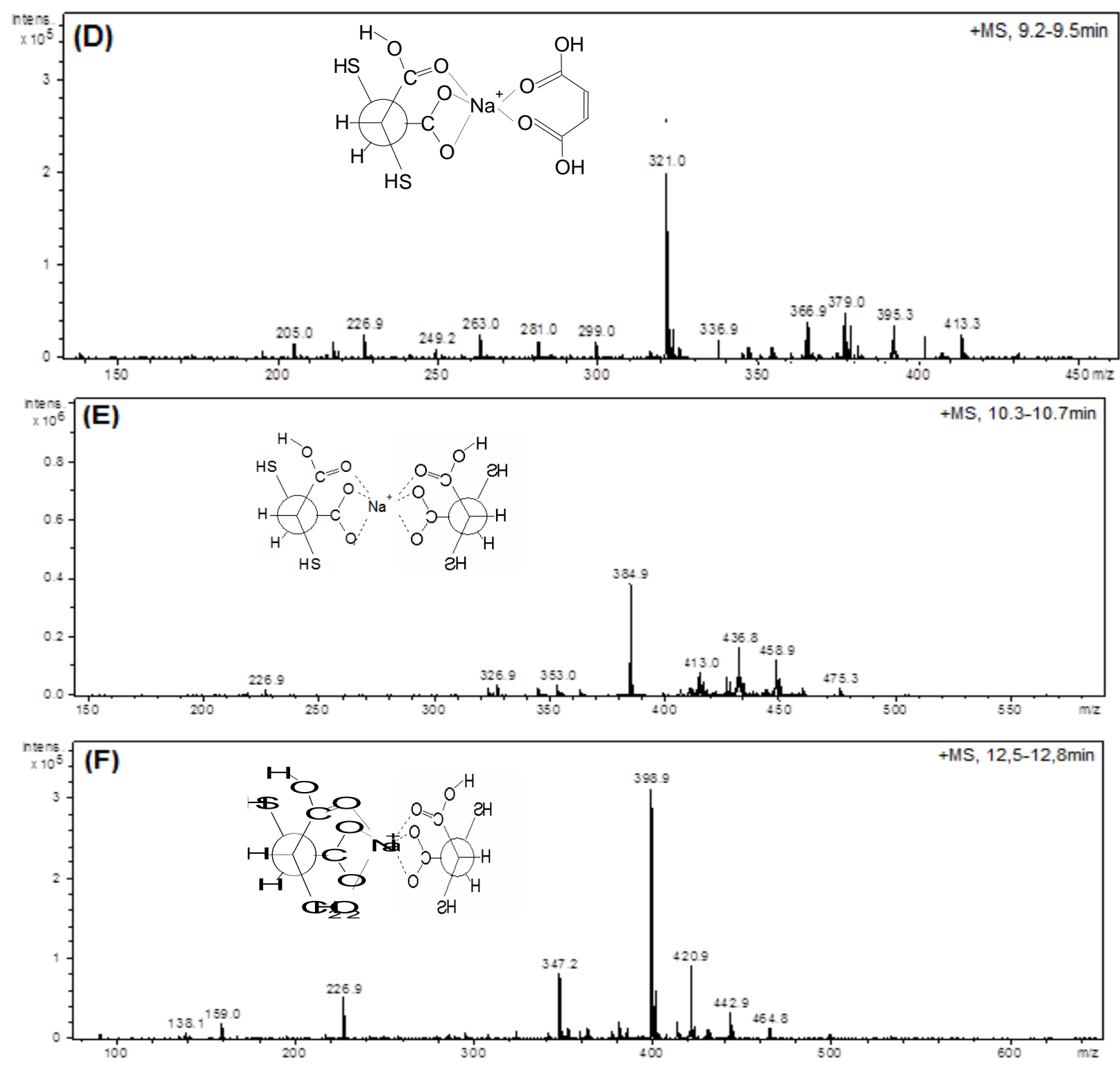

FIGURA 35- Continuação. Espectros de massas referentes aos produtos de degradação do DMSA após degradação fotolítica por luz UV. Os espectros correspondem aos picos cromatográficos na FIG.35. (D) pico (6); (E) pico (7) e (8) e (F) pico (9). A estrutura química do íon base de cada espectro está em destaque. Condições de análise: full MS, voltagem do cone: $30 \mathrm{~V}$, voltagem do capilar: 3,0 kV e temperatura de dessolvatação: $365{ }^{\circ} \mathrm{C}$

Os produtos de degradação de $\mathrm{m} / \mathrm{z} 321,0$ (tempo de retenção 9,41 minutos) e $\mathrm{m} / \mathrm{z} 384,9$ (tempos de retenção 10,31 e 10,61 minutos), FIG.36D e FIG.36E, respectivamente, também foram observados na hidrólise alcalina (FIG.27). A identidade desses íons foi confirmada com 
análises do tipo $\mathrm{MS}^{2}$ e $\mathrm{MS}^{3}$, cujos espectros obtidos foram semelhantes aos encontrados nos estudos de hidrólise alcalina. Para a identificação dos íons de $\mathrm{m} / \mathrm{z}$ 267,1; m/z 352,9 e m/z 398,9 os espectros $M^{2}{ }^{2}$ foram obtidos (FIG.36).
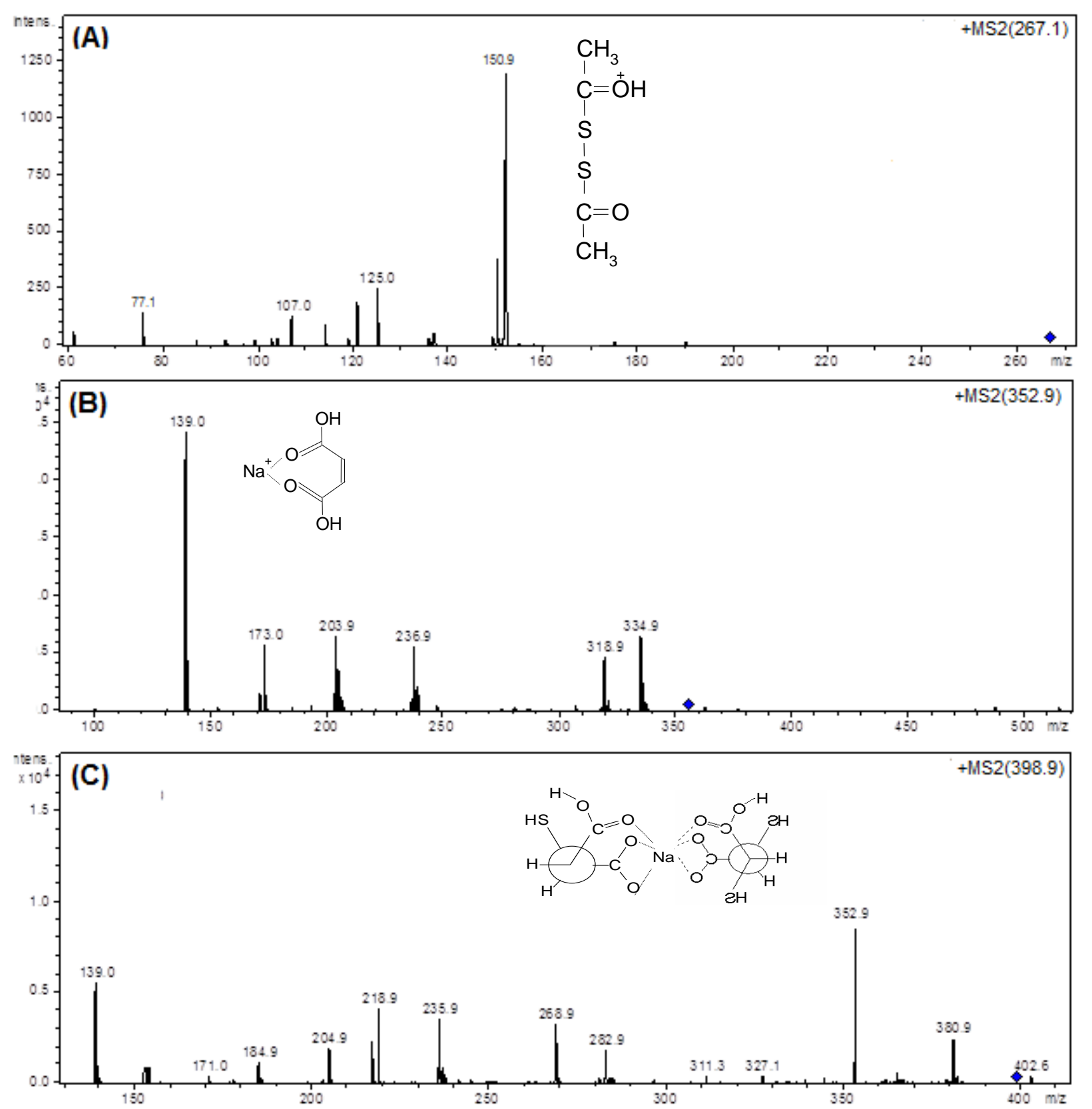

FIGURA 36- Espectros $\mathrm{MS}^{2}$. (A) $\mathrm{m} / \mathrm{z} \quad 267,1$ (FIG.35B); (B) $\mathrm{m} / \mathrm{z} \quad 352,9$ (FIG.35C); (C) m/z 398,9 (FIG.35F). A estrutura química do íon base de cada espectro está em destaque. Condições de análise: $\mathrm{MS}^{2}$, voltagem do cone: $30 \mathrm{~V}$, voltagem do capilar: $3,0 \mathrm{kV}$ e temperatura de dessolvatação: $365^{\circ} \mathrm{C}$. 
Os resultados observados nos espectros full MS, $\mathrm{MS}^{2} \mathrm{e} \mathrm{MS}^{3}$ (FIG.35 e FIG.36) permitiram sugerir um esquema de formação dos principais produtos de degradação fotolítica do DMSA conforme apresentado na FIG.37. 


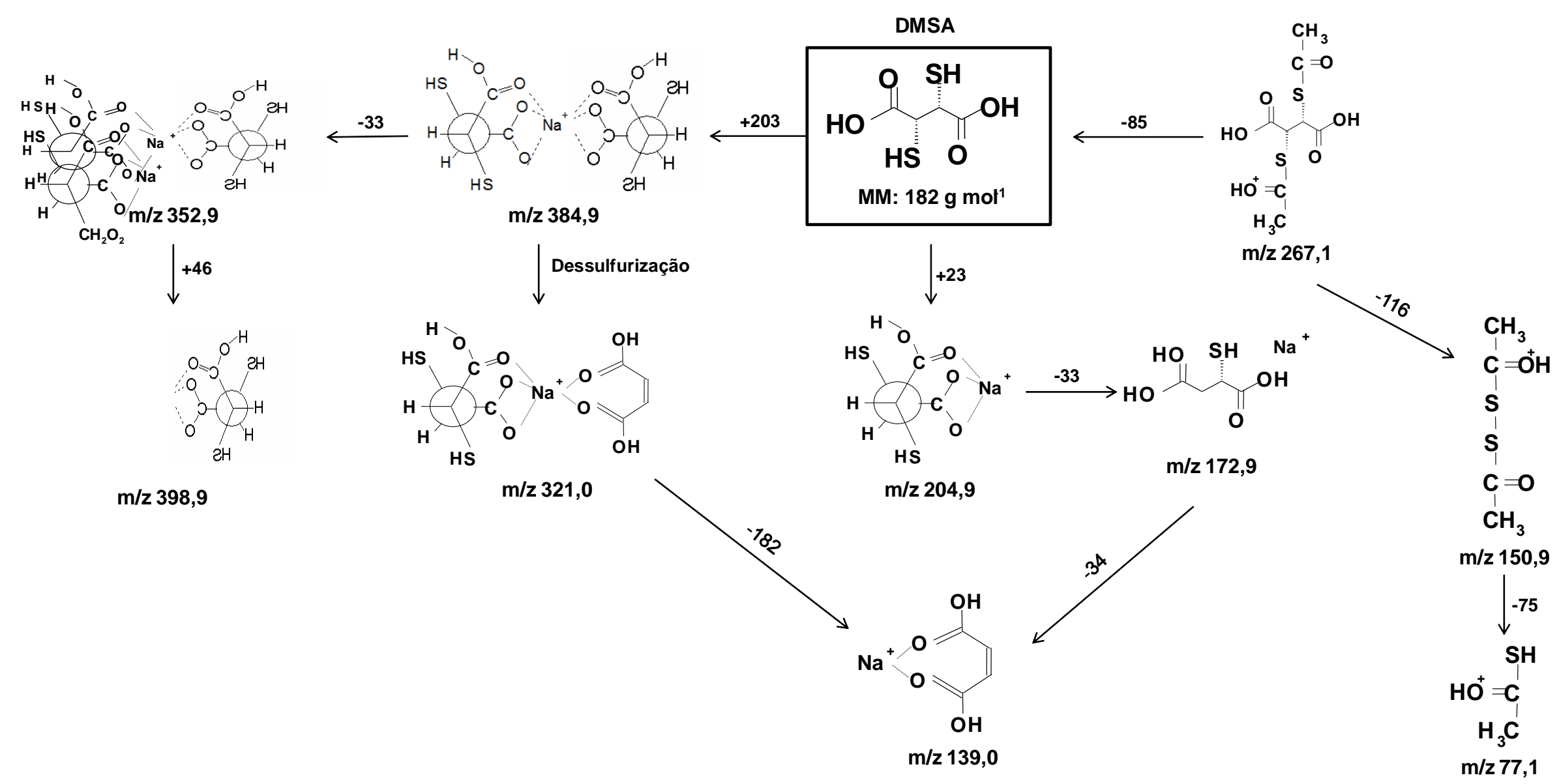

FIGURA 37- Esquema sugerido para a formação dos produtos de degradação do DMSA após fotólise sob radiação de luz UV. Os números indicados nas setas referem-se ao ganho (+) ou a perda (-) de massa pelo íon. Condições de análise: full

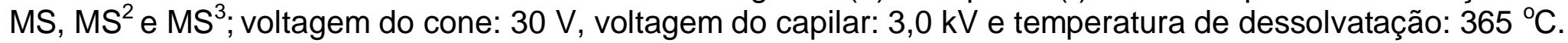


O esquema sugerido para a formação dos produtos de degradação do DMSA após fotólise sob radiação de luz UV (FIG.37) mostrou que as reações fotolíticas são frequentemente reações em cadeia, produzindo intermediários muito reativos que reagem para produzir outros intermediários reativos e assim sucessivamente. A formação de radicais livres a partir da energia liberada pelos elétrons excitados ao retornarem ao estado fundamental é responsável por esse processo (80).

Os espectros $\mathrm{MS}^{2}$ apresentados na FIG.36A mostraram que o íon de m/z 267,1 gera um íon mais intenso de m/z 150,9 (FIG.37). Este, em análises $\mathrm{MS}^{3}$ se fragmenta em íon de $\mathrm{m} / \mathrm{z} 77,1$.

O íon de $\mathrm{m} / \mathrm{z} 267,1$ pode ser identificado como o ácido diacetil dimercaptosuccínico protonado (BATSA), um intermediário do processo de síntese do DMSA, enquanto que o íon de m/z 150,9 é resultante do processo de polimerização do ácido tioacético $(\mathrm{m} / \mathrm{z} 77,1)$, precursor sintético do BATSA.

O íon de $\mathrm{m} / \mathrm{z}$ 352,9 (espectro full MS da FIG.36) foi verificado ser resultante da perda de um dos grupos SH (33 Da) do dímero de DMSA sodiado. O íon de m/z 398,9 pode ser associado ao dímero de DMSA sodiado monosubstituído (substituição de um grupo $\mathrm{SH}$ pelo grupo $\mathrm{CH}_{2} \mathrm{O}_{2}$ ).

No estado sólido (FIG.36B) após 24 horas de exposição à luz UV, observou-se uma coloração amarelada, evidenciando a degradação do DMSA.

Os resultados obtidos nas análises por HPLC-DAD após fotólise (luz UV) do RL de DMSA estão apresentados na FIG.38. Os tempos de degradação fotolítica avaliados foram 6 e 24 horas.

O pico mais intenso ( 2,5 minutos) observado na FIG.38 é referente ao ácido ascórbico, agente estabilizante componente do RL conforme descrito na TAB.1, página 28.

O pico com tempo de retenção em 9,68 minutos foi identificado por espectrometria de massas (FIG.39). Pode-se observar pela FIG.38 o alargamento deste pico. Isso pode estar relacionado ao processo de difusão das moléculas ao interagirem com a fase estacionária (53). 


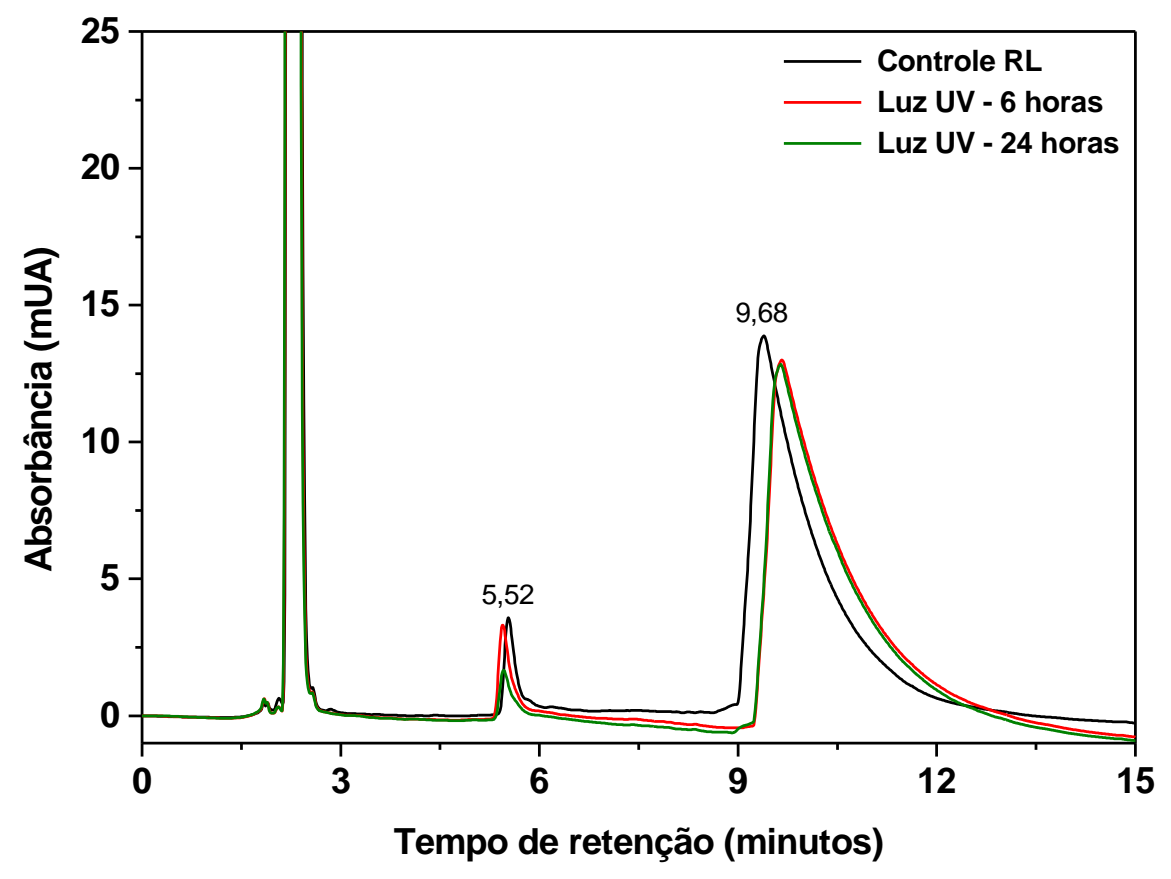

FIGURA 38- Cromatogramas de RL de DMSA em solução aquosa obtidos após degradação fotolitica com radiação UV. Tempos de exposição: 6 e 24 horas. Condições da câmara de estabilidade: temperatura: $25{ }^{\circ} \mathrm{C}$, umidade relativa: $75 \%$, Intensidade luz UV: $200 \mathrm{~W} \mathrm{~m}^{-2}$ por hora. Condições da análise cromatográfica: coluna Shim-pak ODS (150 mm x 4,6 mm, $5 \mu \mathrm{m}$ ); fase móvel: 0,1\% de ácido fórmico: acetonitrila. Gradiente linear 5-60\%B em 15 minutos. Fluxo da fase móvel: $1 \mathrm{~mL} \mathrm{~min}^{-1}$; volume de amostra: $20 \mu \mathrm{L}$ e $\lambda=245 \mathrm{~nm}$.

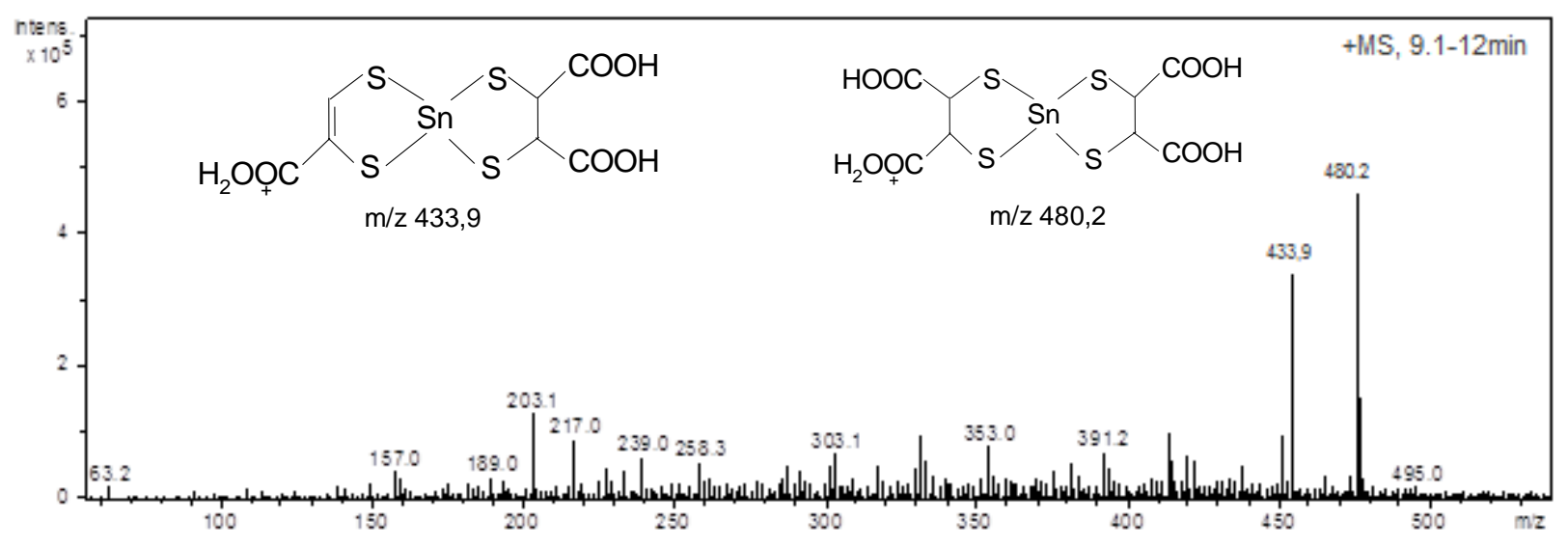

FIGURA 39- Espectros de massas referentes aos produtos de degradação do RL de DMSA após degradação fotolítica por luz UV. Os espectros correspondem ao pico cromatográficos na FIG.38. Condições de análise: full MS, voltagem do cone: $30 \mathrm{~V}$, voltagem do cailar: $3,0 \mathrm{kV}$ e temperatura de dessolvatação: $365^{\circ} \mathrm{C}$. 
O espectro de massas da FIG.39 apresentou duas espécies iônicas principais de m/z 433,9 e m/z 480,2 referentes aos dímeros de DMSA com o íon estanho. Estes íons também foram observados na hidrólise alcalina, porém, na degradação fotolítica o efeito da radiação UV gera espécies muito reativas (radicais livres) e favorece a polimerização estas espécies (80).

\subsubsection{Análise quantitativa e cinética de degradação de DMSA e RL de DMSA}

As porcentagens de degradação do DMSA e do DMSA no RL obtidos por HPLC-DAD sob condições de fotólise com luz UV estão apresentadas na TAB.6

TABELA 6- Porcentagem de degradação do DMSA (API) e do DMSA no RL após fotólise.

DMSA RL de DMSA

\begin{tabular}{ccccc}
\hline $\begin{array}{c}\text { Tempo de } \\
\text { degradação }\end{array}$ & $\begin{array}{c}\text { ("Porcentagem } \\
\text { de degradação }\end{array}$ & $\begin{array}{c}\text { Indice de } \\
\text { pureza }\end{array}$ & $\begin{array}{c}\text { Porcentagem de } \\
\text { degradação }\end{array}$ & $\begin{array}{c}\text { indice de } \\
\text { pureza }\end{array}$ \\
\hline 0 & 0 & 0,9987 & 0 & 0,9993 \\
\cline { 2 - 5 } 1 hora & $(4,11 \pm 0,15) \%$ & 0,9937 & $(1,12 \pm 0,03) \%$ & 0,9965 \\
\cline { 2 - 5 } 4 horas & $(16,32 \pm 0,17) \%$ & 0,9955 & $(13,93 \pm 0,24) \%$ & 0,9982 \\
\cline { 2 - 5 } 6 horas & $(23,50 \pm 0,26) \%$ & 0,9923 & $(21,22 \pm 0,38) \%$ & 0,9981 \\
\hline 12 horas & $(37,10 \pm 0,28) \%$ & 0,9993 & $(29,21 \pm 0,31) \%$ & 0,9997 \\
\cline { 2 - 5 } 24 horas & $(55,81 \pm 0,20) \%$ & 0,9981 & $(54,11 \pm 0,32) \%$ & 0,9983 \\
\hline
\end{tabular}

") Expressa em (média \pm desvio padrão)

$\mathrm{Na}$ fotólise, a porcentagem residual de DMSA após 24 horas de exposição a luz UV foi de $(44,19 \pm 0,12) \%$ para o DMSA e de $(45,89 \pm$ 0,12)\% para o DMSA no RL (TAB.6). O índice de pureza do pico de DMSA foi maior que 0,99 para todos os tempos de exposição analisados.

O gráfico representativo do estudo de cinética da fotólise do DMSA e do RL de DMSA está mostrado na FIG.40. 


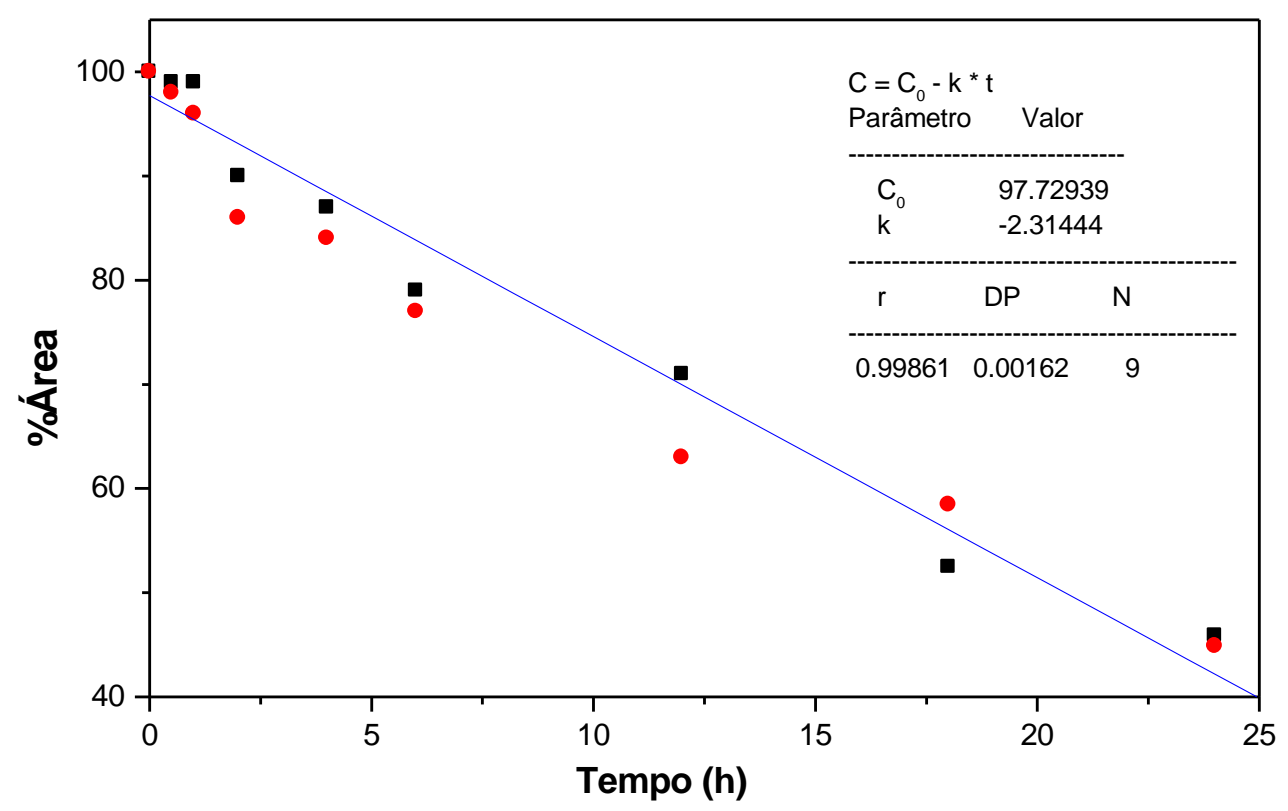

FIGURA 40-. Cinética da degradação das amostras de DMSA (•) e RL de DMSA (-) submetidas à fotólise com luz UV por até 24 horas, onde $\mathrm{C}=\%$ área.

Os parâmetros cinéticos obtidos demonstraram que a decomposição fotolítica do DMSA segue uma reação de ordem zero (FIG.40), ou seja, a velocidade de reação é uma constante e independe da concentração do DMSA.

A constante de velocidade da reação foi igual à inclinação da reta obtida (FIG.40) e sua análise revelou que, nas condições experimentais avaliadas, a taxa da constante de decomposição fotolítica do DMSA na presença de luz UV foi $k=-2,31 h^{-1}$. O coeficiente de correlação linear $(r)$ obtido foi de 0,99861 .

\subsubsection{Oxidação}

A FIG.41 apresenta os cromatogramas do DMSA obtidos por HPLC-DAD após degradação oxidativa com $\mathrm{H}_{2} \mathrm{O}_{2}$. Os tempos de reação avaliados foram 0,$5 ; 1 ; 2$ e 4 horas. 


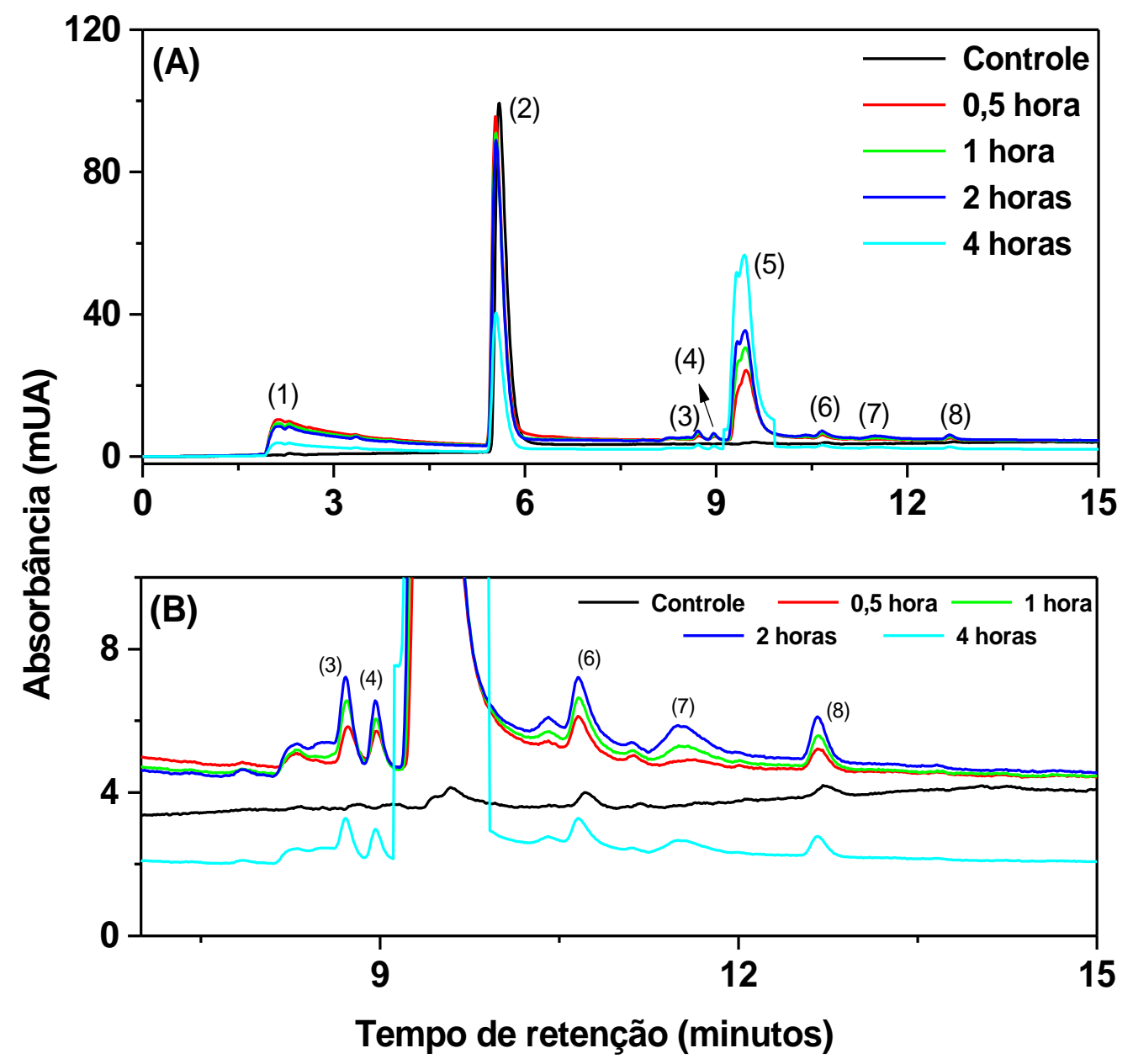

FIGURA 41- (A) Cromatogramas de DMSA obtidos após degradação por oxidação com $\mathrm{H}_{2} \mathrm{O}_{2} 1 \%$. Tempos de reação: 0,$5 ; 1 ; 2$ e 4 horas. (B) Ampliação da FIG.41A no intervalo de 7-15 minutos. Tempos de retenção: (1) 2,14 minutos; (2) 5,58 minutos; (3) 8,73 minutos; (4) 8,97 minutos; (5) 9,44 minutos; (6) 10,67 minutos; (7) 11,83 minutos e (8) 13,25 minutos. Condições da câmara de estabilidade: temperatura: $25^{\circ} \mathrm{C}$, umidade relativa: $75 \%$. Condições da análise cromatográfica: coluna Shim-pak ODS $(150 \mathrm{~mm}$ x 4,6 mm, $5 \mu \mathrm{m}$ ); fase móvel: 0,1\% de ácido fórmico: acetonitrila. Gradiente linear 5-60\%B em 15 minutos. Fluxo da fase móvel: $1 \mathrm{~mL} \mathrm{~min}^{-1}$; volume de amostra: $20 \mu \mathrm{L}$ e $\lambda=245 \mathrm{~nm}$.

Os resultados obtidos e apresentados na FIG.41 mostram a presença de um pico mais polar que o DMSA, eluido em 2,14 minutos (pico 1), e seis picos mais apolares que o DMSA (picos de 3 a 8). Para identificar estes picos foram realizados experimentos de espectrometria de massas sequencial $\left(M S^{2}\right.$ e $\left.M S^{3}\right)$. Os picos 3 e 4 são isômeros de $\mathrm{m} / \mathrm{z}$ 352,9 (FIG.35C); os picos 5, 6 e 7 apresentaram m/z 321,0 (FIG.35D); m/z 384,9 
(FIG.35E) e m/z 398,9 (FIG.35F), respectivamente. Estes produtos de degradação são os mesmos obtidos nos estudos de fotólise com luz UV.

Os espectros de massas referentes ao pico cromatográfico 1 (FIG.41) estão apresentados na FIG.42.
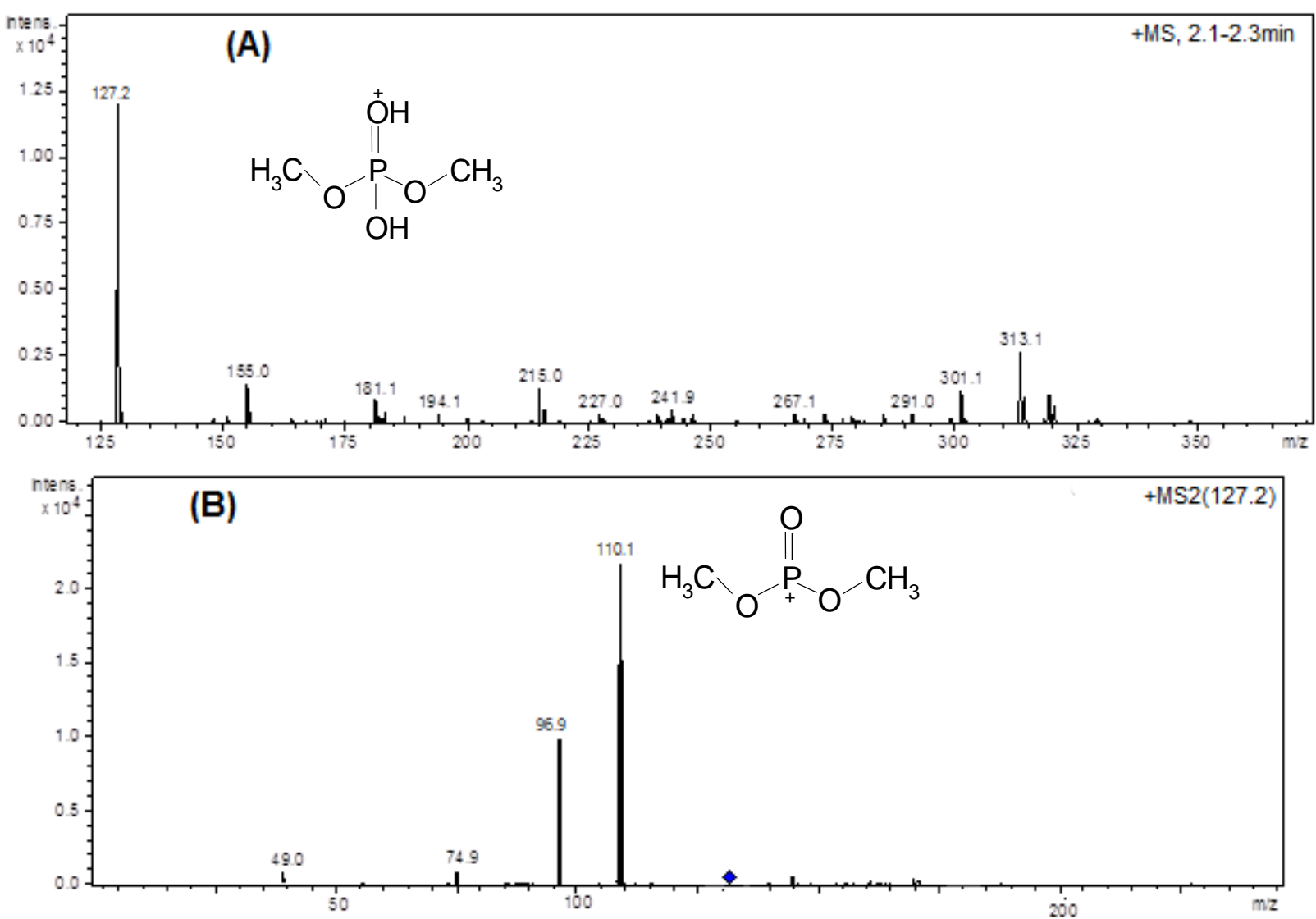

FIGURA 42- Espectros de massas referentes ao pico cromatográfico eluido em 2,14 minutos após degradação do DMSA por oxidação com $\mathrm{H}_{2} \mathrm{O}_{2} 1 \%$. (A) full MS e (B) $\mathrm{MS}^{2}$. A estrutura química do íon base de cada espectro está em destaque. Condições de análise: voltagem do cone: $30 \mathrm{~V}$, voltagem do capilar: $3,0 \mathrm{kV}$ e temperatura de dessolvatação: $365^{\circ} \mathrm{C}$.

Os resultados obtidos por espectrometria de massas para o pico 1 (2,14 minutos FIG. 41) mostraram que este não é um produto de degradação do DMSA após oxidação com $\mathrm{H}_{2} \mathrm{O}_{2}$. $\mathrm{O}$ íon de $\mathrm{m} / \mathrm{z} 127,1$ (FIG.42A) pode ser associado ao ácido hidroximetil fosfônico, um organofosforado utilizado como estabilizante do $\mathrm{H}_{2} \mathrm{O}_{2}(82,83)$. 
O íon de $\mathrm{m} / \mathrm{z}$ 127,1 fragmentado gerou dois íons produtos principais: $\mathrm{m} / \mathrm{z}$ 110,1 e m/z 96,9, referentes á perda do grupo $\mathrm{OH}$ (-17Da) e $\mathrm{CH}_{2} \mathrm{O}(-30 \mathrm{Da})$, respectivamente.

A FIG.43 apresenta os espectros de massas obtidos por full $M S$ e $M^{2}$ do pico 8 (13,25 minutos, FIG.41).
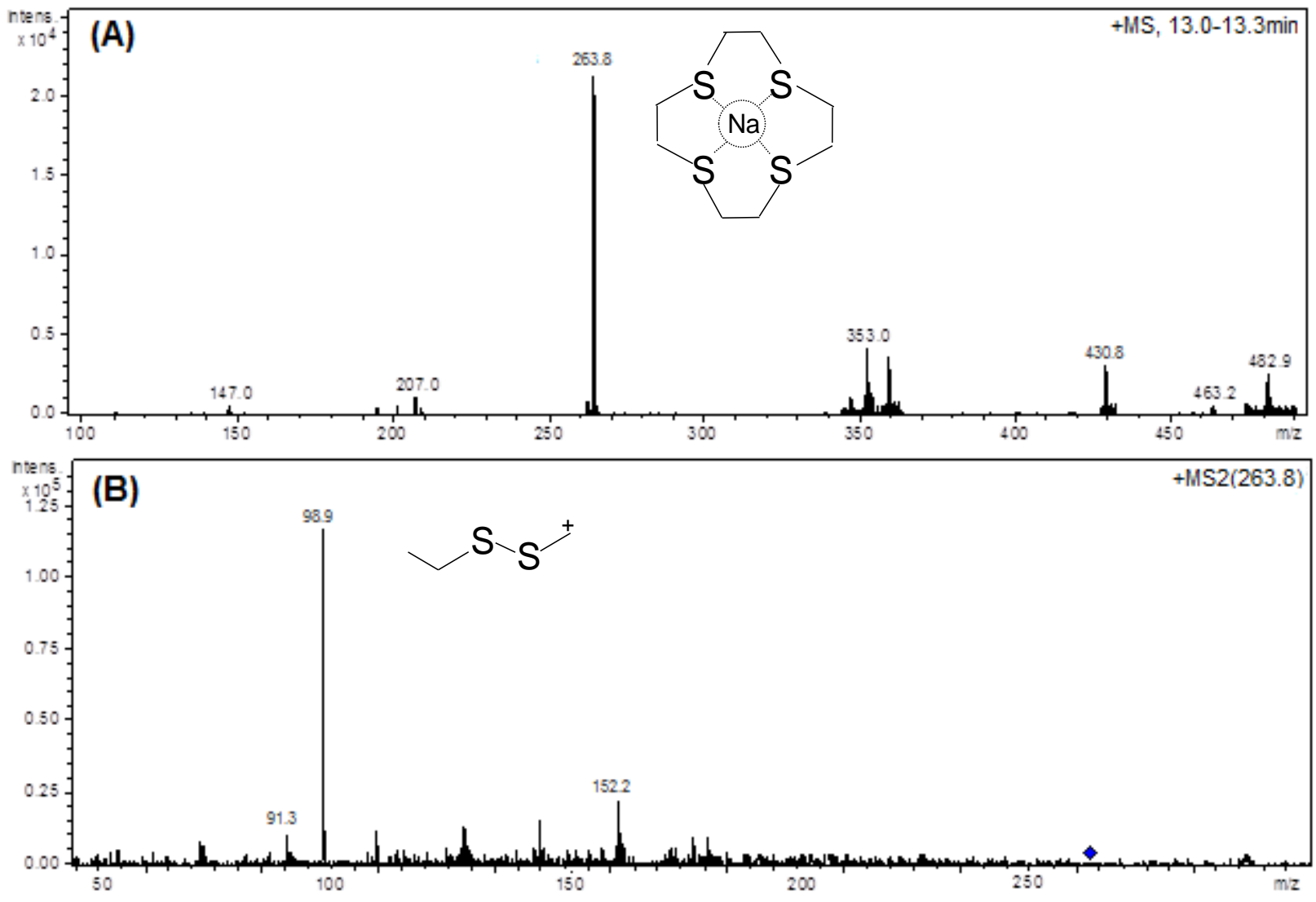

FIGURA 43- Espectros de massas referentes ao pico cromatográfico eluído em 11,53 minutos após degradação do DMSA por oxidação com $\mathrm{H}_{2} \mathrm{O}_{2} 1 \%$. (A) full MS e (B) $\mathrm{MS}^{2}$. A estrutura química do íon base de cada espectro está em destaque. Condições de análise: voltagem do cone: $30 \mathrm{~V}$, voltagem do capilar: $3,0 \mathrm{kV}$ e temperatura de dessolvatação: $365^{\circ} \mathrm{C}$.

O resultado de full MS indicou a presença do íon de m/z 263,8. Este íon pode ser associado a um tioacetal como aduto de sódio, conforme estrutura apresentada na FIG.43A. O fragmento mais intenso observado nas análises $\mathrm{MS}^{2}$ foi o íon de $\mathrm{m} / \mathrm{z}$ 98,9, um dissulfeto.

A FIG.44 apresenta uma sugestão de esquema de formação do produtos de degradação oxidativa do DMSA referente ao pico 8 do cromatograma da FIG.40. 
DMSA

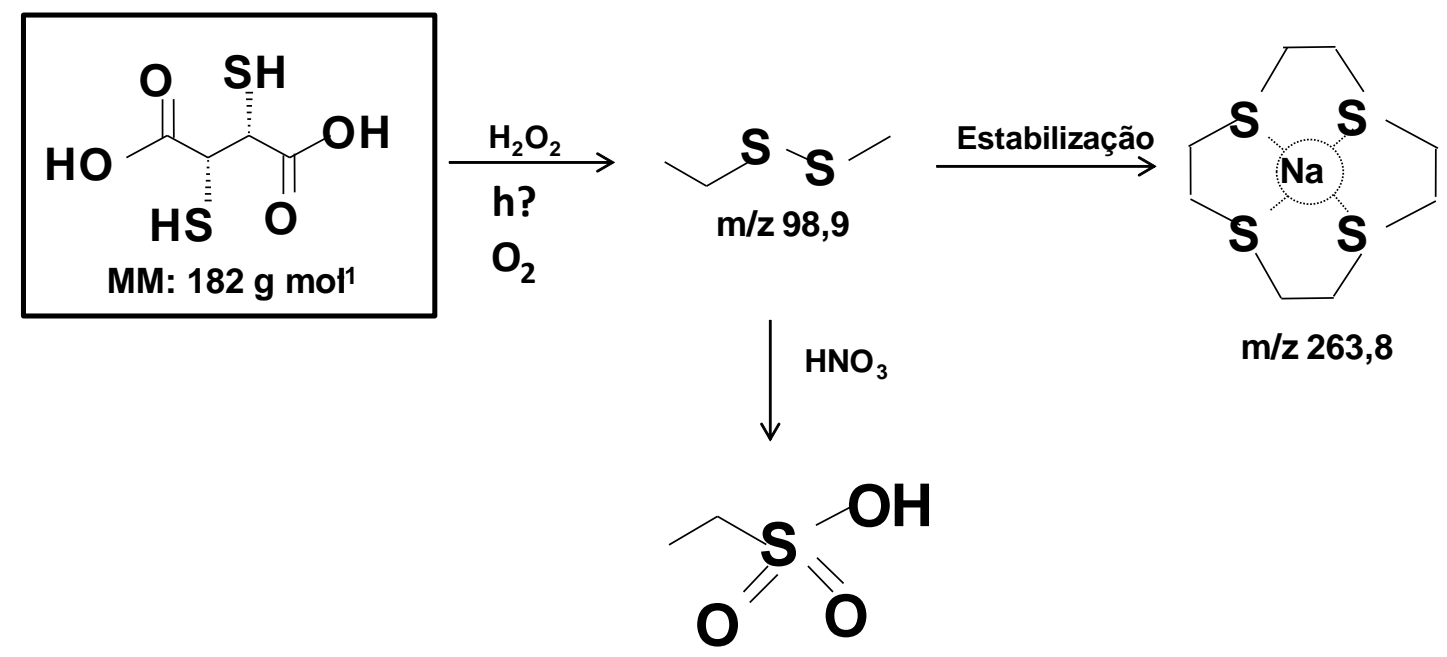

Ácido sulfônico

FIGURA 44- Esquema sugerido para a formação do produto de degradação do DMSA após oxidação com $\mathrm{H}_{2} \mathrm{O}_{2} 1 \%$. Condições de análise: full MS e $\mathrm{MS}^{2}$; voltagem do cone: $30 \mathrm{~V}$, voltagem do capilar: $3,0 \mathrm{kV}$ e temperatura de dessolvatação: $365^{\circ} \mathrm{C}$.

O esquem sugerido para a formação do produto de degradação do DMSA após oxidação (FIG.44) mostrou que as reações oxidativas do DMSA podem ocorrer na presença de $\mathrm{H}_{2} \mathrm{O}_{2}$, luz ou mesmo catalisada pelo oxigênio molecular $\left(\mathrm{O}_{2}\right)$ atmosférico formando dissulfeto. A conversão do dissulfeto a ácido sulfônico pode ocorrer se estiver presente no meio reacional um agente oxidante forte como o ácido nítrico $\left(\mathrm{HNO}_{3}\right)$ ou o permanganato de potássio $\left(\mathrm{KMnO}_{4}\right)$. Nas condições de análise estudadas não foi observado este produto de degradação. A ponte dissulfeto pode ser quebrada e os tióis resultantes reagem formando o tioacetal que se mostrou ser mais estável na forma de aduto sodiado, íon de m/z 263,8 $(81,82)$.

Os resultados obtidos nas análises por HPLC-DAD após oxidação com $\mathrm{H}_{2} \mathrm{O}_{2}$ 1\% do RL de DMSA estão apresentados na FIG.45. 


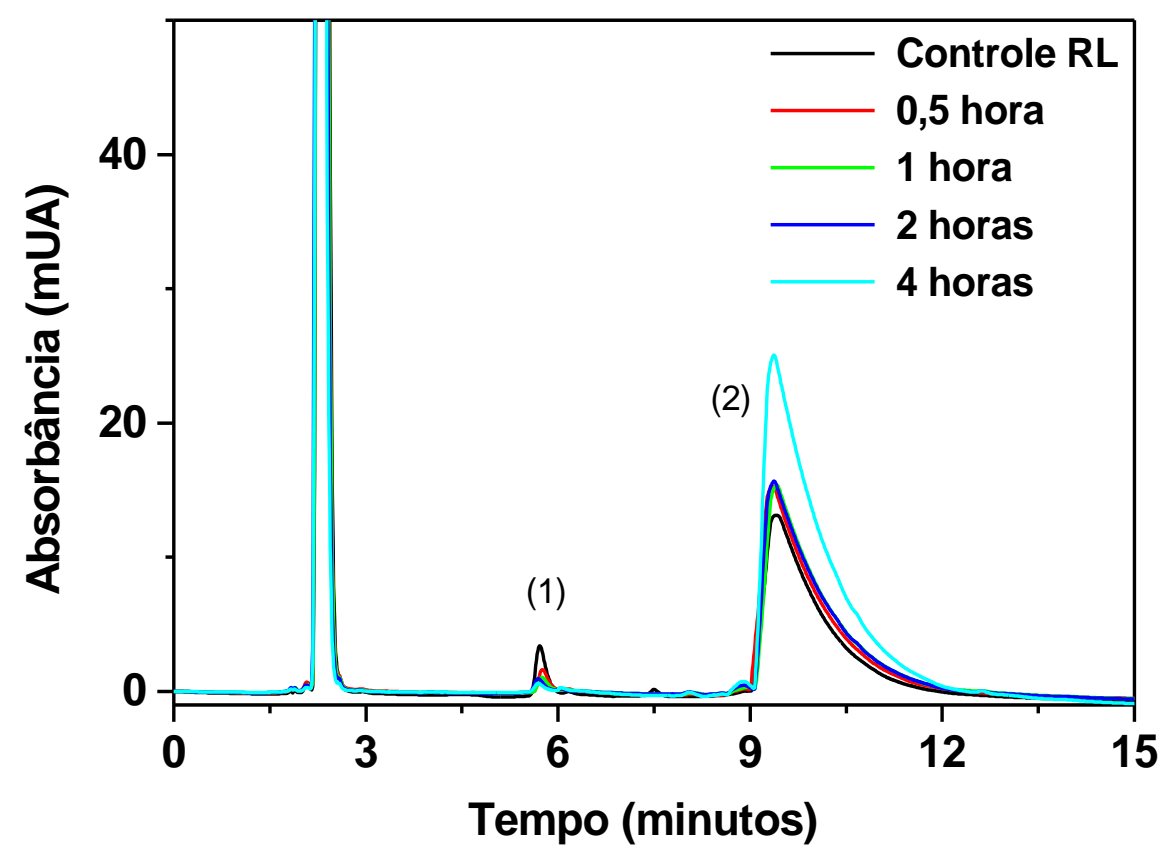

FIGURA 45- Cromatogramas de RL de DMSA obtidos após degradação por oxidação com $\mathrm{H}_{2} \mathrm{O}_{2} 1 \%$. Tempos de reação: 0,$5 ; 1 ; 2$ e 4 horas. Tempos de retenção: (1) 5,57 minutos e (2) 9,46 minutos. Condições da câmara de estabilidade: temperatura: $25{ }^{\circ} \mathrm{C}$, umidade relativa: $75 \%$. Condições da análise cromatográfica: coluna Shim-pak ODS (150 mm x 4,6 mm, $5 \mu \mathrm{m})$; fase móvel: 0,1\% de ácido fórmico: acetonitrila. Gradiente linear 5-60\%B em

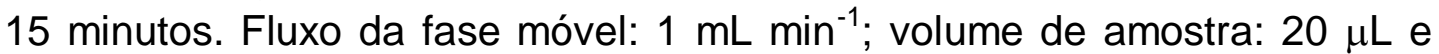
$\lambda=245 \mathrm{~nm}$.

Após 4 horas de reação oxidativa foi observado um pico em 9,46 minutos. O espectro de massas deste pico foi observado. Trata-se dos mesmos produtos de degradação observados na degradação fotolítica com luz UV (m/z 433,9 e m/z 480,2) referentes aos dímeros de DMSA com o íon estanho (FIG.39). 


\subsubsection{Análise quantitativa e cinética de degradação de DMSA e RL de DMSA}

As porcentagens de degradação do DMSA e do DMSA no RL obtidos por HPLC-DAD sob condições de oxidação com $\mathrm{H}_{2} \mathrm{O}_{2}$ estão apresentadas na TAB.7.

TABELA 7- Porcentagem de degradação do DMSA (API) e do DMSA no RL após oxidação.

DMSA

RL de DMSA

\begin{tabular}{ccccc}
\hline $\begin{array}{c}\text { Tempo de } \\
\text { degradação }\end{array}$ & $\begin{array}{c}\text { ("Porcentagem } \\
\text { de degradação }\end{array}$ & $\begin{array}{c}\text { Índice de } \\
\text { pureza }\end{array}$ & $\begin{array}{c}\text { Porcentagem de } \\
\text { degradação }\end{array}$ & $\begin{array}{c}\text { Índice de } \\
\text { pureza }\end{array}$ \\
\hline \multirow{2}{*}{$\begin{array}{c}0 \\
0,5 \text { hora }\end{array}$} & 0 & 0,9897 & 0 & 0,9932 \\
\cline { 2 - 5 } 1 horas & $(3,72 \pm 0,11) \%$ & 0,9914 & $(52,05 \pm 0,21) \%$ & 0,9941 \\
\cline { 2 - 5 } 2 horas & $11,79 \pm 0,19) \%$ & 0,9988 & $(71,93 \pm 0,35) \%$ & 0,9919 \\
\cline { 2 - 5 } 4 horas & $(60,44 \pm 0,41) \%$ & 0,9991 & $(83,33 \pm 0,32) \%$ & 0,9939 \\
\hline
\end{tabular}

${ }^{(*)}$ Expressa em (média \pm desvio padrão)

Na oxidação, a porcentagem residual de DMSA após 4 horas de reação com $\mathrm{H}_{2} \mathrm{O}_{2}$ foi de $(60,44 \pm 0,41) \%$ para o DMSA e de $(83,33 \pm$ 0,32)\% para o DMSA no $\mathrm{RL}$ (TAB.7). O RL de DMSA mostrou-se mais instável que o API DMSA.

Pode-se observar que as reações de oxidação são importantes por gerarem produtos de degradação inativos e que por vezes podem ser tóxicos. Como o oxigênio é o principal responsável pela reação de oxidação, uma alternativa para evitar o processo é o preenchimento total dos recipientes, ou a substituição de oxigênio por outro gás como nitrogênio ou dióxido de carbono. Como o processo é complicado, tem-se a possibilidade de utilizar adjuvantes farmacotécnicos como antioxidantes, que irão estabilizas os radicais impedindo a degradação do fármaco. No caso do $R L$ de DMSA é utilizado o ácido ascórbico.

A maior taxa de degradação do DMSA no $R L$ comparada ao DMSA (TAB.7) pode estar relacionada à oxidação do ácido ascórbico, visto 
ser este suscetível à umidade ou à quantidade constituinte no $\mathrm{RL}$ tem sido menor que o necessário.

O índice de pureza do pico de DMSA foi maior que 0,98 para todos os tempos de reação com $\mathrm{H}_{2} \mathrm{O}_{2}$ analisados.

O gráfico representativo do estudo de cinética da oxidação do DMSA e do RL de DMSA esta demonstrado na FIG.46.

Os parâmetros cinéticos obtidos demonstraram que a decomposição oxidativa do DMSA com $\mathrm{H}_{2} \mathrm{O}_{2}$ segue uma reação de segunda ordem (FIG.46).

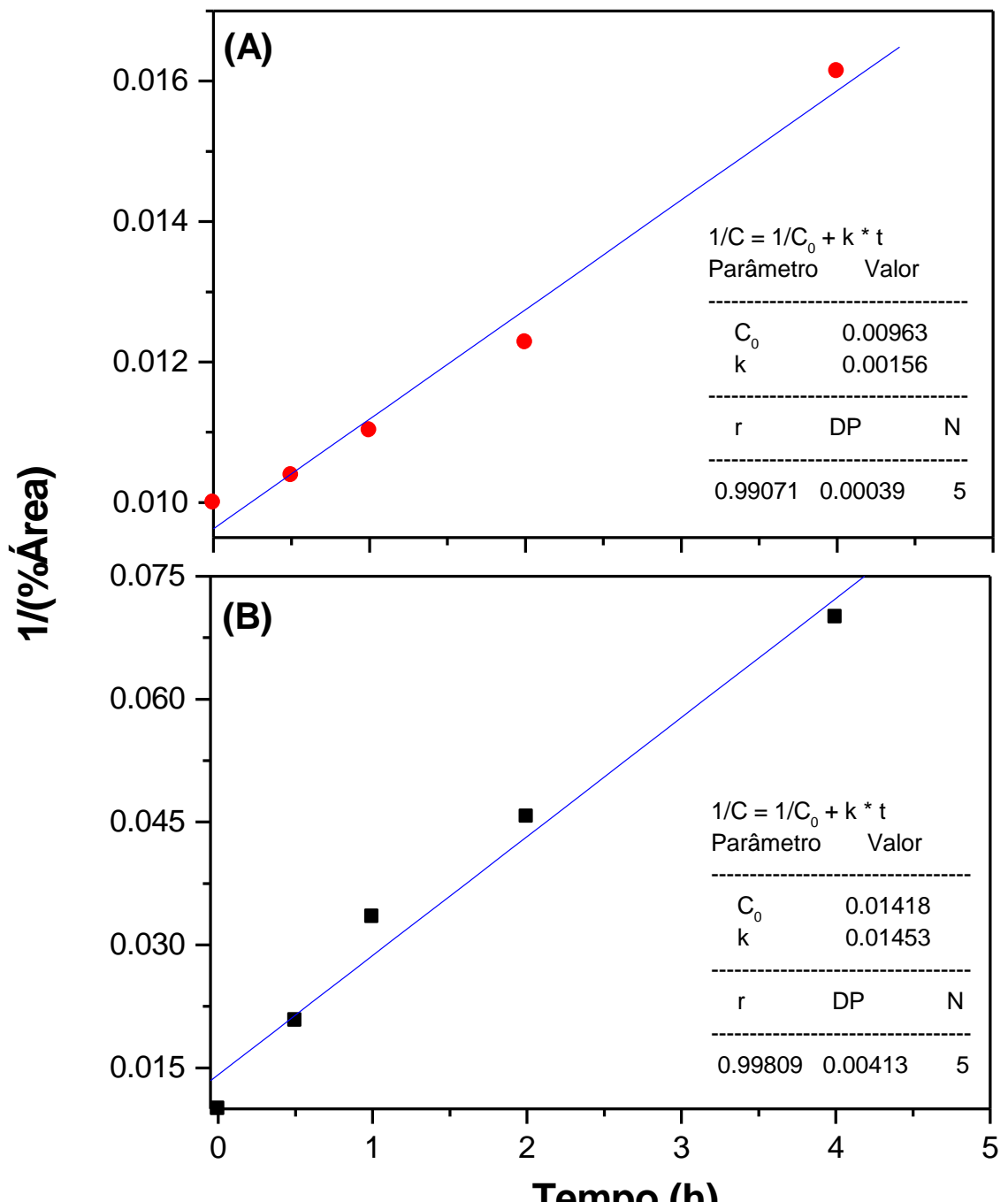

FIGURA 46-. Cinética da degradação das amostras de DMSA (•) e RL de DMSA (घ) submetidas à oxidação com $\mathrm{H}_{2} \mathrm{O}_{2}$ por até 4 horas, onde $\mathrm{C}=\%$ área.

Pode-se verificar que a oxidação do DMSA e do RL de DMSA depende da concentração tanto de DMSA quanto de $\mathrm{H}_{2} \mathrm{O}_{2}$. A constante de 
velocidade da reação foi igual à inclinação da reta obtida (FIG.46) e sua análise revelou que, nas condições experimentais avaliadas, a taxa da constante de decomposição oxidativa do DMSA e do DMSA do RL foi $\mathrm{k}=1,45 \times 10^{-3}$ horas $^{-1}$ e $\mathrm{k}=1,56 \times 10^{-3}$ horas $^{-1}$, respectivamente. $\mathrm{O}$ coeficiente de correlação linear ( $r$ ) obtido foi de 0,99071 para o DMSA e $r=0,99809$ para o DMSA no $R L$.

\subsubsection{Termodegradação}

Os resultados dos estudos de termodegradação do DMSA e do RL de DMSA, ambos em solução, por HPLC-DAD estão apresentados na FIG.47.
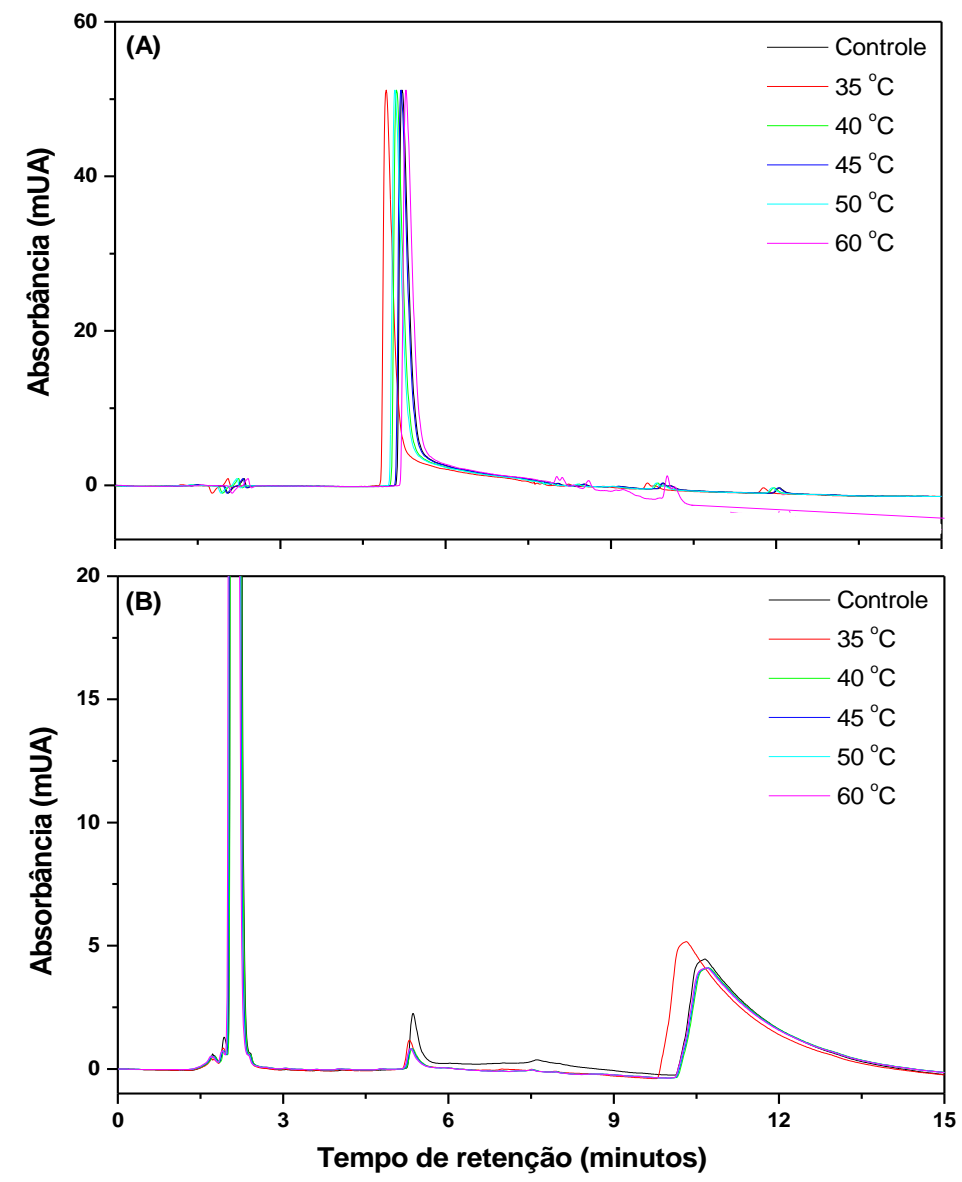

FIGURA 47- Cromatogramas de DMSA (A) e do RL de DMSA (B) obtidos após termodegradação nas temperaturas de $35,40,45,50$ e $60{ }^{\circ} \mathrm{C}$. Condições da câmara de estabilidade: tempo de exposição: 24 horas. umidade relativa: $75 \%$. Condições da análise cromatográfica: coluna Shimpak ODS (150 mm x 4,6 mm, $5 \mu \mathrm{m}$ ); fase móvel: 0,1\% de ácido fórmico: acetonitrila. Gradiente linear 5-60\%B em 15 minutos. Fluxo da fase móvel: 1 $\mathrm{mL} \min ^{-1}$; volume de amostra: $20 \mu \mathrm{L}$ e $\lambda=245 \mathrm{~nm}$. 
A avaliação dos cromatogramas da FIG.47 evidenciou a formação de 2 produtos de degradação principais obtidos à temperatura de $60^{\circ} \mathrm{C}$ com tempo de exposição de 24 horas. Os picos dos produtos de degradação eluídos em 8,15 minutos e 10,19 minutos já foram observados na degradação por fotólise assim como na oxidação com $\mathrm{H}_{2} \mathrm{O}_{2}$ e foram identificados por MS como sendo o íon de m/z 352,9 (FIG.36C) e m/z 384,9 (FIG.35E), respectivamente.

O DMSA e o RL de DMSA na forma sólida também foram avaliados nas mesmas condições de termadegradação em que as soluções foram avaliadas. Não houve diferença significativa entre as duas formas analisadas.

A termodegradação do DMSA e do $R L$ de DMSA nas condições estudadas, não apresentou uma relação de decaimento da concentração do DMSA em função do tempo, logo a ordem de reação não pode ser estimada.

\subsection{Condições otimizadas para análise de ECD e RL de ECD por HPLC- DAD}

Para o desenvolvimento do método cromatográfico de análise por HPLC-DAD a modalidade de separação por fase reversa foi utilizada. A composição da fase móvel foi ajustada para obter melhor separação entre o ECD e seus principais produtos de degradação. $O$ sistema de solventes que apresentou os melhores resultados (picos de eluição simétricos e maior resolução) foi a mistura água: metanol. Esta mistura foi utilizada em todos os estudos de degradação de ECD e RL de ECD por HPLC-DAD.

A influência do fluxo da fase móvel foi estudada. Não foram observadas modificações significativas na resolução cromatográfica para os fluxos de $0,5 \mathrm{~mL} \mathrm{~min} \mathrm{~m}^{-1} ; 0,7 \mathrm{~mL} \mathrm{~min}^{-1}$ e $1,0 \mathrm{~mL} \mathrm{~min}^{-1}$. O fluxo de $1,0 \mathrm{~mL} \mathrm{~min}^{-1}$ foi selecionado.

O espectro de absorção na região do UV: $200-350 \mathrm{~nm}$ obtido no sistema HPLC-DAD para o ECD na concentração de 1,0 $\mathrm{mg} \mathrm{L}^{-1}$ (FIG.48) 
mostrou que o comprimento de onda de máxima absorção $\left(\lambda_{\max }\right)$ do ECD, sem interferentes, é $215 \mathrm{~nm}$.

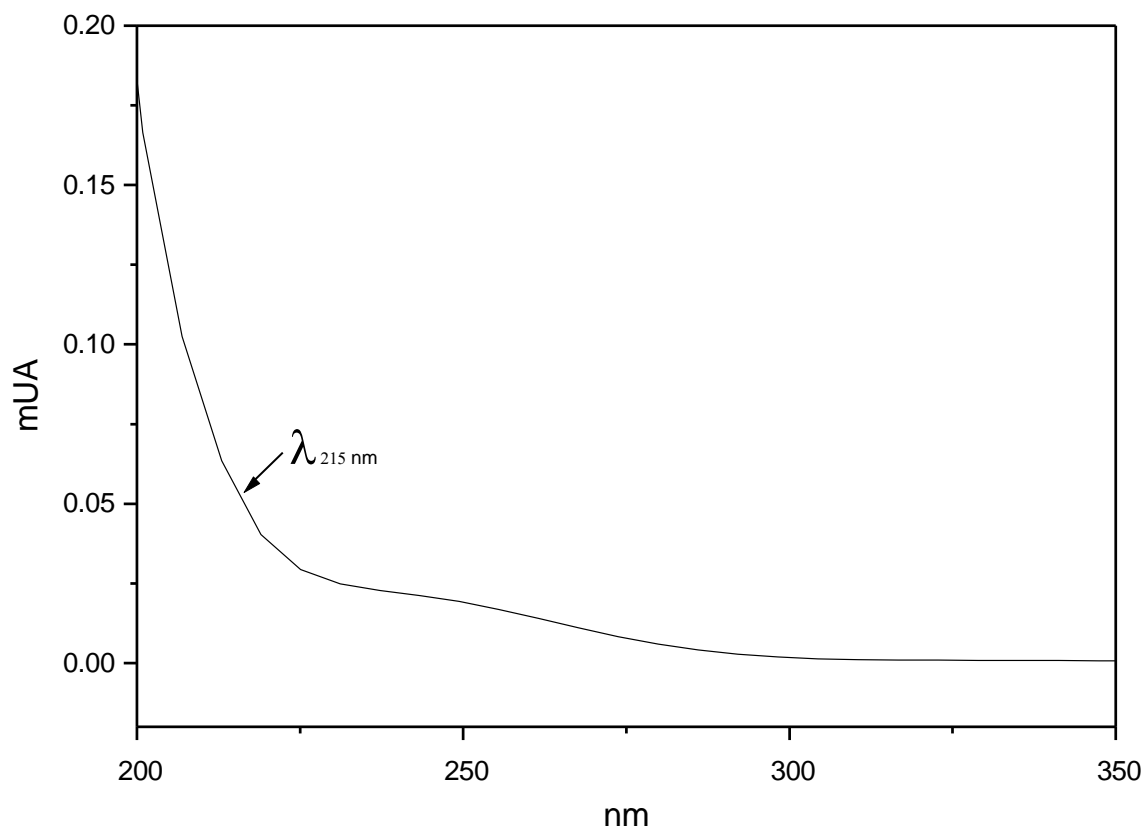

FIGURA 48- Espectro de absorção na região UV em função do comprimento de onda $(\lambda=210-350 \mathrm{~nm})$ de ECD $1 \mathrm{mg} \mathrm{mL}^{-1}$. Condições da análise cromatográfica: coluna Shim-pak ODS (150 mm x 4,6 mm, $5 \mu \mathrm{m})$; fase móvel: água (A): metanol (B). Modo isocrático: $40 \% A-60 \% B$ em 15 minutos.

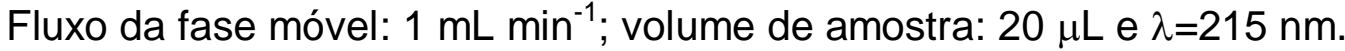

O pico cromatográfico do $E C D$ no $R L$ de $E C D$ foi identificado através da adição de padrão de ECD.

A especificidade do método, bem como a identificação do ECD, foi verificada pela sobreposição dos cromatogramas e sobreposição do espectro no UV obtido para o padrão de ECD e para as amostras de RL, comparando-se o tempo de retenção no cromatograma e a absorção no espectro de UV em $\lambda_{\max }=215 \mathrm{~nm}$.

A pureza do pico do ECD foi estimada através do índice de similaridade. Para isso, foram obtidos os espectros de absorção no UV de três pontos distintos do pico (5,170; 5,403 e 5,665 minutos). A TAB.8 apresenta os índices de similaridade de pureza de pico obtidos para o ECD e o RL de ECD. 
TABELA 8- Índice de similaridade de pureza de pico para ECD e RL de ECD por HPLC-DAD.

\begin{tabular}{cccc}
\hline \multicolumn{2}{c}{ ECD } & \multicolumn{2}{c}{ RL de ECD } \\
\hline $\begin{array}{c}\text { Tempo de } \\
\text { retenção }\end{array}$ & $\begin{array}{c}\text { Índice de } \\
\text { similaridade }\end{array}$ & $\begin{array}{c}\text { Tempo de } \\
\text { retenção }\end{array}$ & $\begin{array}{c}\text { Índice de } \\
\text { similaridade }\end{array}$ \\
\hline 5,170 minutos* $^{*}$ & 0,998321 & 5,471 minutos & 0,999429 \\
5,403 minutos & 0,999231 & 5,552 minutos & 0,999639 \\
5,665 minutos & 0,999749 & 5,773 minutos & 0,998741 \\
\hline
\end{tabular}

*ponto de referência (região de máxima absorbância no pico)

A similaridade entre os espectros de UV do ECD foi observada e não houve coeluição de interferentes no tempo de retenção do ECD. Deste modo, pode-se inferir que o método consegue separar especificamente ECD de impurezas e produtos de degradação.

\subsection{Condições otimizadas para análise de ECD e RL de ECD por LC- MS $^{\text {n }}$}

Os modos de ionização positivo $\left(\mathrm{ESI}^{+}\right)$e negativo $\left.(\mathrm{ESl})^{-}\right)$foram avaliados para as amostras de ECD $50 \mathrm{ng} \mathrm{mL}^{-1}$. As FIG.49A e FIG.49B apresentam os espectros de massas obtidos no modo positivo e no modo negativo, respectivamente. 

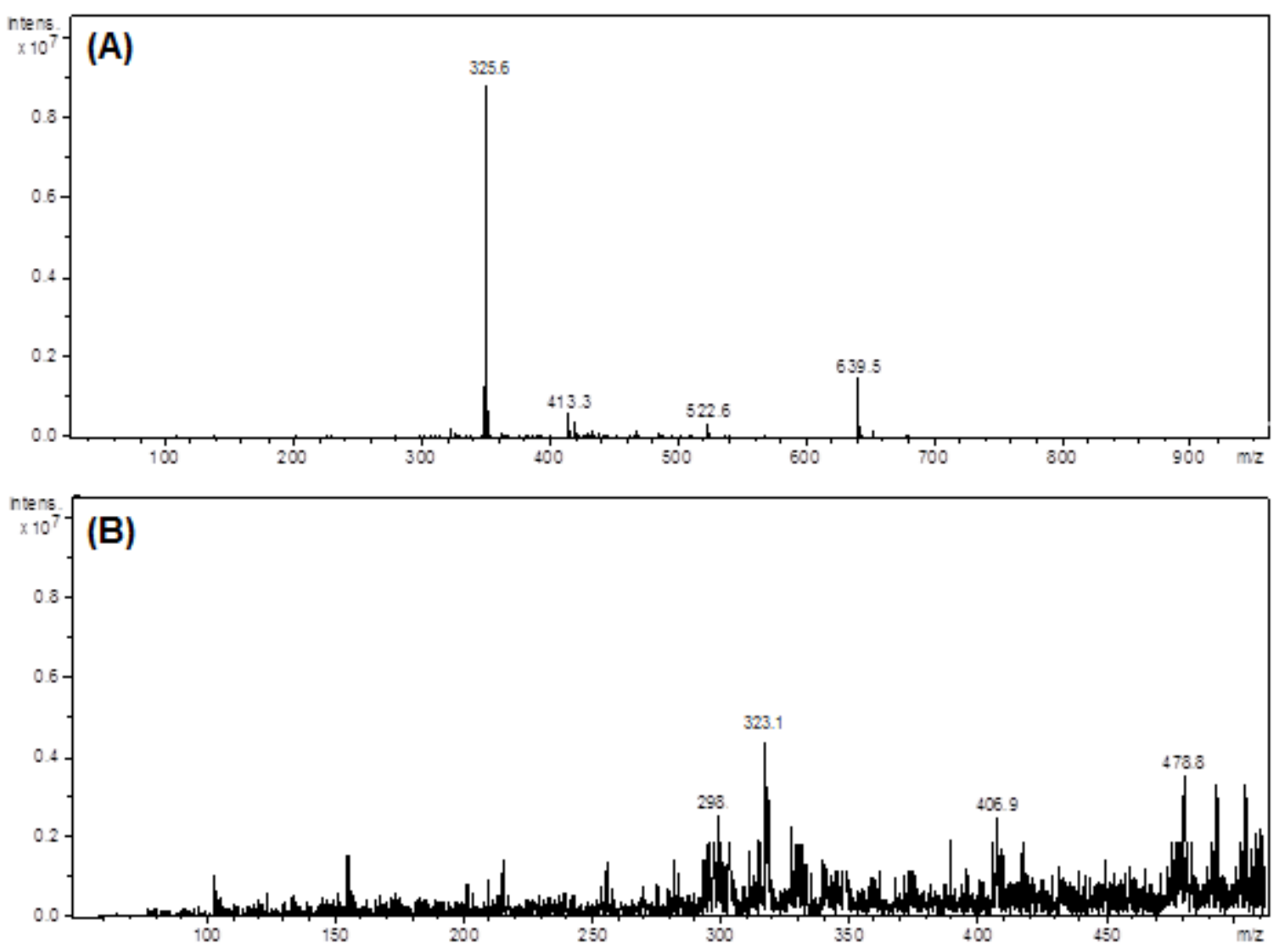

FIGURA 49- Espectros de massas do ECD (A) ESI ${ }^{+}$; condições de análise: voltagem do cone: $25 \mathrm{~V}$, voltagem do capilar: $3,0 \mathrm{kV}$ e temperatura de dessolvatação: $325^{\circ} \mathrm{C}$. (B) ESI': condições de análise: voltagem do cone: $35 \mathrm{~V}$, voltagem do capilar: $3,5 \mathrm{kV}$ e temperatura de dessolvatação: $325^{\circ} \mathrm{C}$.

As análises de ECD no modo de ionização positivo (FIG.49A) apresentaram menor relação sinal/ruído e íons mais intensos quando comparadas as análises realizadas no modo de ionização negativo (FIG.49B). O íon de interesse foi observado em $\mathrm{m} / \mathrm{z}$ 325,6 e corresponde ao ECD protonado, representado por $[\mathrm{M}+\mathrm{H}]^{+}$, onde $M$ é a massa molecular do $\operatorname{ECD}\left(M=324,46 \mathrm{~g} \mathrm{~mol}^{-1}\right)$. O modo de ionização positivo foi escolhido para realizar os estudos de degradação do ECD e do RL de ECD.

\subsection{Identificação do ECD e cálculo do teor de ECD nos RL.}

O perfil cromatográfico do ECD (API) e do RL de ECD obtidos por HPLC-DAD estão apresentados nas FIG.50A e FIG.50B, respectivamente. O ECD API eluiu em 5,40 minutos enquanto o ECD no RL eluiu em 5,55 minutos. 


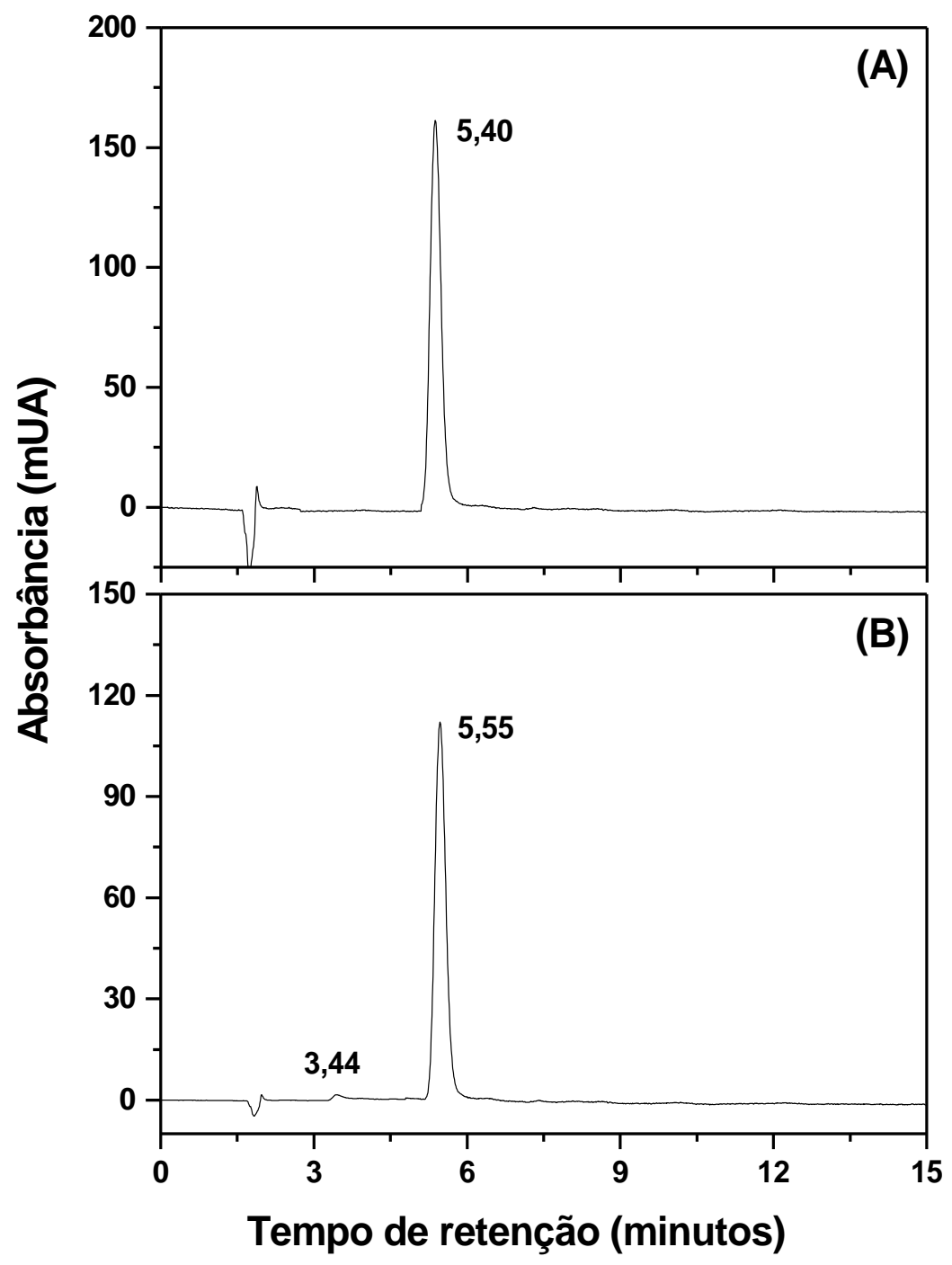

FIGURA 50- (A) Cromatograma de ECD $1 \mathrm{mg} \mathrm{mL}^{-1}$. (B) Cromatograma de $\mathrm{RL}$ de ECD. Condições de análise: coluna Shim-pak ODS (150 mm x 4,6 $\mathrm{mm}, 5 \mu \mathrm{m})$; fase móvel: água: metanol. Modo isocrático (40\%A:60\%B, v/v) em 15 minutos. Fluxo da fase móvel: $1 \mathrm{~mL} \mathrm{~min}^{-1}$; volume de amostra: $20 \mu \mathrm{L}$ e $\lambda=215 \mathrm{~nm}$.

Pode-se observar nos cromatogramas de HPLC-DAD (FIG.50A e FIG.50B) que houve uma variação no tempo de retenção do $E C D$ no $R L$ (5,55 minutos) quando comparado ao ECD API (5,40 minutos) (variação de $2,78 \% \pm 0,02 \%)$. Isto pode estar relacionado à presença de excipiente no $R L$ (conforme descrito na TAB.1 - página 28) os quais modificam o ambiente químico da molécula de ECD. Uma impureza com tempo de retenção de 3,44 minutos foi observada no cromatograma do RL de ECD (FIG.50B). Espectro de massas para o pico com tempo de retenção igual a 5,40 minutos e 5,55 minutos estão apresentados na FIG.51. 

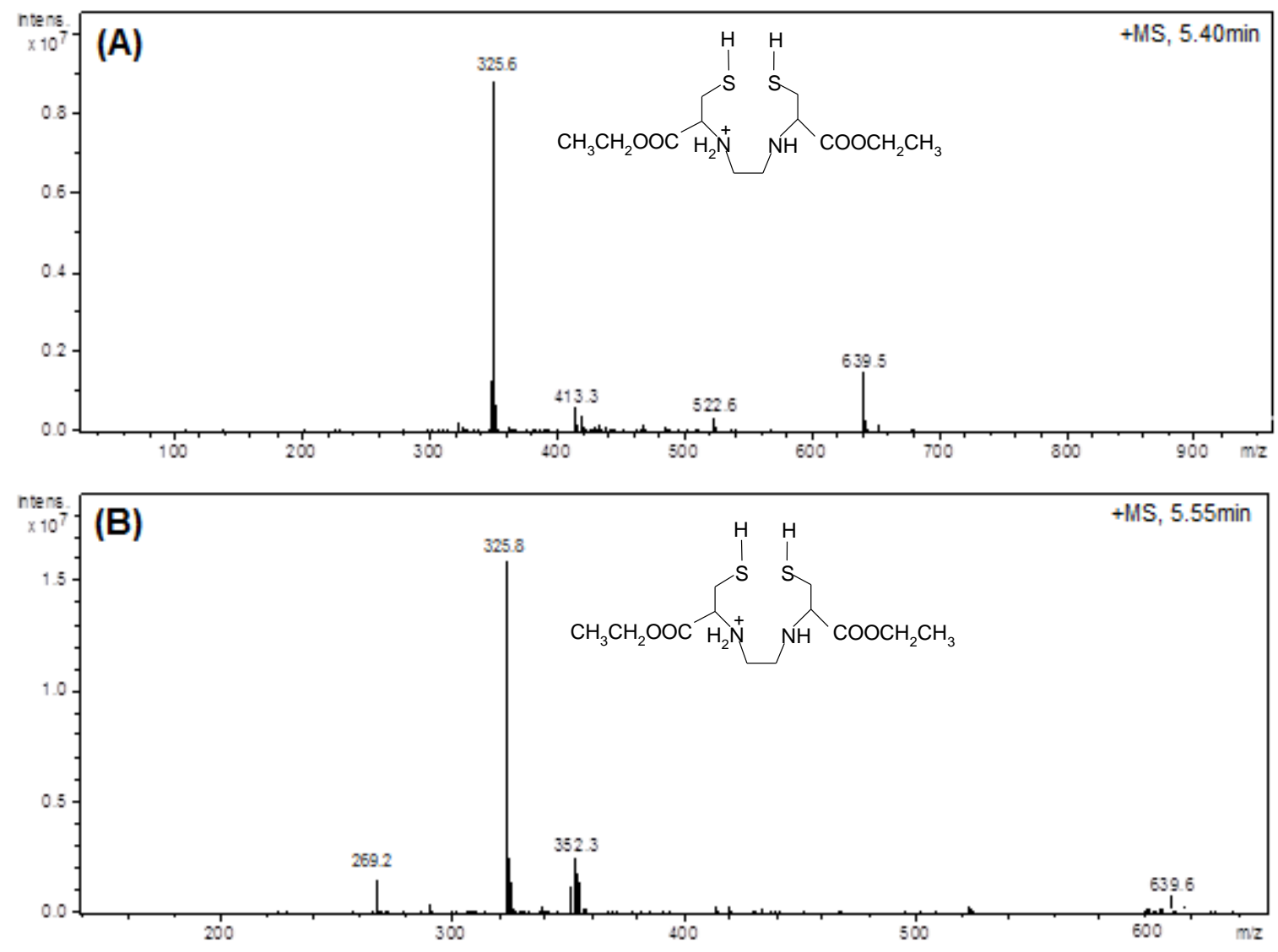

FIGURA 51- (A) Espectro de massas para o pico com tempo de retenção igual a 5,40 minutos da FIG.50A. (B) Espectro de massas para o pico com tempo de retenção igual a 5,55 minutos da FIG.50B. Prováveis estruturas químicas do íon base de $\mathrm{m} / \mathrm{z} 325,6$ e m/z 325,8 é destacada. Condições de análise: Full MS ESI+; voltagem do cone: $25 \mathrm{~V}$, voltagem do capilar: $3,0 \mathrm{kV}$ e temperatura de dessolvatação: $325^{\circ} \mathrm{C}$.

Os espectros de massas da FIG.51 mostram que os íons de $\mathrm{m} / \mathrm{z} 325,6$ e 325,8 correspondem ao ECD protonado $[\mathrm{M}+\mathrm{H}]^{+}$.

Empregando o método previamente desenvolvido e validado segundo a Resolução RE $n^{\circ} 899$ (guia para validação de métodos analíticos e bioanalíticos), os $\mathrm{RL}$ foram analisados quanto ao teor médio de $\mathrm{ECD}$ (63).

Os valores médios de ECD nos RL obtidos por HPLC-DAD e os respectivos coeficientes de variação estão apresentados na TAB.9. 
TABELA 9 - Teor de ECD em reagentes liofilizados obtidos por HPLC-DAD.

\begin{tabular}{ccc}
\hline $\mathbf{R L}$ & $\begin{array}{c}\mathbf{C M D} \pm \mathbf{D P} \\
\left(\mathbf{m g ~ m L}^{-1}\right)\end{array}$ & $\begin{array}{c}\text { Exatidão } \\
(\%)\end{array}$ \\
\hline Lote A & $0,99 \pm 0,31$ & 99,00 \\
Lote B & $0,97 \pm 0,13$ & 97,00 \\
Lote C & $0,94 \pm 0,20$ & 94,00 \\
Lote D & $1,01 \pm 0,09$ & 101,00 \\
Lote E & $0,99 \pm 0,41$ & 99,00 \\
\hline
\end{tabular}

CMD: concentração média determinada

DP: desvio-padrão

De acordo com a TAB.9, os RL analisados apresentaram teor de ECD dentro de $90-110 \%$ conforme especificado pela RE 899 da ANVISA (63). O lote $C$ foi o que apresentou o menor teor de ECD. Este lote havia sido fabricado há 5 meses, enquanto os demais lotes tinham uma data de fabricação de, no máximo, 3 meses antes das análises.

\subsection{Estudo de degradação forçada do ECD e RL de ECD}

\subsubsection{Hidrólise ácida}

Os resultados obtidos nas análises por HPLC-DAD após degradação ácida com $\mathrm{HCl} 0,1 \mathrm{~mol} \mathrm{~L}^{-1}$ do ECD estão apresentados na FIG.52. Os tempos de degradação ácida avaliados foram 0,5; 1; 2; 4 e 24 horas. 

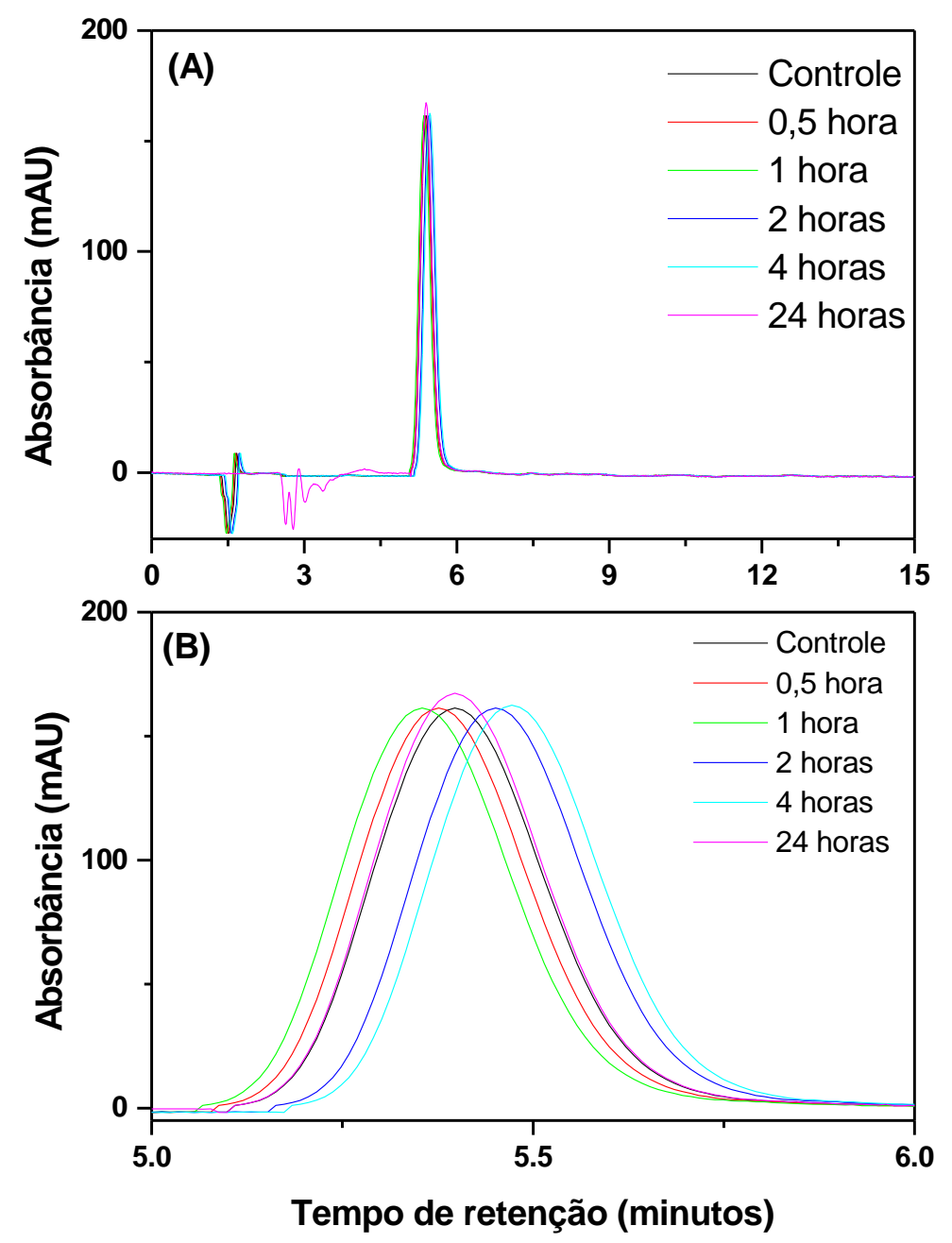

FIGURA 52- (A) Cromatogramas de ECD $1 \mathrm{mg} \mathrm{mL}^{-1}$ obtidos após hidrólise ácida com HCl 0,1 $\mathrm{mol} \mathrm{L}^{-1}$. Tempos de degradação: 0,5; $1 ; 2 ; 4$ e 24 horas. (B) Ampliação da FIG.52A no intervalo de 5-6 minutos. Condições da câmara de estabilidade: temperatura: $25{ }^{\circ} \mathrm{C}$, umidade relativa: $75 \%$. Condições da análise cromatográfica: coluna Shim-pak ODS (150 mm x 4,6 $\mathrm{mm}, 5 \mu \mathrm{m})$; fase móvel: água: metanol. Modo isocrático (40\%A:60\%B, v/v) em 15 minutos. Fluxo da fase móvel: $1 \mathrm{~mL} \mathrm{~min}^{-1}$; volume de amostra: $20 \mu \mathrm{L}$ e $\lambda=215 \mathrm{~nm}$.

Os estudos de hidrólise ácida com $\mathrm{HCl} 0,1 \mathrm{~mol} \mathrm{~L}^{-1}$ do ECD não apresentaram degradação significativa nas condições avaliadas. Observouse, conforme apresentado na FIG.52, uma variação no tempo de retenção do ECD. Apesar de o ECD apresentar estereoisômeros, assim como o DMSA, não foi possível, inferir a variação do tempo de retenção com a formação de uma espécie estereoisomérica que predominaria em meio ácido. No caso do DMSA houve uma degradação causada pela hidrólise ácida observada pela diminuição do teor de DMSA (aproximadamente 12\%) 
já para o ECD não foi observada perda significativa do teor de ECD (máximo de $1,5 \%)$.

A variação do tempo de retenção para o ECD na hidrólise ácida pode ser explicada pelo uso contínuo do material de empacotamento da coluna, embora a eficiência da coluna, medida através no número de pratos teóricos $(\mathrm{N})$ tenha permanecido constante ( $\mathrm{N}$ para ECD controle: 6794; N para ECD após 24 horas de hidrólise ácida: 6723; variação de $\mathrm{N}=$ $1,05 \%)$.

As amostras de RL de ECD também foram submetidas à hidrólise ácida com $\mathrm{HCl} 0,1 \mathrm{~mol} \mathrm{~L}^{-1}$ por tempo total de 24 horas. Não foi observada a formação de impurezas adicionais àquelas presentes na amostra controle (FIG.50B) e eluída em 3,44 minutos.

Os espectros UV $(\lambda=215 \mathrm{~nm})$ das amostras de ECD API e ECD no RL em todos os tempos de degradação ácida foram avaliados e apresentaram o mesmo perfil, conforme já apresentado na FIG.48. Isso permitiu sugerir que os picos eluídos entre 5,38 - 5,46 minutos (FIG.52) referem-se ao ECD. A pureza de pico obtida foi maior que $99,03 \%$ tanto para o ECD API quanto para o ECD no RL.

Para confirmação da identidade dos compostos encontrados nas análises por HPLC-DAD sob hidrólise ácida de ECD e RL de ECD e eluídos entre 5,38 - 5,46 minutos, análises por $\mathrm{LC}_{\mathrm{MS}}{ }^{\mathrm{n}}$ foram realizadas. Todos os espectros de massas obtidos apresentaram o mesmo perfil que os espectros da FIG.51, com m/z 325,6.

\subsubsection{Hidrólise alcalina}

Os resultados obtidos nas análises por HPLC-DAD após hidrólise alcalina com $\mathrm{NaOH} 0,1 \mathrm{~mol} \mathrm{~L}^{-1}$ do ECD estão apresentados na FIG.53. Os tempos de degradação avaliados foram 0,5; 1; 2 e 4 horas. 


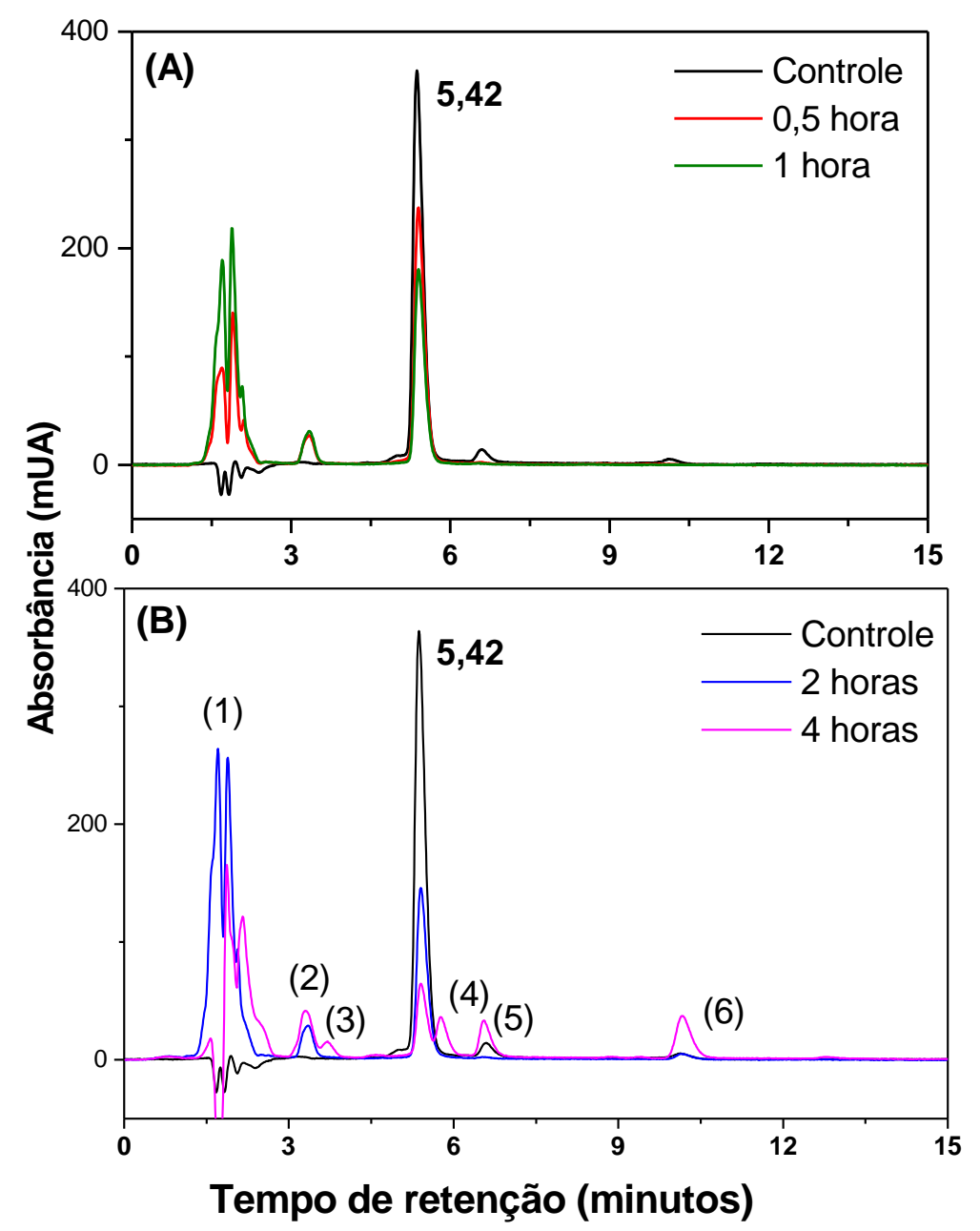

FIGURA 53- Cromatogramas de ECD $1 \mathrm{mg} \mathrm{mL}^{-1}$ obtidos após hidrólise alcalina com NaOH $0,1 \mathrm{~mol} \mathrm{~L}^{-1}$. Tempos de reação: 0,$5 ; 1 ; 2$ e 4 horas. Tempo de retenção: (1) 1,71 minutos; (2) 3,34 minutos; (3) 3,69 minutos; (4) 5,74 minutos; (5) 6,60 minutos e (6) 10,15 minutos. Condições da câmara de estabilidade: temperatura: $25{ }^{\circ} \mathrm{C}$, umidade relativa: $75 \%$. Condições da análise cromatográfica: coluna Shim-pak ODS (150 mm x 4,6 mm, $5 \mu \mathrm{m})$; fase móvel: água: metanol. Modo isocrático (40\%A:60\%B, v/v) em 15 minutos. Fluxo da fase móvel: $1 \mathrm{~mL} \mathrm{~min}^{-1}$; volume de amostra: $20 \mu \mathrm{L}$ e $\lambda=215 \mathrm{~nm}$.

O perfil de degradação do ECD após hidrólise alcalina por 4 horas com NaOH 0,1 $\mathrm{mol} \mathrm{L}^{-1}$ (FIG.53) apresentou três picos cormatográficos com características mais polares que o ECD (picos em 1,71; 3,34 e 3,69 minutos, referentes aos números (1), (2) e (3) da FIG.53, respectivamente). O ECD apresentou tempo de retenção de 5,42 minutos.

Produtos de degradação mais apolares que o ECD também foram observados $(5,74 ; 6,60$ e 10,15 minutos, referentes aos números (4), 
(5) e (6) da FIG.53, respectivamente). Todos os produtos de degradação do ECD obtidos nas análises por HPLC-DAD, após hidrólise alcalina (FIG.53), foram identificados por LC-MS $^{n}$ e os espectros encontrados estão apresentados na FIG.54. A estrutura química do íon base de cada espectro também está apresentada na FIG.54.
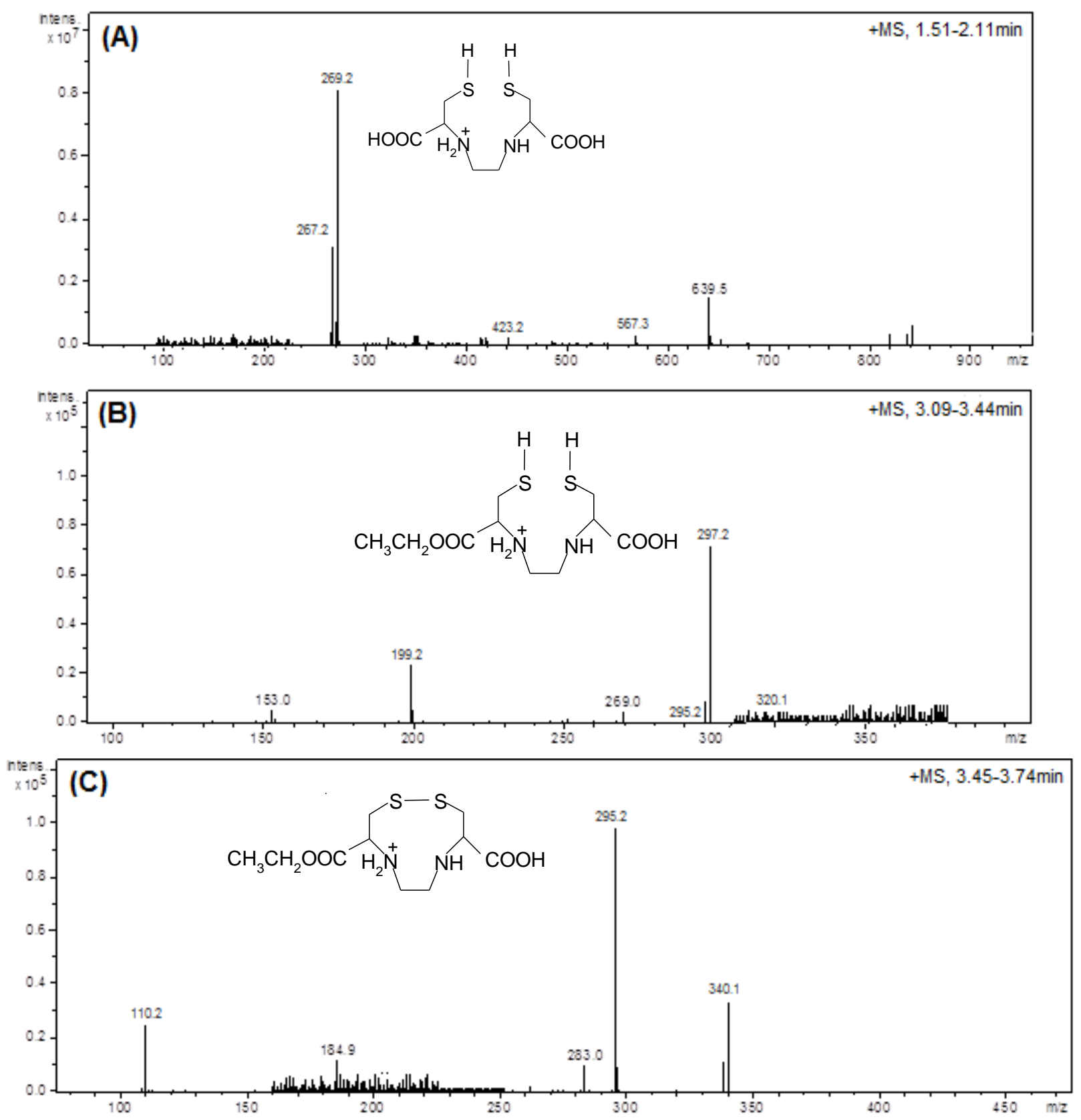

FIGURA 54- Espectros de massas obtidos dos produtos de degradação do ECD sob hidrólise alcalina com $\mathrm{NaOH} 0,1 \mathrm{~mol} \mathrm{~L}^{-1}$ apresentados na FIG.53 . (A) pico (1); (B) pico (2) e (C) pico (3). A estrutura química do íon base de cada espectro está em destaque. Condições de análise: full MS, voltagem do cone: $25 \mathrm{~V}$, voltagem do capilar: $3,0 \mathrm{kV}$ e temperatura de dessolvatação: $325{ }^{\circ} \mathrm{C}$.. 


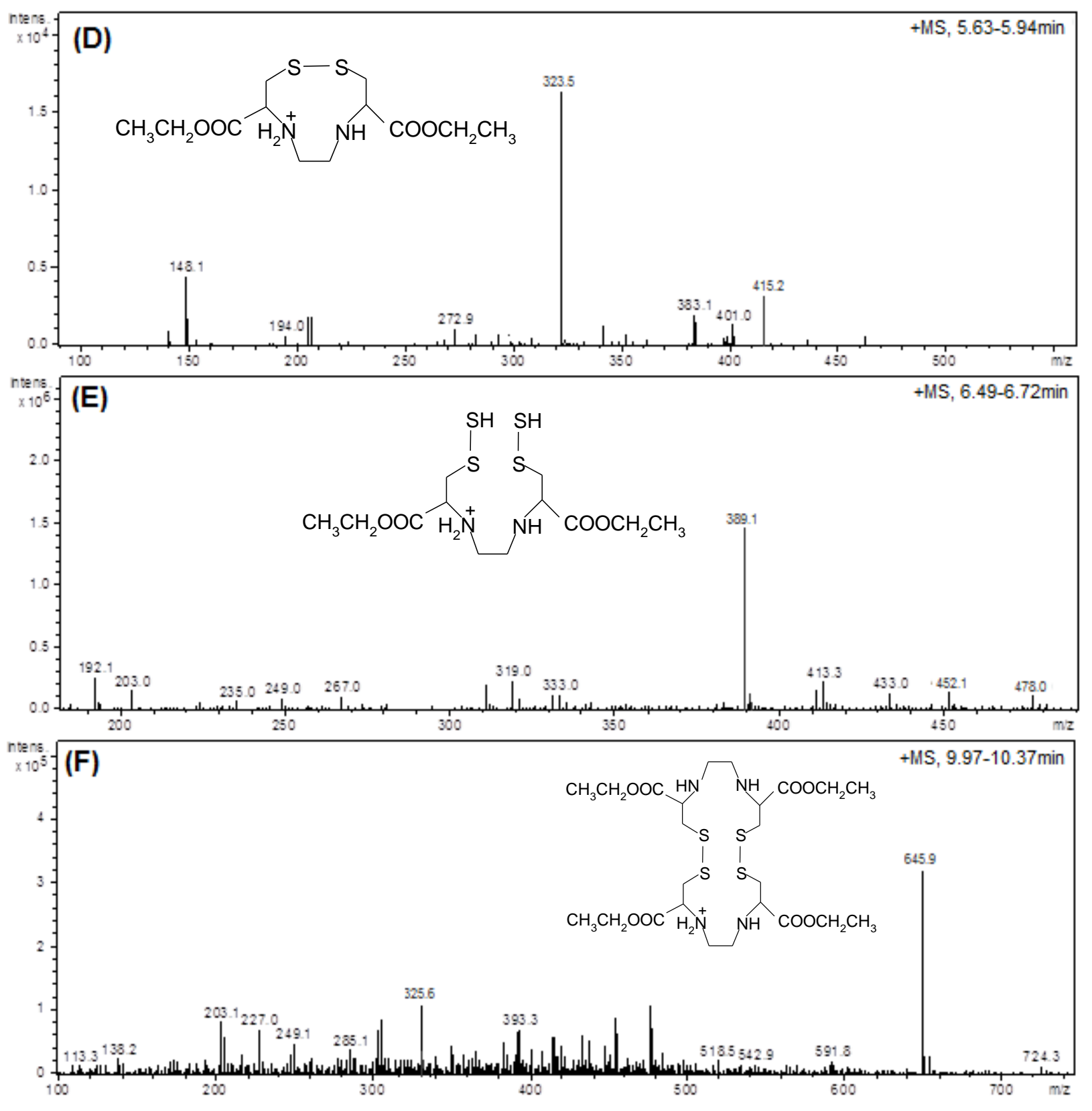

FIGURA 54- Continuação. Espectros de massas obtidos dos produtos de degradação do ECD após hidrólise alcalina com $\mathrm{NaOH} 0,1 \mathrm{~mol} \mathrm{~L}^{-1}$ apresentados na FIG.53. (D) pico (4); (E) pico (5); (F) pico (6). A estrutura química do íon base de cada espectro está em destaque. Condições de análise: full MS, voltagem do cone: $25 \mathrm{~V}$, voltagem do capilar: $3,0 \mathrm{kV}$ e temperatura de dessolvatação: $325^{\circ} \mathrm{C}$..

As análises por LC-MS ${ }^{n}$ do ECD sob hidrólise alcalina (FIG.54) mostraram que o pico com tempo de retenção de 1,71 minutos (pico 1 da FIG.53), foi identificado como o íon protonado do EC ([M+H] $\left.]^{+}\right)$em m/z 269,2. 
O íon de m/z 267,2 é EC apresentando uma ponte dissulfeto. Análise por dissociação induzido por colisão (CID) em experimentos do tipo $\mathrm{MS}^{2}, \mathrm{MS}^{3} \mathrm{e}$ $\mathrm{MS}^{4}$, foi realizada com o íon precursor de EC ( $\left.\mathrm{m} / \mathrm{z} 269,2\right)$. Os principais íons fragmentos gerados após CID do íon de m/z 269,2 e um esquema de fragmentação estão apresentados na FIG.55.

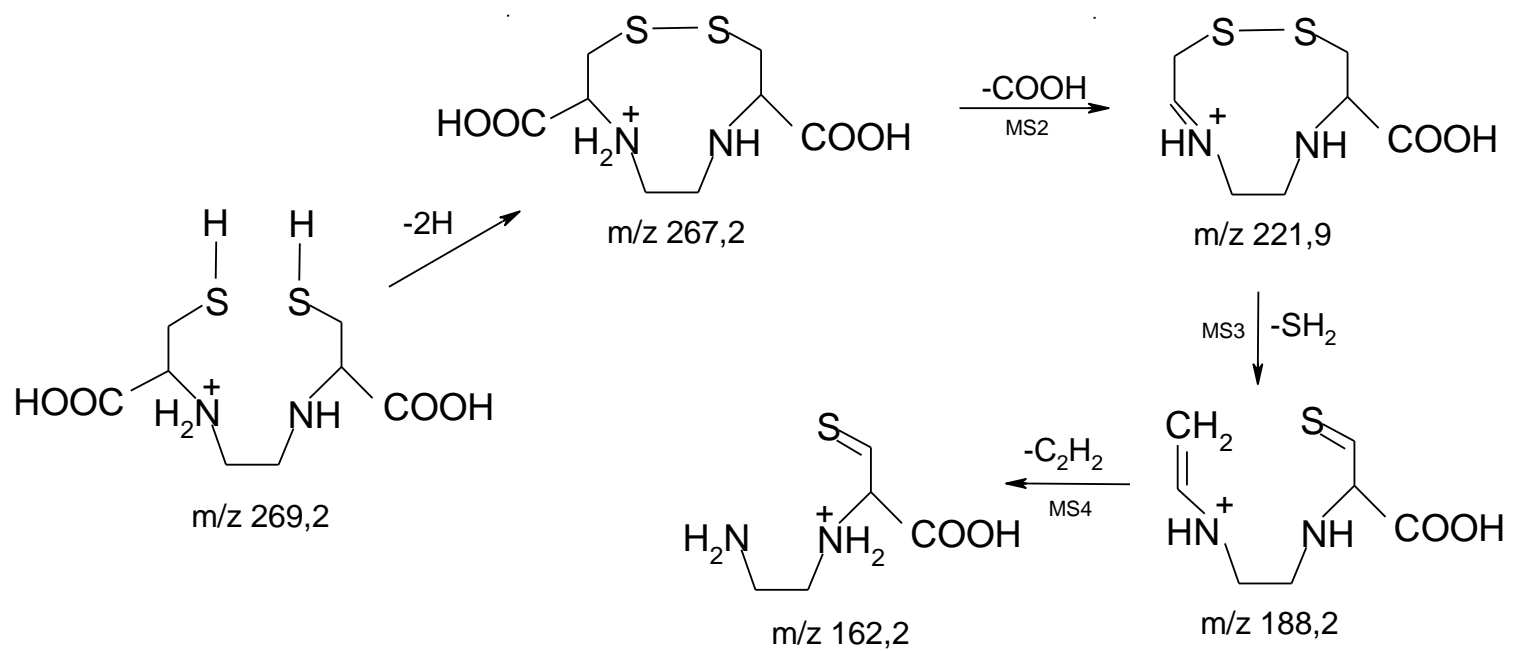

FIGURA 55- Esquema sugerido para a formação dos produtos de degradação do EC após hidrólise alcalina. Os grupos indicados nas setas referem-se à perda (-) de massa pelo íon. Condições de análise: full MS, $\mathrm{MS}^{2}, \mathrm{MS}^{3}$ e $\mathrm{MS}^{4}$; voltagem do cone: $25 \mathrm{~V}$, voltagem do capilar: $3,0 \mathrm{kV}$ e temperatura de dessolvatação: $325^{\circ} \mathrm{C}$.

EC apresenta um grupo ditiol $\left(\mathrm{S}_{2}\right)$ facilmente oxidável formando o dissulfito conforme ilustrado na FIG.55. A presença desta impureza em quantidades apreciáveis pode influenciar na marcação do ECD com tecnécio-99m e consequentemente afetar a qualidade da imagem cintilográfica realizada com este radiofármaco. Mikiciuk e colaboradores também encontraram EC em soluções de ECD em seus estudos de estabilidade (84).

Os picos com tempo de retenção de 3,34 e 3,69 minutos (picos 2 e 3 da FIG.53, respectivamente), foram identificados como o íon protonado do ECD na forma monoéster (ECDM). Íon de m/z 297,2 refere-se ao ECDM (FIG.54B) e o Íon de m/z 295,2 ao ECDM com ponte dissulfeto (FIG.54C). 
Os produtos de degradação mais apolares que o $\operatorname{ECD}(5,74$; 6,60 e 10,15 minutos, referentes aos números (4), (5) e (6) da FIG.53, respectivamente) foram identificados como ECD oxidado com uma ponte dissulfeto de m/z 323,2 (FIG.54D); ECD oxidado com duas pontes dissulfetos de m/z 389,1 (FIG.54E); e o dímero de ECD de m/z 645,9,2 (FIG.54F).

As análises de $\mathrm{MS}^{\mathrm{n}}$ possibilitaram sugerir um esquema para a formação dos principais produtos de degradação do ECD sob condições de hidrólise alcalina com $\mathrm{NaOH} 0,1 \mathrm{~mol} \mathrm{~L}^{-1}$ (FIG.56).

O esquema sugerido para a formação dos produtos de degradação do ECD (FIG.56) mostrou que várias espécies iônicas podem ser formadas resultantes da hidrólise alcalina.

A existência das formas monoéster-monoácidas (ECDM) e diácida (EC) do ECD já havia sido observada por Verbuyckt e colaboradores, além da presença de derivados dissulfetos. A marcação de RL de ECD contendo esses produtos de degradação pode resultar na formação dos correspondentes complexos ECDM- ${ }^{99 \mathrm{~m}} \mathrm{Tc}$ e EC- ${ }^{-99 \mathrm{~m}} \mathrm{Tc}$, este último um agente de imagem renal $(6,85)$. Desta forma, o tecnécio na forma de pertecnetato de sódio, disponível para marcação com o ECD ficaria reduzido, além da possível perda do $E C D-{ }^{-99 m} T c$ por adsorção em seringa (até $10 \%$ ), conforme estudos realizados por Koslowsky e colaboradores (86).

A formação de dímero de ECD observada na FIG.56 pode ser associada à presença de umidade no API. Os clusters de água são separados pela energia de ionização aplicada e as espécies de ECD reagem entre si em um processo de dimerização $(87,88)$. 


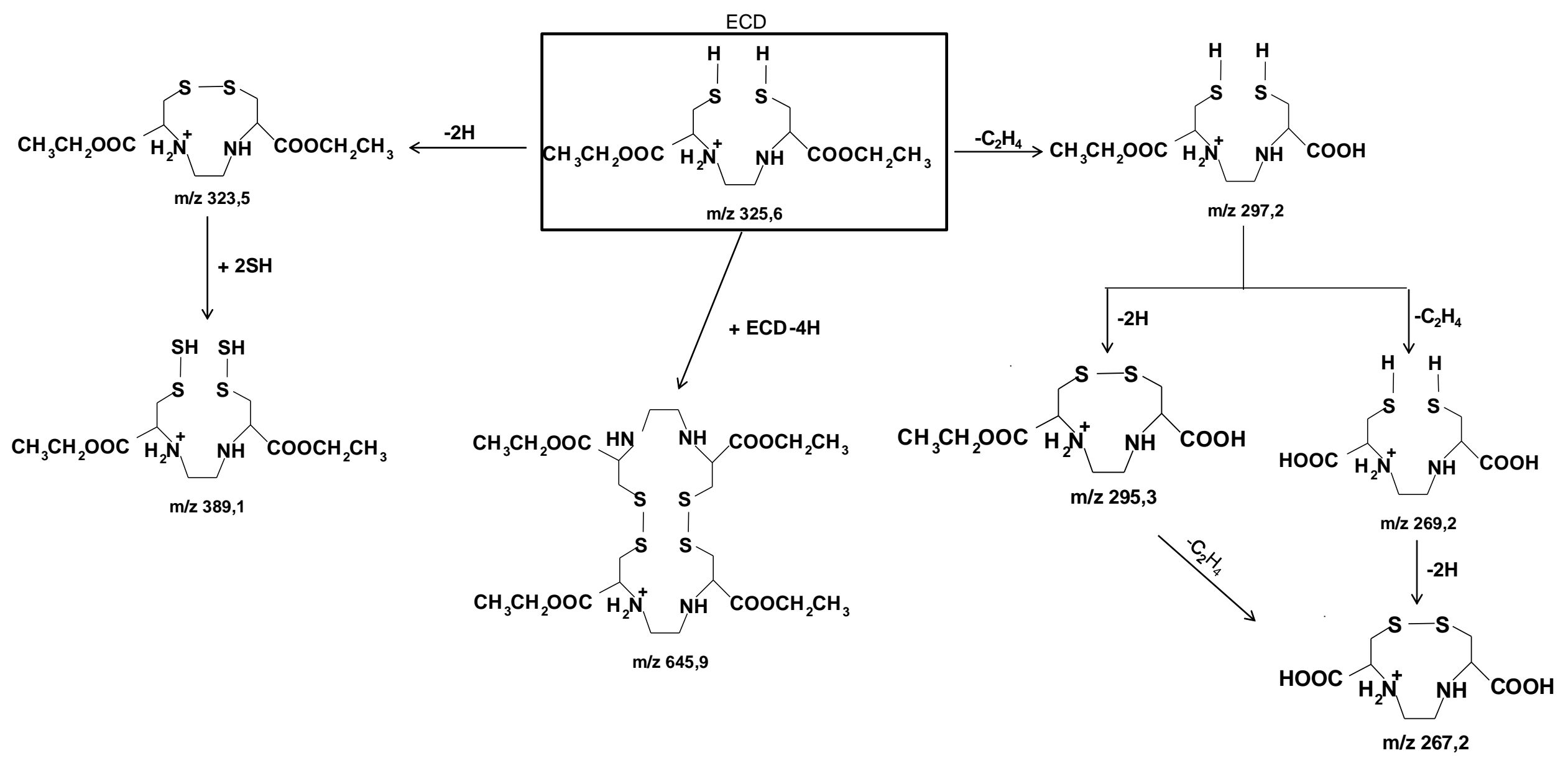

FIGURA 56- Esquema sugerido para a formação dos produtos de degradação do ECD após hidrólise alcalina. Os grupos indicados nas setas referem-se à perda (-) ou ganho (+) de massa pelo íon. Condições de análise: full $\mathrm{MS}, \mathrm{MS}^{2}, \mathrm{MS}^{3}$ e $\mathrm{MS}^{4}$; voltagem do cone: $25 \mathrm{~V}$, voltagem do capilar: $3,0 \mathrm{kV}$ e temperatura de dessolvatação: $325^{\circ} \mathrm{C}$. 
Os resultados obtidos nas análises por HPLC-DAD após degradação alcalina com NaOH $0,1 \mathrm{~mol} \mathrm{~L}^{-1}$ do $\mathrm{RL}$ de ECD estão apresentados na FIG.57. Os tempos de degradação avaliados foram 0,$5 ; 1$; 2 e 4 horas.

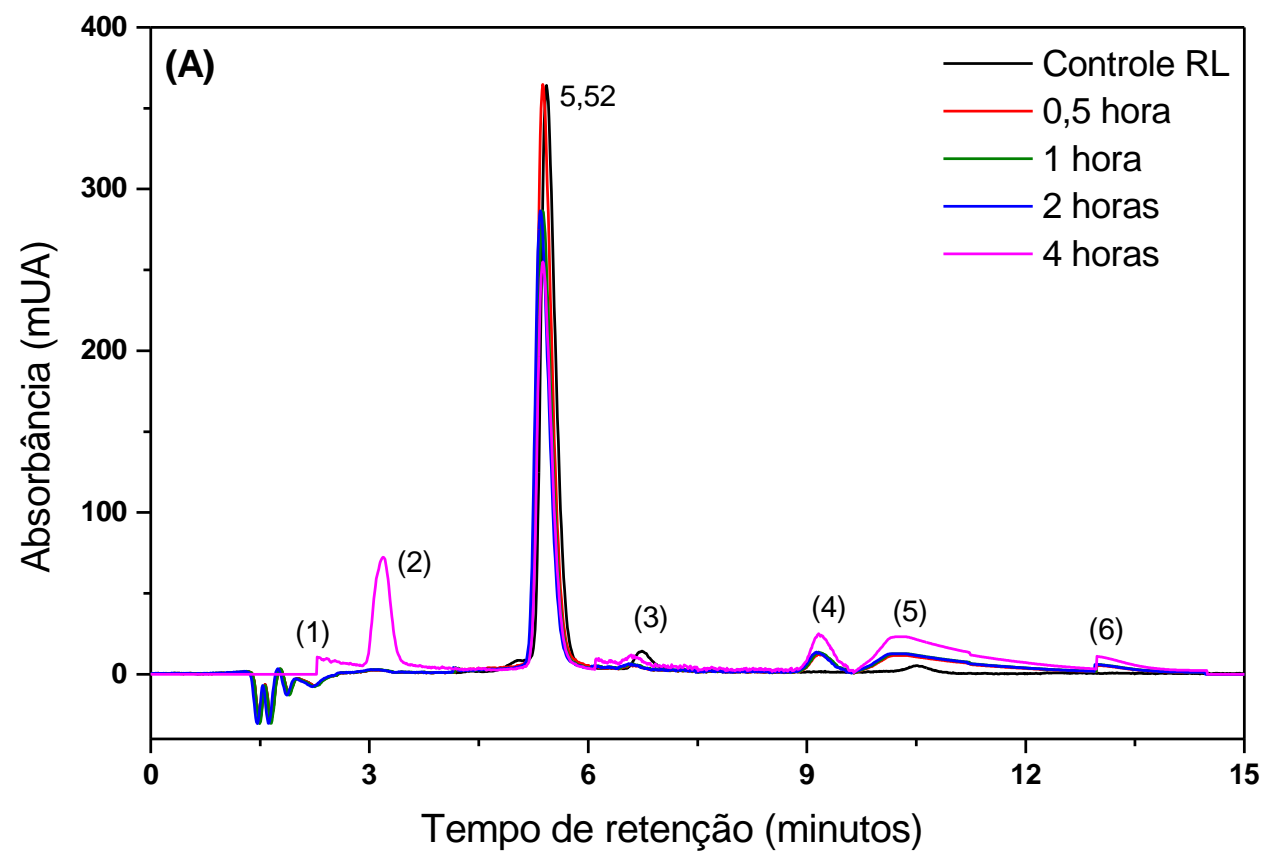

FIGURA 57- Cromatogramas de RL de ECD obtidos após hidrólise alcalina com NaOH 0,1 mol L-1. Tempos de reação: 0,5; $1 ; 2$ e 4 horas. Tempos de retenção: (1) 2,17 minutos; (2) 3,16 minutos; (3) 6,72 minutos; (4) 9,17 minutos; (5) 10,18 minutos e (6) 13,07 minutos. Condições da câmara de estabilidade: temperatura: $25{ }^{\circ} \mathrm{C}$, umidade relativa: $75 \%$. Condições da análise cromatográfica: coluna Shim-pak ODS (150 mm x 4,6 mm, $5 \mu \mathrm{m})$; fase móvel: água: metanol. Modo isocrático (40\%A:60\%B, v/v) em 15 minutos. Fluxo da fase móvel: $1 \mathrm{~mL} \min ^{-1}$; volume de amostra: $20 \mu \mathrm{L}$ e $\lambda=215 \mathrm{~nm}$.

Os cromatogramas do $R L$ de ECD após hidrólise alcalina com $\mathrm{NaOH} 0,1 \mathrm{~mol} \mathrm{~L}^{-1}$. apresentaram dois produtos de degradação mais polares que o ECD (picos 1 e 2-FIG.57) e quatro produtos de degradação mais apolares que o ECD (picos 3, 4, 5 e 6-FIG.57). A identificação desses produtos de degradação foi realizada pelo uso da espectrometria de massas.

Os produtos de degradação 1, 2, 3 e 5 da FIG.57 são os mesmos que foram observados nos estudos de degradação alcalina do ECD API (FIG.53 e FIG.54) e correspondem aos íon de m/z 267,2; m/z 297,2; m/z 389,1 e $\mathrm{m} / \mathrm{z}$ 645,9, respectivamente. 
A FIG.58 apresenta os espectros de massas no modo full MS referente aos picos (4) e (6) da FIG.57.

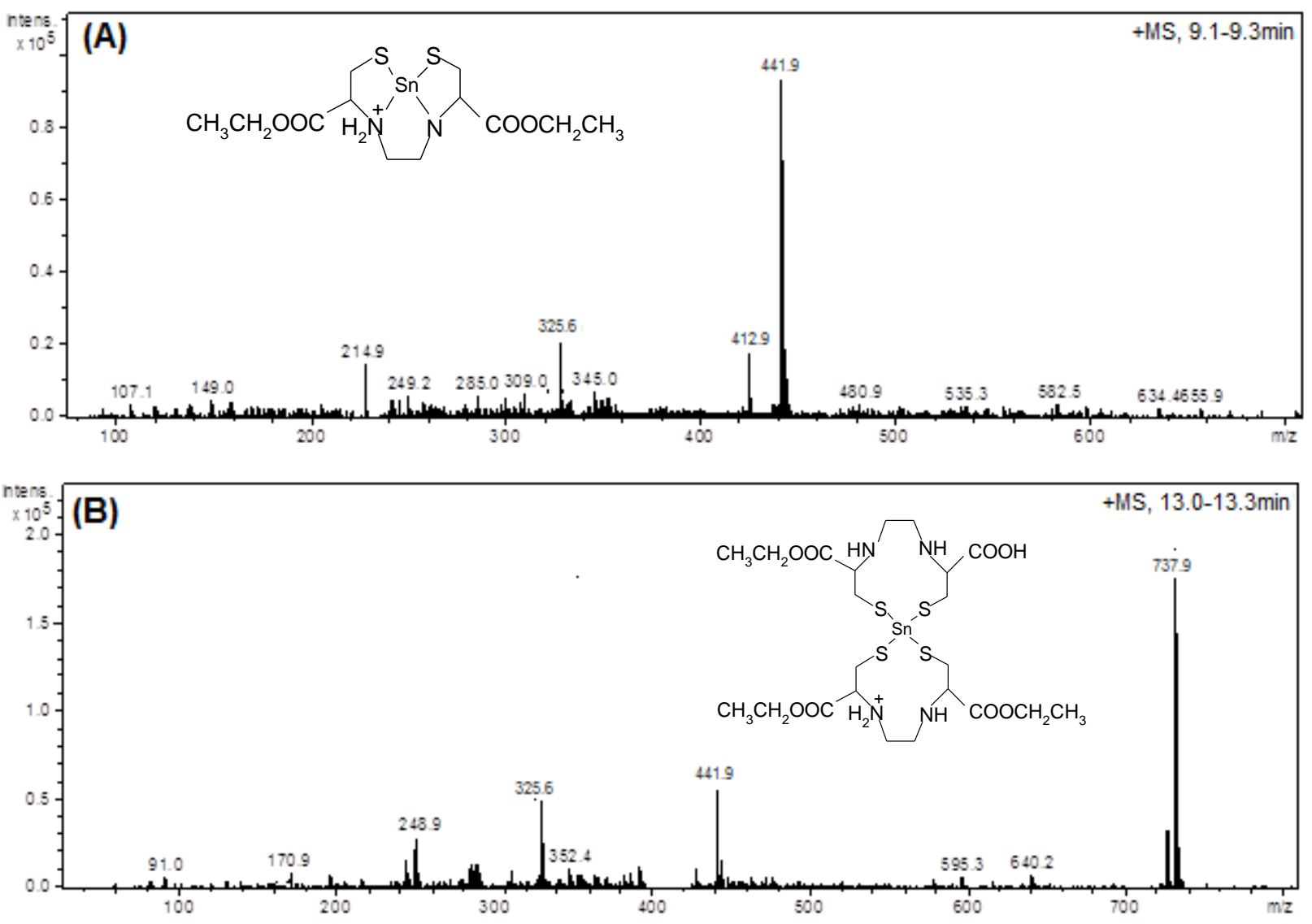

FIGURA 58- Espectros de massas obtidos dos produtos de degradação do $\mathrm{RL}$ de ECD sob hidrólise alcalina com $\mathrm{NaOH}$ apresentados na FIG.58 . (A) pico (4) e (B) pico (6). A estrutura química do íon base de cada espectro está em destaque. Condições de análise: full MS, voltagem do cone: $25 \mathrm{~V}$, voltagem do capilar: $3,0 \mathrm{kV}$ e temperatura de dessolvatação: $325^{\circ} \mathrm{C}$.

Os RL de ECD apresentam em sua composição o agente redutor cloreto estanoso $\left(\mathrm{SnCl}_{2} \cdot 2 \mathrm{H}_{2} \mathrm{O}\right)$. O íon estanho $(\mathrm{Sn})$, nas condições avaliadas, funciona como um quelante e se complexa ao ECD formando os íons de $\mathrm{m} / \mathrm{z}$ 441,9 (ECD-Sn) e m/z 737,9 ([ECD $\left.\left.{ }_{2}+\mathrm{Sn}\right]-\mathrm{C}_{2} \mathrm{H}_{2}-2 \mathrm{H}\right)$, referentes aos produtos de degradação alcalina representados pelos picos cromatográficos (4) e (6) da FIG.57, respectivamente.

Os resultados de $M^{2}$ e $M S^{3}$ realizadas para os íons de $\mathrm{m} / \mathrm{z}$ 441,9 e m/z 737,9, permitiram sugerir um esquema para a formação dos 
principais produtos de degradação alcalina do ECD no $R L$ conforme apresentado na FIG.59.

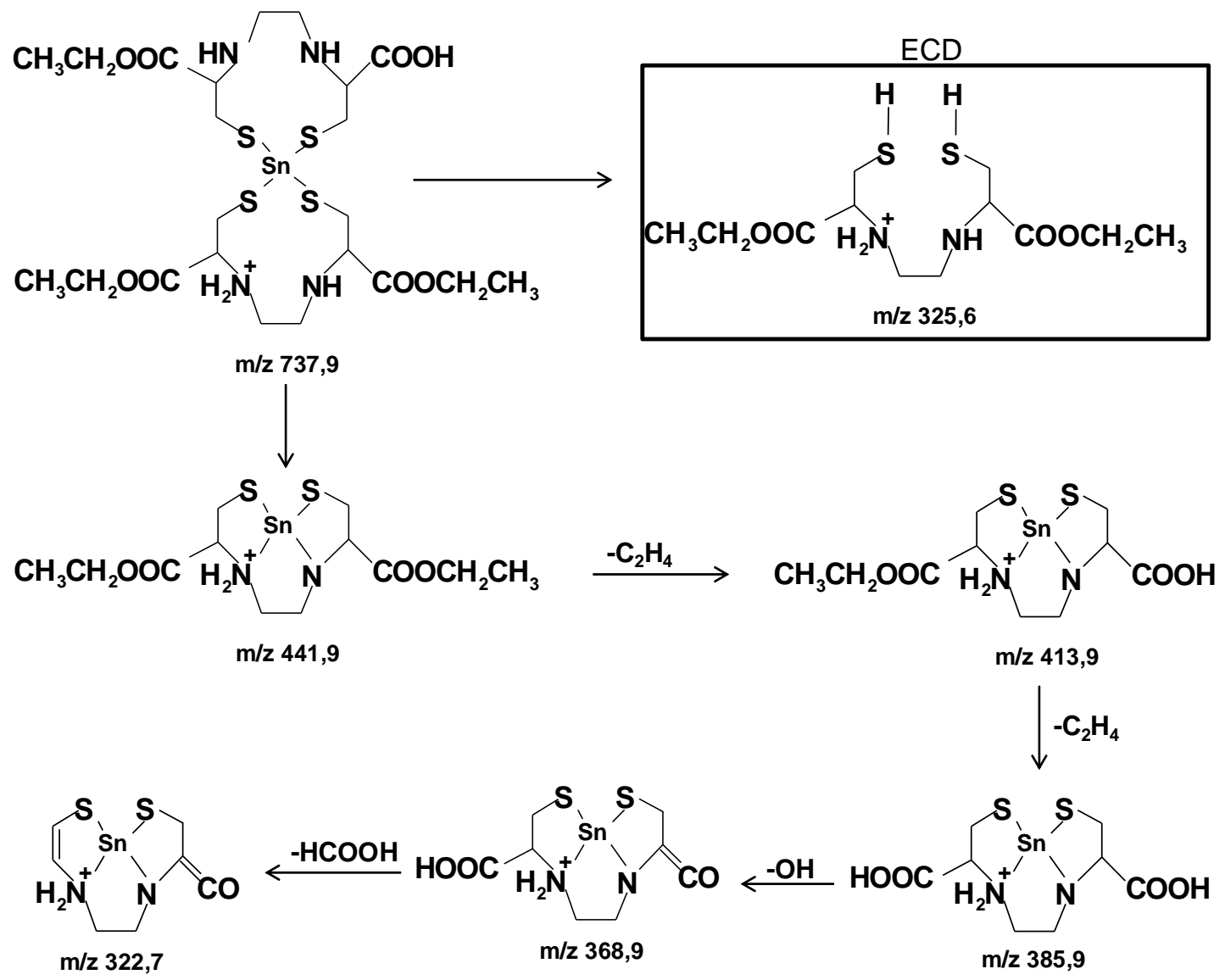

FIGURA 59- Esquema sugerido para a formação dos produtos de degradação do RL de ECD após hidrólise alcalina. Os grupos indicados nas setas referem-se à perda (-) de massa pelo íon. Condições de análise: full MS, $\mathrm{MS}^{2}, \mathrm{MS}^{3}$ e $\mathrm{MS}^{4}$; voltagem do cone: $25 \mathrm{~V}$, voltagem do capilar: $3,0 \mathrm{kV}$ e temperatura de dessolvatação: $325^{\circ} \mathrm{C}$.

Pode-se observar a coordenação do íon estanho (Sn), proveniente do agente redutor cloreto estanoso com o ECD em alguns produtos de degradação após hidrólise alcalina do $R L$ de ECD.

O esquema proposto para a degradação do RL de ECD na FIG. 59 apresenta alguns compostos de estanho. $O$ íon precursor de $\mathrm{m} / \mathrm{z}$ 737,9 gerou o íon de $\mathrm{m} / \mathrm{z} 441,9$, este pela perda do grupo $\mathrm{C}_{2} \mathrm{H}_{4}(28 \mathrm{Da}$ ) gerou o íon de $\mathrm{m} / \mathrm{z} 413,9$. 
O íon de $\mathrm{m} / \mathrm{z} 413,9$ gerou os íons de $\mathrm{m} / \mathrm{z} 385,9$ (perda de um grupo $\mathrm{C}_{2} \mathrm{H}_{4}$ ), m/z 368,9 (perda de dois grupos $\mathrm{OH}$ ) e m/z 377,7 (perda do grupo $\mathrm{HCOOH}$ ).

\subsubsection{Análise quantitativa e cinética de degradação de ECD e RL de ECD}

As porcentagens de degradação do ECD e do ECD no $R L$ obtidos por HPLC-DAD sob condições de hidrólise alcalina com $\mathrm{NaOH} \mathrm{0,1}$ mol L ${ }^{-1}$ estão apresentadas na TAB.10.

TABELA 10- Porcentagem de degradação do ECD (API) e do ECD no RL nas diferentes condições de degradação alcalina.

ECD

RL de ECD

\begin{tabular}{ccccc}
\hline $\begin{array}{c}\text { Tempo de } \\
\text { degradação }\end{array}$ & $\begin{array}{c}\text { ("Porcentagem } \\
\text { de degradação }\end{array}$ & $\begin{array}{c}\text { Índice de } \\
\text { pureza }\end{array}$ & $\begin{array}{c}\text { ("Porcentagem } \\
\text { de degradação }\end{array}$ & $\begin{array}{c}\text { Indice de } \\
\text { pureza }\end{array}$ \\
\hline 0 & 0 & 0,9897 & 0 & 0,9944 \\
\cline { 2 - 5 } 0,5 hora & $(7,00 \pm 0,15) \%$ & 0,9899 & $(27,77 \pm 0,09) \%$ & 0,9921 \\
\cline { 2 - 5 } $\begin{array}{c}1 \text { hora } \\
2 \text { horas }\end{array}$ & $(12,48 \pm 0,21) \%$ & 0,9914 & $(38,44 \pm 0,31) \%$ & 0,9888 \\
\cline { 2 - 5 } 4 horas & $(21,33 \pm 0,27) \%$ & 0,9982 & $(49,83 \pm 0,20) \%$ & 0,9863 \\
\cline { 2 - 5 } & $(29,36 \pm 0,31) \%$ & 0,9981 & $(82,55 \pm 0,25) \%$ & 0,9749 \\
\hline
\end{tabular}

(")(") Expressa em (média \pm desvio padrão)

$\mathrm{Na}$ hidrólise alcalina com $\mathrm{NaOH} 0,1 \mathrm{~mol} \mathrm{~L}^{-1}$, a porcentagem residual de ECD após 4 horas de exposição foi de $(70,64 \pm 0,22) \%$ para o ECD e de $(17,45 \pm 0,37) \%$ para o ECD no RL (TAB.10). Pode-se verificar a maior estabilidade do ECD no RL.

O índice de pureza do pico de ECD foi maior que 0,97 para todos os tempos de exposição analisados.

O gráfico representativo do estudo de cinética da hidrólise alcalina do ECD e do RL de ECD esta demonstrado na FIG.60. 


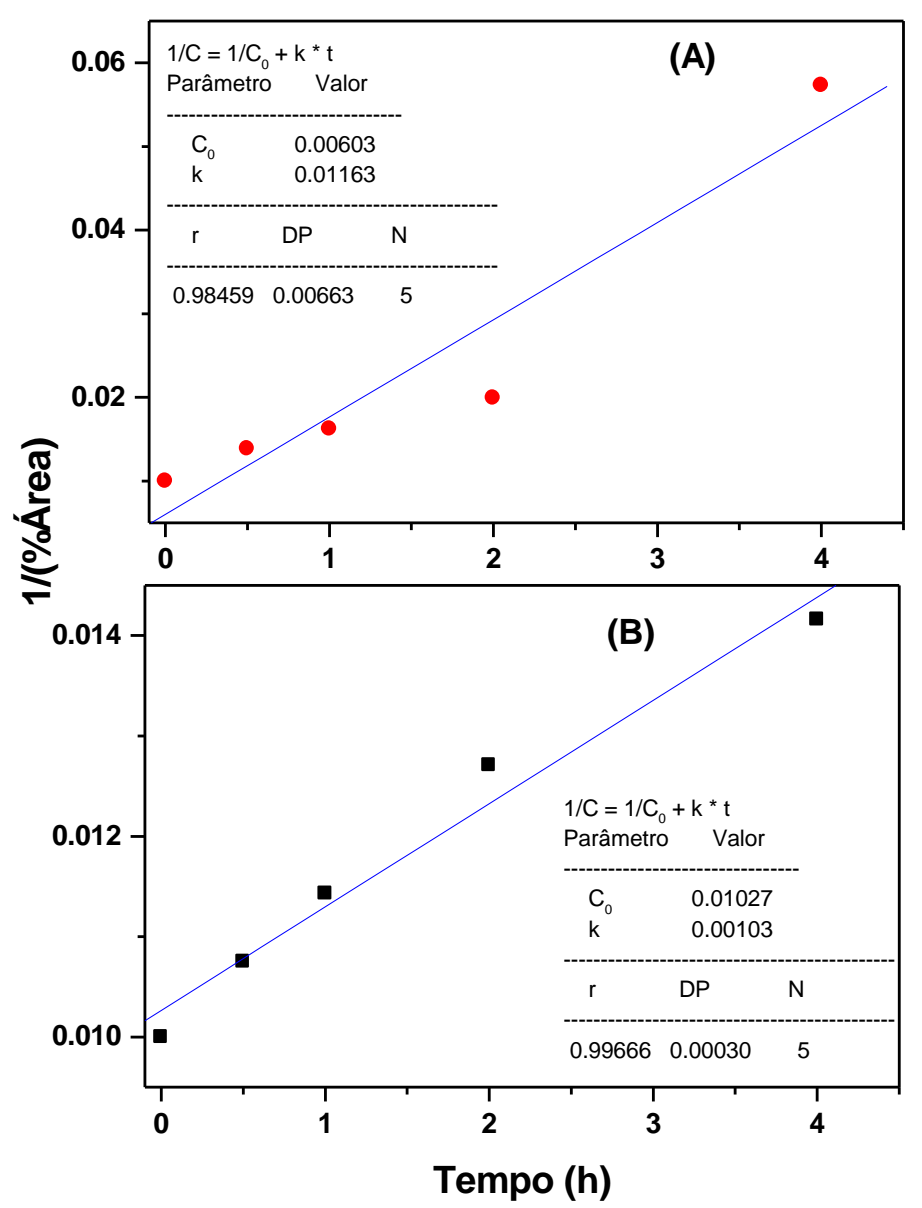

FIGURA 60-. Cinética da degradação das amostras de (A) ECD $(\bullet)$ e (B) RL de ECD (-) submetidas à hidrólise alcalina com $\mathrm{NaOH} 0,1 \mathrm{~mol} \mathrm{~L}^{-1}$ por 4 horas, onde $\mathrm{C}=\%$ área.

Os parâmetros cinéticos obtidos demonstraram que a decomposição hidrolítica do ECD em condição alcalina segue uma reação de segunda ordem.

Pode-se verificar que a hidrólise alcalina do ECD e do $R L$ de ECD depende da concentração tanto de ECD quanto de $\mathrm{NaOH}$. A constante de velocidade da reação foi igual à inclinação da reta obtida (FIG.60) e sua análise revelou que, nas condições experimentais avaliadas, a taxa da constante de decomposição hidrolítica do ECD em meio alcalino foi $\mathrm{k}=1,16$ $\times 10^{-2}$ horas $^{-1}$. O coeficiente de correlação linear $(r)$ obtido foi de 0,9845 . Para o ECD no $R L$ a constante de reação obtida foi $k=1,03 \times 10^{-3}$ horas $^{-1} \mathrm{e}$ coeficiente de correlação linear ( $r$ ) foi de 0,9966 . 
Pode-se observar que a velocidade de degradação por hidrólise alcalina com $\mathrm{NaOH} 0,1 \mathrm{~mol} \mathrm{~L}^{-1}$ do ECD API é aproximadamente 12 vezes maior quando comparada à velocidade de degradação do ECD no RL, considerando as mesmas condições de análise.

\subsubsection{Hidrólise neutra}

As amostras de ECD e RL de ECD submetidas à hidrólise neutra não apresentaram degradação significativa após o período avaliado de até 6 horas. Mikiciuk e colaboradores descreveram a instabilidade do ECD. Segundo esses autores o ECD se decompõe 30 minutos após ser dissolvido em solução de tampão fosfato pH 6.0 (84). Experimento similar foi realizados, porém nenhum produto foi identificado.

\subsubsection{Oxidação}

A FIG.61 apresenta os cromatogramas do ECD e RL de ECD obtidos por HPLC-DAD após degradação oxidativa com $\mathrm{H}_{2} \mathrm{O}_{2} 1 \%$. Os tempos de reação avaliados foram 0,5; 1; 2 e 4 horas. 


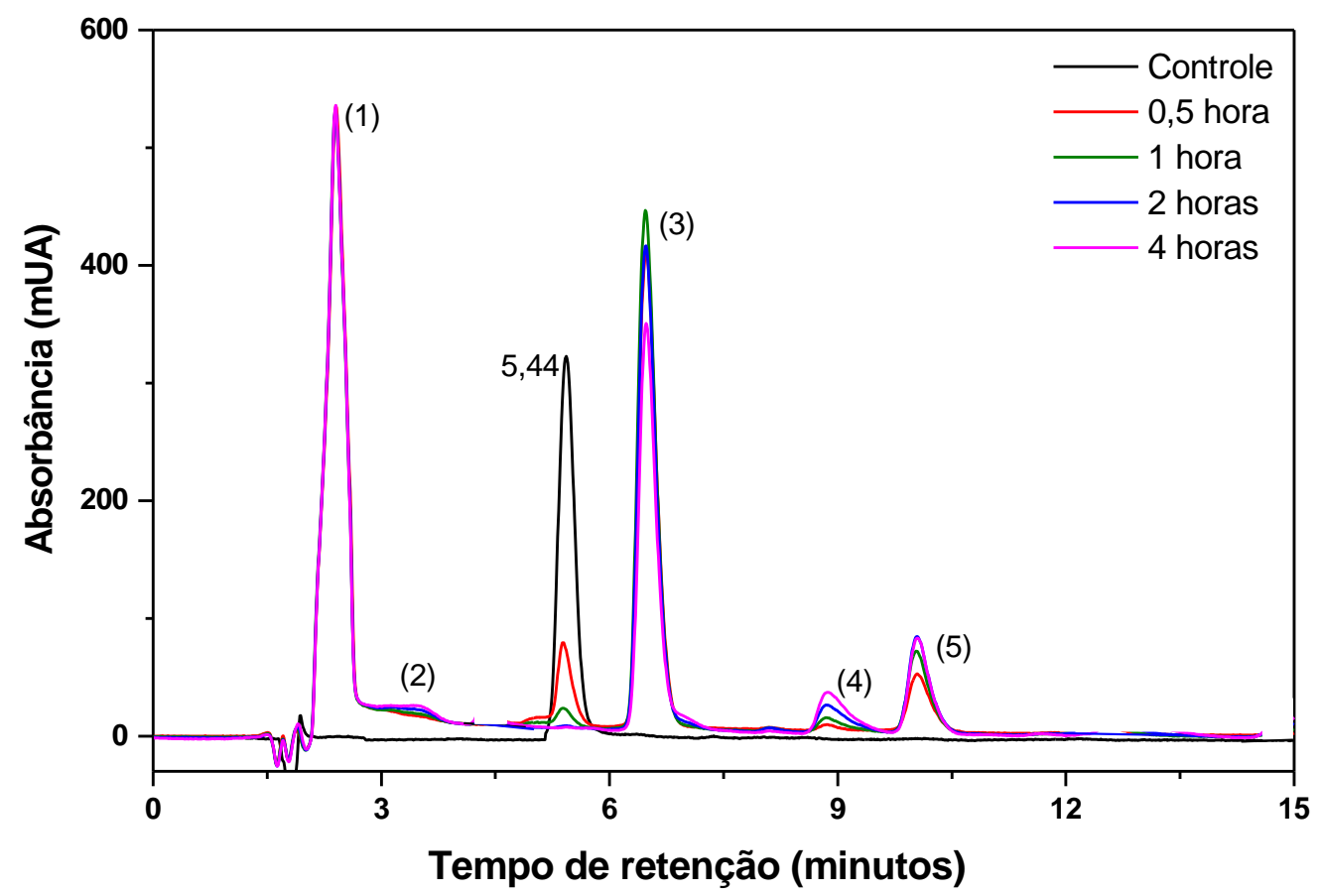

FIGURA 61- Cromatogramas obtidos após degradação do ECD por oxidação com $\mathrm{H}_{2} \mathrm{O}_{2} 1 \%$. Tempos de reação: 0,$5 ; 1 ; 2$ e 4 horas. Tempos de retenção: (1) 2,17 minutos; (2) 3,59 minutos; (3) 6,28 minutos; (4) 8,71 minutos e (5) 10,16 minutos. Condições da câmara de estabilidade: temperatura: $25{ }^{\circ} \mathrm{C}$, umidade relativa: $75 \%$. Condições da análise cromatográfica: coluna Shim-pak ODS (150 mm x 4,6 mm, $5 \mu \mathrm{m})$; fase móvel: água: metanol. Modo isocrático (40\%A:60\%B, v/v) em 15 minutos.

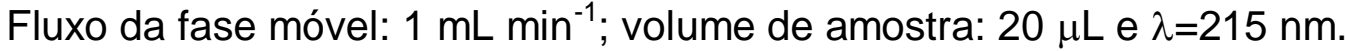

Os resultados obtidos e apresentados na FIG.61 mostram a presença de cinco picos dos quais quatro deles são produtos de degradação. O ECD apresentou tempo de retenção de 5,44 minutos. O pico 1, com tempo de retenção de 2,17 minutos corresponde ácido hidroximetil fosfônico, um organofosforado utilizado como estabilizante do $\mathrm{H}_{2} \mathrm{O}_{2}$ e não é um produto de degradação $(82,83)$.

Os picos 2, 3, 4 e 5 correspondem ao ECD monoéster monoácido (ECDM) de m/z 295,2; ECD oxidado de m/z 323,5; ECD oxidado com duas pontes dissulfeto de $\mathrm{m} / \mathrm{z} 389,1$ e dímero de ECD de $\mathrm{m} / \mathrm{z} 645,9$, respectivamente. Apesar destes produtos de degradação terem sido observados na hidrólise alcalina (FIG.53) aqui houve um aumento na 
quantidade das formas oxidadas, mostrando que o ECD é facilmente oxidado.

Qiao e colaboradores estudaram a dinâmica de oxidação do ECD em solução ( $80 \%$ de acetonitrila: $20 \%$ de água, v/v). Eles observaram que a quantidade de ECD diminui com o tempo enquanto que a quantidade de produtos de ECD oxidados aumenta (89).

Os resultados obtidos nas análises por HPLC-DAD após oxidação com $\mathrm{H}_{2} \mathrm{O}_{2} 1 \%$ do $\mathrm{RL}$ de ECD apresentaram os mesmos produtos de degradação que os observados na hidrólise alcalina (FIG.57).

\subsubsection{Análise quantitativa e cinética de degradação de ECD e RL de ECD}

As porcentagens de degradação do ECD e do ECD no RL obtidos por HPLC-DAD sob condições de oxidação com $\mathrm{H}_{2} \mathrm{O}_{2}$ estão apresentadas na TAB.11

TABELA 11- Porcentagem de degradação do ECD (API) e do ECD no RL após oxidação.

ECD RL de ECD

\begin{tabular}{ccccc}
\hline $\begin{array}{c}\text { Tempo de } \\
\text { degradação }\end{array}$ & $\begin{array}{c}\text { ("Porcentagem } \\
\text { de degradação }\end{array}$ & $\begin{array}{c}\text { Índice de } \\
\text { pureza }\end{array}$ & $\begin{array}{c}\text { Porcentagem de } \\
\text { degradação }\end{array}$ & $\begin{array}{c}\text { Índice de } \\
\text { pureza }\end{array}$ \\
\hline 0 & 0 & 0,9952 & 0 & 0,9917 \\
\cline { 2 - 5 } 0,5 hora & $(75,27 \pm 0,17) \%$ & 0,9942 & $(62,81 \pm 0,30) \%$ & 0,9932 \\
\cline { 2 - 5 } 1 horas & $(92,83 \pm 0,23) \%$ & 0,9956 & $(88,17 \pm 0,11) \%$ & 0,9871 \\
\cline { 2 - 5 } 2 horas & $(96,96 \pm 0,23) \%$ & 0,9893 & $(91,43 \pm 0,51) \%$ & 0,9898 \\
\cline { 2 - 5 } 4 horas & $(98,42 \pm 0,31) \%$ & 0,9890 & $(92,39 \pm 0,68) \%$ & 0,9823 \\
\hline${ }^{(*)}$ Expressa em (média \pm desvio padrão) & & &
\end{tabular}

Na oxidação, a porcentagem residual de ECD após 4 horas de reação com $\mathrm{H}_{2} \mathrm{O}_{2} 1 \%$ foi de $(1,58 \pm 0,27) \%$ para o ECD e de $(7,61 \pm 0,47) \%$ para o ECD no $R L$ (TAB.11). O ECD no RL mostrou-se mais estável que o ECD API. 
O índice de pureza do pico de ECD foi maior que 0,98 para todos os tempos de reação com $\mathrm{H}_{2} \mathrm{O}_{2}$ analisados.

O gráfico representativo do estudo de cinética da oxidação do ECD e do RL de ECD está demonstrado na FIG.62.

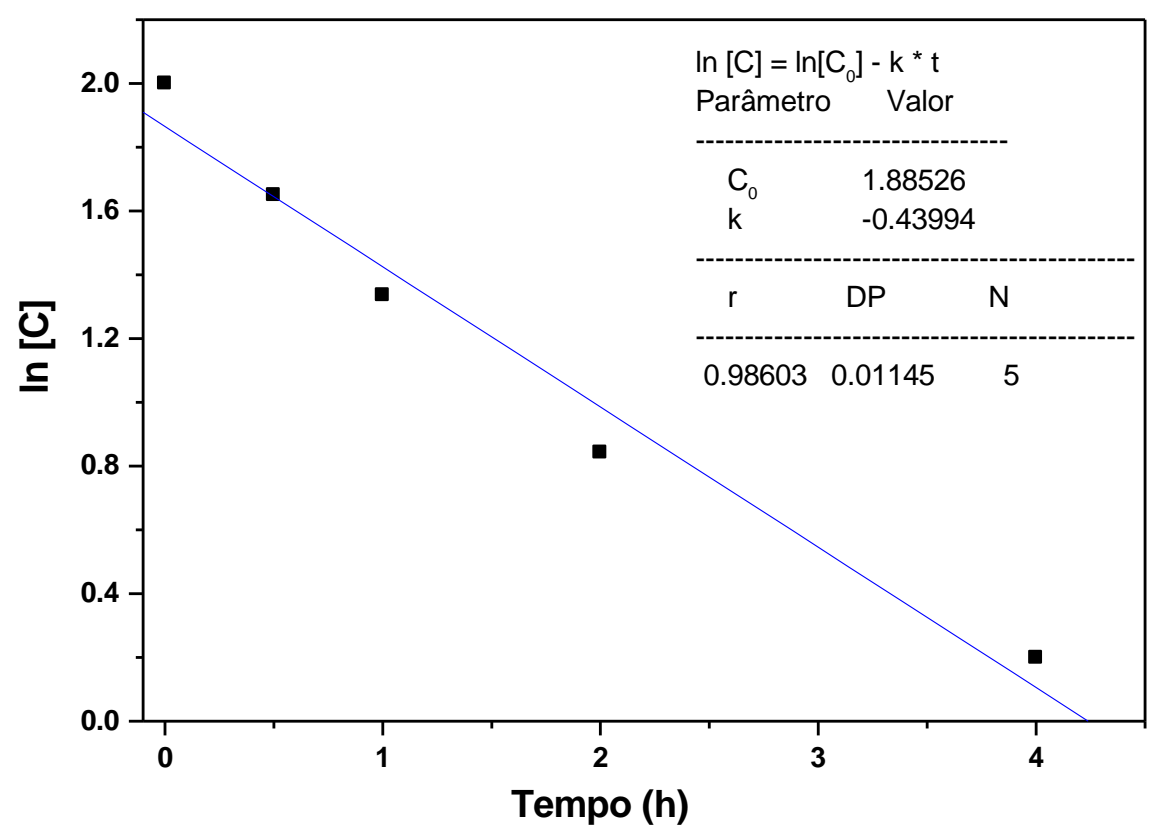

FIGURA 62-. Cinética da degradação das amostras de ECD submetidas à oxidação com $\mathrm{H}_{2} \mathrm{O}_{2} 1 \%$ por até 4 horas, onde $\mathrm{C}=\%$ área.

Os parâmetros cinéticos obtidos demonstraram que a decomposição oxidativa do $\mathrm{ECD}$ com $\mathrm{H}_{2} \mathrm{O}_{2} \quad 1 \%$ segue uma reação de primeira ordem (FIG.62).

Pode-se verificar que a oxidação do ECD depende da concentração de ECD. A constante de velocidade da reação foi igual à inclinação da reta obtida (FIG.62) e sua análise revelou que, nas condições experimentais avaliadas, a taxa da constante de decomposição oxidativa do ECD foi $k=4,40 \times 10^{-1}$ horas $^{-1}$. O coeficiente de correlação linear ( $r$ ) obtido foi de 0,98603 . 


\section{CONCLUSÕES}

Neste trabalho foi avaliado o potencial que as técnicas HPLCDAD e LC-MS ${ }^{n}$ possuiem para a análise de DMSA e ECD e seus reagentes liofilizados (RL).

O método analítico indicativo de estabilidade desenvolvido foi considerado específico e seletivo para detectar e quantificar os principais produtos de degradação de DMSA, RL de DMSA, ECD e RL de ECD.

Os estudos de degradação realizados foram capazes de delinear a estabilidade dos API e RL frente às condições forçadas, pois:

- DMSA, ECD, RL de DMSA e RL de ECD mostraram-se estável com relação ao estresse hidrolítico ácido e neutro. Observou-se apenas um deslocamento no tempo de retenção dos cromatogramas de HPLC-DAD;

- DMSA, ECD, RL de DMSA e RL de ECD mostraram-se instáveis em meio alcalino apresentando alguns produtos de degradação. A cinética de degradação para DMSA e ECD sob condições alcalinas foi de segunda ordem;

- Ambos API e RL foram susceptíveis à degradação por oxidação com $\mathrm{H}_{2} \mathrm{O}_{2}$. DMSA apresentou uma cinética de degradação de segunda ordem enquanto que para o ECD a cinética encontrada foi de primeira ordem;

As análises dos espectros obtidos por LC-MS $^{n}$ em experimentos do tipo full $M S, M S^{2}, M^{3}$ e $M S^{4}$ permitiram propor as estruturas químicas dos principais produtos de degradação de DMSA, ECD e seus RL.

Conclui-se que as análises por HPLC-DAD e LC-MS ${ }^{n}$ podem ser utilizadas no estudo de estabilidade de API e seus RL, identificando e quantificando suas impurezas e produtos de degradação. 


\section{REFERÊNCIAS BIBLIOGRÁFICAS}

1) GARCIA, E.J. Um espaço para a radiofarmácia. Pharm. Bras., v. 31, p. 4-8, 2006.

2) ALSANTE, K.M.; ANDO, A.; BROWN, R.; ENSING, J.; HATAJIK, T.D.; KONG, W.; TSUDA, Y. The Role of Degradant Profiling in Active Pharmaceutical Ingredients and Drug Products. Adv. Drug Del. Rev., v. 59, p. 29-37, 2007.

3) ARGENTINE, M.D.; OWENS, P.K.; OLSEN, B.A. Strategies for investigation and control of process-related impurities in drug substances. Adv. Drug. Del. Rev., v. 59, p. 2-28, 2007.

4) [ANVISA] AGÊNCIA NACIONAL DE VIGILÂNCIA SANITÁRIA. Guia para realização de estudos de estabilidade de insumos farmacêuticos ativos: Resolução RDC n45. Rio de Janeiro: ANVISA, 2012 - Disponível em: $<$ http://www.anvisa.gov.br/e-legis/>. Acesso em: 10 jan. 2013.

5) BAERTSCHI, S.W. Analytical Methodologies for Discovering and Profiling Degradation-Related Impurities. Trends Anal. Chem., v. 25, n. 8, p. 758-767, 2006.

6) VERDUYCKT, T.; KIEFFER, D.; HUYGHE, D.; CLEYNHENS, B.; VERBEKE, K.; VERBRUGGEN, A.; BORMANS, G. Identity confirmation of ${ }^{99 \mathrm{~m}}$ Tc-MAG3, ${ }^{99 \mathrm{~m}} \mathrm{Tc}-\mathrm{Sestamibi}$ and ${ }^{99 \mathrm{~m} T c-E C D}$ using radio-LC-MS. J. Pharm. Biomed. Anal., v. 32, p. 669-678, 2003.

7) YING, M.; KIESEWETTER, D.O.; LANG, L.; GU, D.; CHEN, X. Applications of LC-MS in PET radioligand development and metabolic elucidation. Curr. Drug. Metab., v. 11, n. 6, p. 483-493, 2010.

8) FDA, "International Conference on Harmonization: Guideline on Impurities in New Drug Products," Federal Register (Notices) 62 (96), 27453-274561 (19 May 1997) (ICH Q3B) and

9) FDA, "International Conference on Harmonization: Draft Revised Guidance on Impurities in New Drug Products," Federal Register (Notices) 65 (139), 44791-44797 (19 July 2000) [ICH Q3B(R)]. ICH Q3B(R) currently is at Step 3.

10) ALMEIDA, E. V.; MATSUDA, M. M. N. Analysis of technetium-99m radiopharmaceuticals by HPLC: analytical methods validation, Lambert Academic Publishing - LAP: Alemanha (Saarbrücken), 2010. 
11) [ANVISA] AGÊNCIA NACIONAL DE VIGILÂNCIA SANITÁRIA. Boas Práticas de Fabricação de Radiofarmacos. Resolução RDC $n^{\circ} 63$. Rio de Janeiro: ANVISA, 2009 - Disponível em: <http://www.anvisa.gov.br/e-legis/>. Acesso em: 01 set. 2013.

12) [IAEA] International Atomic Energy Agency. Radiopharmaceuticals:_Pro duction and Availability, 2010. Disponível em: <www.iaea.org/About/Policy/G C/GC51/.../English/gc51inf-3-att2_en.pdf>. Acesso em: 10 jan. 2013.

13) OLIVEIRA, R.; SANTOS, D.; FERREIRA, D.; COELHO, P.; VEIGA, F. Preparações radiofarmacêuticas e suas aplicações. Braz. J. Pharm. Sci., 42 (2), 151-165, 2006.

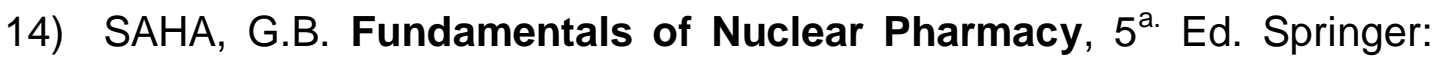
New York, 2003.

15) ARAÚJO, E.B. A utilização do elemento tecnécio-99m no diagnóstico de patologias e disfunções dos seres vivos. Quim. Nova, n. 6, p. 31-35, 2005

16) [IPEN] Instituto de Pesquisas Energéticas e Nucleares. Disponível em: $<$ https://www.ipen.br/sitio/index.php?idc=598>. Acesso em: 22 fev. 2013.

17) BRAMBILLA, T.P. Desenvolvimento de métodos para marcação de DMSA pentavalente com ${ }^{99 m} \mathrm{Tc}$ e ${ }^{188} \mathrm{Re}$. 2009. Dissertação (Mestrado)Instituto de Pesquisas Energéticas e Nucleares - IPEN, São Paulo.

18) LUGON, M.M.V. Determinação de Sn(II) por polarografia: aplicação no controle de qualidade de reagentes liofilizados para radiodiagnósico. 2008. Dissertação (Mestrado)- Instituto de Pesquisas Energéticas e Nucleares - IPEN, São Paulo.

19) [IAEA] International Atomic Energy Agency. Technetium-99m radiopharmaceuticals: manufacture of kits. Technical reports series $\mathrm{n}^{\circ} .466$, 2008. Disponível em:

$<w w w-p u b$.iaea.org/MTCD/publications/PDF/te_1414_web.pdf>. Acesso em: 15 set. 2012.

20) OWUNWANNE, A.; PATEL, M.; SADEK, S. The handbook of radiopharmaceuticals, Chapman \& Hallmedical: London, 1995.

21) STANÍK, R.; SVETLIK, J.; BENKOVSKY, I. DMSA and its complexes with radioisotopes: review. J. Radioanal. Nucl. Chem., v. 293, p. 545-554, 2012. 
22) MORETTI, J. L.; RAPIN, J. R.; SACCAVIN, J. C.; LAGERON, A.; PONCIN, M. L.; BARDY, A. 2,3-Dimercaptosuccinic acid chelates: structure and pharmacokinetic studies". Int. J. Nucl. Med. Biol., v. 11, n. 314, p. 270274, 1984.

23) BLOWER, P. J.; SINGH, J.; CLARKE, S. E. M. The chemical identity of pentavalent technetium-99m-dimercaptosuccinic acid. J. Nucl.Med., v. 32, p. 845-849, 1991.

24) STANÍK, R.; BENKOVSKÝ, I. ${ }^{99 \mathrm{~m}} \mathrm{Tc}$-DMSA complex preparation: the effect of $\mathrm{pH}$ and ammount of reducing agent. Acta Facult. Pharm. Univ. Comenianae, v. 57, p. 1-7, 2010.

25) MUSHTAQ, A.; PERVEZ, I.H.; MANSUR, M.; JEHANGIR, M. A freeze dried kit for ${ }^{99 m} \mathrm{Tc}(\mathrm{V})$ dimercaptosuccinic acid. J. Radioanal. Nucl. Chem., v. 243, n. 3, p. 827-829, 2000.

26) GRATTAN-SMITH, J. D.; LITTLE, S. B.; JONES, R. A. Evaluation of reflux nephropathy, pyelonephritis and renal dysplasia. Pediatr. Radiol., v. 38, Suppl. 1, p. S83-105, 2008.

27) GILANI, A. K.; MODARESI, E. J.; GHOLAMREZANEZHAD, A.; GHOLAMI, A.; MAMISHI, S.; EFTEKHAR,I M.; BEIKI, D.;FARD-ESFAHANI, A.; $\quad$ FALLAHI, $\quad$ B.; ANVARI, Predictors of abnormal renal cortical scintigraphy in children with first urinary tract infection: the importance of time factor. Int. Urol. Nephrol., v. 42, n. 4, p. 1041-1047, 2010.

28) PATEL, M. C.; PATEL, R. B.; RAMANATHAN, P.; RAMAMOORTHY, N.; KRISHNA, B. A.; SHARMA, S. M. Clinical evaluation of ${ }^{99 \mathrm{~m}} \mathrm{Tc}(\mathrm{V})$-dimercapto succinic acid (DMSA) for imaging medullary carcinoma of thyroid and its metastasis. Eur. J. Nucl. Med., v. 13, n. 10, p. 507-510, 1988.

29) HIRANO, T.; OTAKE, H.; YOSHIDA, I.; ENDO, K. Primary lung cancer SPECT imaging with pentavalent technetium-99m-DMSA. J. Nucl. Med., $v$. 36, n. 2, p. 202-207, 1995.

30) ADAMS, S.; BAUM, R. P.; HERTEL, A.; SCHUMM-DRAEGER, P. M.; USADEL, K. H.; HÖR. G. Comparison of metabolic and receptor imaging in recurrent medullary thyroid carcinoma with histopathological findings. Eur. J. Nucl. Med., v. 25, n. 9, p. 1277-1283, 1998.

31) PAPANTONIOU, V.; VALSAMAKI P.; SOTIROPOULOU, E.; TSAROUCHA, A.; TSIOURIS S.; SOTIROPOULOU, M.; MARINOPOULOS, S.; KOUNAD,I E.; KARIANOS, T.; FOTHIADAKI, A.; ARCHONTAKI, 
A.; SYRGIANNIS, K.; PTOHIS, N.; MAKRIS, N.; LIMOURIS, G.; ANTSAKLIS, A. Increased breast density correlates with the proliferationseeking radiotracer $(99 \mathrm{~m}) \mathrm{Tc}(\mathrm{V})$-DMSA uptake in florid epithelial hyperplasia and in mixed ductal carcinoma in situ with invasive ductal carcinoma but not in pure invasive ductal carcinoma or in mild epithelial hyperplasia. Mol. Imaging., v. 10, n. 5, p. 370-376, 2011.

32) ERGÜN, E.L.; KARA, P.O.; GEDIK, G.K.; KARS, A.; TÜRKER, A.;CANER, B. The role of Tc-99m (V) DMSA scintigraphy in the diagnosis and follow-up of lung cancer lesions. Ann. Nucl. Med., v.21, n. 5, p. 275-283, 2007.

33) KIRATLI, P.O.; KIRATLI, H.; ERCAN, M.T. Visualization of orbital retinoblastoma with technetium-99m (V) dimercaptosuccinic acid. Ann. Nucl. Med., v.12, n. 3, p. 157-9, 1998.

34) LAM, A.S.; KETTLE, A.G.; O'DOHERTY, M.J.; COAKLEY, A.J.; BARRINGTON, S.F.; BLOWER, P.J. Pentavalent 99Tcm-DMSA imaging in patients with bone metastases. Nucl. Med. Commun., v. 18, n. 10, p. 907-914, 1997.

35) CAMACHO, V.; ESTORCH, M.; FRAGA, G.; MENA, E.; FUERTES, J.; HERNÁNDEZ, M. A.; FLOTATS, A.; CARRIÓ, I. DMSA study performed during febrile urinary tract infection: a predictor of patient outcome?. Eur. J. Nucl. Med. Mol. Imaging., v. 31, n. 6, p. 862-866, 2004.

36) ARAÚJO, E.B. Conjuntos de reativos liofilizados de compostos diaminoditiólios para marcação com ${ }^{99 \mathrm{~m}} \mathrm{Tc}$. Estudo farmacocinético e elaboração de modelos compartimentalizados dos respectivos complexos. 1995. Tese (Doutorado)- Instituto de Pesquisas Energéticas e Nucleares, São Paulo.

37) MANG'ERA, K.O., BELLANDE, E., PASQUALINI, R., VERBRUGGEN, A. Comparison of reversed phase and reversed phase ion pair high performance liquid chromatography for analysis of TcO and TcN complexes of L,L- ethylene dicysteine di-ethylester and its acid analogues. J. Pharm. Biomed. Anal., v. 14, p. 1241-1244, 1996.

38) VERBRUGGEN, A.M.; NOSCO, D.D.; VAN NEROM, C.; BORMANS, G.M.; ADRIAENS, P.; DE ROO, M. TC-99m L,L-ethylenedicysteine, a potential alternative to Tc-99m MAG3. J. Nucl. Med., v. 31, p. 908-914, 1991.

39) SINGH, R.; REHMAN, Z. Current trends in forced degradation study for pharmaceutical product development. J. Pharm. Educ. Res., v. 3, n. 1, p. 54-63, 2012. 
40) NGWA, G. Forced degradation as an integral part of HPLC

stability-indicating method development. Drug Deliv. Tech., v. 10, n. 5, 2010.

41) BRÜMMER, H. How to approach a forced degradation study. Technical Bulletin. Life Sci., n. 31, 2011.

42) EUROPEAN PHARMACOPEIA, 8 Ed., Strasbourg, Council of Europe, v. $1,2015$.

43) [USP] United States Pharmacopeia. United States Pharmacopeia Convention, v.1, 2015.

44) REYNOLDS, D.W.; FACCHINE, K.L.; MULLANEY, J.F.; ALSANTE, K.M.; HATAJIK, T.D.; MOTTO, M.G. Available guidance and best practices for Conducting forced Degradation studies. Pharm. Tech., p. 48-56, 2002.

45) SILVA, K.E.R.; ALVES, L.D.S.; SOARES, M.F.R.; PASSOS, R.C.S.; FARIA, A.R.; ROLIM NETO, P.J. Modelos de avaliação da estabilidade de fármacos e medicamentos para a indústria farmacêutica. Rev. Ciênc. Farm. Básica Apl., v. 30, n. 2, p. 129-135, 2009.

46) ANSEL, H.C.; POPOVICH, N.G.; ALLEN JÚNIOR, L.V. Farmacotécnica: formas farmacêuticas e sistemas de liberação de fármacos. 8. ed. Porto Alegre: Artmed, 2007.

47) SINGH, S.; BAKSHI, M. Guidance on conduct of stress tests to determine inherent stability of drugs. Pharm Technol., v. 24, p. 1-14, 2000.

48) AVERY, H.E. Cinética química básica y mecanismos de reaccion. Barcelona: Reverte, 1982.

49) FORMOSINHO, A.A; ARNAUT, L.G. Fundamentos de cinética química. Coimbra: Imprensa da Universidade, 2003.

50) SAWANT, S.D.; BARGE, V.U. Identification and characterization of forced degradation products of paliperidone using LC-APCI-Ion Trap-MS. J. Pharm. Res., v.6, p. 39-47, 2013.

51) HARRIS, D.C. Análise química quantitativa. $7^{\mathrm{a}}$ Ed. Rio de janeiro: LTC, 2008.

52) COLLINS, CAROL H.; BRAGA, G.L.; BONATO, P.S. Introdução a métodos cromatográficos. São Paulo: editora da Unicamp, 2006. 
53) QIU, F.; NORWOOD, D.L. Identification of pharmaceutical impurities. J. Liq. Chromatogr., v. 30, p. 877-935, 2007.

54) MARQUES, L.A. Aplicação de técnicas avançadas de espectrometria de massas em ciências de alimentos e perfumaria. 2006. Dissertação (Mestrado)- Universidade Estadual de Campinas, Campinas.

55) OLIVEIRA, L.S.O.B. Quantificação de betametasona em estudo de biodisponibilidade relativa por espectrometria de massas com a utilização da técnica de fotoionização. 2008. Dissertação (Mestrado)Universidade Estadual de Campinas, Campinas.

56) LANÇAS, F.M. A cromatografia líquida moderna e a espectrometria de massas: finalmente "compatíveis?". Scien. Chrom., v. 1, n. 2, 2009.

57) WATSON, J.T.; SPARKMAN, O.D. Introduction to Mass Spectrometry: instrumentation, applications and strategies for data interpretation. England: John Wiley \& Sons Ltd., 2007.

58) KORFMACHER, W.A. Foundation review: principles and applications of LC-MS in new drug discovery. Drug Discov. Today, v. 10, n. 20, p. 13571367, 2005.

59) MARCHI, I.; Rudaz, S.; Veuthey, J. Atmospheric pressure photoionization for coupling liquid-chromatography to mass spectrometry: A review. Talanta, v. 78, p. 1-18, 2009.

60) MALLET, C.R.; LU, Z.; MAZZEO, J.R. A study of ion suppression effects in electrospray ionization from mobile phase additives and solid-phase extracts. Rapid Commun. Mass Spectrom., v. 18, n. 1, p. 49-58, 2004.

61) CROTTI, A.E.M.; VESSECCHI, R.; CALLEGARI, J.L.; LOPES, N.P. Espectrometria de massas com ionização por "electrospray": processos químicos envolvidos na formação de íons de substâncias orgânicas de baixo peso molecular. Quim. Nova, v. 29, n. 2, p. 287-292, 2006.

62) SINKO, P.J. Martin. Físico farmácia e ciências farmacêuticas, Editora Artmed. 5르. 2008.

63) [ANVISA] Agência Nacional de Vigilância Sanitária do Ministério da Saúde; Resolução RE ${ }^{\circ}$ 899, de 29 de maio de 2003. Guia para validação de métodos analíticos e bioanalíticos. 02 de junho de 2003. Disponível na internet < http://www.anvisa.gov.br>. Acesso: em 10 mar. 2013.

64) GUHLKE, S.; SCHEITHAUER, S.; OETJEN, K.; SARTOR,J.; BENDER, H.; BIERSACK, H.J. ${ }^{188} \mathrm{Re}(\mathrm{V})$-DMSA: in-vitro and in-vivo studies on the individual stereo isomers. Radiochim. Acta., v. 92, p. 277-283, 2004. 
65) PARK, J; LEE, T.; CHOI, T.; CHEON, G.; CHOI, C.; AWH, O. Acomparative study of ${ }^{188} \operatorname{Re}(\mathrm{V})$-meso-DMSA and ${ }^{188} \operatorname{Re}(\mathrm{V})$-rac-DMSA: preparation and in vivo evaluation in nude mice xenografted with a neuroendocrine tumor. Nucl. Med. Biol., v. 34, n. 8, p. 1029-1036, 2007.

66) SPIES, H.; SCHELLER, D. Chemical and ${ }^{1} \mathrm{H}$ NMR Spectroscopic Investigations of Stereoisomeric Tc(V)DMSA Complexes. Inorg Chim Acta, v. 116, p. 1-4, 1986.

67) SANTOS, M.M.M.C. Compostos de coordenação de Mo(VI) e W(VI) com ácido málico e tiomálico e outros ligandos. 1984. Tese (Doutorado)Universidade de Coimbra, Portugal.

68) LAJUNEN, L.H.J; CHOPPIN, G.R. Complex formation equilibria between fumaric acid and lanthanides. Inorg Chim Acta, v. 119, n.1, p. 83-85, 1986.

69) ALLAN, J.R.; BONNER, J.G.; BOWLEY, H.J.; GERRARD, D.L.; HOEY,S. Thermal studies on fumaric acid and crotonic acid compounds of Cobalt(II) and Nickel(II). Thermochim Acta, v. 141, n.1, p. 227-233, 1989.

70) NAVON, N.; MASARWA, A.; COHEN, H.; MEYERSTEIN, D. pH dependence of the stability constants of copper(I) complexes with fumaric and maleic acids in aqueous solutions. Inorg Chim Acta, v. 261, n.1, p. 2935, 1997.

71) DEVEREUX, M.; MCCANN, M.; LEON, V.; GERAGHTY, M.; MCKEE, V.; WIKAIRA, J. Synthesis and fungitoxic activity of manganese(II) complexes of fumaric acid: X-ray crystal structures of $\left[\mathrm{Mn}\right.$ (fum)(bipy) $\left.\left(\mathrm{H}_{2} \mathrm{O}\right)\right]$ and $\left[\mathrm{Mn}(\text { Phen })_{2}\left(\mathrm{H}_{2} \mathrm{O}_{2}\right)_{2}\right]$ (fum) $4 \mathrm{H}_{2} \mathrm{O}$ (fumH ${ }_{2}=$ fumaric acid; bipy=2,2'-bipyridine; phen=1,10-phenanthroline). Polyhedron, v. 19, n.10, p. 1205-1211, 2000.

72) Lazarou KN, Terzis A, Perlepes SP; Raptopoulou, c.p. Synthetic, structural and spectroscopic studies of complexes derived from the copper(II) perchlorate/fumaric acid/N,N0-chelates tertiary reaction systems. Polyhedron, v. 29, n.1, p. 46-53, 2010.

73) ZHENG, Y.Q.; LIN, J.L.; CHEN, B.Y. New catenary coordination polymers using fumarato ligand as bridging spacer: crystal structures of $\left[\mathrm{Mn}(\text { phen })_{2}\left(\mathrm{H}_{2} \mathrm{O}\right)_{2}\right] \mathrm{L} \cdot 4 \mathrm{H}_{2} \mathrm{O}, \mathrm{Mn}$ (phen) $\left(\mathrm{H}_{2} \mathrm{O}\right)_{2} \mathrm{~L}$ and $\mathrm{Zn}$ (phen) $\mathrm{L} \cdot \mathrm{H}_{2} \mathrm{~L}$ with $\mathrm{H}_{2} \mathrm{~L}$ fumaric acid. J Mol Struct, v. 646, n.1-3, p. 151-159, 2003.

74) APOSHIAN HV, MERSHON MM, BRINKLEY FB; HSU, C.A.; HACKLEY, B.E. Anti-lewisite activity and stability of Meso-dimercaptosuccinic acid and 2,3-dimercapto-1-propanesulfonic acid. Life Sci, v. 32, n.19, p. 2149-2156, 1982.

75) JOHNSON \& JOHNSON BABY PRODUCTS COMPANY. Martin K. O. Lindemann, Elvin R. Lukenbach. Process for the preparation of 2,3- 
dimercaptosuccinic acid and its lower alkyl esters. Pat. 4.550.193, 29 out. 1985.

76) COOK, A.M.; STEEL, L.J. The stability of thioglycollate solutions. I. Effects of method of preparation os solutions, $\mathrm{pH}$, and temperature upon the oxidation of thioglycollate. II. Miscellaneous factors associated with the oxidation and stability. J. Pharm. Pharmacol., v. 11, n.14, p. 216-223 and p. 434-441, 1959.

77) FILGUEIRAS, C.A.L. A nova química do estanho. Quim. Nova, v. 21, n. 2, p. 176-192, 1998.

78) WARDELL, J.L.; SPENCER, G.M. Tin: Organometallic Chemistry, em King, R. B., editor-in-chief; Encyclopedia of Inorganic: Chemistry, vol. 8, John Wiley \& Sons, Chichester, 1994, p. 4195.

79) GALVEZ, J.; GARCíA, D.; MORENO, J.L. Labelling of DMSA with ${ }^{99 \mathrm{~m}} \mathrm{Tc}$ without exogenous reducing agents. Intern. J. App. Radio Is0t., v. 31, p. $715-717,1980$.

80) TØNNESEN, H.H. Photostability of drugs and drug formulations. London: CRC, 2004.

81) G. Capozzi and G. Modena (1974) Oxidation of Thiols. In The Chemistry oj the Thiol Group, (Saul Patai, Ed.) pp 785-840, John Wiley \& Sons, New York.

82) LO CONTE; CARROLL, K.S. The chemistry of thiol oxidation and detection. Oxidative Stress and Redox Regulation falta completar

83) [FISPQ] Ficha de Informação de Segurança de Produtos Químicos. Disponível em: <http://www.merckmillipore.br/>. Acesso em: 10 set. 2013.

84) MIKICIUK, E.O.; BILICHOWSKI, I. Determination of L,L-Ethylene Dicysteine-ethylester stability by RP HPLC. Chem. Anal. (Warsaw), v.45, p. 809-813, 2000.

85) KABASAKAL, L. Technetium-99m ethylene dicysteine: a new renal tubular function agente. Eur. J. Nucl. Med., v. 27,n. 3, p. 351-357, 2000.

86) KOSLOWSKY, I.L.; BRAKE, S.E.; BITNER, S.J. Evaluation of the stability of ${ }^{99 \mathrm{~m}} \mathrm{TC}-\mathrm{ECD}$ and stabilized ${ }^{99 \mathrm{~m}} \mathrm{Tc}$-HMPAO stored in seringes. Nucl. Med., v. 29, n. 4, p. 197-200, 2001.

87) TUBARO, M.; TRALDI, P.; BOLZATI, C.; TISATO, F.; REFOSCO, F.; BENINI, E.; CAVAZZA-CECCATO, M. Characterisation via electrospray ionization multistage mass spectrometry of three related series of nitrido technetium complexes containing phosphinothiolate and dithiocarbamate ligands. Rapid. Commun. Mass. Spectrom., v. 19, p. 1874-1880, 2005. 
88) TISATO, F.; BOLZATI, C.;PORCHIA, M.; REFOSCO, F. Mass. Spectrom. Ver., v. 23, p. 309-332, 2004.

89) QIAO, J.; SUN, X.;ZHU, L. Study of the oxidation dynamics of ethyl cysteinate dimer in solution by ultra-performance liquid chromatography with tandem mass spectrometry. Rapid. Commun. Mass. Spectrom., v. 23, p. 1264-1268, 2009. 